\title{
Variable frequency air coupled ultrasonic phased array sensors
}

by

Taran J.S. Sachdeva, B.Eng

\begin{abstract}
A thesis submitted to
The Faculty of Graduate Studies and Research

in the partial fulfilment of the requirement for the degree of

Masters of Applied Science

In
\end{abstract}

\author{
Aerospace Engineering \\ Carleton University \\ Ottawa, Ontario, Canada
}

August 2016

(C) Copyright

2016, Taran J.S. Sachdeva 


\section{Abstract}

The design and development of low cost variable frequency ultrasonic phased array is presented. The research outlines the working principles of a traditional piezo-electric ultrasonic range sensor and elaborates on the improvements in propagation and reception that can be achieved using a phased array approach. The phased array approach is extended to work with air-capacitive ultrasonic transducer, the design and development of which is outlined in the work detailed in the thesis

A simulation study of the excitation modal frequencies comparing the analytical approach and the numerical air-damped approach are presented. These modal frequencies are used to excite the transducer and study the effects of frequency with respect to range.

A circuit design to generate the phased array is developed based on the LM555 integrated circuit. The frequency control and resolution are determined using a digital potentiometer, which is controlled by a AT-Mega 328p microcontroller. Upon reception an amplifier and an eighth order multiple feedback band pass filter is designed to isolate the frequencies of interest.

The time of arrival (TOA) approach is used to extract the position of the target based on the time difference between propagation and detection of the wave. The TOA algorithm is used to determine the position of the target using an air-capacitive transducer and it was found that the maximum range of propagation and detection is limited to $55 \mathrm{~cm}$ with an angular resolution of 15 degrees. 


\section{Acknowledgements}

I would like to give thanks to the following individuals for their continued support with the research project and beyond:

- My family for encouragement and support. To my wife Sanjam, for her continuing support, patience and assistance in my work.

- To my supervisor and mentor Dr. Jeremy Laliberté for his unconditional support and guidance throughout my thesis. I am extremely grateful to have been given an opportunity to learn and pursue this research under his supervision.

- My grandmother, her endless love and blind faith in me, it has been my source of guidance, I would not be where I am today without her

उठेंगे तो तूफ़ान बन कर , अभी उठने की ठानी नहीं है । 


\section{Table of Content}

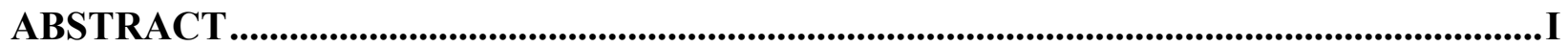

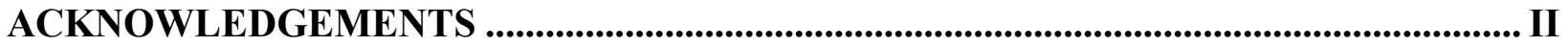

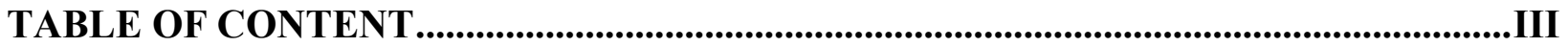

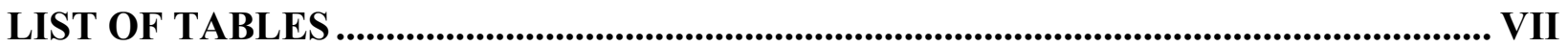

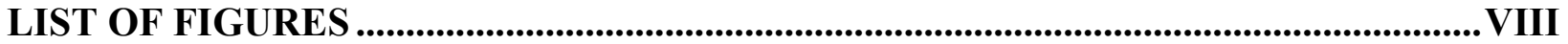

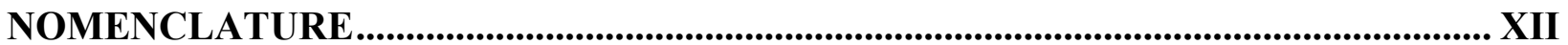

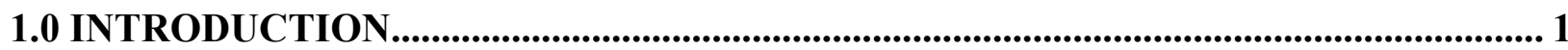

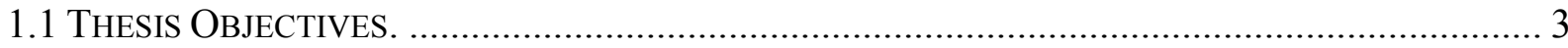

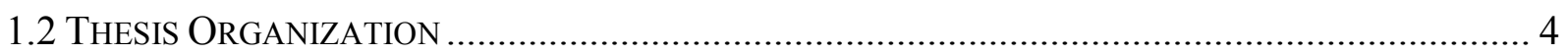

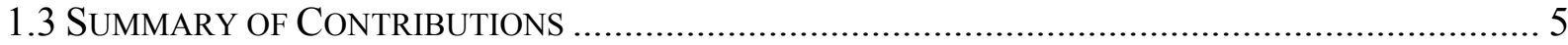

2.0 REVIEW OF RANGE FINDING SENSING TECHNOLOGIES .................................... 7

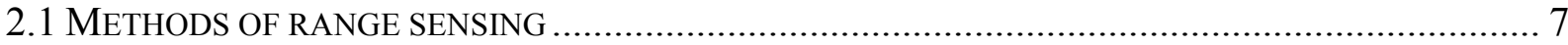

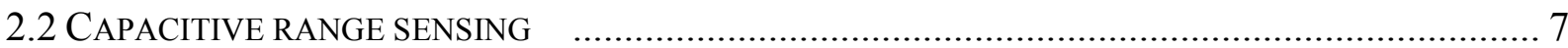

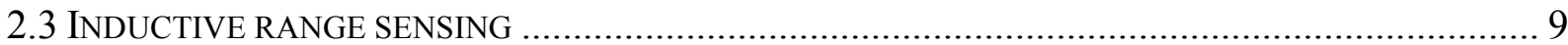

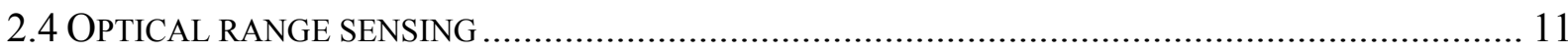

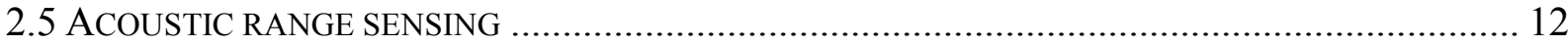

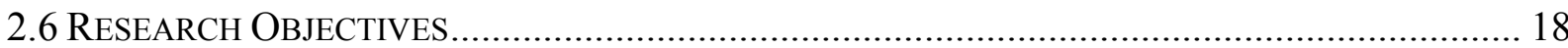

3.0 BACKGROUND THEORY OF ACOUSTICS AND SOUND PROPAGATION .......... 20

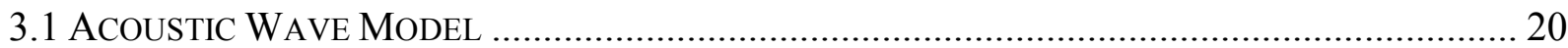




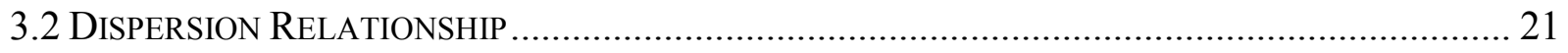

3.3 CONSERVATION OF MASS AND MOMENTUM (VELOCITY AND DENSITY RELATIONSHIP) ........ 21

3.4 CONSERVATION OF MOMENTUM (PRESSURE AND VELOCITY RELATIONSHIP) ........................ 23

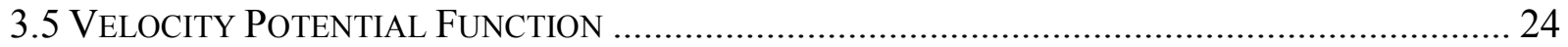

3.6 MODELLING SPHERICAL SOUND WAVES EMITTING FROM A POINT SOURCE TRANSDUCER ..... 25

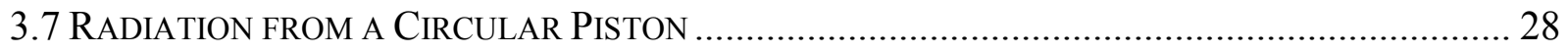

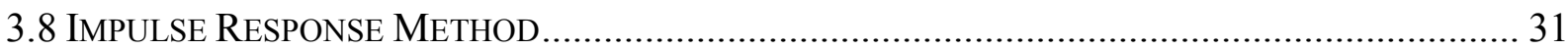

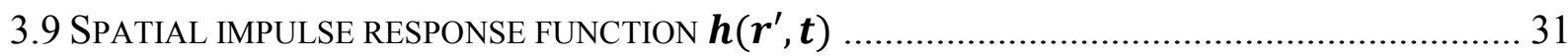

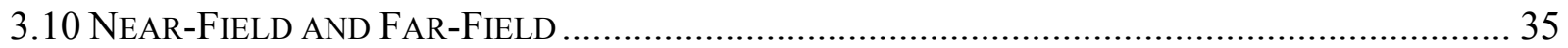

3.11 DiRECTIVITY FUNCTION, SENSOR SIZE AND WAVELENGTH RELATIONSHIP ........................... 38

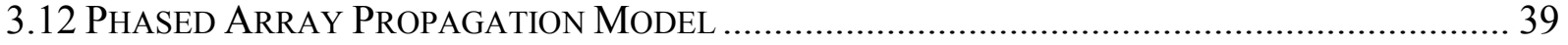

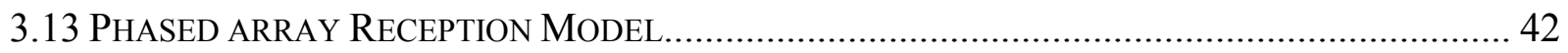

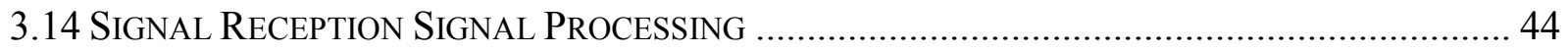

3.15 SeNSOR SIZE AND ModeLling Methodology............................................................... 51

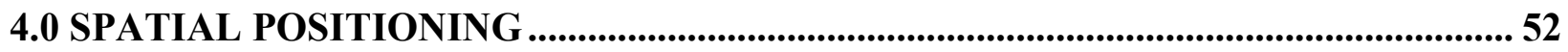

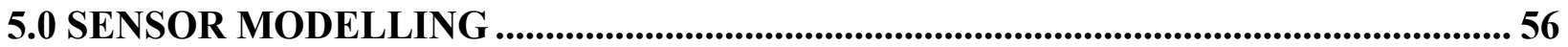

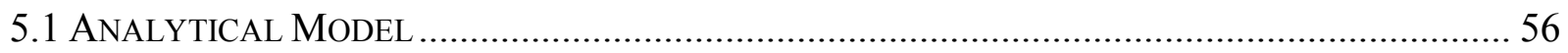

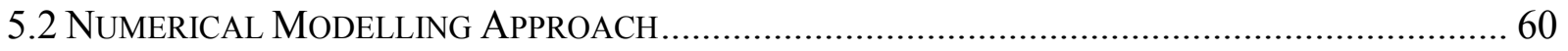

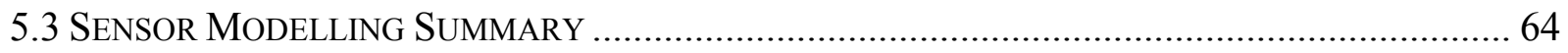

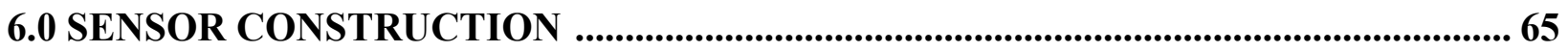

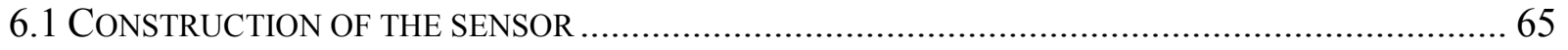

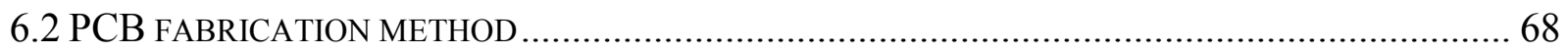


6.3 Methodology DisCUSSION

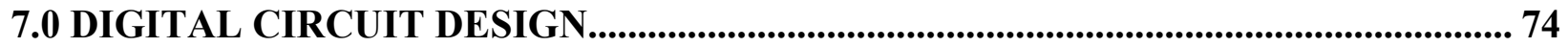

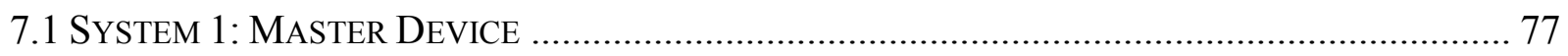

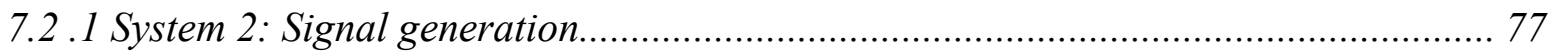

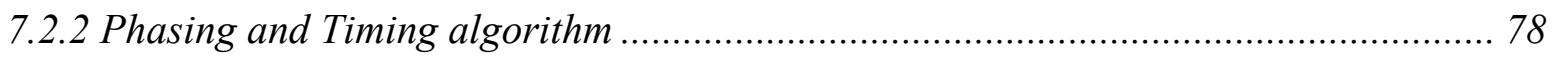

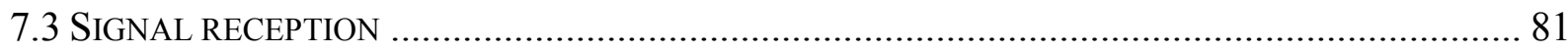

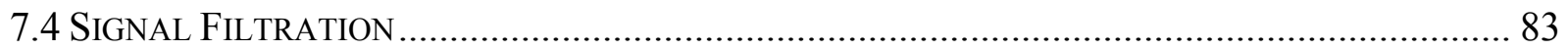

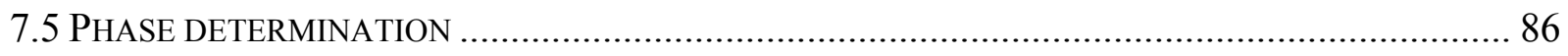

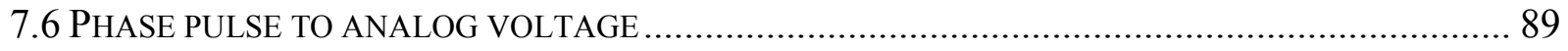

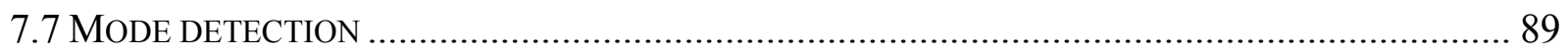

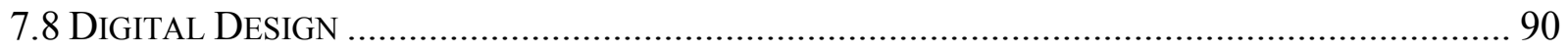

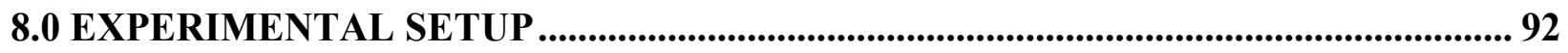

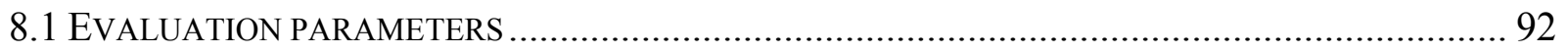

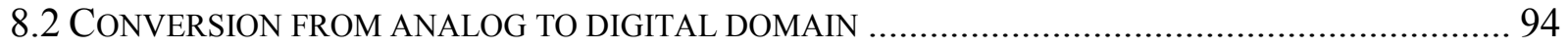

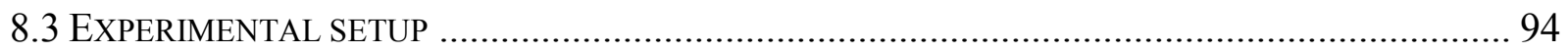

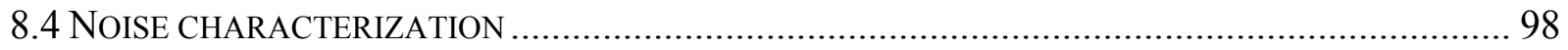

9.0 DISCUSSION OF EXPERIMENTAL RESULTS................................................. 101

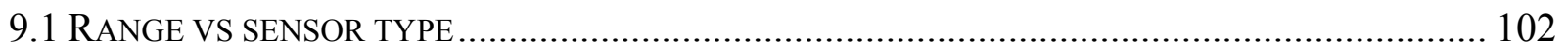

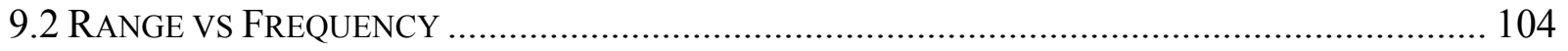

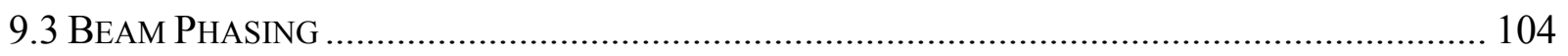

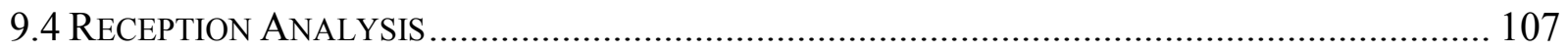

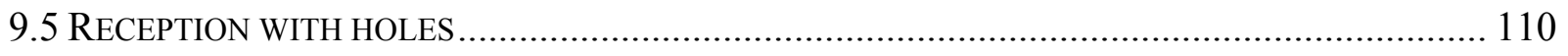




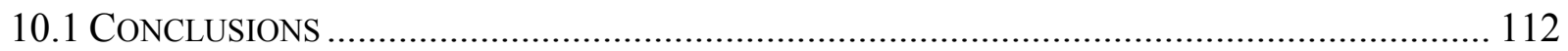

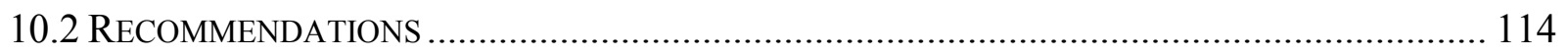

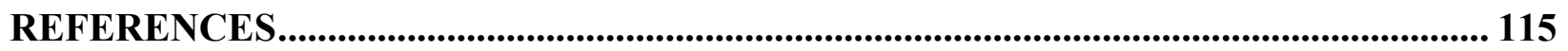

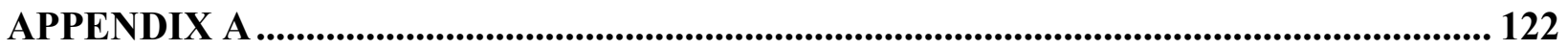

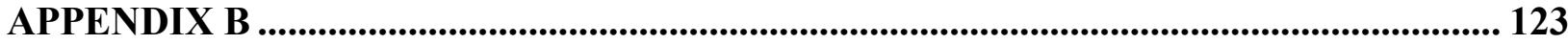

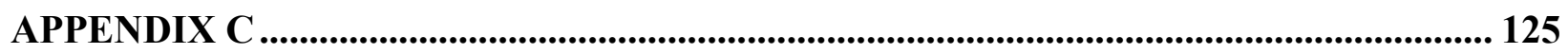

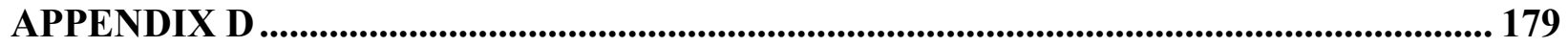

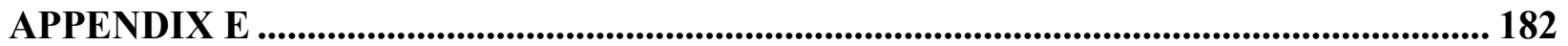




\section{List of Tables}

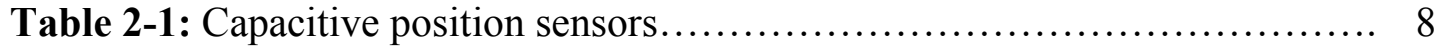

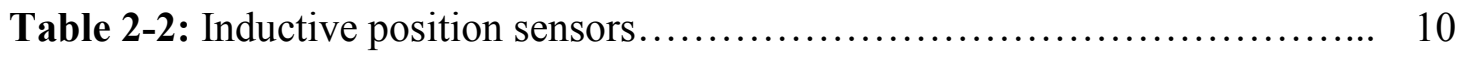

Table 2-3: Infrared position sensors....................................... 11

Table 2-4: Ultrasonic position sensors..................................... 13

Table 2-5: Transmission coefficients of various piezoelectric materials.......... 15

Table 4-1: Comparison of various localization methodologies................... 52

Table 5-1: Frequencies and mode shapes from ANSYS and MATLAB.......... 59

Table 5-2: Mesh studies analysis with computation time........................ 63

Table 6-1: Repeatability test based on IC pin spacing for three PCBs............ 73

Table 8-1: Characteristics of Knowles ${ }^{\circledR}$ model: SPU0410LR5H microphone...... 93

Table 8-2: Sound source to output voltage comparison........................... 94 


\section{List of Figures}

Figure 1-1: Gross mass vs Reynolds number for various flying platforms......... 1

Figure 1-2: Weight of payload versus wingspan of the aerial platform............ 2

Figure 1-3: Ultrasonic range sensor for indoor applications LV-MaxSonar- EZ0 2 MB1000....................................................

Figure 2-1: Capacitive range sensor output signal with respect to change in target 8 position

Figure 2-2: Inductive position sensor

Figure 2-3: Types of ultrasonic range detection sensors.................... 13

Figure 2-4: PZT transducer composite structure, adapted from................. 14

Figure 2-5: Internal components of a disassembled PZT range sensor.................... 16

Figure 2-6: Equivalent circuit for a PZT transducer......................... 17

Figure 2-7: Phased array PZT range sensor on Parrot AR Drone............................. 18

Figure 3-1: Mass and momentum balance.............................. 21

Figure 3-2: Effect on impedance components with changing wavelength ratio.... 28

Figure 3-3: Geometry and parameters of a circular piston..................... 29

Figure 3-4: Projection of the impulse on the source........................ 32

Figure 3-5: Planar projection of point $\mathrm{P}$ on the source..................... 33

Figure 3-6 : Two projections of point $\mathrm{P}$ on surface of the transducer............ 33

Figure 3-7: Near-field plane wave dispersing into far field spherical wave....... 37

Figure3-8: Angular representation of half power angle..................... 38

Figure 3-9: Constructive and destructive pattern using time delays............. 39

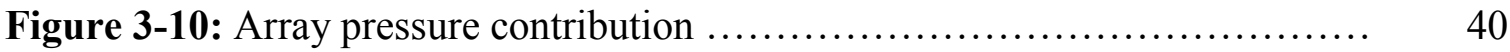


Figure 3-11: Phased array reception model.................................................... 42

Figure 3-12: Attenuation of ultrasonic waves in air....................... 43

Figure 3-13: Array factor response of a phased array sensor with 3 sensor elements 46 with $6 \mathrm{~mm}$ diameter placed $4 \mathrm{~mm}$ apart at a) $100 \mathrm{kHz}$ b) $50 \mathrm{kHz}$ and c) $30 \mathrm{kHz}$

Figure 3-14: Reception beamforming gain with respect to incidence angle represented in linear and polar plot at $30 \mathrm{kHz}$

Figure 3-15: Reception beamforming gain with respect to incidence angle represented in linear and polar plot at $50 \mathrm{kHz}$

Figure 3-16: Reception beamforming gain with respect to incidence angle represented in linear and polar plot at $100 \mathrm{kHz}$

Figure 3-17: Qualitative 3D visualization of the gain patterns at $30 \mathrm{kHz}, 50 \mathrm{kHz}$ and $100 \mathrm{kHz}$

Figure 3-18: Beam patterns produced by a 3 transducer linear array as a function of frequency....

Figure 4-1: Position localization using TOA technique.

Figure 5-1: Air-coupled transducer frequency response and transducer deflection 62 amplitude

Figure 5-2: Comparison of frequency vs mode shape for analytical and numerical 64 methods.

Figure 6-1: Model of an air-capacitive transducer with Mylar film.

Figure 6-2: Air-Capacitive sensor array of 3 elements.

Figure 6-3: PCB fabrication process layout

Figure 6-4: Circuit design on transparency.

Figure 6-5: UV exposure chamber setup

Figure 6-6: Pre-sensitized board after photo development process

Figure 6-7: Etching process using Muriatic acid. 


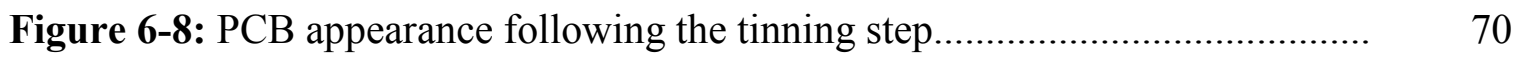

Figure 6-9: Time rate deposition of Liquid Tin solution (MG Chemicals CAT No. 71

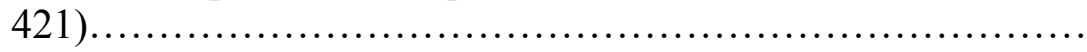

Figure 6-10: Consistency and repeatability test results..................... 72

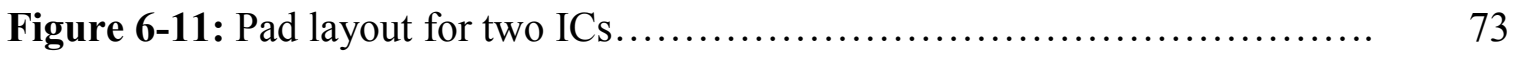

Figure 7-1: Constructive and destructive pattern produced by a two element 74 array

Figure 7-2: High level sensor system architecture $\ldots \ldots \ldots \ldots \ldots \ldots \ldots \ldots \ldots \ldots \ldots \ldots$

Figure 7-3: Digital potentiometer controlled oscillator...................... 78

Figure 7-4: Timer counter control register $0 \mathrm{~A}$ and $0 \mathrm{~B} \ldots \ldots \ldots \ldots \ldots \ldots \ldots \ldots \ldots \ldots \ldots \ldots$

Figure 7-5: Ultrasonic wave transmitter amplification circuit $\ldots \ldots \ldots \ldots \ldots \ldots \ldots \ldots$

Figure 7-6: Three stage amplifier using Texas Instrument TL074CPWR.......... 82

Figure 7-7: Ideal (top) filter performance versus actual (bottom) performance of a 83 filter............................................................

Figure 7-8: Filter types and the effect of the order of the filter. Adapted from...... 84

Figure 7-9: Fourth order multiple feedback bandpass filter design.............. 85

Figure 7-10: Filter frequency vs amplitude performance $\ldots \ldots \ldots \ldots \ldots \ldots \ldots \ldots \ldots . . \ldots 6$

Figure 7-11: Phase comparator selection within a phased lock loop schematic..... 87

Figure 7-12: Two cases of phase comparator output...................... 88

Figure 7-13: Lead/Lag timing diagram for phase for quadrant determination..... $\quad 88$

Figure 7-14: Mode sensing circuit using NOR gate and an AND gate............ 90

Figure 8-1: Internal layout and design of the anechoic chamber............... 95

Figure 8-2: Automated SPL data acquisition setup........................ 96

Figure 8-3: Data acquisition system layout $\ldots \ldots \ldots \ldots \ldots \ldots \ldots \ldots \ldots \ldots \ldots \ldots \ldots \ldots \ldots \ldots \ldots \ldots$

Figure 8-4: Anechoic chamber assembly with automated SPL acquisition........ 98 
Figure 8-4: External microphone noise characterization

Figure 8-6: Noise spectrum relative to a $20.63 \mathrm{kHz}$ PZT source placed at $0.5 \mathrm{~m}$ distance

Figure 9-1: Comparison of output SPL between the PZT and air-capacitive 102transducers.................................................. 103

Figure 9-2: Comparison of theoretical performance to the actual performance of a 104PZT and air- capacitive based phased array transducer............ 106

Figure 9-3: Experimental results of range vs angular position.................. 107

Figure 9-4: Effects of moving reception beam former lobe .................. 109

Figure 9-5: Air-capacitive transducer with holes in black plate................ 110 


\section{Nomenclature}

\begin{tabular}{|c|c|}
\hline$A_{\phi}$ & Amplitude of velocity potential function \\
\hline$D^{*}$ & Flexural rigidity \\
\hline$N_{l o o p}$ & Number of loops \\
\hline$R_{*}$ & Radius of Inductor \\
\hline$R^{*}$ & Reflection coefficient \\
\hline$R_{0}$ & Rayleigh distance \\
\hline$T^{*}$ & Transmission coefficient \\
\hline$U_{a}$ & Amplitude of surface normal velocity of breathing sphere \\
\hline$u_{a}$ & Surface normal velocity of breathing sphere \\
\hline$v_{m}$ & Spatial noise \\
\hline$y_{m}$ & Output signal \\
\hline$\lambda^{*}$ & Eigenvalues \\
\hline$\tau_{m}$ & Time shift \\
\hline$\epsilon_{0}$ & Permittivity of space \\
\hline$a$ & Radius \\
\hline$A^{*}$ & Area \\
\hline $\mathrm{B}$ & Magnetic Field \\
\hline $\mathcal{B}$ & Beamforming function \\
\hline $\mathrm{C}$ & Capacitance \\
\hline $\mathrm{c}$ & Speed of sound \\
\hline
\end{tabular}




\begin{tabular}{|c|c|}
\hline $\mathrm{D}$ & Directivity function \\
\hline$E$ & Young's modulus \\
\hline $\mathrm{h}$ & Thickness \\
\hline$h(r, t)$ & Impulse response function \\
\hline $\mathrm{i}$ & Current \\
\hline I & Intensity \\
\hline $\ln$ & Bessels function of the second kind \\
\hline j & $\sqrt{-1}$ \\
\hline$J_{n}$ & Bessels function of the first kind \\
\hline k & Wavenumber \\
\hline $\mathrm{L}$ & Inductance \\
\hline $\mathrm{n}$ & Noise \\
\hline $\mathrm{p}$ & Pressure \\
\hline$P$ & Point in space \\
\hline r & Radial dimension \\
\hline$S$ & Elemental area of baffle \\
\hline SNR & Signal to noise ratio \\
\hline$،$ & Axial direction indicator \\
\hline $\mathrm{t}$ & Time \\
\hline $\mathrm{T}$ & Time dependent forcing harmonic function \\
\hline $\mathrm{V}$ & Voltage \\
\hline $\mathrm{V}$ & Volume \\
\hline
\end{tabular}




\begin{tabular}{|c|c|}
\hline W & Spatial deflection function \\
\hline $\mathrm{x}$ & Distance \\
\hline y & Distance \\
\hline $\mathrm{z}$ & Distance \\
\hline$\Pi$ & Sound power \\
\hline G & Wave propagation functions \\
\hline$Z$ & Acoustic impedance \\
\hline$f$ & Frequency \\
\hline$u$ & Velocity \\
\hline$C$ & Damping vector \\
\hline $\boldsymbol{F}$ & Forcing vector \\
\hline $\boldsymbol{K}$ & Stiffness vector \\
\hline M & Gain magnitude \\
\hline$M$ & Mass vector \\
\hline $\boldsymbol{R}$ & Coupling and interaction vector \\
\hline $\boldsymbol{U}$ & Displacement vector \\
\hline$\delta$ & Dirac delta function \\
\hline$\theta$ & Angle in $\mathrm{x}-\mathrm{z}$ plane \\
\hline$\kappa$ & Relative Permittivity \\
\hline$\lambda$ & Wavelength \\
\hline$\xi$ & Vorticity \\
\hline$\rho$ & Density \\
\hline$\sigma$ & Elemental area \\
\hline
\end{tabular}


$\psi$

$\omega$

$\phi$
Angle in $x-y$ plane

Circular frequency

Velocity potential function 


\section{Chapter 1}

\section{Introduction}

As applications for unmanned aerial systems (UAS) increase, their environmental awareness for indoor applications is tremendously constrained by the sensors available onboard. Micro-air-vehicles (MAVs) rely primarily on global positioning system (GPS) for navigation in outdoor applications [1]. For low altitude and indoor application, the GPS is highly unreliable and other sensors are needed to perform guidance-navigation and control (GNC) [1].

Traditionally, ultrasonic range sensors are employed for collision avoidance as they are considered light weight and reliable [1,2]. However, as the weight of the MAVs is reducing significantly with advancement in material sciences, the weight of the sensor payload has increased proportionally. As shown in Figure 1-1, the weight of a modern MAV including payload is below $1 \mathrm{~kg}$. Also, from Figure 1-2, it can be seen that the weight of the payload on an MAV accounts for less than $0.1 \%$ of its gross weight.

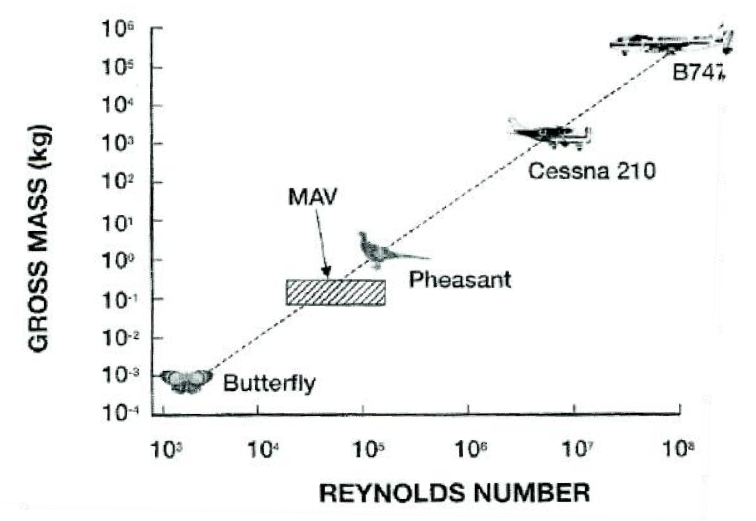

Figure 1-1: Gross mass vs Reynolds number for various flying platforms [2]. 


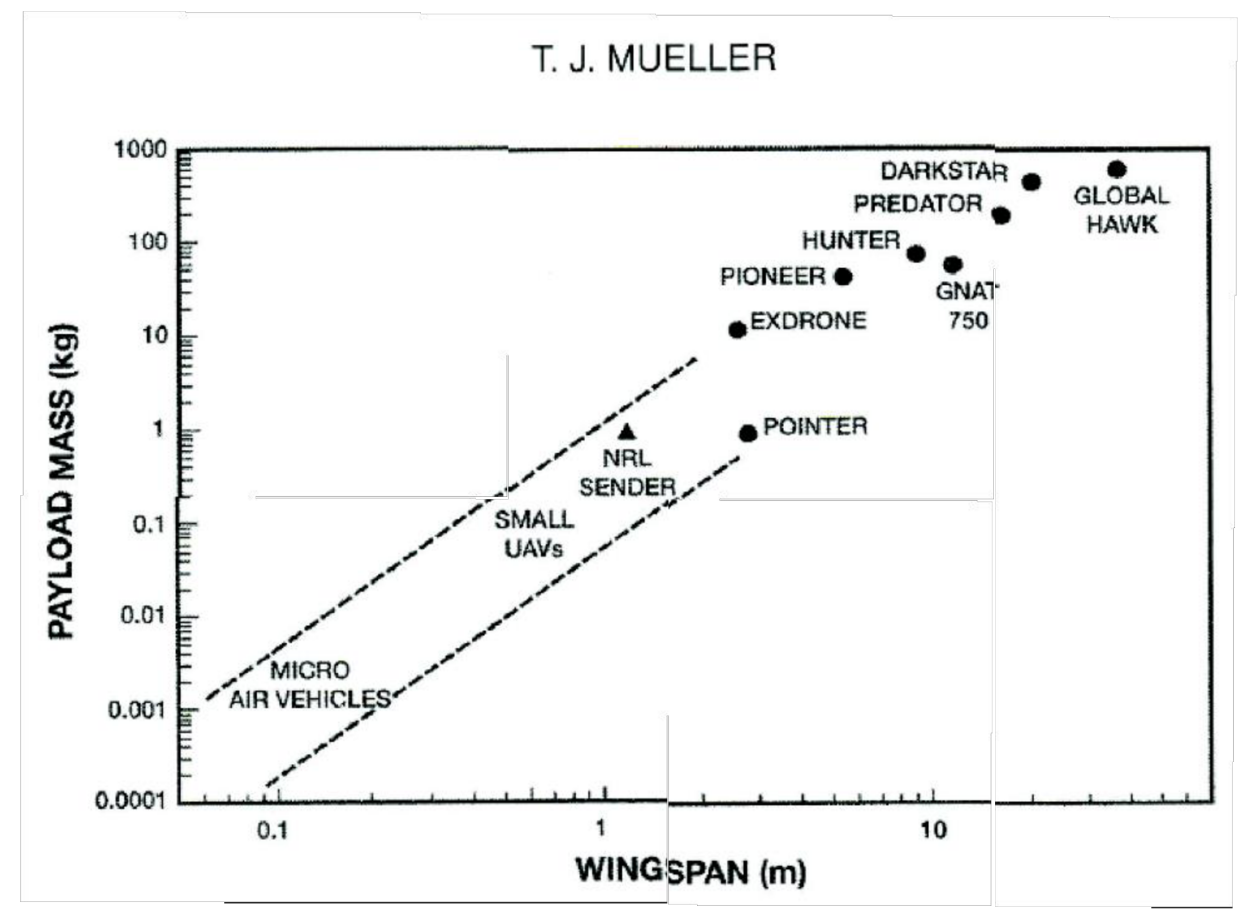

Figure 1-2: Weight of payload versus wingspan of the aerial platform [2].

A modern ultrasonic range sensor is shown in Figure 1-3 and has a weight of $4.3 \mathrm{~g}$. On an MAV platform, a number of these sensors are employed at strategic locations to increase situational awareness and object detection [3]. However, the weight of the sensor modules increases the payload weight significantly making the design infeasible for MAV application.

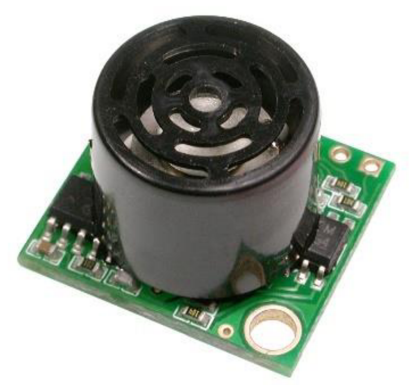

Figure 1-3: Ultrasonic range sensor for indoor applications LV-MaxSonar- EZ0 MB1000 [4] 
In this thesis, an attempt is made towards improving the performance of these ultrasonic range sensors by using a phased array approach to steer the beam without the use of mechanical servos or actuators. The phased array approach allows for a reduction in the number of sensors employed by varying the angular control of a detection beam. The reduction in the sensor weight is accompanied by an improvement in the performance, inherent to a phased array system, thus offering a higher signal to noise ratio (SNR) [5].

\subsection{Thesis Objectives.}

The research presented focuses on development and design of a low cost air-coupled ultrasonic transducer that can be operated over a frequency range. Since most commercially available piezoelectric ultrasonic range sensors operate at $42 \mathrm{kHz}$, a variable frequency design is selected with an operation range between $30 \mathrm{kHz}$ and $100 \mathrm{kHz}$.

The air-coupled ultrasonic transducer design is expanded to a phased array to study the effects of phased array transmission and reception. The phased array transducer design is compared to a piezoelectric transducer design to quantify the performance of the air-capacitive transducer.

To make the system efficient for a UAS application, a low power computational device is required, specifically a microcontroller, is required. This allows for the system to be embedded as a standalone unit on a UAS platform. 


\subsection{Thesis Organization}

The thesis is organized into the following chapters:

Chapter 2: Commonly available range sensors are discussed with a brief insight into the physics involved. An overview of the Lead Zinc Titanate (PZT) based ultrasonic sensor is given, followed by a brief analysis of the air-capacitive design. The current limitation of the PZT are discussed along with the benefits of a phased array approach.

Chapter 3: An in-depth analysis into the physics of sound generation using an air-capacitive sensor is described using a single sensor. Using the single source propagation model, a single point receiver model is established. The single source and single receiver model is expanded to an array response for phased array propagation and reception modelling. Lastly, parameters to measure the performance of the sensor are described and the desired performance from the sensor array are established.

Chapter 4: The physical model outlined in Chapter 3 forms the basis of the analytical approach used to measure the theoretical performance. However, the lack of air coupling at the surface of the sensor is neglected by the analytical approach. A numerical method using Galerkin's approach is used to discretize the problem and allow for the inclusion of the air coupling mechanism. The results from the numerical and analytical approaches are then compared to visually and mathematically represent the effect of air-coupling at the surface of the sensor.

Chapter 5: The system design of the sensor array involving three sensors is described. The time of arrival (TOA) technique using a phased array approach is adapted to the three element array design. Similarly, a position and angle extraction algorithm is developed to estimate the position of the target. 
Chapter 6: The construction methodology using photolithography is described in detail. Also, A variety of other methods are discussed briefly and a repeatability test is performed on the photolithography technique to highlight the robustness and repeatability of the process.

Chapter 7: A component level digital design is detailed along with the circuit design. The system is divided into two main parts; propagation and reception model. The propagation model focuses on developing a focused beam at a specified angle and frequency. The reception model includes filtration, amplification and phase determination of the received signal. The outputs from the phased array system are forwarded to the user interface module.

Chapter 8: The results obtained using the modelling approach outlined in the aforementioned chapter are discussed. Two transducer design; PZT and air-capacitive, are used for the analysis. The performance of each sensor is discussed along with the effects of varying frequency, measurement range, phasing capabilities and target detection.

Chapter 9: Conclusions drawn from the research are presented along with recommendation for future work including improvements of the current design.

\subsection{Summary of Contributions}

In this research, a variable frequency air-capacitive ultrasonic phased array sensor is designed and developed. The air-coupled vibration modal frequency is determined using Ansys Workbench's fluid structure interaction simulation.

A printed circuit board manufacturing method was designed to test a PZT transducer array along with an air-coupled transducer array. To facilitate the testing of the phased array design, an anechoic chamber was also designed and constructed. The frequency and noise isolation response of the anechoic chamber was characterized for correction factor. 
A novel circuit design involving a variable frequency design is implemented using a LM 555 timer. The variable frequency design is user controlled and forwards the frequency signal to a microcontroller for phasing. The AT-Mega 328p platform, is selected as the microcontroller as it has 3 on board timers that can be used for phasing the output beam to a specific angle. During the reception phase, the circuit design employs an eighth order multiple feedback bandpass filter for signal isolation and noise reduction. The time delay captured by the circuit design is used as an input to a time of arrival algorithm used to determine the target position in space.

Experiments are conducted to quantify the performance of the phased array air-capacitive ultrasonic sensor. The effects of phasing output and beamforming reception model are described. The phased array approach enhances the performance over an individual sensor by manipulating regions of signal amplification and nulls, thus producing a directional effect.

This thesis has contributed to the understanding of phased array ultrasonic sensor design, particularly in the application of obstacle detection. Furthermore, effects of variables in manufacturing and design of the transducer were studied and quantified to attain desired performance. 


\section{Chapter 2}

\section{Review of Range Finding Sensing Technologies}

This chapter highlights the various methods of range sensing and divides the sensors according to their method of sensing. A comparison between the sensor types is performed and their feasibility for a MAV application are detailed. Based on the evaluation of each sensor's capability and its feasibility with the design requirements, a sensor design is selected and discussed.

\subsection{Methods of range sensing}

There is a multitude of methods to determine the range of a target, which includes optical, acoustic, inductive and capacitive methods. The optical and acoustic methods rely on the "pulse and echo" technique, where the range of a target is determined by the time of flight of the signal wave from the source (pulse) to the target and back to a receiver (echo) [6]. On the other hand, the inductive and capacitive transducers measure the change in electromagnetic and electrostatic field, respectively [7].

\subsection{Capacitive range sensing}

The capacitive sensor measures the change in capacitance induced by a target present in the field of the sensor. From equation 2.1, it can be seen that the measured capacitance depends directly on the composition of the target [7]

$$
C=\frac{\kappa \epsilon_{0} A^{*}}{x}
$$


The excitation circuitry, which measures the change in the capacitance by measuring the capacitor's time constant, varies the current proportionally with respect to the changing capacitance to maintain a constant electric field [7]. Figure 2-1, highlights the change in the output signal, used to determine the change in capacitance.

\section{- -ा1سएسए}

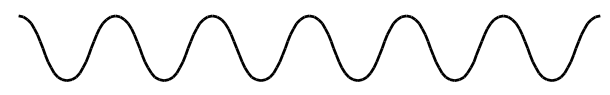

- IIIIII)

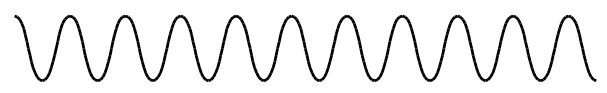

- IIIIIIL

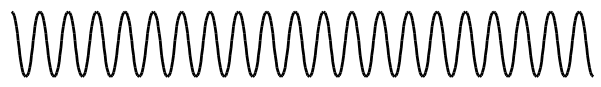

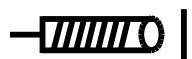

Figure 2-1: Capacitive range sensor output signal with respect to change in target position

There will be a critical distance $x_{\max }$, where the change in capacitance will result in an insignificant change in current measurement as shown by the following equation $[8,9]$ :

$$
i(t)=C \frac{d V(t)}{d t}
$$

Table 2-1: Capacitive position sensors $[10,11,12,13,14]$

\begin{tabular}{|c|l|}
\hline Capacitive Sensor & Maximum range $\left(x_{\max }\right)$ \\
\hline Balluff BCS0077/0078 & $30 \mathrm{~mm}$ \\
\hline Omron E2K-C & $25 \mathrm{~mm}$ \\
\hline Rockwell 875C-M10NN30-A2/D4 & $30 \mathrm{~mm}$ \\
\hline Eaton E53 Average & $35 \mathrm{~mm}$ \\
\hline \multicolumn{1}{|c|}{ Ave } & $\mathbf{3 0 ~} \mathbf{m m}$ \\
\hline
\end{tabular}


Table 2-1 shows the maximum range $x_{\max }$ of several commercially available capacitive sensors. Since the average maximum range is limited to a mere $30 \mathrm{~mm}$, it is evident that the capacitive sensors do not present a feasible option for long range sensing for the current application.

\subsection{Inductive range sensing}

The inductive sensor works similar in principle to a capacitive sensor in that it measures the change in the field variable, which in this case is inductance. An alternating current is passed through the inductor as shown in Figure 2-2; this produces an alternating magnetic field. The relationship between the magnetic field and the current is given by equation $2.3[8,9]$.
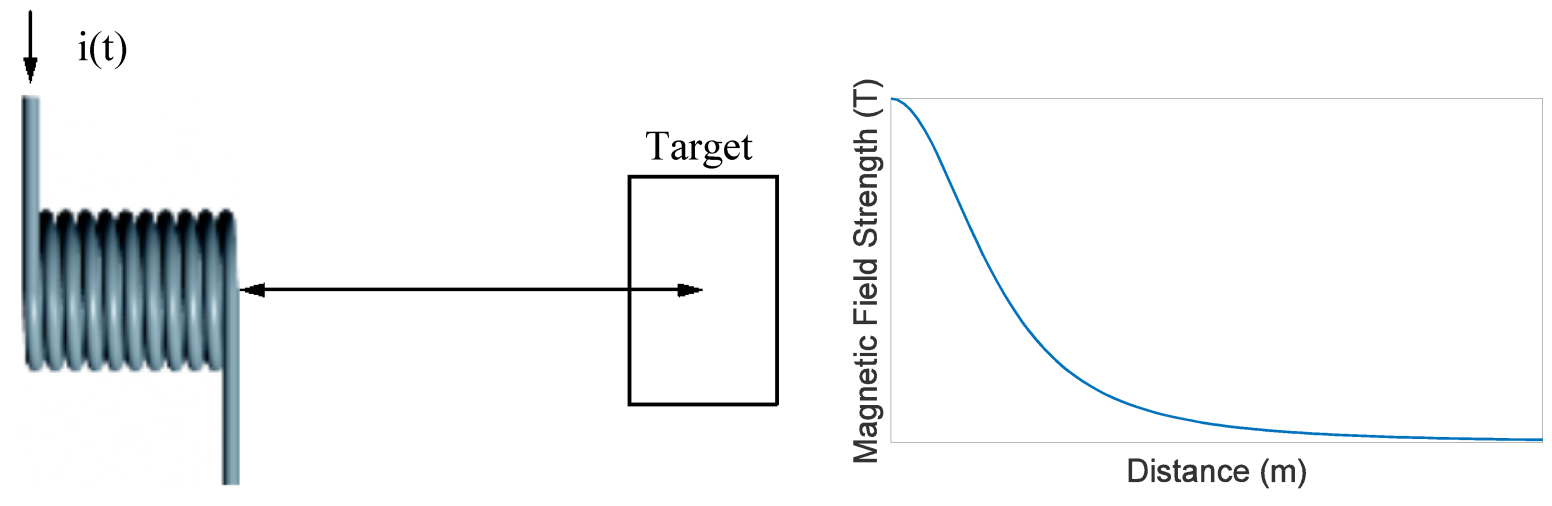

Figure 2-2: Inductive position sensor

$$
B=N_{\text {loop }} \frac{\mu}{2} \frac{i(t) R_{*}^{2}}{\left(x^{2}+R_{*}^{2}\right)^{\frac{3}{2}}}
$$

The time-varying magnetic field induces a surface current on the target object, thus changing the magnitude of the magnetic field. The oscillator drive circuitry is designed to maintain a fixed magnetic field. Therefore, a change in the magnetic field produces a measurable change in alternating current $[7,9]$. 
An inductive sensor can only sense metallic objects since nonconductive materials do not have free electrons and cannot produce surface charges [7]. Figure 2-2 and Equation 2.3 outline the highly nonlinear relationship between sensing distance and the magnetic flux. This non-linear relationship drastically reduces the measurement range, however by increasing the number of coil windings or current flow, a higher magnetic field can is produced, increasing the measurement range [9]. Table 2-2 outlines the maximum sensing range of a few commercially available inductive sensors.

Table 2-2: Inductive position sensors $[15,16,17,18]$

\begin{tabular}{|l|l|}
\hline inductive Sensor & Maximum range $\left(x_{\max }\right)$ \\
\hline Balluff BAW003L & $60 \mathrm{~mm}$ \\
\hline Omron E2Q5-N40ME1-M1 & $40 \mathrm{~mm}$ \\
\hline Rockwell 872C & $40 \mathrm{~mm}$ \\
\hline Eaton E56CDL100UAE01 & $100 \mathrm{~mm}$ \\
\hline \multicolumn{1}{|c|}{ Average } & $\mathbf{6 0 ~} \mathbf{~ m m}$ \\
\hline
\end{tabular}

As seen from Table 2-2, by increasing the magnetic field the range of the sensor is significantly higher than a capacitive sensor as seen in Table 2-1. The increased range of the inductive sensor is still well under a meter, and in comparison, to optical and acoustic methods does not present a feasible option for an MAV application. 


\subsection{Optical range sensing}

The optical method of range sensing employs a light source such as a laser or infrared and a receiver to detect the reflected beam. The time delay between the projected and reflected beam is measured to determine the range of the target object. The infrared range sensors employ an infrared light emitting diode (IR-LED) that emits IR light with a fixed wavelength, typically between 0.9-1.7 $\mu \mathrm{m}$ [19]. Since, the emitted IR beam is of short wavelength, air molecules scatter the light. The relationship between the wavelength of light and the scattering is given by [20,21]:

$$
I \propto \frac{1}{\lambda^{4}}
$$

As the wavelength of light increases, the intensity decreases, this poses a severe limitation to the detection range, where a $10 \%$ increase in the wavelength can result in a $31.8 \%$ reduction in the intensity of light. Along with scattering, the range of an IR device decreases in the presence of a heat source and sunlight. Table 2-3, outlines the range sensing capabilities of a few IR range sensors.

Table 2-3: Infrared position sensors [22,23,24,25]

\begin{tabular}{|l|l|}
\hline Infrared Sensor & Maximum range $\left(x_{\max }\right)$ \\
\hline Sharp GP2Y0A21YK0F & $80 \mathrm{~cm}$ \\
\hline Sharp GP2Y0A710K0F & $350 \mathrm{~cm}$ \\
\hline Sharp GP2Y0A02YK0F & $150 \mathrm{~cm}$ \\
\hline Sharp GP2Y0A60SZ0F & $150 \mathrm{~cm}$ \\
\hline Average & $\mathbf{1 8 2 . 5} \mathbf{c m}$ \\
\hline
\end{tabular}


The shortcomings of the IR-based sensors are mitigated by replacing the non-collimated LED source with a collimated laser source. A laser range sensor has a longer distance measurement range than an LED sensor due to the monochromatic and collimated nature of the light being emitted $[26,21]$. The beam of light emitted by an IR-LED is a broader spectrum as compared to a laser light source, requiring the receiver to be of a wider bandwidth thus reducing the probability of signal detection $[19,26]$.

The optical method of range sensing significantly improves the range sensing capability of the sensor; however, the limitations restrict their use. Laser and IR sensors are unable to detect optically transparent materials such as glass and clear plastics. Their performance is further degraded by the presence of smoke (increased diffraction) and non-reflective or light-absorbing materials. In the case of IR, the temperature of the target alone can degrade the range perception of the sensor severely [19,21].

\subsection{Acoustic range sensing}

Non-contact acoustic range measurement employs the echo location technique to locate targets in the field of the sensor. The methodology is similar to the optical methods discussed previously, where the time of flight of an acoustic wave from the emitter to the object and back again is measured by the sensor circuitry to determine the range of the target [27].

This acoustic range sensing system involves a transmitter and a receiver, in some modern sensors a transceiver, to determine the range of the target [28]. Figure 2-3, highlights the two common types of ultrasonic range sensors used in range sensing applications. Figure 2-3 a, shows an ultrasonic sensor with a transceiver design while Figure 2-3 b, employs a separate transmitter and receiver. The transceiver design offers weight reduction by combining the transmitter and the 
receiver. However, this weight reduction is achieved at the expense of a fixed maximum range, as the sensor has to switch between propagation and reception mode. Table 2-4 outlines the performance of a few ultrasonic range sensors along with their weight.

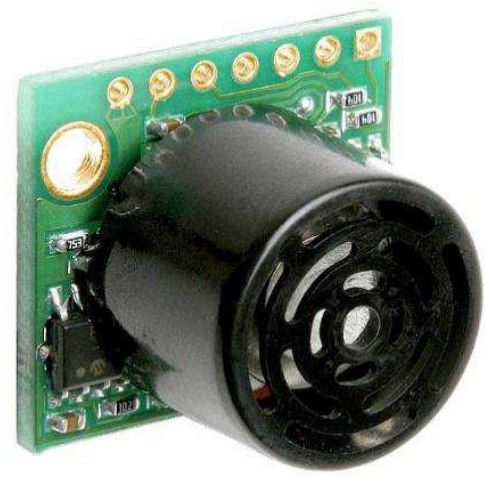

a) Transceiver design

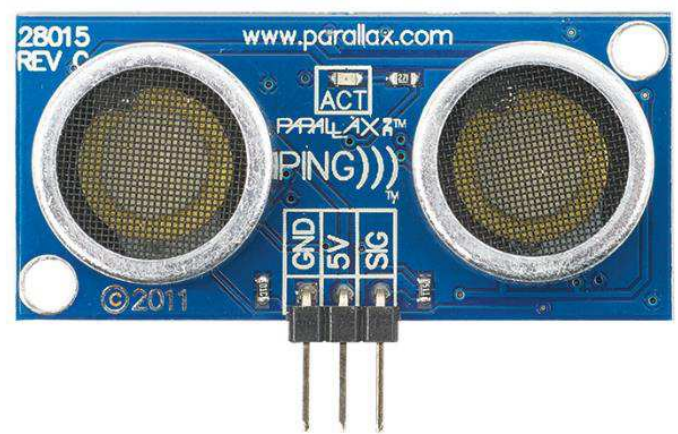

b) Separate transmitter and receiver design

Figure 2-3: Types of ultrasonic range detection sensors [29,30]

Table 2-4: Ultrasonic position sensors [31,32,33]

\begin{tabular}{|l|l|l|}
\hline Ultrasonic Range Sensor & Range & Weight \\
\hline Maxbotics LV-MaxSonar -EZ 0 & $600 \mathrm{~cm}$ & $4.3 \mathrm{~g}$ \\
\hline Maxbotics X L-MaxSonar -WR 1 & $1000 \mathrm{~cm}$ & $50 \mathrm{~g}$ \\
\hline Parallax Ping Sensor & $300 \mathrm{~cm}$ & $9 \mathrm{~g}$ \\
\hline Average & $\mathbf{6 3 3 . 3 c m}$ & \\
\hline
\end{tabular}

The transducers are typically made from piezo-ceramics, most commonly involving the lead zirconium titanate (PZT) [34]. The piezo-ceramic used in ultrasonic range finders involves 
the 1-3 configuration, where the parallel PZT fibers are embedded in and supported by a polymer matrix as shown in Figure 2-4 [34,35,36].
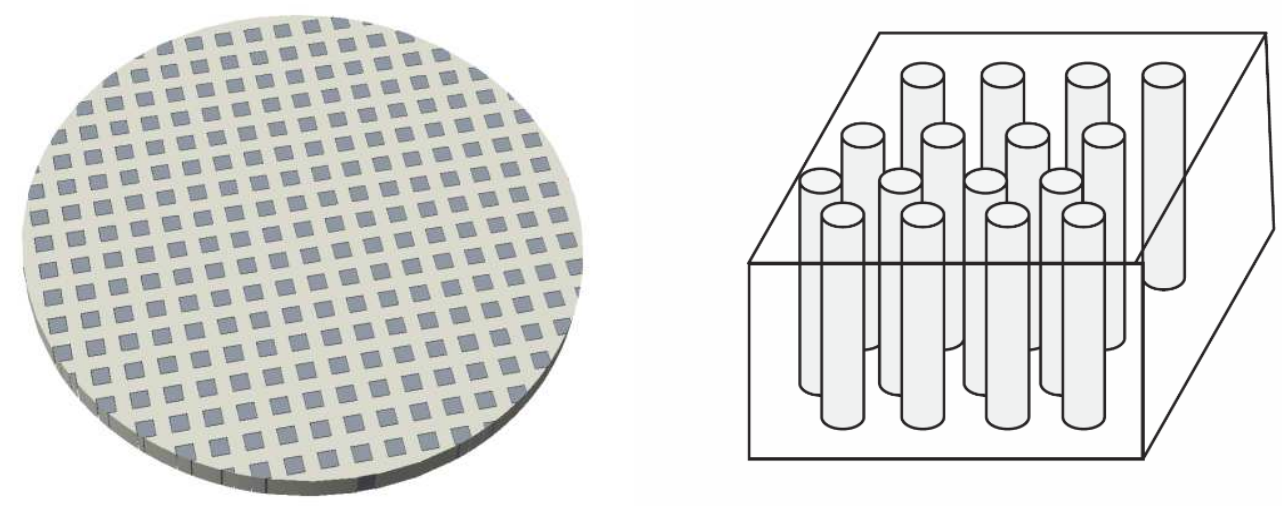

Figure 2-4: PZT transducer composite structure, adapted from [34]

Upon application of an alternating electrical potential, the piezo-ceramic fibers contract and elongate due to the piezoelectric effect, inducing an internal vibration of the composite structure. Exciting the PZT at resonant frequencies produces greater sound pressure, thus increasing the measurement range of the sensor [34].

The disadvantaged of piezo-ceramic transducers is the inefficiency in air-coupled application due to the acoustic impedance mismatch that occurs on the surface boundary of the transducer during oscillation. The energy transmission and reflections coefficients is given by the following equation [27,37]

$$
\begin{aligned}
& T^{*}=\frac{4 Z_{1} Z_{2}}{\left(Z_{1}+Z_{2}\right)^{2}} \\
& R^{*}=\left(\frac{Z_{1}-Z_{2}}{Z_{1}+Z_{2}}\right)^{2}
\end{aligned}
$$


Where $Z_{1}$ and $Z_{2}$ are specific acoustic impedances of the two medium given by

$$
\begin{aligned}
& Z_{1}=\rho_{1} c_{1} \\
& Z_{2}=\rho_{2} c_{2}
\end{aligned}
$$

The transmission coefficient highlights the transfer of acoustic energy from the sensor to the medium at the interface. On the other hand, the reflection coefficient accounts for the reflected energy within that reverberates within the sensor's structure. Table 2-5 outlines the transmission coeffient of some common piezoelectric materials.

Table 2-5: Transmission coefficients of various piezoelectric materials [38]

\begin{tabular}{|l|c|c|c|c|}
\hline Material & Density & Speed of sound & \multicolumn{1}{|c|}{$\begin{array}{c}\text { Acoustic } \\
\text { Impedance }\end{array}$} & $T_{\text {air }}$ \\
\hline Quartz $\mathrm{SiO}_{2}$ & 2650 & 5760 & $15.3 \times 10^{6}$ & $10.8 \times 10^{-5}$ \\
\hline $\begin{array}{l}\text { Zirconate } \\
\text { piezoceramic } \\
\text { PZT-5 }\end{array}$ & 7750 & 3880 & $30 \times 10^{6}$ & $5.5 \times 10^{-5}$ \\
\hline $\begin{array}{l}\text { Lead-niobate } \\
\text { Piezoceramic } \\
\text { PbNb } 2 O_{6}\end{array}$ & 5800 & 2800 & $16 \times 10^{6}$ & $10.3 \times 10^{-5}$ \\
\hline $\begin{array}{l}\text { Piezopolymer } \\
\text { PVDF }\end{array}$ & 1780 & 2260 & $4.6 \times 10^{6}$ & $35.9 \times 10^{-5}$ \\
\hline
\end{tabular}

In order to overcome the transmission losses due to impedance mismatching, an ultrasonic focusing aperture is used with a PZT transducer as shown in Figure 2-5. The aperture axially focuses the ultrasonic beam in order to provide directionality to the ultrasonic energy being transmitted while simultaneously reducing scattering [27,34]. 


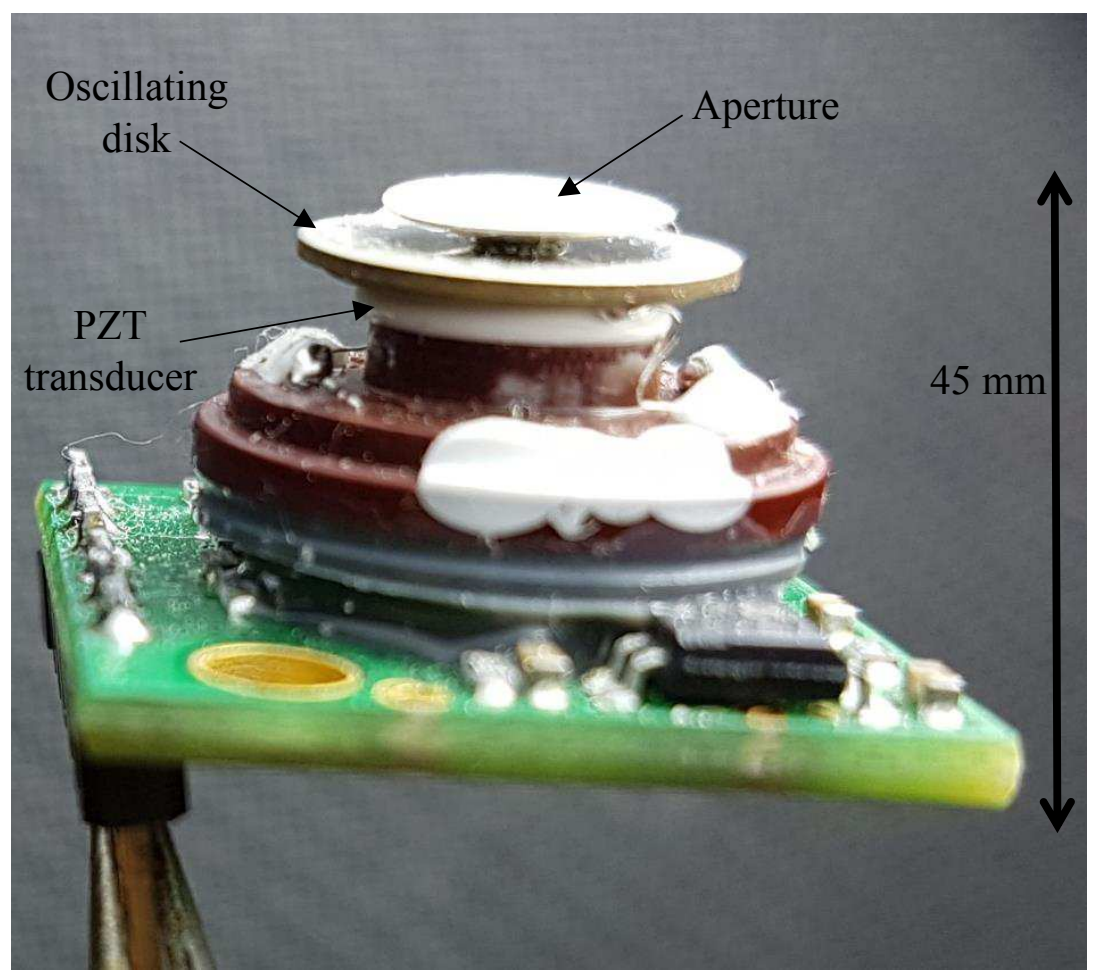

Figure 2-5: Internal components of a disassembled PZT range sensor.

While the impedance mismatch highlights the transmission losses between the medium and the transducer, the PZT also requires large amounts of power to drive the oscillating sensor. Since the dynamic behavior of a PZT is very complex, its dynamic behavior is given by the equivalent circuit show in Figure 2-6. It can be seen that in order to oscillate the sensor at high frequencies, the drive circuitry must be capable of providing high current at high voltages. Additionally, the resonance frequency of the PZT is entirely dependent on the geometry and the internal capacitance of the PZT transducer. 


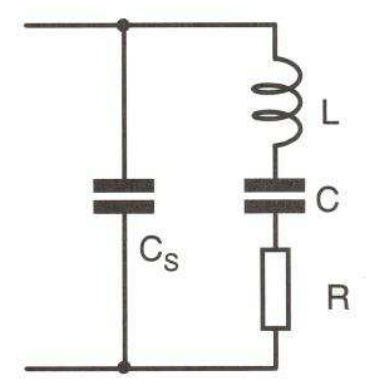

$$
f=\frac{1}{2 \pi} \sqrt{\frac{C+C_{S}}{L C C_{S}}}
$$

Figure 2-6: Equivalent circuit for a PZT transducer, adapted from [27,39]

Electrostatic coupled or air-capacitive sensors, improve on the bandwidth of the acoustic sensors versus PZT devices. While being driven at lower voltages, these sensors are purely capacitive in nature and have lower internal electrical capacitance as compared to PZT transducers. This reduces the time constant that allows the circuit to be excited at very high frequencies ranging from $10 \mathrm{kHz}-10 \mathrm{MHz}$ [27].

While ultrasonic range sensors improve upon the issues related to indoor flight, when compare to the aforementioned optical methods, the acoustic methods of range sensing are accompanied with their own set of limitations. The acoustic sensors are very sensitive to ambient noise especially if the noise present in the environment is within the operating frequency of the sensor (e.g. ultrasonic room occupant sensors). Target acoustic absorption is another factor that deteriorates the acoustic range sensor's detection capability as the target absorbs the sound wave and the reflected amplitude is significantly reduced. However, for MAV application, an ultrasonic sensor is favorable over an optical sensor due to lower power consumption. A typical ultrasonic range sensor operates between $3 \mathrm{~V}$ to $5 \mathrm{~V}$ and requires between 3 to $5 \mathrm{~mA}$ of current, while the most advanced and compact laser range finder consumes $100 \mathrm{~mA}$ at $5 \mathrm{~V}$. 


\subsection{Research Objectives}

Conventional PZT-based ultrasonic range sensors are employed in a variety of UAS platforms including but not limited to fixed wing, rotorcraft and multirotor systems. Most of the aforementioned systems also employ Global Navigation Satellite System (GNSS) receivers that cannot be used for indoor MAV flight and navigation. The GNSS-based navigation approach is also impractical for outdoor MAV applications due to platforms' limited power and payload capacity $[40,41]$.

The PZT-based ultrasonic sensors are capable of providing short range situational awareness when placed at specific locations, their weight and accompanying control system renders them heavy enough to be neglected for MAV applications [38]. Figure 2-7 shows an early attempt by a prior student made towards incorporating a coupled array of PZT ultrasonic range sensors to enhance the system's sensing capability from 1-D to 2-D. However, the increase in weight and size, outweighs the benefits in sense and avoid application [42]. While there are mechanical methods to physically rotate the sensor perpendicular to its measurement axis, these methods also add extra weight to the aircraft and draw increased power.
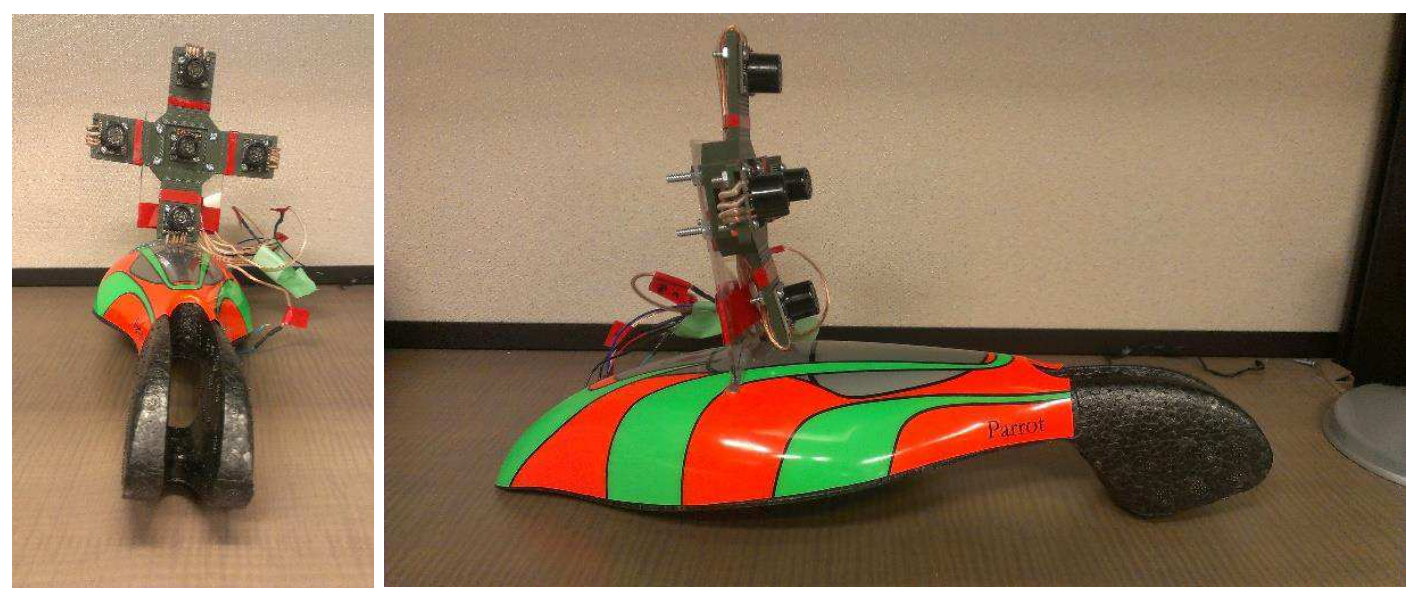

Figure 2-7: Phased array PZT range sensor on Parrot AR Drone. 
A phased array approach involving multiple sensors can allow the outbound ultrasonic signal beam to be steered, similar to mechanical actuation or actively scanned radar systems. The phasing approach eliminates the extra weight and power required by the mechanical system. This phased array air coupled capacitive ultrasonic range determination technique will be the focus of the thesis. The following chapters elaborate on the principles, design and construction of this novel sensor system. 


\section{Chapter 3}

\section{Background Theory of Acoustics and Sound Propagation}

Sound being a pressure wave travels through a medium by transferring energy from one particle to another. In order for the wave to propagate through the medium, it must possess the physical properties of inertia and elasticity. Such a vibratory motion is termed as sound when the medium of wave transfer is a liquid such as air $[33,44]$.

The problem of acoustic analysis can be resolved by three approaches - wave acoustics, ray acoustics and energy acoustics [45]. The classical analysis of sound generation and propagation focuses on the wave acoustics approach, due to its fundamental nature. Therefore, in the following analysis the wave acoustics approach is adopted for modelling of the transducer [44,45].

\subsection{Acoustic Wave Model}

A sound wave is the transfer of information from a point in space to another through the vibratory motion of waves. The important parameters that allow the measurement of the transportation of this information in space are pressure $(P)$, velocity $(u)$ and density $(\rho)[44,45]$. 


\subsection{Dispersion Relationship}

The parameters, pressure, velocity and density are all time and spatially interdependent functions. The mathematical relationship describing the interdependency is given by the Dispersion relationship $[45,27,46]$ :

$$
\lambda=\frac{c}{f}
$$

Where $\lambda$ is the wavelength, containing the spatial component and $f$ is the frequency, containing the time domain component. The interdependency between time and space is related by the wave propagation speed of the medium, $c[45,27]$. The interdependencies shown by the dispersion relationship form the basis of physical acoustic analysis.

\subsection{Conservation of Mass and Momentum (velocity and density relationship)}

A one dimensional mass flow through an elemental control volume $d V$ is illustrated in Figure 3-1. Where $u_{x}$ represents the velocity along the x-axis.

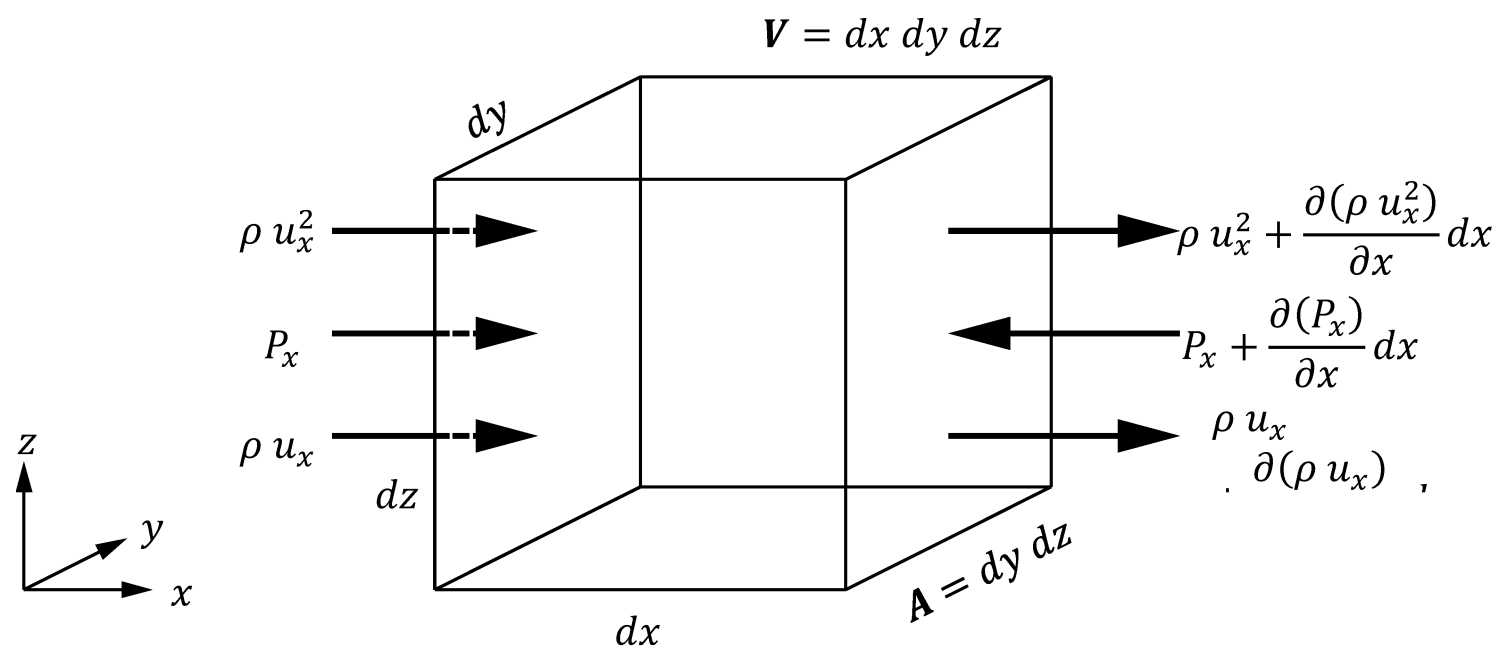

Figure 3-1: Mass and momentum balance, adapted from [44,45] 
From the principle of conservation of mass [44]:

$$
\frac{\partial(\rho A d x)}{\partial t}=(\rho u A)_{x}-(\rho u A)_{x+d x}
$$

Using Taylor-series expansion [44]:

$$
\frac{\partial(\rho A d x)}{\partial t}=\left\{(\rho u A)_{x}-(\rho u A)_{x}-\frac{\partial(\rho u A)_{x}}{\partial x} \partial x\right\}
$$

Equation (3.2) can be simplified to the following expression:

$$
\frac{\partial \rho}{\partial t}+\frac{\partial\left(\rho u_{x}\right)}{\partial x}=0
$$

Expanding the equation from one dimension to all three dimensions leads to the following expression:

$$
\frac{\partial \rho}{\partial t}+\rho \vec{\nabla} \cdot \vec{u}=0
$$

Where the Nabla operator defines the divergence of the velocity in all three axes.

It is important to note that the term $\frac{\partial \rho}{\partial t}$ takes into the account the fluctuation of the density with respect to time and therefore varies with position and time [27]. On the other hand, the density model associated with the velocity is time independent and only has spatial components determining its value $[44,45]$. Therefore, equation (3.5) defines the direct relationship between velocity and density. 


\subsection{Conservation of momentum (pressure and velocity relationship)}

The equation of conservation of momentum can also be obtained using a similar approach by balancing the forces around the elemental volume $d V$ in one dimension. From Figure 3-1 the elemental force balance is shown as follows.

$$
\frac{\partial\left(\rho u_{x} A\right) d x}{\partial t}=\left(\rho u^{2} A\right)_{x}-\left(\rho u^{2} A\right)_{x+d x}+(P A)_{x}-(P A)_{x+d x}
$$

By performing a Taylor series expansion, the above expression simplifies to:

$$
\frac{\partial\left(\rho u_{x}\right)}{\partial t}=\frac{\partial\left(\rho u_{x}^{2}\right)}{\partial x}-\frac{\partial P}{\partial x}
$$

Representing the equation in three dimensions yields:

$$
\rho\left\{\frac{\partial \vec{u}}{\partial t}+(\vec{u} \cdot \vec{\nabla}) \vec{u}\right\}+\vec{\nabla} P=0
$$

The equation is the famous Euler equation and is also known as the nonlinear, inviscid momentum equation $[44,46]$. For the wave propagation model, the nonlinearities of Euler's equation can be simplified using linearization where by the higher order convection terms in the function are neglected $[45,46]$ thus producing the following expression known as the linear inviscid force equation encompassing the conservation of momentum in three dimensions or the linearized Euler's Equation [46].

$$
\rho \frac{\partial \vec{u}}{\partial t}+\vec{\nabla} p=0
$$

Therefore, the linearized Euler's Equation, fully describes the relationship between excess pressure and velocity [45]. 
Finally, the relationship between density and pressure can be established by employing the state equation as described by $[47,48]$ as:

$$
\frac{\partial P}{\partial \rho}=c^{2}
$$

\subsection{Velocity Potential Function}

In a velocity field, the curl of the velocity is equal to the vorticity, however for an irrotational flow, the vorticity is 0 at every point $[48,49]$.

$$
\xi=\vec{\nabla} \times \vec{u}=0
$$

Consider a scalar $\phi$, which defines the velocity potential such that [49]:

$$
\vec{u}=\vec{\nabla} \phi
$$

Then $\partial \phi$ by definition is given as $[50,51]$ :

$$
\partial \phi=u_{x} \partial x+u_{y} \partial y+u_{z} \partial z
$$

The velocity potential holds great significance in the field of acoustics and sparks an obvious interest into the physical interpretation of the function itself. To understand the function, the Euler equation is integrated with respect to the time domain [46]:

$$
\int-\frac{1}{\rho} \frac{\partial p}{\partial x} d t=\int \frac{d u_{x}}{d t} d t=u_{x}+u_{0}
$$

To develop a linear model, the nonlinearity introduced by $\frac{d u}{d t}$ an instantaneous motion of an infinitely short interval is assumed. The impulsive force $\phi$ per unit mass can be described by the following equation $[48,49]$ : 


$$
\phi=\int \frac{p}{\rho} d t
$$

Thus, producing the $\mathrm{x}$-axis partial differential of equation (3.2):

$$
u_{x}=-\frac{\partial \phi}{\partial x}
$$

Therefore, "the velocity potential function is identical with the impulsive response force per unit mass of fluid that would generate the motion described by it from rest" [46].

\subsection{Modelling spherical sound waves emitting from a point source transducer}

To develop the wave propagation model, the first approximation is made by assuming the transmitter to be a point source. Since the point source will be emitting the sound waves in all three dimensions, a spherical geometry is selected to simplify the model. The geometry is then used to determine the wave equation in spherical coordinates.

Since sound waves propagate radially out from the source, therefore the spherical coordinate system model reduces from a three dimensional model to a one dimensional model with radial distance $(r)$ as the variable. The resulting wave equation is:

$$
\frac{\partial^{2}(r \phi(r, t))}{\partial r^{2}}-\frac{1}{c^{2}} \frac{\partial^{2}(r \phi(r, t))}{\partial t^{2}}=0
$$

Where $\phi, c$ and $r$ represent the velocity potential, speed of sound in air and radial distance, respectively.

From the principles of harmonic motion, the solution to the velocity potential can be approximated using the general solution of harmonic systems [52]:

$$
\phi(r, t)=\frac{G_{1}\left(t-\frac{r}{c}\right)}{r}+\frac{G_{2}\left(t+\frac{r}{c}\right)}{r}
$$


From harmonic motion analysis, it is known that $G_{1}$ and $G_{2}$ are any arbitrary functions defining the direction of wave propagation. The function $G_{1}$ defines the waves propagation radially outwards and the function $G_{2}$ defining the propagation from the boundary defined by the radius back towards the source $[44,52]$. Since the focus of the analysis is on waves propagating away from the source, the function $G_{2}$ is neglected. On the other hand, the solution to $G_{1}$ is assumed to be a complex harmonic solution and is shown to be [44]:

$$
\phi(r, t)=\frac{A_{\phi}}{r} e^{j(\omega t-k r)}
$$

Where $A_{\phi}$ is a constant determined by boundary condition at the surface of the point source and $k$ is the wave number.

Now, by extrapolating from the model of a breathing sphere of radius $a$, and a surface normal velocity solution given by [44]:

$$
u_{a}=U_{a} e^{j \omega t}
$$

Substituting equation (3.19) into (3.20) given that the relation is described by the expression $\frac{\partial \phi}{\partial r}=$ $u_{r}$, results in the solution of the scalar constant $A_{\phi}$ as a solution with respect to the normal surface velocity and is given as [44]:

$$
A_{\phi}=-U_{a}\left\{\frac{a^{2}}{1+j k a}\right\} e^{j k a}
$$

By substituting the scalar $A_{\phi}$ into the velocity potential function produces the following expressions [27]:

$$
\phi(r, t)=-\frac{U_{a}}{r}\left\{\frac{a^{2}}{1+j k a}\right\} e^{i(\omega t-k(r-a))}
$$


By introducing the concept of source strength $Q(t)$, defined as the surface area multiplied by the surface velocity produces the expression [44,27]:

$$
Q(t)=4 \pi a^{2} U_{a} e^{j \omega t}=Q_{p} e^{j \omega t}
$$

The expression for the velocity potential can then be rewritten as [45]:

$$
\phi(r, t)=-\frac{Q(t)}{4 \pi r}\left\{\frac{1}{1+j k a}\right\} e^{-j k(r-a)}
$$

Similarly, pressure $(p)$, velocity $(u)$, acoustic impedance $\left(Z_{a}\right)$, intensity $(I)$ and sound power (I) can be evaluated and are given as follows [44]:

$$
\begin{gathered}
p(r, t)=-\rho\left\{\frac{\partial \phi}{\partial t}\right\}=-j k \rho c \phi(r, t)=\frac{Q_{p}}{4 \pi r}\left\{\frac{j k \rho c}{1+j k a}\right\} e^{\{\omega t-k(r-a)\}} \\
u(r, t)=\frac{\partial \phi}{\partial r}=-\left\{\frac{1+j k r}{r}\right\} \phi(r, t)=\frac{Q_{p}}{4 \pi r}\left\{\frac{1+j k r}{1+j k a}\right\} e^{\{\omega t-k(r-a)\}} \\
Z_{a}=\rho c\left\{\frac{k^{2} r^{2}}{1+k^{2} r^{2}}+j \frac{k r}{1+k^{2} r^{2}}\right\} \\
I(r)=\frac{Q_{p}^{2} k^{2} \rho c}{32 \pi^{2} r^{2}\left(1+k^{2} a^{2}\right)} \\
\Pi=\int_{S} \vec{I} \cdot d \vec{S}=4 \pi r^{2} I(r)=q=\frac{Q_{r m s}^{2} k^{2} \rho c}{4 \pi\left(1+k^{2} a^{2}\right)}
\end{gathered}
$$

From equation (3.27) it can be seen that the acoustic impedance has a reactive and resistive component represented by their imaginary and real parts, respectively. When the acoustic impedance is dictated only by the real component, the sound pressure fluctuations and the velocity are in phase. This case only happens when the value of $k r \gg 1$ and allows for sound power to propagated outwards from the source. On the other hand, when the acoustic impedance is reactive 
or complex and $k r \ll 1$, then the pressure fluctuations are out of phase with the velocity therefore producing no sound power as shown in Figure 3-2.

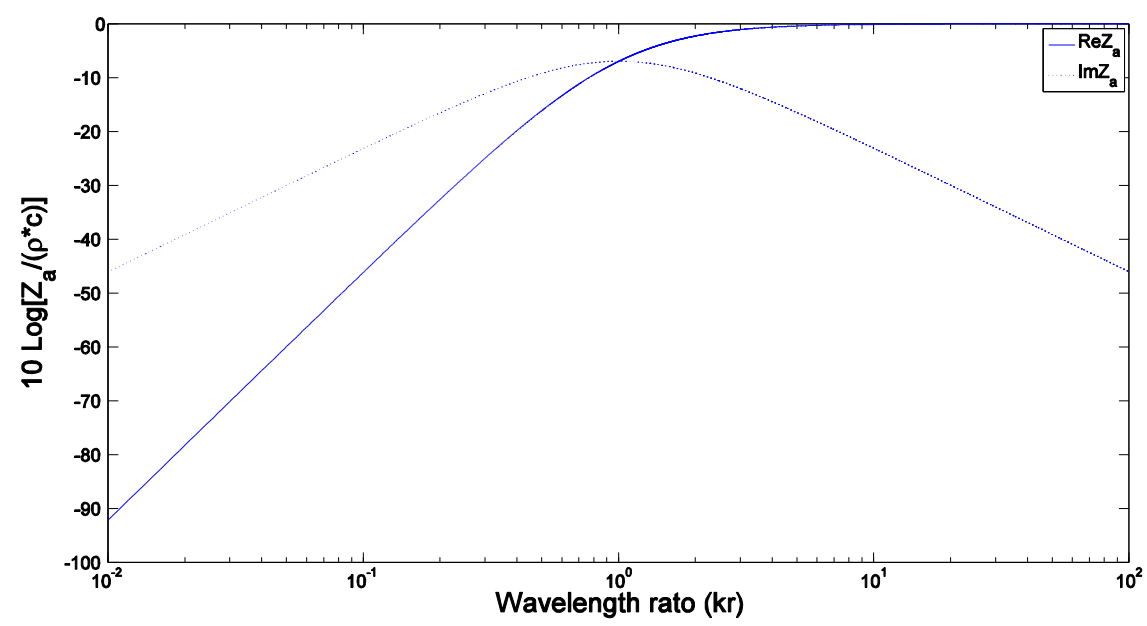

Figure 3-2: Effect on impedance components with changing wavelength ratio

\subsection{Radiation from a Circular Piston}

The expansion of the point source radiating waves spherically can now be extrapolated to model sources that have a definite surface geometry. In order to model the system, it is assumed that the circular piston is mounted on an infinite baffle, such that sound it radiated only in the forward direction. It is also assumed that the surface of the transducer is excited with a uniform surface velocity $\left(u_{n}\right)$ across its face $[27,44-46,51]$.

Figure 3-3 shows the resulting geometry, where the radiating circular piston is located in the $x-y$ plane. Assuming an infinitesimal area, on the radiating piston $\overrightarrow{d A}$ produces the differential pressure $d p$ at a point $P$ in the axial direction of the piston with a distance $r^{\prime}$ is given by [44,53]:

$$
d p=j \frac{\rho c k}{2 \pi r^{\prime}}\left(u_{n} d A\right) e^{j\left(\omega t-k r^{\prime}\right)}
$$




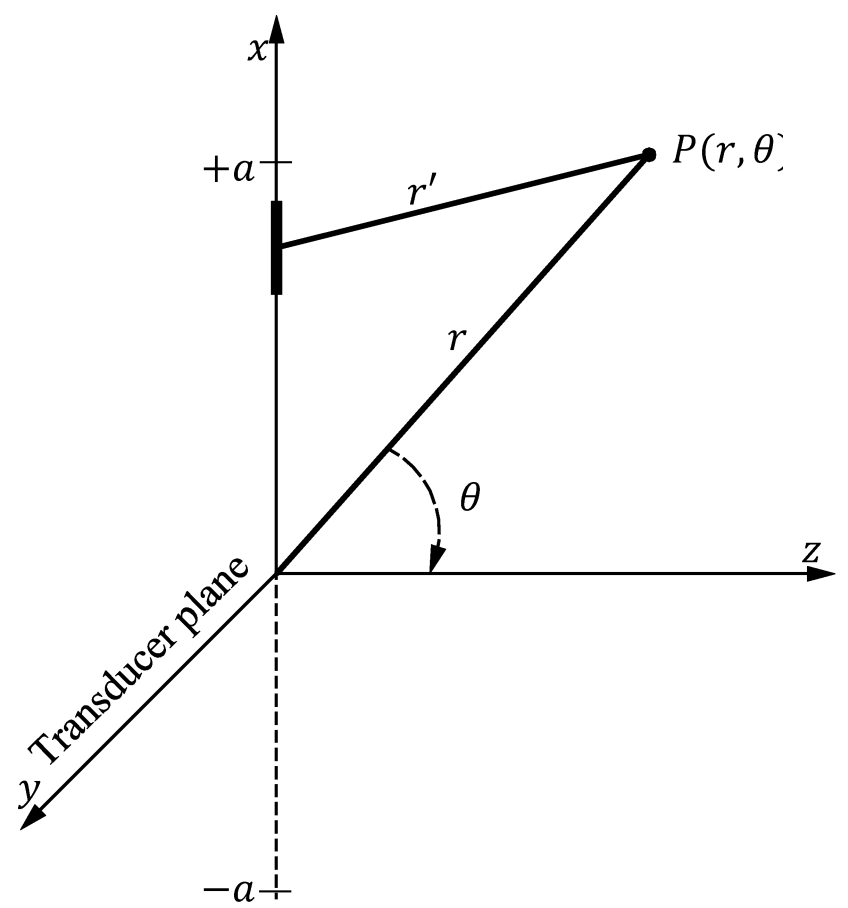

Side view

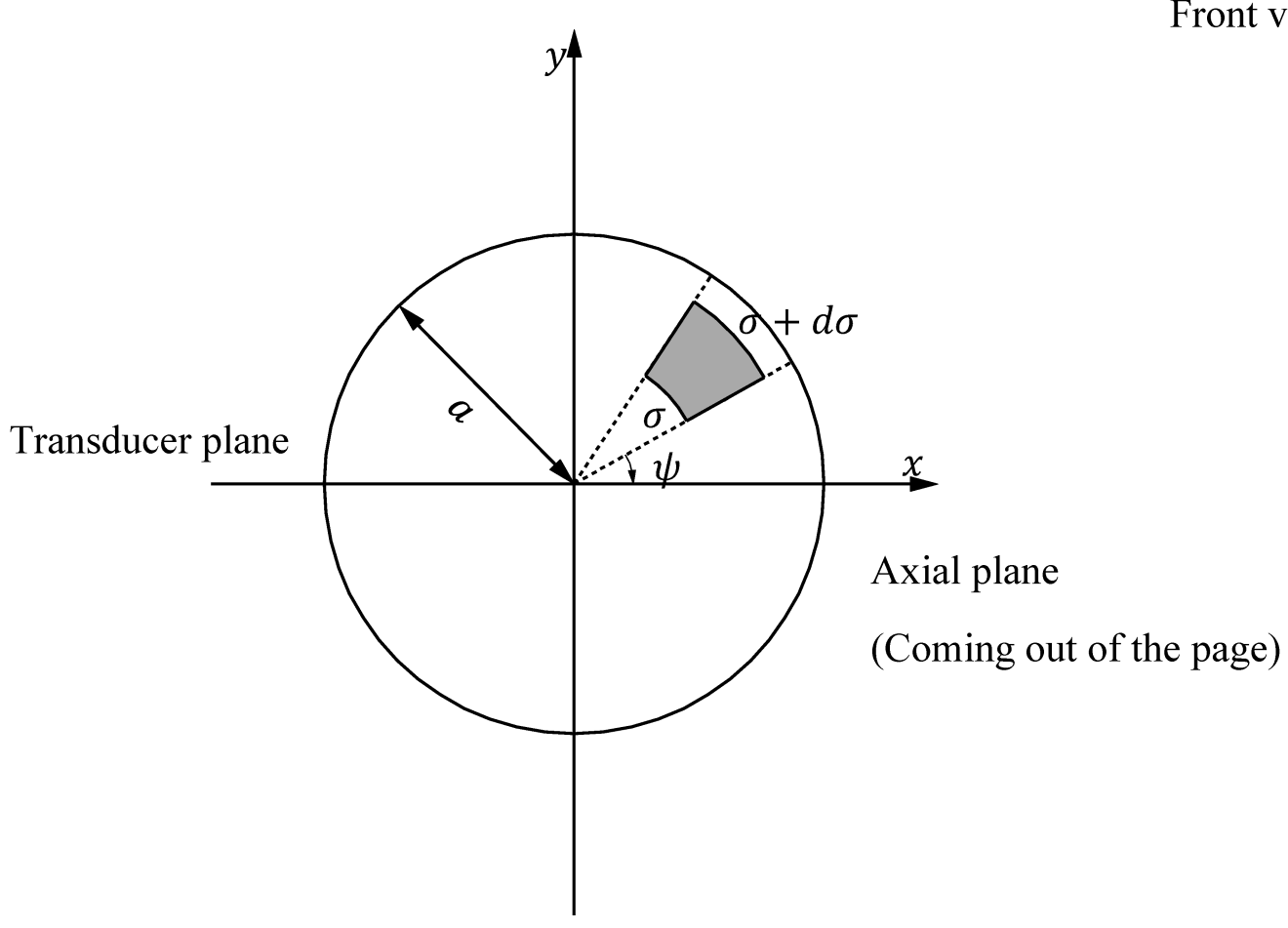

Figure 3-3: Geometry and parameters of a circular piston. Adapted from [53] 
Where $r^{\prime}$ from geometry in Figure 3-3 is defined as:

$$
r^{\prime}=\left(r^{2}+\sigma^{2}-2 r \sigma \sin (\theta) \cos (\psi)\right)^{\frac{1}{2}}
$$

Eq. (3.21) can be used to obtain the velocity potential function $(\phi)$, since velocity function and pressure can be related using Eq. (3.25) [53]:

$$
p\left(r^{\prime}, t\right)=-\rho\left\{\frac{\partial \phi\left(r^{\prime}, t\right)}{\partial t}\right\}=-j k \rho c \phi\left(r^{\prime}, t\right)
$$

The velocity potential $(\phi)$ at a point $P$ can be described by the velocity potential function as follows [53] :

$$
\phi\left(r^{\prime}, t\right)=\int_{S} \frac{u_{n}\left(r^{\prime}, t-\frac{R}{c}\right)}{2 \pi R} d S
$$

Where $u_{n}$ is the piston's axial velocity in the $z$ direction.

The pressure field model expressed in equation (3.32) when integrated over the surface of the piston can only be approximated on the $z$ axis and is given by the following expression:

$$
p(r, t)=\rho c u_{n}\left(e^{-j k \sqrt{r^{2}+\sigma^{2}}}-e^{-j k r}\right)
$$

As shown by multiple authors $[43-46,51,53,27]$ due to the analytical complexity associated with equation (3.30), only axial solutions are available for the nearfield solution given by equation (3.34). However, in the far-field the wave behaves like a spherical wave propagating from a point source $[27,44-46]$. 


\subsection{Impulse Response Method}

Since Eq. (3.30) is not directly integrable, it only provides axial analytical solutions. The impulse response method aims at providing the exact solution of the pressure field in the near and far field at any point in space, irrespective of its axial position. The impulse response method relies on the spatial impulse response function $h(r, t)$ and the source velocity waveform $u(t)$. Harris [54] outlines the relationship between velocity potential function $(\phi)$ as convolution of the velocity waveform and the spatial response:

$$
\phi\left(r^{\prime}, t\right)=u(t) * h\left(r^{\prime}, t\right)
$$

The relationship between pressure $(p)$ and velocity potential is defined by Equation (3.32):

$$
p\left(r^{\prime}, t\right)=-\rho\left\{\frac{\partial \phi\left(r^{\prime}, t\right)}{\partial t}\right\}
$$

Thus pressure is defined as [54,55]:

$$
p\left(r^{\prime}, t\right)=\rho \frac{\partial\left[u(t) * h\left(r^{\prime}, t\right)\right]}{\partial t}
$$

\subsection{Spatial impulse response function $h\left(r^{\prime}, t\right)$}

The spatial impulse response function defines the velocity potential at a point $P$, in the $z$ direction, resulting due to the impulsive velocity excitation of the piston. From Figure 3-4 it can be seen that infinitesimal area $d S$, when treated as a point source, produces a spherical wave.

The impulse response at point $P$ is the result of the impulse generated by the infinitesimal area $d S$, produced at time $t$. Since the wave is travelling spherically from the elemental area $d S$, the time it takes to reach point $P$ can be determined by $\frac{R}{c}$, where $R$ is the radial distance of point 
$P$, from the source. Thus the impulse, represented by the Dirac delta function occurred at $\delta\left(t-\frac{R}{c}\right)$.

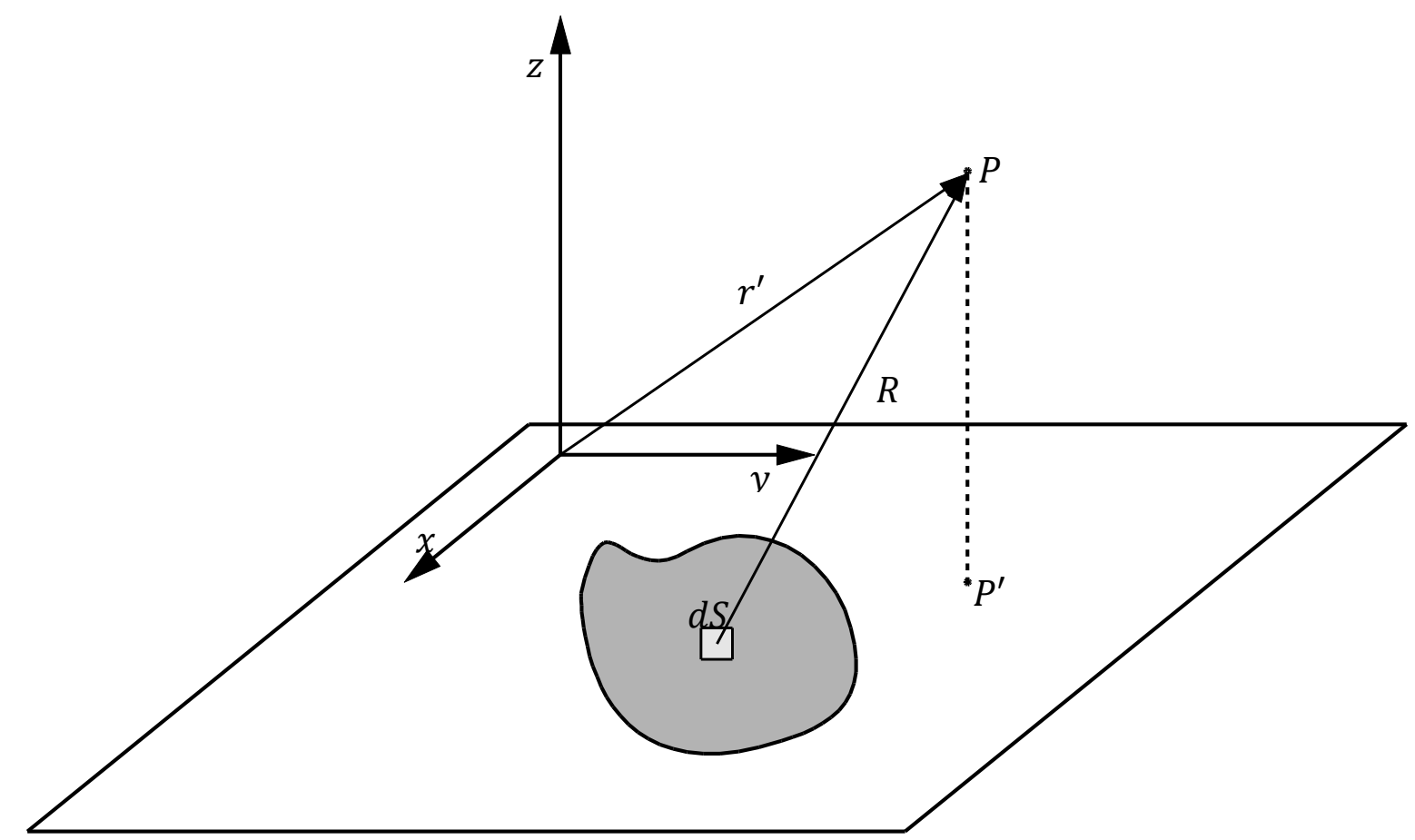

Figure 3-4: Projection of the impulse on the source. Adapted from $[55,56]$

This impulse response observed at point $P$, is the sum of all the points that lie on the source (baffle) and are at a distance $R$ away from point $P$, as shown in Figure 3-5. 


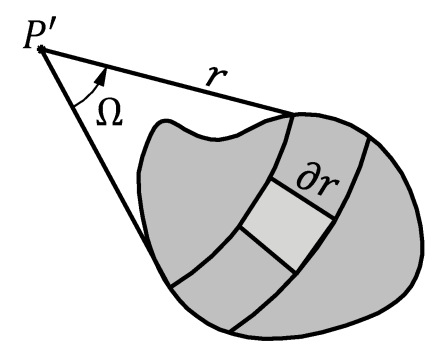

Figure 3-5: Planar projection of point $\mathrm{P}$ on the source. Adapted from $[55,56]$

Therefore, the spatial impulse response function $h\left(r^{\prime}, t\right)$ can be written as [53-56]:

$$
h\left(r^{\prime}, t\right)=\int_{R 1}^{R 2} \int_{0}^{\theta_{1}(R)} \frac{\delta\left(t-\frac{R}{c}\right)}{2 \pi} d \theta d R
$$

Since there are two possible scenarios for the projection of point $P$, one where the projection of $P$ given by $P^{\prime}$ lies on the surface of the source and another scenario where $P^{\prime}$ is outside the bounds of the arbitrary source surface $S$. Figure 3-6 shows the two cases
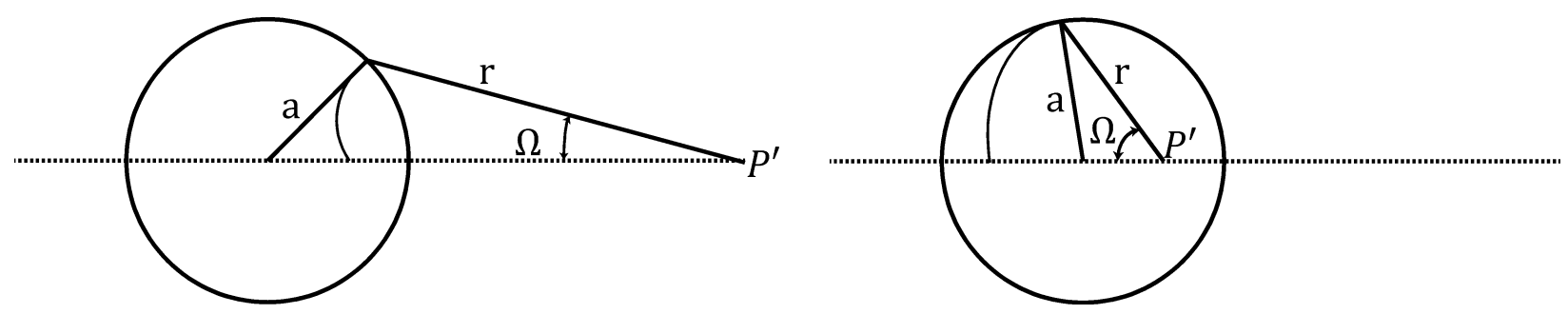

Figure 3-6 : Two projections of point $\mathrm{P}$ on surface of the transducer. Adapted from [54] 
From the geometry, defining $\Omega(r)$ as the half angle subtended by the arc in the $x-y$ plane, centered at point $P^{\prime}$. The elemental area source is, in accordance with Figure 3-5 can be defined as $[54,56]$ :

$$
d S=\Omega(\mathrm{R}) r d r
$$

By substituting back into Equation (3.38) and integrating from the surface of the source to infinity produces the following equation:

$$
h\left(r^{\prime}, t\right)=\int_{0}^{\infty} \frac{\delta\left(t-\frac{R}{c}\right) \Omega\left(r^{\prime}, R\right)}{2 \pi} d R
$$

by substituting $\tau=\frac{R}{c}$ into Equation (3.40)

$$
h\left(r^{\prime}, t\right)=\int_{0}^{\infty} \frac{\delta(t-\tau) \Omega\left(r^{\prime}, \tau\right)}{2 \pi} d \tau
$$

using the sifting property of the Dirac Delta function, Equation (3.41) can be reduced to :

$$
h\left(r^{\prime}, t\right)=c \frac{\Omega\left(r^{\prime}, t\right)}{2 \pi}
$$

The above equation is quite an important solution to the time limited impulse response model development as it directly implies that the instantaneous spatial impulse response function $h\left(r^{\prime} t\right)$, is directly related to the geometry.

Equation (3.40) outlines only the generic solution of the spatial impulse response function, a shape specific numerical model has been established for circular [53-56] and rectangular sources $[58,59,60]$. 


\subsection{Near-Field and Far-Field}

Far-field can be described from the geometry outlined in Figure 3-3, it can be seen that as $r \gg a$, the expression for $r^{\prime}$ in $\mathrm{Eq}$ (3.21) reduces to [53]:

$$
r^{\prime}=r-\sigma \sin (\theta) \cos (\psi)
$$

By using the small angle approximation at long distances, the approximation $r^{\prime} \approx r$ can be made and the pressure $(p)$ can be defined as:

$$
p(r, \theta, t)=j \frac{\rho c k a^{2} U_{p}}{2 r} e^{i(\omega t-k r)}\left[\frac{2 J_{1}(k a \sin (\theta))}{k a \sin (\theta)}\right]
$$

The term inside the square brackets is termed as the directivity function and is used to define the pressure in the direction.

$$
D(\theta)=\frac{2 J_{1}(k a \sin (\theta))}{k a \sin (\theta)}
$$

From the above derivation it can be seen that far field is the region along the $z$ axis where the particle velocity is in phase with the pressure, therefore allowing for the energy to be transported through sound waves.

As the point $p$ is brought closer to the source, this results in the opposite effect where $r \ll a$. Since analytical solutions are only available for point along the axis of the piston, this results in the expression for $r^{\prime}$ to be simplified to:

$$
r^{\prime}=\left(r^{2}+\sigma^{2}\right)^{\frac{1}{2}}
$$

By substituting Equation (3.46) into Equation (3.30): 


$$
d p=j \frac{\rho c k}{2 \pi} U_{p} \frac{e^{j\left(\omega t-k\left(r^{2}+\sigma^{2}\right)^{\frac{1}{2}}\right)}}{\left(r^{2}+\sigma^{2}\right)^{\frac{1}{2}}}
$$

By integrating the above expressions, the pressure $p$ is defined for the nearfield as:

$$
p=\rho c U_{p} e^{j \omega t}\left(e^{-j\left(k\left(r^{2}+\sigma^{2}\right)^{\frac{1}{2}}\right)}-e^{-j k r}\right) d A
$$

In the case of nearfield, the velocity is generally out of phase with respect to the pressure thus having small contribution in terms of the power of the source [42]. Also, as the frequency increases, the wave number $(k)$ increases, therefore reducing the pressure contribution.

Equation (3.48) also sheds light on the geometric contributions to the pressure. It is quite evident from the geometry that the first term inside the brackets is the pressure contribution from the center and the second term is the direct contribution of the edge of the oscillator. Therefore, it is important to note that these pressure waves have an interfering pressure field produced by each component, which at times, cancels. This cancellation of pressure is the most dominant result when the distance from the center in the $z$ axis is large compared to the wavelength $\lambda$.

The transition point between near field and far-field is defined by the Rayleigh distance given by the following expression $[42,43,53]$ :

$$
R_{0} \equiv \frac{S}{\lambda}
$$

Where $S$ is the piston's surface area, in the case of circular piston this is given by $[42,43,53]$ :

$$
R_{0}=\frac{S}{\lambda}=\frac{k a^{2}}{2}
$$


The Equation (3.42) can now be written as:

$$
p=\frac{j R_{0} P_{0}}{r} e^{\left[\omega t-k\left(r-R_{0}\right)\right]} \quad ; P_{0}=\rho c u_{n}
$$

Equation (3.51) illustrates that in the near field region, the pressure can be approximated by using plane wave impedance relationship. As the distance is increased beyond $R_{0}$ the beam spreads by dispersing pressure in spherical manner as shown in Figure 3-7 [42]. This concludes that in the far-field the piston behaves as a monopole source.

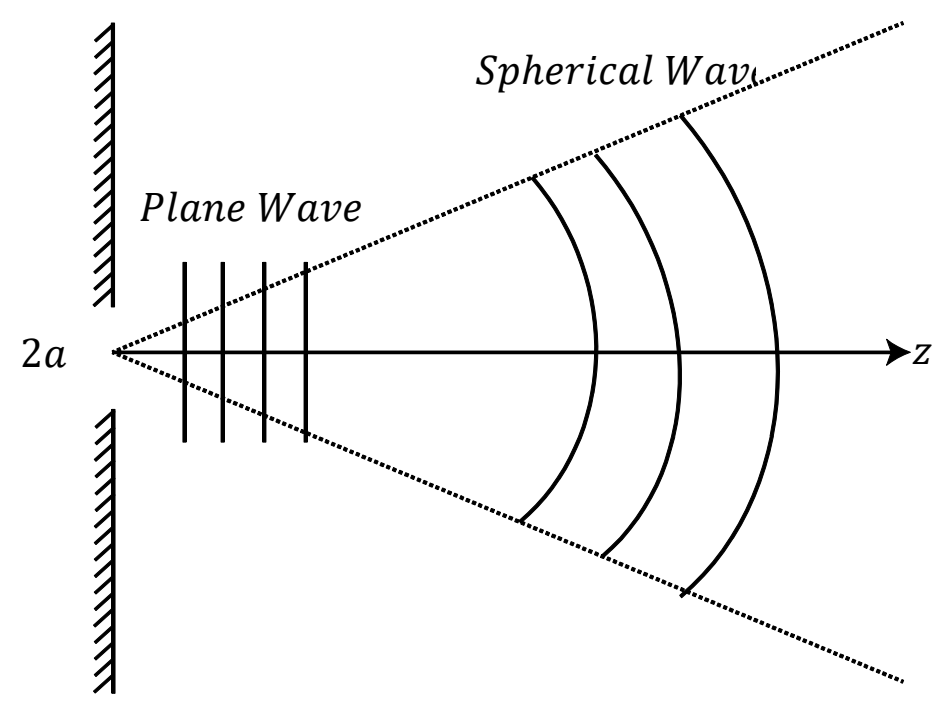

Figure 3-7: Near-field plane wave dispersing into far field spherical wave; adapter from [42] 


\subsection{Directivity function, sensor size and wavelength relationship}

There is an important relationship between the size of the sensor and the excitation frequency as shown in the directivity function:

$$
D_{\text {element }}(\theta)=\frac{2 J_{1}(k a \sin (\theta))}{k a \sin (\theta)}
$$

As the sensor size decreases for a specific frequency, the source behaves like a monopole with a spherical wave front. On the other hand, when the sensor size is increased, side lobes and dead zones start appearing which indicated the directional nature of the sound produced by the transducer [42]. As shown in Figure 3-8 the main lobe is a highly directed beam in the center containing the sound.

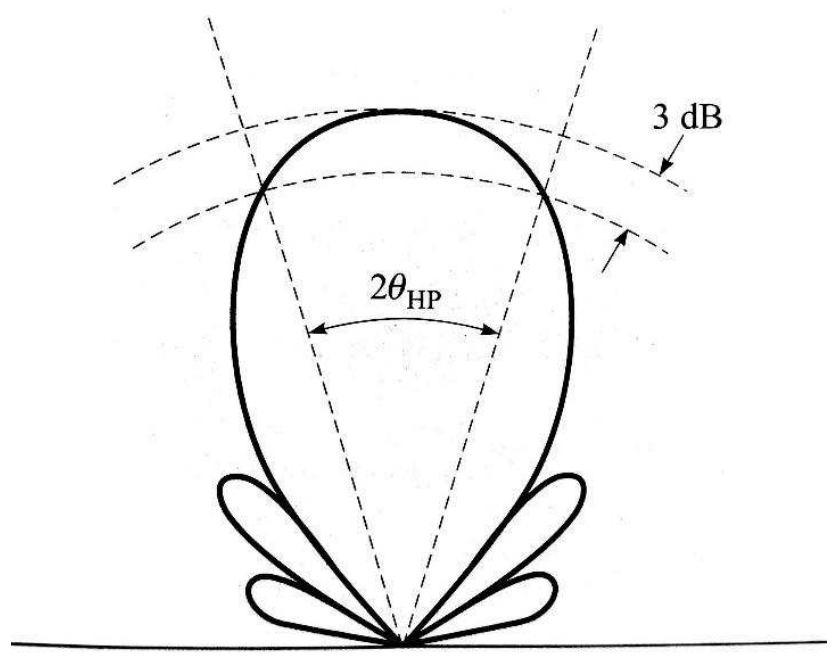

Figure3-8: Angular representation of half power angle [42] 
An important performance parameter of an acoustic transducer is its half power beam width and is defined as the angle between the half power points on the major lobe. The half power angle, defining a $3 \mathrm{~dB}$ loss in sound pressure level (SPL), is given by the following expression [42]:

$$
2 \theta_{H P}=2 \sin ^{-1}\left(\frac{1.616}{k a}\right)
$$

\subsection{Phased Array Propagation Model}

The pressure generated at a point $P$ in the far field is the sum of contributions of all the elements in the array. Since all the elements of the array lie on the same plane, by approximating each element as a point source, the pressure contribution can be evaluated.

The position of point $P$ here, represents the position along the polar coordinates where the amplitude of the pressure is maximum. By varying the phase of the propagated wave emitting from each element, a constructive and destructive pattern can be established such that the position of point $P$ can be varied as shown in Figure 3-9.

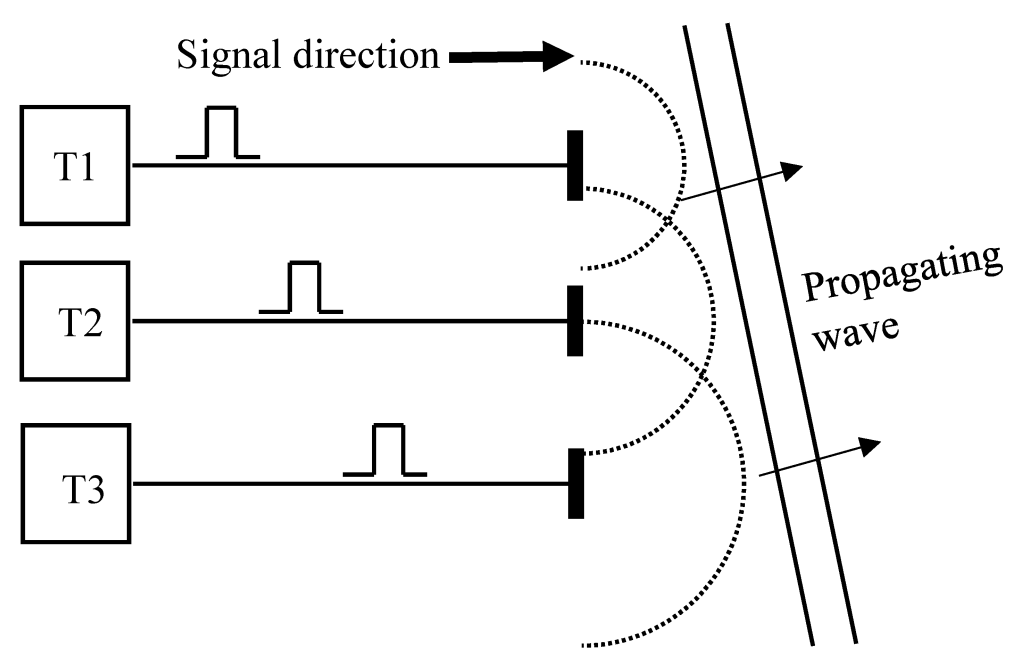

Figure 3-9: Constructive and destructive pattern using time delays 
From Eq (3.51), it can be shown that by approximating a variable A to be defined as

$$
A_{p}=j \rho c k A_{\phi}
$$

The pressure at a point $P$ by a single element can be written as $[42,53]$ :

$$
p(r, t)=p_{0}=\frac{A}{r} e^{j(\omega t-k r)}
$$

Figure 3-10 shows an array with an odd number of $\mathrm{N}$ elements, with the distance $\mathrm{d}$ between them.

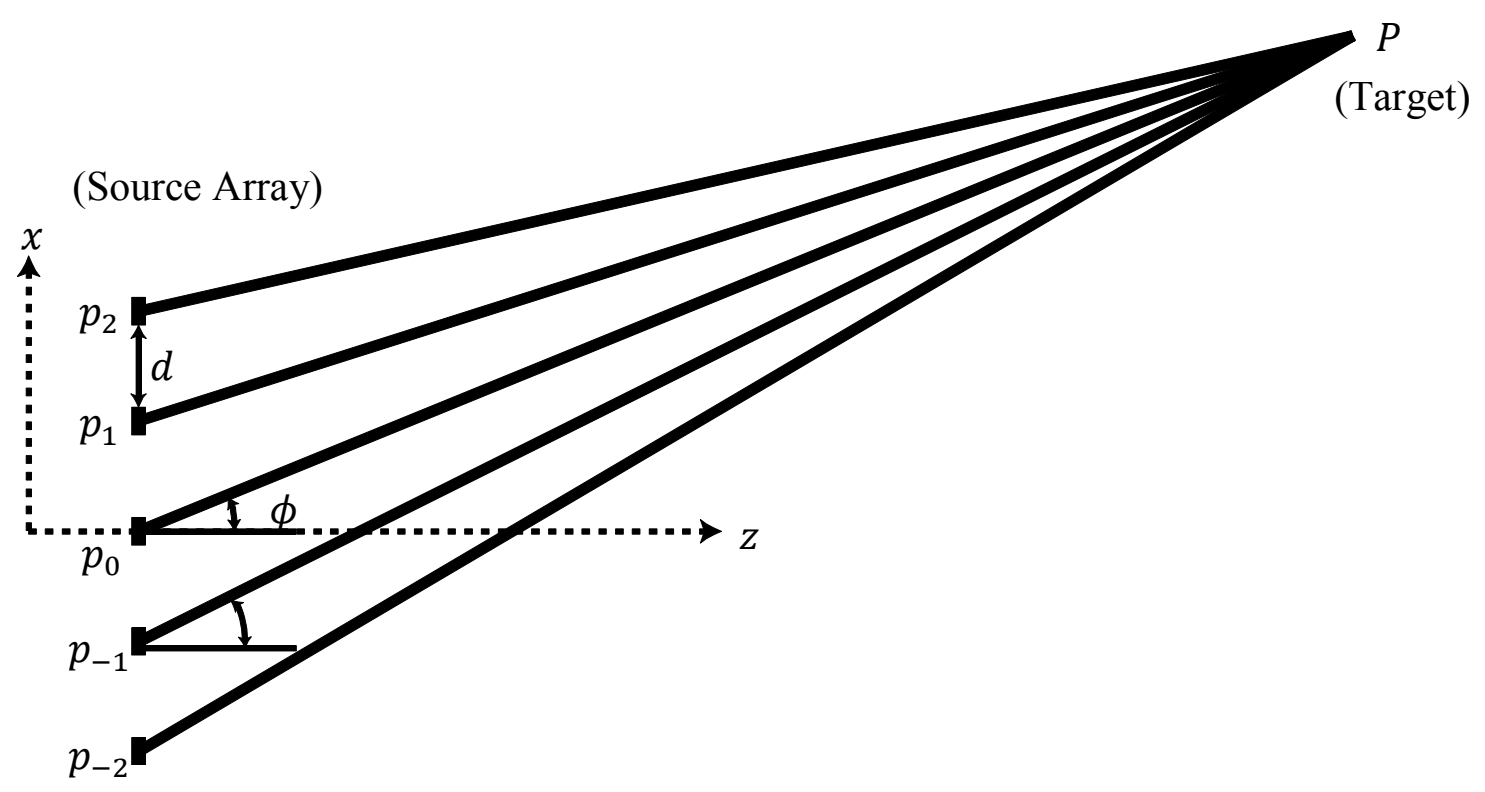

Figure 3-10: Array pressure contribution

The pressure contribution of individual sources towards the left of the central element are given by $[42,53]$ :

$$
p_{+1}=\frac{A}{r} e^{j[\omega t-k(r+d \sin (\theta))]}=p_{0} e^{-j 2 \phi}
$$

Here $\phi$ represents the angle and not the velocity potential function. 
Therefore, the pressure contribution of elements to the right and left of the array are given by the following functions $[46,53]$ :

$$
\begin{aligned}
& p_{+n}=p_{0} e^{-j 2 n \phi} \\
& p_{-n}=p_{0} e^{j 2 n \phi}
\end{aligned}
$$

By summation of pressures produced by both sides of the array,

$$
p=p_{0}\left[\cdots+e^{-j 4 \phi}+e^{-j 2 \phi}+1+e^{j 2 \phi}+e^{j 4 \phi}+\cdots\right]
$$

The right hand side of the equation (3.59) represents a geometric series that can be simplified to produce the following results [46]:

$$
p=p_{0} \frac{\sin (N \phi)}{\sin (\phi)}
$$

Therefore, the directivity function can be written as $[42,62]$ :

$$
D_{\text {Point Array }}(\phi)=\frac{\sin (N \phi)}{N \sin (\phi)}
$$

Where $D_{\text {point array }}(\phi)$ represents the directivity function of the entire array

The directivity of point array and the geometry of the source can be related to provide the directivity of the phased array as follows $[42,62]$ :

$$
D(\theta)=D_{\text {element }}(\theta) D_{\text {Point Array }}(\phi)
$$

Therefore, it can be concluded that $D_{\text {element }}(\theta)$ is a modulation function that relates the point array directivity function to the phased array. 


\subsection{Phased array Reception Model}

Since the focus of the application is to evaluate distance with limited computational resources and power, the impulse response and other computationally intensive approaches are neglected. The focus is shifted towards an approach that is the inverse of the point source model.

The model assumes that the sound is emitted from the target, as if it were the source and is then captured by the reception array as shown in Figure 3-11.

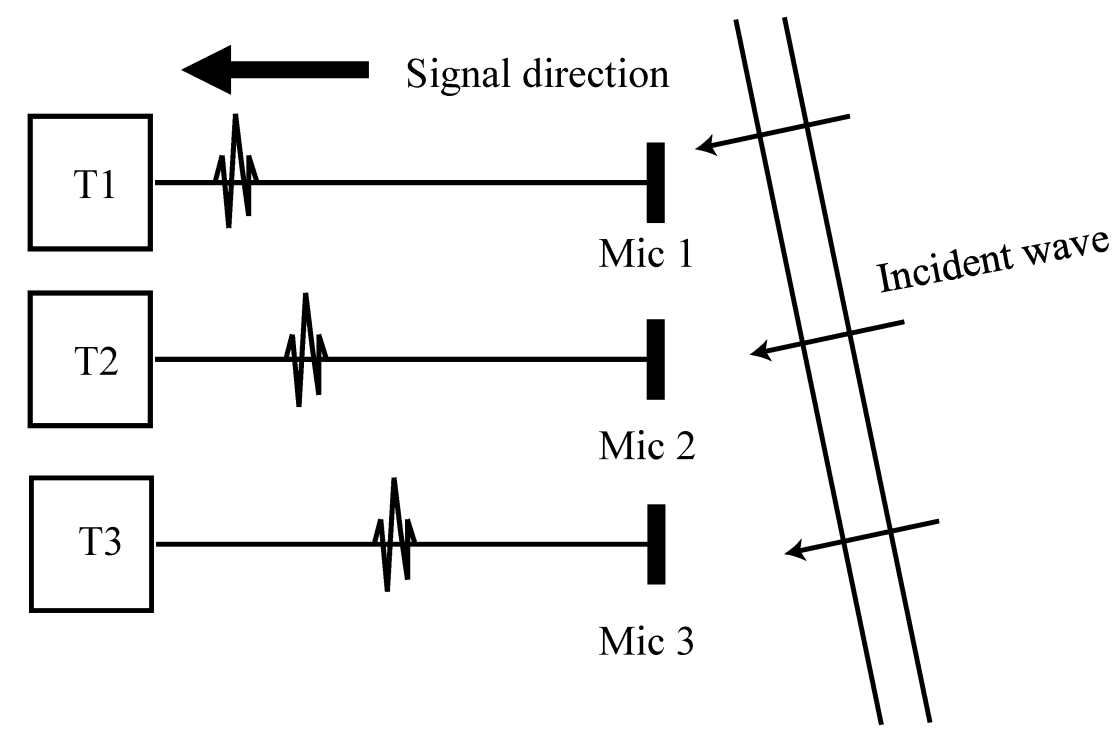

Figure 3-11: Phased array reception model.

The pressure produced by source $s^{n}$ can be related to the transmitter's pressure by using the pressure equation (3.55). The amplitude reduction from the transmitted wave can be related to the reflected wave at the source point $s^{n}$ by the following expression:

$$
p_{r}(x, z, t)=\underline{R} p(x, y, t)
$$

Where $\underline{R}$ denotes the complex reflection factor, and is related to the impedance and surface absorption $[64,65]$. However, to simplify the model, it is assumed that the $\underline{R}=1$, implying a specular reflection. 
With the simplified model, it is evident that the pressure observed by the receiver is simply due to the effect of attenuation. In order to account for attenuation, the expressions for the wave number is expanded into complex angular wave number given by:

$$
\underline{k}=k-j \frac{m}{2}=\frac{\omega}{c}-j \frac{m}{2}
$$

Where $m$ represents the attenuation constant of the medium. Figure 3-12 show the attenuation per unit length for $50 \mathrm{kHz}$ and $100 \mathrm{kHz}$ measured at a variety of humidity levels and temperature.
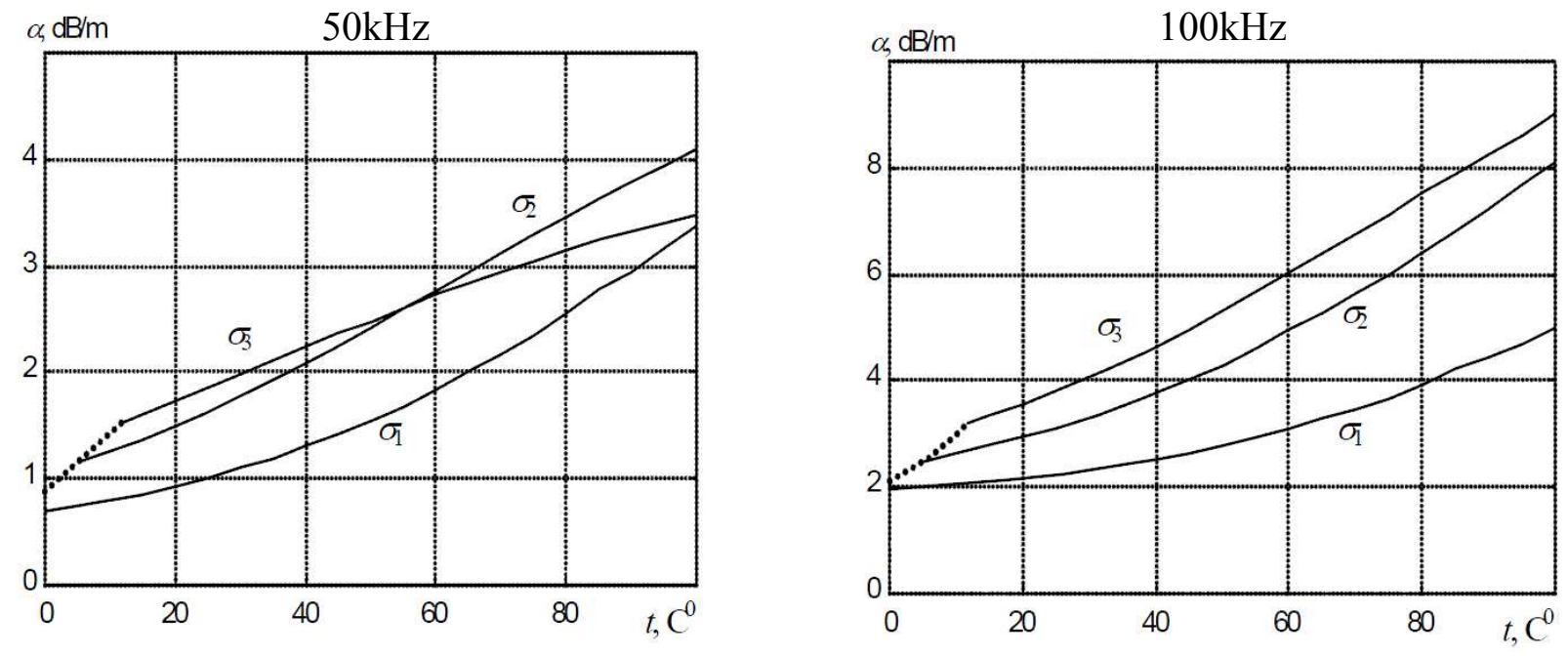

Figure 3-12: Attenuation of ultrasonic waves in air [64]

By assuming standard temperature and pressure with the relative humidity selected at $40 \%$, the attenuation in air is approximated to be $1.6 \mathrm{~dB} / \mathrm{m}$ [64]. Since the desired range for the sensor is selected to be $10 \mathrm{~m}$, the observed attenuation of the signal upon reception is expected to be reduced by $32 \mathrm{~dB}$ or more.

As the waves propagate from the source $s^{n}$ as spherical waves, the radius of the wave increases as it is reflected back from the target. Since the sensor array's width is small as 
compared to the reflected wave front, it is essentially perceived as a plane wave when the signal is received.

\subsection{Signal Reception Signal Processing}

Since the signals received are continuous in time domain however are dependent on the discrete time domain of the chipset processing the received signal. It is assumed that each incoming signal is occurring at a discrete time index $k$. The output from $m$ sensors can now be characterized as [63]:

$$
y_{m}(k)=x_{m}(k)+v_{m}(k)
$$

Where $y_{m}$ is the descrete time output, $x_{m}$ is the received signal and $v_{m}$ is the spatial noise added to the system. Referring to Figure 3-11, as the wave propagates over the sensor, the time delay between reception can be attributed directly to the spatial position of the sensors such that the output signal can be written as [63]:

$$
y_{m}(k)=x\left(k-t-\tau_{m}\right)+v_{m}(k)
$$

Where

$$
\tau_{m}=\frac{(m-1) d \cos (\theta)}{c}
$$

By converting the signal into frequency domain equation (3.66) becomes:

$$
Y_{m}(\omega)=X_{m}(\omega) e^{-j \omega\left(t+\tau_{m}\right)}+V_{m}(\omega)
$$

By employing the Delay and Sum (DS) beamforming technique, the output of the beamformer can be defined as 


$$
Z(\omega)=X(\omega) e^{-j \omega t}+\frac{1}{M} \sum_{m=1}^{M} V_{m}(\omega) e^{j \omega\left(\tau_{m}\right)}
$$

The effectiveness of the DS beamformer becomes quite obvious when the input signal-tonoise ratio $(i S N R)$ given by equation (3.69) is compared to the output signal-to-noise ratio $($ oSNR) given by equation (3.70) :

$$
\begin{array}{r}
i \operatorname{SNR}(\omega)=\frac{E\left[|X(\omega)|^{2}\right]}{E\left[\left|V_{1}(\omega)\right|^{2}\right]} \\
\operatorname{oSNR}(\omega)=\frac{E\left[|X(\omega)|^{2}\right]}{\frac{1}{M} E\left[\left|\sum_{m=1}^{M} V_{m}(\omega) e^{j \omega\left(\tau_{m}\right)}\right|^{2}\right]}
\end{array}
$$

The output gain can now be evaluated by taking the ratio of the output and input SNRs :

$$
\mathcal{G}(\omega)=\frac{\operatorname{oSNR}(\omega)}{i S N R(\omega)}=M
$$

Therefore, the improved performance of the DS beamformer is by a factor of $M$. The reception beam pattern can now be defined as a magnitude of the transfer function between the input and output signal $[63,61]$. By substituting the equation (3.69) and (3.70) into equation (3.71) the beamformer output is defined as:

$$
\mathcal{B}(\omega, \theta)=\left|\frac{Z(\omega)}{X(\omega)}\right|=\left|\frac{\sin \left[\frac{M \omega d}{2 c}\left(\cos \theta-\cos \theta_{s}\right)\right]}{M \sin \left[\frac{\omega d}{2 c}\left(\cos \theta-\cos \theta_{s}\right)\right]}\right|
$$

Where $\theta_{s}$ is the expected direction of the source and $\theta$ is incidence angle of the plane wave with respect to the sensor. Figure 3-13 to 3-17 shows the beamformer gain output for a three element sensor that is excited at $30 \mathrm{kHz}, 50 \mathrm{kHz}$ and $100 \mathrm{kHz}$. Figure 3-18 highlights the interference pattern as the frequency is increased. 


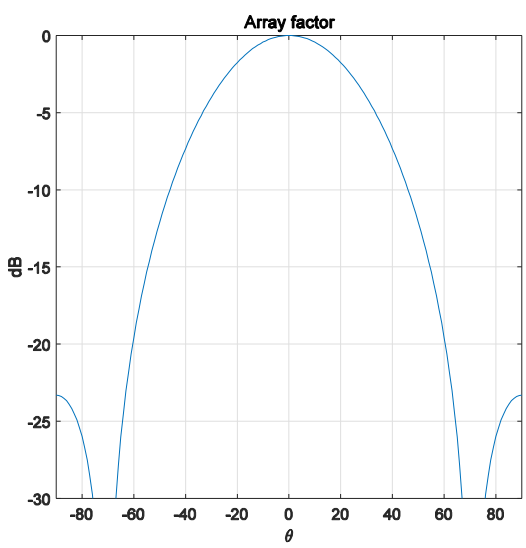

a) $30 \mathrm{kHz}$

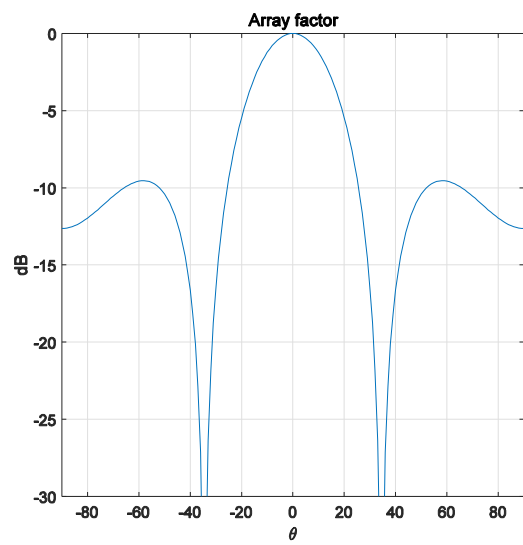

b) $50 \mathrm{kHz}$

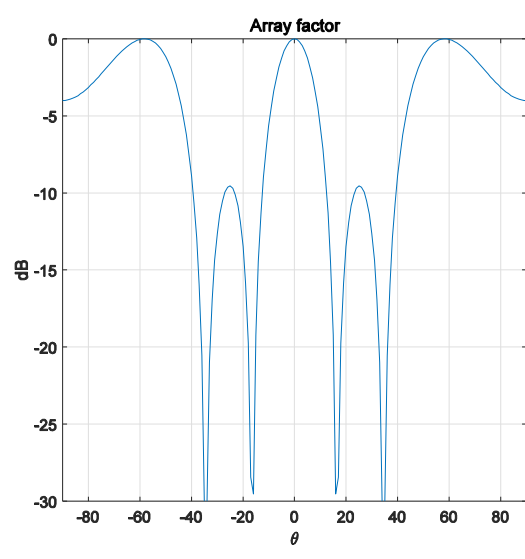

c) $100 \mathrm{kHz}$

Figure 3-13: Array factor response of a phased array sensor with 3 sensor elements with $6 \mathrm{~mm}$ diameter placed $4 \mathrm{~mm}$ apart at a) $100 \mathrm{kHz}$ b) $50 \mathrm{kHz}$ and c) $30 \mathrm{kHz}$. 


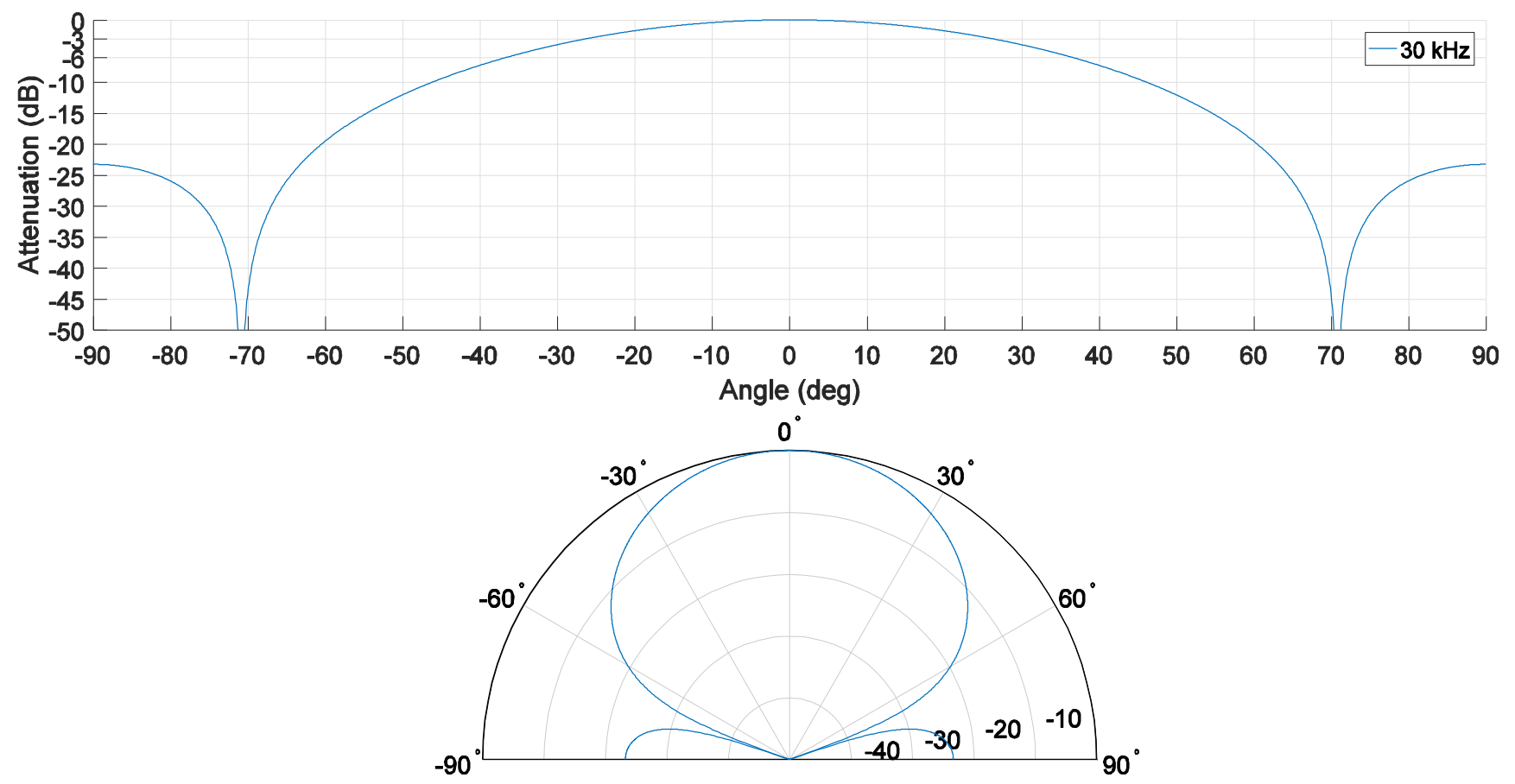

Figure 3-14: Reception beamforming gain with respect to incidence angle represented in linear and polar plot at $30 \mathrm{kHz}$ 


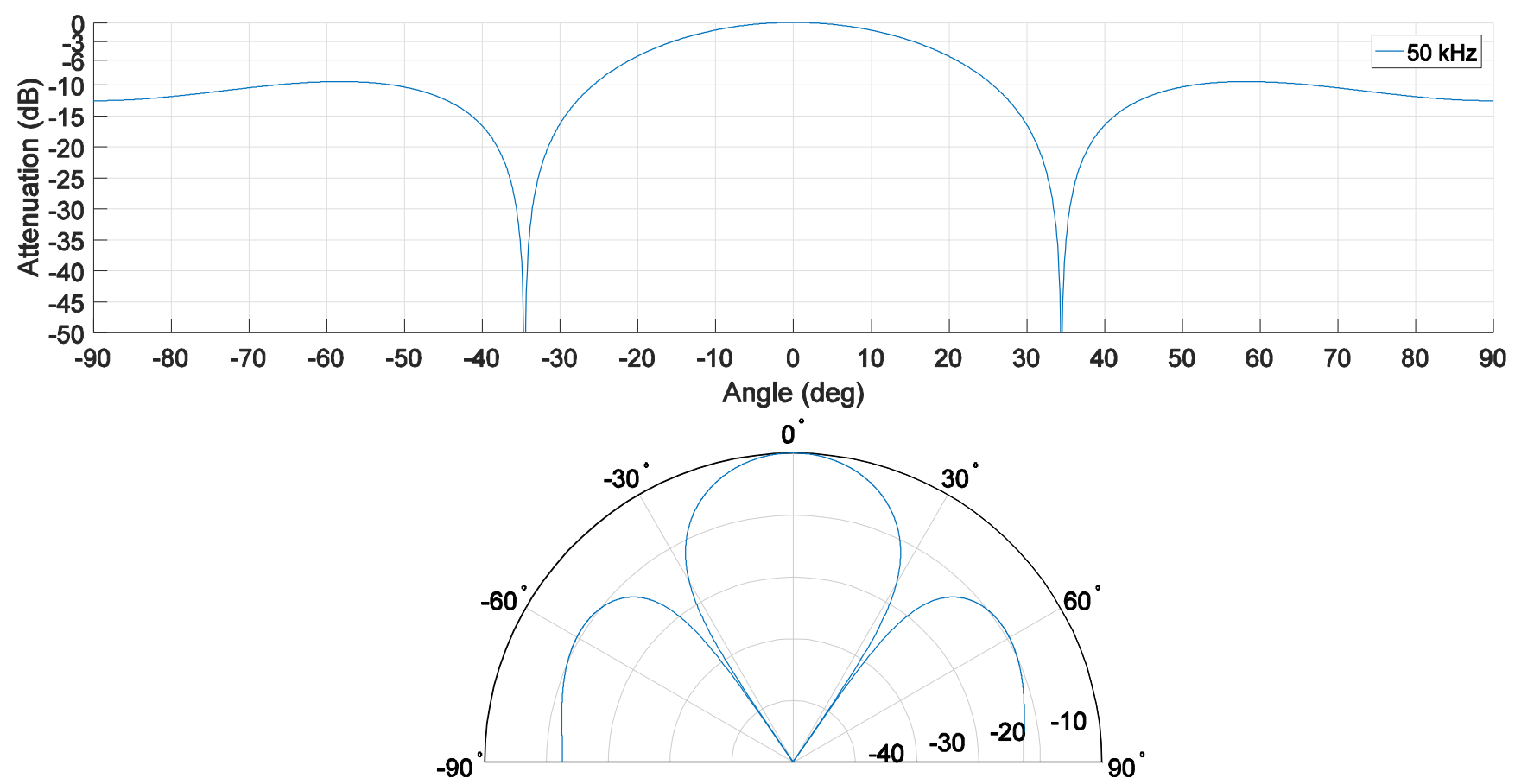

Figure 3-15: Reception beamforming gain with respect to incidence angle represented in linear and polar plot at $50 \mathrm{kHz}$. 


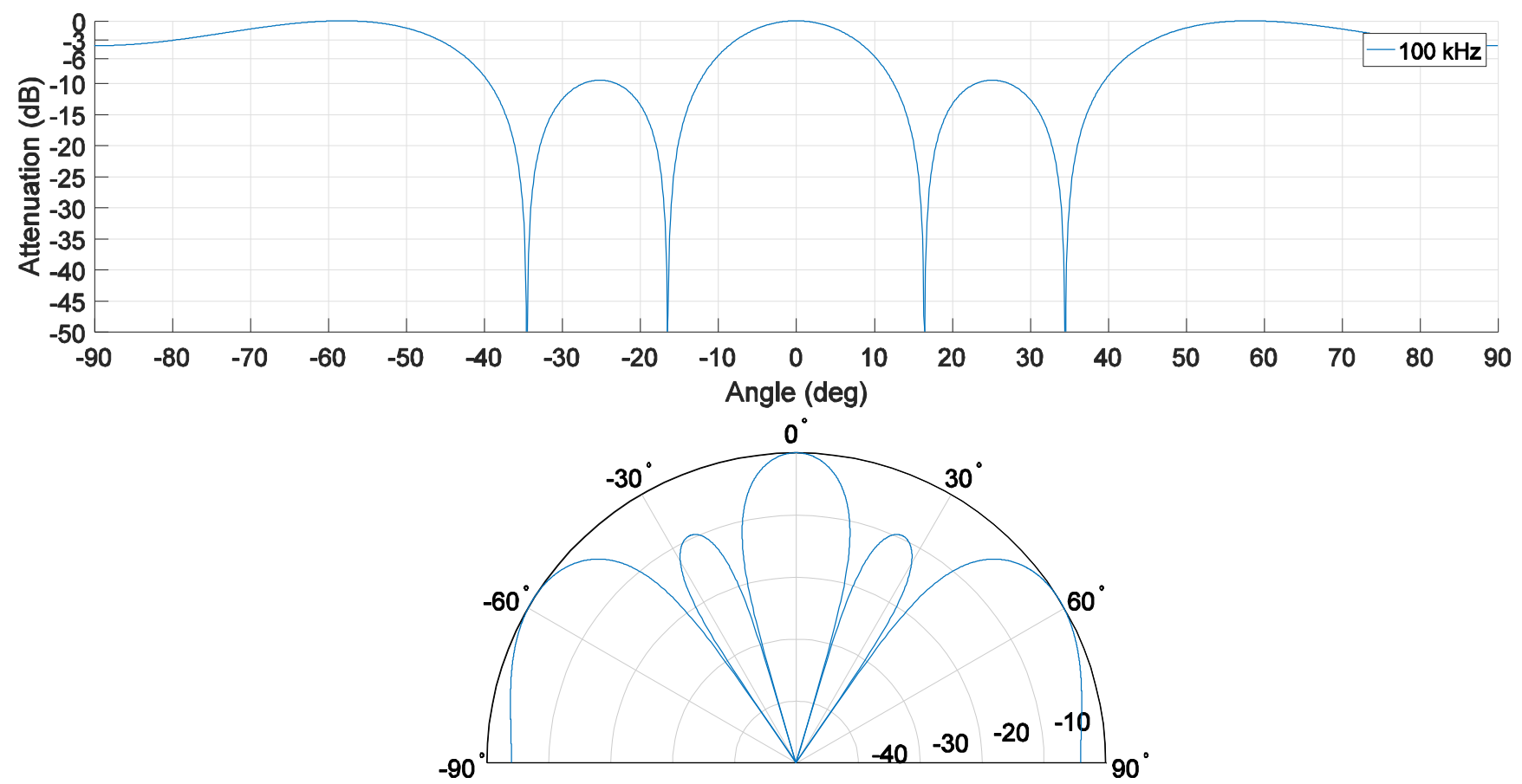

Figure 3-16: Reception beamforming gain with respect to incidence angle represented in linear and polar plot at $100 \mathrm{kHz}$ 


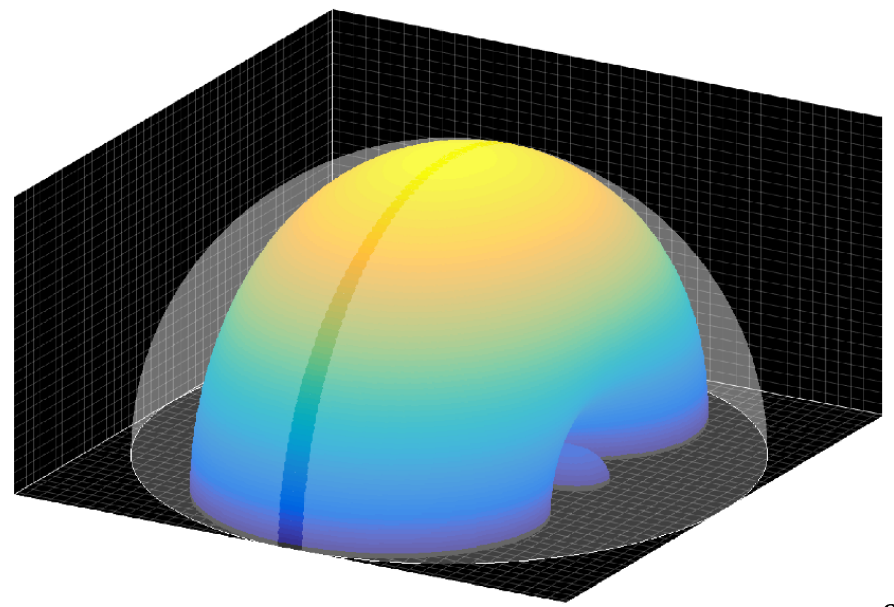

a) $30 \mathrm{kHz}$ Beam pattern

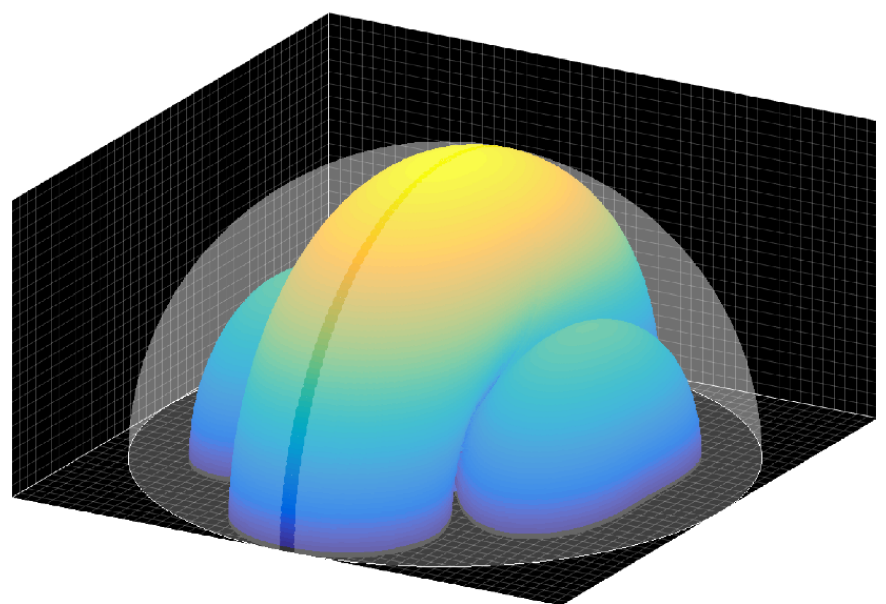

b) $50 \mathrm{kHz}$ Beam pattern

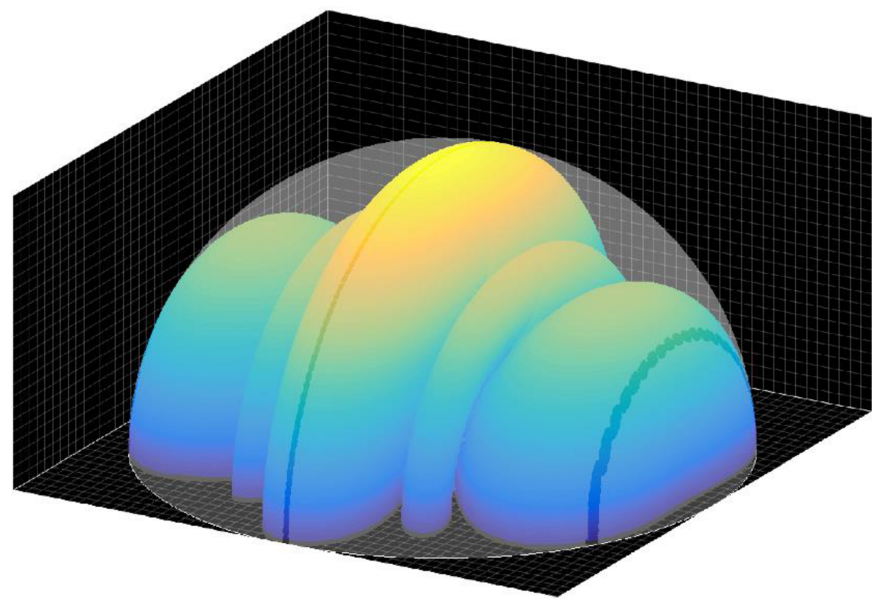

c) $100 \mathrm{kHz}$ Beam pattern

Figure 3-17: Qualitative 3D visualization of the gain patterns at $30 \mathrm{kHz}, 50 \mathrm{kHz}$ and $100 \mathrm{kHz}$ 


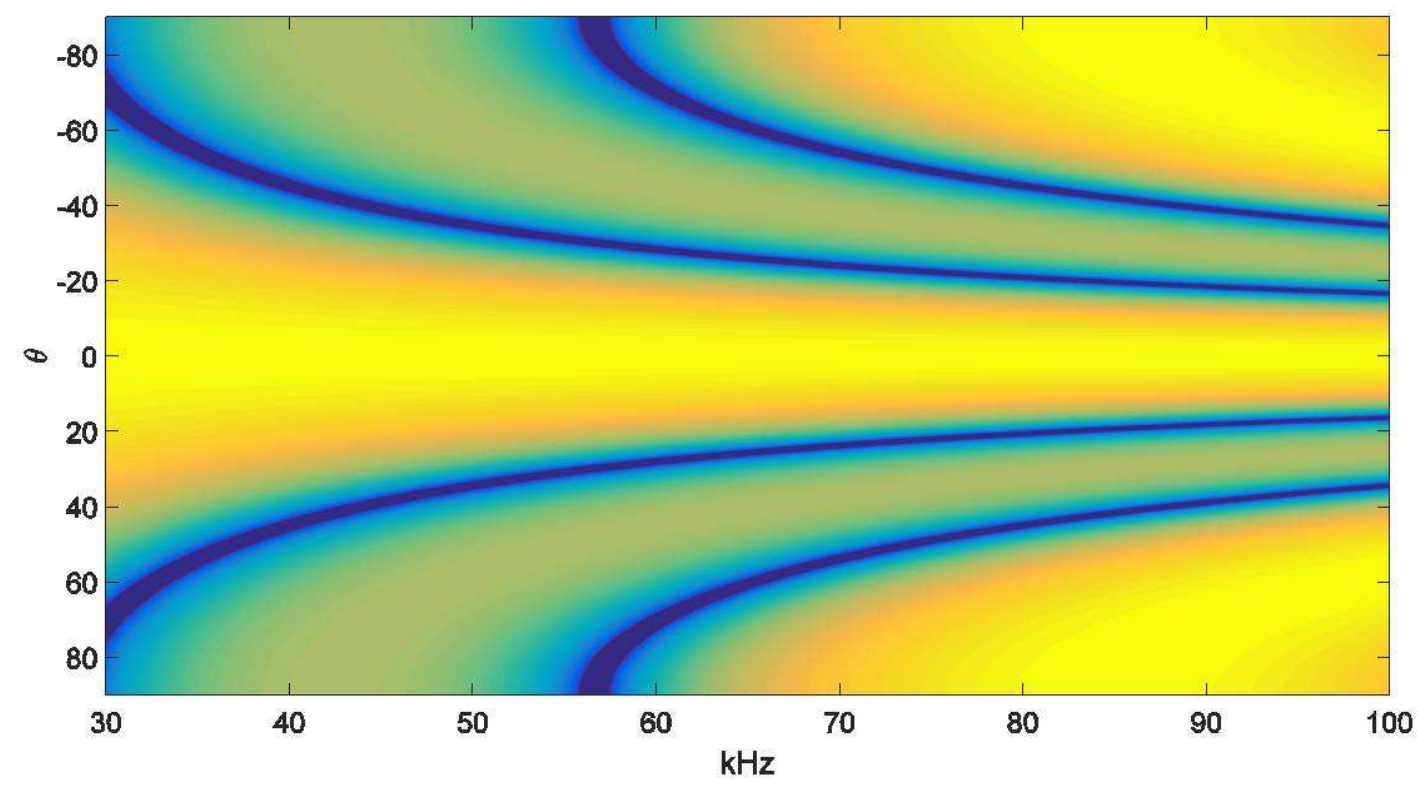

Figure 3-18: Beam patterns produced by a 3 transducer linear array as a function of frequency.

\subsection{Sensor Size and Modelling Methodology.}

Since the sensors under consideration are to be modelled for range sensing applications, the nearfield model of the sensor is neglected. In the far field, the mathematical model of a baffled piston reduces to that of a monopole excited at given frequency. Therefore, equations predicting the pressure, intensity, impedance and particle velocity for a monopole are used for the modelling and performance evaluation.

The transducer design under consideration is driven at frequencies ranging from $30 \mathrm{kHz}$ to $100 \mathrm{Khz}$, this results in wavelengths between $11.43 \mathrm{~mm}$ to $4.29 \mathrm{~mm}$. From literature $[42,46,53,66]$ it is suggested that by reducing the sensor radius compared to the wavelength $(k a \gg 1)$, the reactive impedance can be reduced. Therefore, the sensor size of $3 \mathrm{~mm}$ in radius is selected, which produces $\mathrm{ka}$ values ranging between 1.65 to 5.50 , and is used in the work described in the later chapters for the design and construction of the phased array. 


\section{Chapter 4}

\section{Spatial Positioning}

The acoustic model for transmission and reflection in the previous chapters needs to be related to the source's position. This chapter will present the mathematical and signal processing model that is implemented to extract the position information of the source based on the response generated by a phased array transducer [6].

Four techniques of source localization were considered namely; time of arrival (TOA), time difference of arrival (TDOA), received signal strength (RSS) and direction of arrival (DOA) [6]. Table 4-1 outlines the advantages and the information that can be obtained from each methodologies.

Table 4-1: Comparison of various localization methodologies [6]

\begin{tabular}{|c|c|c|c|c|}
\hline Model & Information & Advantages & Disadvantages & $\begin{array}{c}\text { Time } \\
\text { Synchronization }\end{array}$ \\
\hline TOA & Range & Accuracy is high & $\begin{array}{c}\text { Line of sight } \\
\text { operation }\end{array}$ & Yes \\
\hline TDOA & $\begin{array}{c}\text { Range } \\
\text { difference }\end{array}$ & Accuracy is high & $\begin{array}{c}\text { Line of sight } \\
\text { operation }\end{array}$ & No \\
\hline RSS & Range & Simple and inexpensive & Low accuracy & No \\
\hline DOA & Bearing & $\begin{array}{r}\text { At least two sensors are } \\
\text { required }\end{array}$ & $\begin{array}{c}\text { Significant post } \\
\text { processing } \\
\text { required }\end{array}$ & No \\
\hline
\end{tabular}


From Table 4-1, the TOA technique has very high accuracy, but requires synchronization of the source and receivers [6]. Since the transducer functions as the transmitter and the receiver over timed, the system is time synchronous by default and is therefore selected as the reception processing model. The TOA technique only provides the position information and can be used to extrapolate angular position by evaluating the time delay. In the analysis, it is assumed that the sensors position is static and does not change during the position acquisition stage.

Letting the position of the target from each sensor be represented by following equation:

$$
\boldsymbol{r}=\boldsymbol{f}(\boldsymbol{x})+\boldsymbol{n}
$$

Where $\boldsymbol{r}$ is the position measurement vector obtained from the sensors directly, $\boldsymbol{n}$ is the additive zero mean noise and $\boldsymbol{x}$ is the position vector of the target [6].

The time of pulse emission is known, along with the time at which the pulse is received, this can be used to evaluated the time from target to receiver to be written as

$$
t_{l}=\frac{d_{l}}{c}, \quad l=1,2, \ldots, L
$$

Therefore, the model described in spatial domain by equation (4-1) is as follows:

$$
\begin{gathered}
r=\left[\begin{array}{lll}
r_{1} & r_{2} & r_{3}
\end{array}\right] \\
n=\left[\begin{array}{lll}
n_{1} & n_{2} & n_{3}
\end{array}\right] \\
f(x)=\left[\begin{array}{l}
\sqrt{\left(x-x_{1}\right)^{2}+\left(y-y_{1}\right)^{2}} \\
\sqrt{\left(x-x_{2}\right)^{2}+\left(y-y_{2}\right)^{2}} \\
\sqrt{\left(x-x_{3}\right)^{2}+\left(y-y_{3}\right)^{2}}
\end{array}\right]
\end{gathered}
$$


From the equation it can be seen that the parameters of the target positions are a function of the sensor position vector. Also it is evident that the approximation of the position target shown by equation (4.5) is non-linear. Thus by using a linear least square localization approach to evaluating the position, the nonlinearity can be simplified to a linear model given by [6]:

$$
A x+q=b
$$

Where $\boldsymbol{q}$ has the noise terms embedded in it. By assuming $\boldsymbol{q}$ to be very small such that the noise term can be neglected, the model can be simplified further to be a linear system of equation defined by the only the parameters $\boldsymbol{A}$ and $\boldsymbol{b}$ :

$$
\begin{gathered}
\boldsymbol{A x}=\boldsymbol{b} \\
\boldsymbol{A}=\left[\begin{array}{ll}
-2\left(x_{2}-x_{1}\right) & -2\left(y_{2}-y_{1}\right) \\
-2\left(x_{3}-x_{1}\right) & -2\left(x_{3}-x_{1}\right)
\end{array}\right] \\
\boldsymbol{b}=\left[\begin{array}{l}
r_{2}^{2}-x_{2}^{2}-y_{2}^{2}-r_{1}^{2}+x_{1}^{2}+y_{1}^{2} \\
r_{3}^{2}-x_{3}^{2}-y_{3}^{2}-r_{1}^{2}+x_{1}^{2}+y_{1}^{2}
\end{array}\right]
\end{gathered}
$$

From the above model the position $\boldsymbol{x}$ of the target can be obtained as follows :

$$
x=\left(A^{T} A\right)^{-1} A^{T} b
$$

The model presented above forms the spatial localization algorithm for an array of sensors that lie in two dimensions. Since the array that is currently being developed lies in only one dimension, the model can be simplified by assuming y coordinates to be zero.

From three sensors, three equations of position are obtained, however the system only requires two spatial coordinates. This result in the system being over constrained since there are more equations than variables. This implies that the system has either no solution or more than one 
solution, the latter is true for the current system and is an anomaly occurring due to the geometry of the problem. As shown in Figure 4-1, the equation describing the propagation distance is the equation of a circle, as the propagation distance from each transducer is obtained as the radius of the circle.

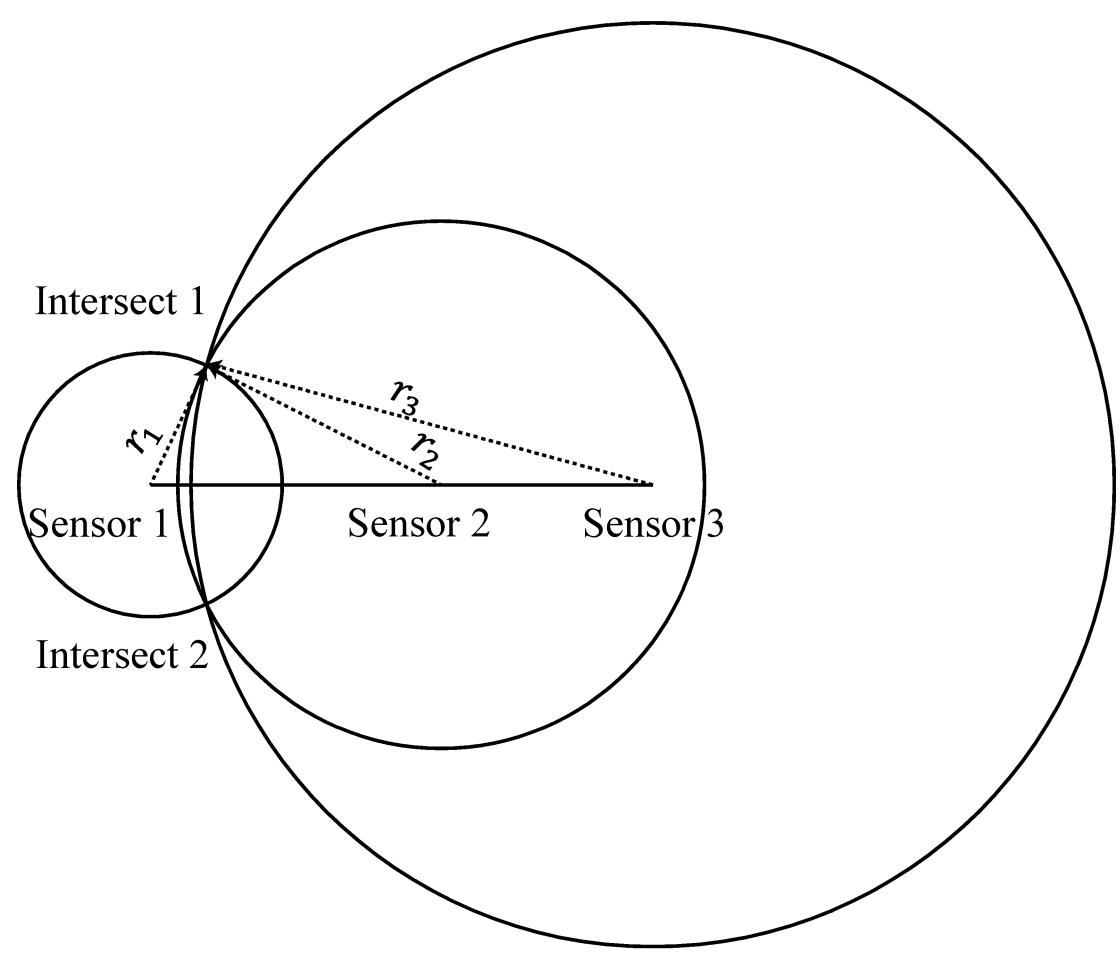

Figure 4-1: Position localization using TOA technique

Figure 4-1 highlights that two solutions exist, one where the target's approximate distance is in front of the transducer and in the other case is where the distance is behind the transducer. Thus, by neglecting the negative values, the solution still holds and is validated by experiment. 


\section{Chapter 5}

\section{Sensor Modelling}

This chapter presents the development of the analytical and numerical model for the aircapacitive transducer. The analytical model was developed using the vibration equation of continuous systems and aims at providing the vibration mode shapes and modal frequencies. The modal analysis coupled with a known electrostatic force allows for the evaluation of the displacement of the sensor membrane. The results of the analytical analysis are then compared with numerical analysis using software based finite element analysis (FEA) using Ansys Acoustic Analysis package.

\subsection{Analytical Model}

The analytical model is developed directly from the classical plate theory developed by Liessa [57]. To develop the analytical model, the following assumptions are made:

1. The membrane is clamped around the edges;

2. It has the physical dimensions are outlined in Appendix A; and

3. The properties outlined in Appendix B are homogenous over the entire membrane.

The displacement of a membrane is defined as a vibration of a continuous system constrained by boundary conditions. The free vibration solution for a continuous system can be found using the method of separation of variable and is given as the product of the time dependent and space dependent functions which are independent of each other [52]:

$$
w(x, t)=W(x) T(t)
$$


Since the displacement is occurring in the transverse plane, equation (5.1) can also be re- written with the Laplacian operator as $[67,68,69]$ :

$$
D \nabla^{4} w+\rho \frac{\partial^{2} w}{\partial t^{2}}=0
$$

Where $D$ is the flexural rigidity given by:

$$
D^{*}=\frac{E h^{3}}{12\left(1-v^{2}\right)}
$$

In free vibration, the time dependent forcing function is absent, therefore the only mode of vibration is free vibration. This reduces the equation (5.1) to:

$$
w(x, t)=W \cos \omega t
$$

Where, $\omega=$ circular frequency

By substituting equation 5.4 into 5.2 the following relationship is obtained $[68,69]$ :

$$
\left(\nabla^{4}-k^{4}\right) W=0
$$

Where $k=$ convenience factor

$$
k^{4}=\frac{\rho \omega^{2}}{D^{*}}
$$

The above equation can be factored and rewritten as $[67,68]$ :

$$
\left(\nabla^{2}-k^{2}\right)\left(\nabla^{2}+k^{2}\right) W=0
$$

By applying the theory of linear differential equations to equation 5.6, the following two solutions are obtained $[67,68]$ :

$$
\nabla^{2} W_{1}+k^{2} W_{1}=0
$$




$$
\nabla^{2} W_{2}-k^{2} W_{2}=0
$$

Since the plate being assessed is circular therefore the coordinate system used for evaluating the solution is based on polar coordinates, where the displacement function is given as the sum of all of the Fourier series [67] :

$$
W(r, \theta)=\sum_{n=0}^{\infty} W_{n}(r) \cos (n \theta)+\sum_{n=0}^{\infty} W_{n}^{*}(r) \sin (n \theta)
$$

By substituting the Fourier series into equation (5.7), the following two functions are obtained:

$$
\begin{array}{r}
\frac{d^{2} W_{n_{1}}}{d r^{2}}+\frac{1}{r} \frac{d W_{n_{1}}}{d r}-\left(\frac{n^{2}}{r^{2}}-k^{2}\right) W_{n_{1}}=0 \\
\frac{d^{2} W_{n_{2}}}{d r^{2}}+\frac{1}{r} \frac{d W_{n_{2}}}{d r}-\left(\frac{n^{2}}{r^{2}}-k^{2}\right) W_{n_{2}}=0
\end{array}
$$

Similarly, two identical equations are obtained for the $W_{n}^{*}$. It is important to note that the above equations are recognized as the Bessel's function, having the following solution:

$$
\begin{gathered}
\begin{array}{l}
W_{n_{1}}=A_{n} I_{n}(k r)+B_{n} Y_{n}(k r) \\
W_{n_{2}}=C_{n} I_{n}(k r)+D_{n} K_{n}(k r)
\end{array} \\
\text { Where } J_{n}=\text { Bessel's function of the first kind } \\
I_{n}=\text { Modified Bessel's function of the first kind }
\end{gathered}
$$

Since the plate has no internal hole, the Bessel's function of the second kind and the modified Bessel's function of the second kind are discarded. This reduces the final equation to the sum of the two displacements $W_{n_{1}}$ and $W_{n_{2}}$ and can be written as follows [67] :

$$
W_{n}=\left[A_{n} J_{n}(k r)+C_{n} I_{n}(k r)\right] \cos n \theta
$$

The following boundary conditions were used for the clamped plate analysis $[67,68,69]$ 


$$
\begin{aligned}
& W(a)=0 \\
& \frac{\partial W(a)}{\partial r}=0
\end{aligned}
$$

By substituting equation (5.12) into (5.11) the following characteristic determinant is obtained

$$
\left|\begin{array}{ll}
J_{n}\left(\lambda^{*}\right) & I_{n}\left(\lambda^{*}\right) \\
J_{n}{ }^{\prime}\left(\lambda^{*}\right) & I_{n}{ }^{\prime}\left(\lambda^{*}\right)
\end{array}\right|=0
$$

The following recursion relationship can be used to find out the derivative of the Bessel's function

$$
\begin{aligned}
& \lambda J_{n}^{\prime}\left(\lambda^{*}\right)=n J_{n}\left(\lambda^{*}\right)-\lambda^{*} J_{n+1}\left(\lambda^{*}\right) \\
& \lambda I_{n}^{\prime}\left(\lambda^{*}\right)=n I_{n}\left(\lambda^{*}\right)+\lambda^{*} I_{n+1}\left(\lambda^{*}\right)
\end{aligned}
$$

By expanding equation 5.13 the following relationship can be obtained.

$$
J_{n}\left(\lambda^{*}\right) I_{n+1}\left(\lambda^{*}\right)+I_{n}\left(\lambda^{*}\right) J_{n+1}\left(\lambda^{*}\right)=0
$$

\begin{tabular}{|c|c|c|c|}
\hline Mode Shape & ANSYS [Hz] & MATLAB [Hz] & $\%$ Difference \\
\hline 1 & 114.97 & 158.2 & 27.3 \\
\hline 2 & 239.21 & 247 & 3.2 \\
\hline 3 & 392.54 & 355.6 & 10.4 \\
\hline 4 & 514.37 & 483.9 & 6.3 \\
\hline 5 & 684.65 & 631.9 & 8.3 \\
\hline 6 & 784.17 & 799.7 & 1.9 \\
\hline 7 & 952.41 & 987.2 & 3.5 \\
\hline 8 & 1003.5 & 1194.5 & 16.0 \\
\hline
\end{tabular}

Using equation (5.15) an iterative solver was developed in MATLAB to solve for the eigenvalues.

The roots of these equations were obtained for desired frequency ranges and are outlined in Table $5-1$.

Table 5-1 Frequencies and mode shapes from ANSYS and MATLAB 
Table 5-1 highlight the comparison between analytical method and Galerkin's method. The analytical method relies on the eigenvalues of the solution in equation (5.15) whereas the numerical approach relies on solving the wave equation numerically and obtaining the results. The main reason for the disparity in values is mainly due to structural damping that is taken into account by Ansys Workbench and is observed in the dataset where the frequency outputs are lower than the values obtained from the analytical analysis.

\subsection{Numerical Modelling Approach}

Unlike the analytical approach, the numerical modelling approach relies on the elemental deflections which are translated into internal and external forces. By evaluating these internal and external forces, a more accurate propagation model can be approximated. Also, the numerical modelling approach allows for the inclusion of the coupling medium inside and around the transducer. As seen from the equation (5.1), the analytical analysis lacks the structural feedback from the coupled medium which includes the reverberation occurring within the structure of the transducer. The numerical model can be extended further to consider the impedance mismatch at the surface.

The harmonic response of a structural system with mass matrix $[\boldsymbol{M}]$, damping matrix $[\boldsymbol{C}]$, stiffnes matrix $[\boldsymbol{K}]$ and a force vector $\{\boldsymbol{f}\}$ with nodal displacement $\{\boldsymbol{u}\}$ is given as follows [reference]

$$
\left[\boldsymbol{M}_{\boldsymbol{s}}\right]\{\ddot{\boldsymbol{U}}\}+\left[\boldsymbol{C}_{\boldsymbol{s}}\right]\{\dot{\boldsymbol{U}}\}+\left[\boldsymbol{K}_{\boldsymbol{s}}\right]\{\boldsymbol{U}\}=\left\{\boldsymbol{F}_{\boldsymbol{s}}\right\}
$$

Equation (5.16) can be represented in terms of the harmonic frequencies as follows:

$$
\left(-\omega^{2}\left[\boldsymbol{M}_{\boldsymbol{s}}\right]+j \omega\left[\boldsymbol{C}_{\boldsymbol{s}}\right]+\left[\boldsymbol{K}_{\boldsymbol{s}}\right]\right)\{\boldsymbol{U}\}=\left\{\boldsymbol{F}_{\boldsymbol{s}}\right\}
$$


Therefore, the nodal displacement vector can be expressed as:

$$
\{\boldsymbol{U}\}=\left(-\omega^{2}\left[\boldsymbol{M}_{s}\right]+j \omega\left[\boldsymbol{C}_{\boldsymbol{s}}\right]+\left[\boldsymbol{K}_{s}\right]\right)^{-1}\left\{\boldsymbol{F}_{s}\right\}
$$

Similarly, by using the pressure-formulated element approach outlined in ref. 60 , the forces nodal forces on the fluid elements can be expressed as a function of pressure as shown [60] :

$$
\left[\boldsymbol{M}_{\boldsymbol{f}}\right]\{\ddot{\boldsymbol{p}}\}+\left[\boldsymbol{C}_{\boldsymbol{f}}\right]\{\dot{\boldsymbol{p}}\}+\left[\boldsymbol{K}_{\boldsymbol{f}}\right]\{\boldsymbol{p}\}=\left\{\boldsymbol{F}_{\boldsymbol{f}}\right\}
$$

For a coupled analysis, the mass, stiffness and damping of the coupled medium along with the interaction surface is accounted by the introducing the coupling matrix $[R]$. The resulting expression highlighting the coupling is shown as [70]

$$
\left[\begin{array}{cc}
\boldsymbol{M}_{S} & 0 \\
\rho_{0} \boldsymbol{R}^{T} & \boldsymbol{M}_{\boldsymbol{f}}
\end{array}\right]\left\{\begin{array}{l}
\ddot{\boldsymbol{U}} \\
\ddot{\boldsymbol{p}}
\end{array}\right\}+\left[\begin{array}{cc}
\boldsymbol{C}_{S} & 0 \\
0 & \boldsymbol{C}_{\boldsymbol{f}}
\end{array}\right]\left\{\begin{array}{c}
\dot{\boldsymbol{U}} \\
\dot{\boldsymbol{p}}
\end{array}\right\}+\left[\begin{array}{cc}
\boldsymbol{K}_{S} & -\boldsymbol{R} \\
0 & \boldsymbol{K}_{\boldsymbol{f}}
\end{array}\right]\left\{\begin{array}{l}
\boldsymbol{U} \\
\boldsymbol{p}
\end{array}\right\}=\left\{\begin{array}{l}
\boldsymbol{F}_{S} \\
\boldsymbol{F}_{f}
\end{array}\right\}
$$

For harmonic analysis, Equation (5.20) can be reduced to the following expression without the higher order terms.

$$
\left[\begin{array}{cc}
-\omega^{2} \boldsymbol{M}_{\boldsymbol{s}}+j \omega \boldsymbol{C}_{\boldsymbol{s}}+\boldsymbol{K}_{\boldsymbol{s}} & -\boldsymbol{R} \\
-\omega^{2} \rho_{0} \boldsymbol{R}^{\boldsymbol{T}} & -\omega^{2} \boldsymbol{M}_{\boldsymbol{f}}+j \omega \boldsymbol{C}_{\boldsymbol{f}}+\boldsymbol{K}_{\boldsymbol{f}}
\end{array}\right]\left\{\begin{array}{l}
\boldsymbol{U} \\
\boldsymbol{p}
\end{array}\right\}=\left\{\begin{array}{l}
\boldsymbol{F}_{\boldsymbol{S}} \\
\boldsymbol{F}_{\boldsymbol{f}}
\end{array}\right\}
$$

The unsymmetric matrix shown in Equation (5.21) requires higher computational time as the off diagonal entries are not transposes of each other. This inversion of an unsymmetric matrix is very computationally intensive and requires considerable amount of computation time. To reduce the computation time, the geometry of the sensor is simplified by using symmetric planes.

To model the sensor using numerical FEA approach, Ansys Workbench Acoustics analysis software was selected. A modal analysis using a circular disc, clamped at the edges, was conducted in Ansys Workbench. The geometry used for the analysis is shown in Figure 5-1 and a detailed 
model is available in Appendix $\mathrm{C}$ along with the material properties for Mylar listed in Appendix B. The resulting mode shapes and their corresponding frequencies are outlined in Figure 5-1.

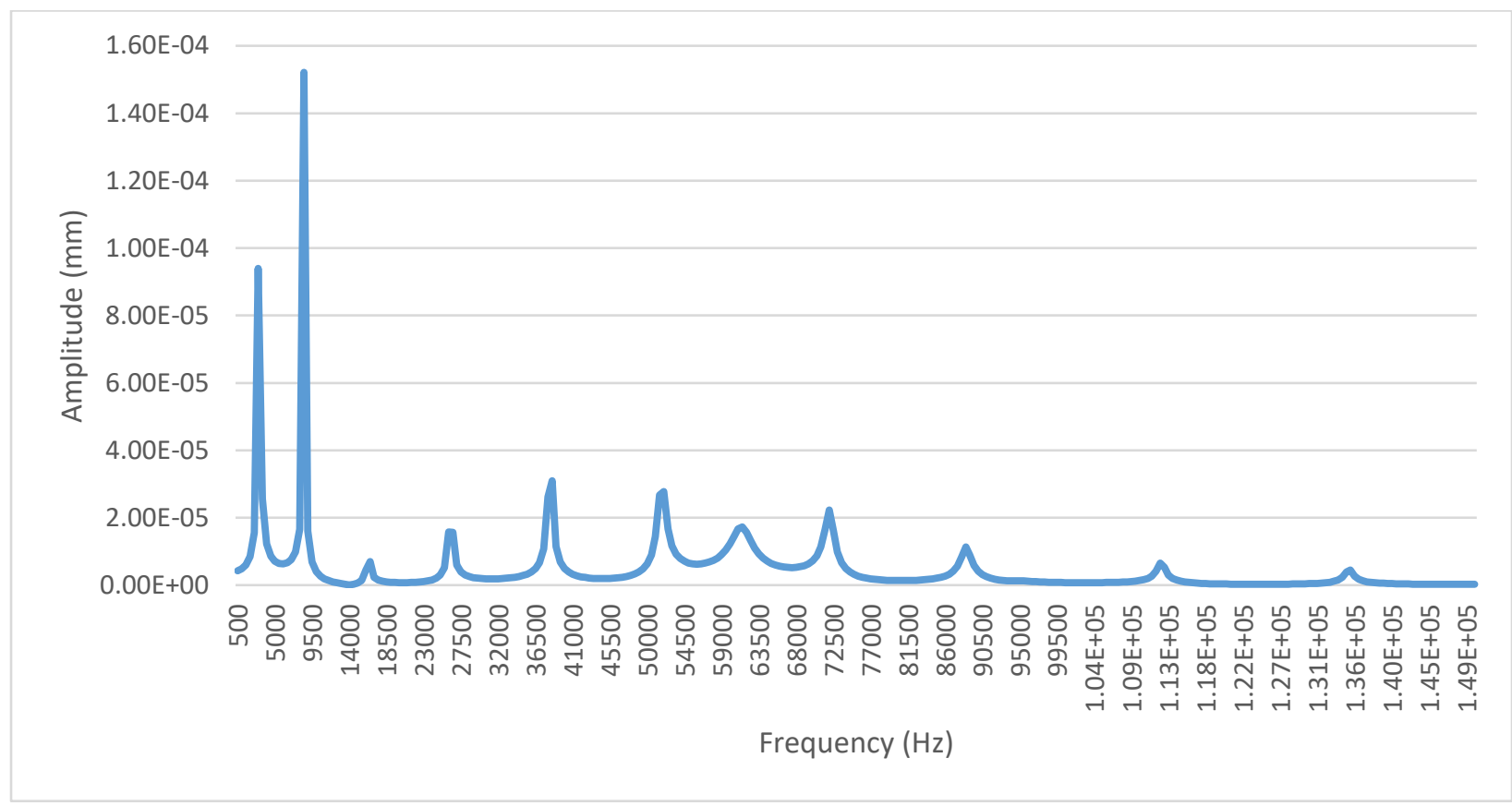

Figure 5-1: Air-coupled transducer frequency response and transducer deflection amplitude

From Figure 5-1, the mode shapes are readily visible as the intermediate peaks occurring as the transducer is excited over a range of frequencies. The lower frequencies have a very high amplitude, however after passing the second mode shape the amplitude reduces drastically. In the range of operation of the current design, operating between 30 to $100 \mathrm{kHz}$, the output deflection is observed to be an order of magnitude lower when compared to low frequency excitation.

A mesh studies was performed to validate the selection of mesh size and is available in Table 5-2. The element size for the FEA analysis is inversely proportional to the computation time, making larger elements preferable. However, as stated in the Ansys software guidelines [71], in order to capture the full wave vibratory motion of the disc, the largest element size should be 
1/10 of the wavelength, placing a limit on the maximum element size. Therefore, an element size of $0.1 \mathrm{~mm}$ was selected for further FEA analysis.

Table 5-2: Mesh studies analysis with computation time

\begin{tabular}{|c|c|c|c|c|c|c|c|c|c|}
\hline Mode \# & Theoretical & $\begin{array}{l}0.02 \\
\mathrm{~mm}\end{array}$ & \%error & $\begin{array}{l}0.05 \\
\mathrm{~mm}\end{array}$ & $\%$ ERROR & $\begin{array}{l}0.10 \\
\mathrm{~mm}\end{array}$ & $\%$ ERROR & $\begin{array}{l}0.20 \\
\mathrm{~mm}\end{array}$ & $\%$ ERRO \\
\hline & $\begin{array}{l}\text { Computation } \\
\text { Time } \\
\text { (Minutes) }\end{array}$ & & & & 187 & & 100 & & 36 \\
\hline 1 & 1160.484 & 1160.4 & 0.007 & 1160.7 & 0.019 & 1161.1 & 0.053 & 1162 & 0.1 \\
\hline 6 & 4517.169 & 4517.2 & 0.001 & 4518.2 & 0.023 & 4519.9 & 0.060 & 4523.7 & 0.1 \\
\hline 15 & 10120.16 & 10119 & 0.012 & 10121 & 0.008 & 10125 & 0.048 & 10135 & 0.1 \\
\hline 30 & 17967.11 & 17960 & 0.040 & 17964 & 0.017 & 17973 & 0.033 & 17995 & 0.1 \\
\hline 51 & 28054.42 & 28037 & 0.062 & 28044 & 0.037 & 28059 & 0.016 & 28110 & 0.2 \\
\hline 74 & 40384.23 & 40347 & 0.092 & 40357 & 0.067 & 40384 & 0.001 & 40493 & 0.2 \\
\hline 105 & 54953.68 & 54884 & 0.127 & 54899 & 0.099 & 54946 & 0.014 & 55165 & 0.3 \\
\hline 140 & 71768.48 & 71646 & 0.171 & 71666 & 0.143 & 71741 & 0.038 & 72168 & .5 \\
\hline 175 & 90824.36 & 90624 & 0.221 & 90653 & 0.189 & 90767 & 0.063 & 91632 & 0.8 \\
\hline 222 & 112121.3 & 111810 & 0.278 & 111850 & 0.242 & 112040 & 0.073 & 113660 & 1.3 \\
\hline
\end{tabular}

The results from the air-coupled harmonic analysis is show in Figure 5-2. It can be seen that the natural frequencies outlined by the harmonic analysis with and without air are offset due to the air and structural coupling. The analysis was conducted for frequencies between the range of $1 \mathrm{~Hz}$ to $150 \mathrm{kHz}$ which includes the operating range of the transducer under consideration. 


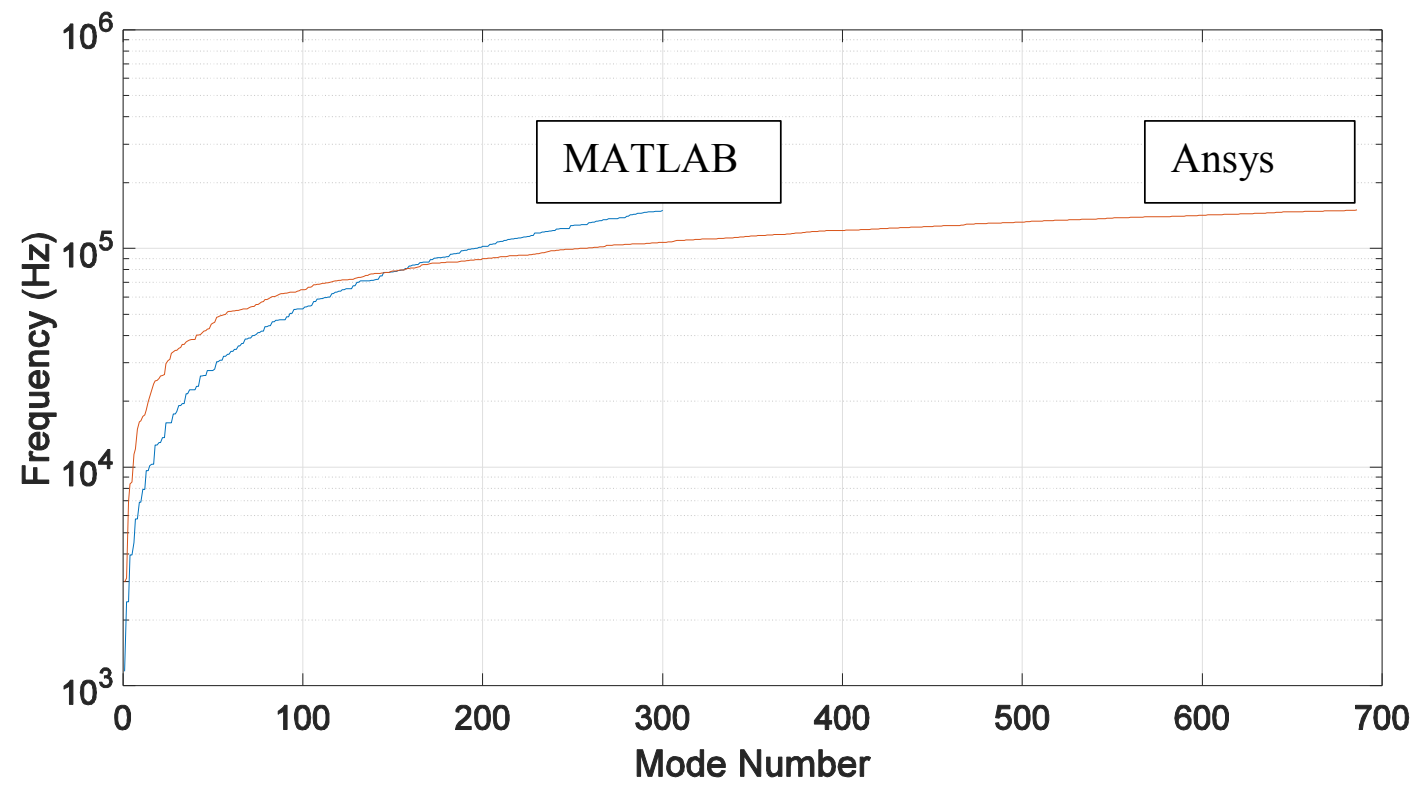

Figure 5-2: Comparison of frequency vs mode shape for analytical and numerical methods

The sound pressure level in the field by extrapolating the transducer's film displacement and accounting for the static pressure. The results are used for comparison to the experimental performance in the later chapters of this thesis.

\subsection{Sensor Modelling Summary}

The analysis outlined in this chapter highlight the importance of mathematical modelling used to approximate the transducer's performance. The air coupling modelling is emphasized and used for developing the model as it allows for a more accurate representation of the operation of the sensor. The analytical model presented, is used as a feedback mechanism to establish a coarse co-relation between air coupled frequencies and non-coupled frequencies. 


\section{Chapter 6}

\section{Sensor Construction}

In this Chapter, the construction and development of the air coupled array and the accompanying circuitry are described. The printed circuit board (PCB) designed for the sensor array was built using the photolithography technique. This technique allows for the layout of smaller traces and component pad widths necessary for surface mount devices (SMD), while offering increased simplicity, reliability and repeatability.

\subsection{Construction of the sensor}

The air capacitive sensor consists of a back plate and a metallized membrane as show in Figure 6-1. The, back plate is made from copper and the membrane is made from metallized biaxially-oriented polyethylene terephthalate (BoPET) film, commercially known as Mylar. The thickness of the membrane was selected to be 10 micrometer ( 0.00039 inches) in order to reduce the inertia of the membrane at high acoustic frequencies [38].

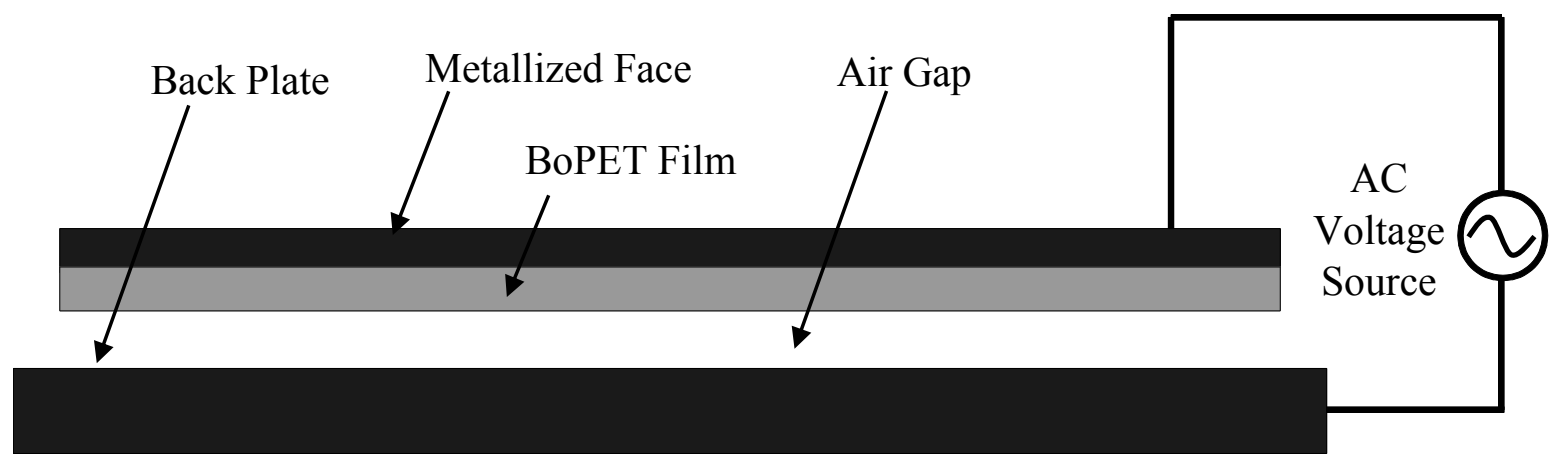

Figure 6-1: Model of an air-capacitive transducer with Mylar film[38,27] 
The film was first put in tension such that all folds and kinks are removed. A paint can was used to hold the film in tension while pre-machined rings are attached to the film using ultraviolet glue. The film was then cut and removed along with excess film around the sensor resulting in the assembly as shown in Figure 6-2.

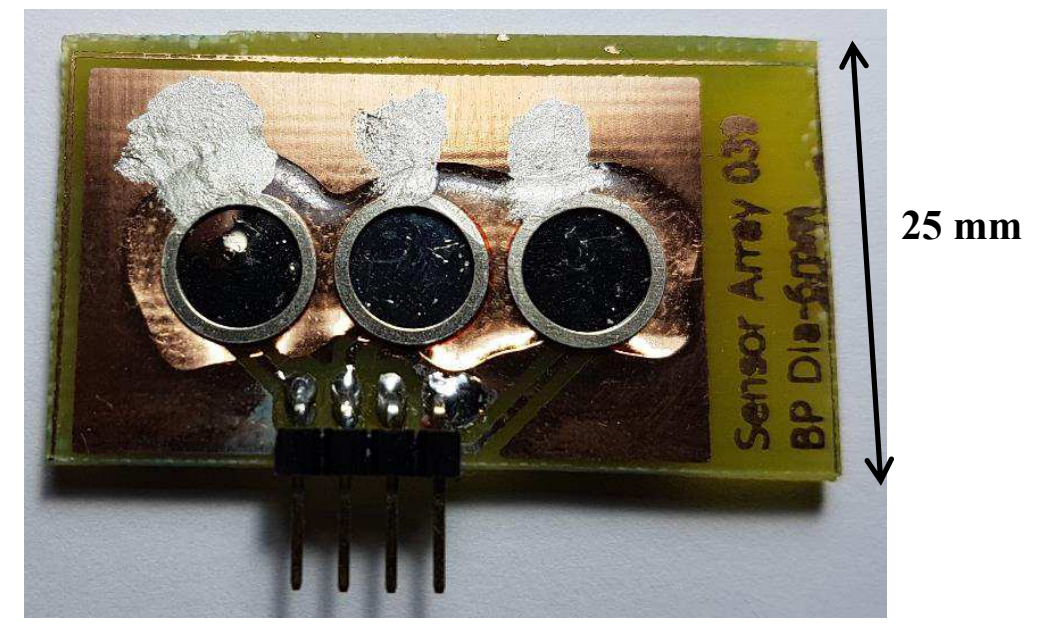

Figure 6-2: Air-Capacitive sensor array of 3 elements

The membrane was placed such that the non-metalized face of the film was between the back plate and the metalized face as shown in Figure 6-1. The non-metalized face of the film served as the partial dielectric along with air gap between the film and the back plate. Finally, the membrane was bonded to the back plate using ultraviolet glue. The back plate was designed using Cadsoft Eagle CAD software and was manufactured using the process outlined in Figure 6-3. 


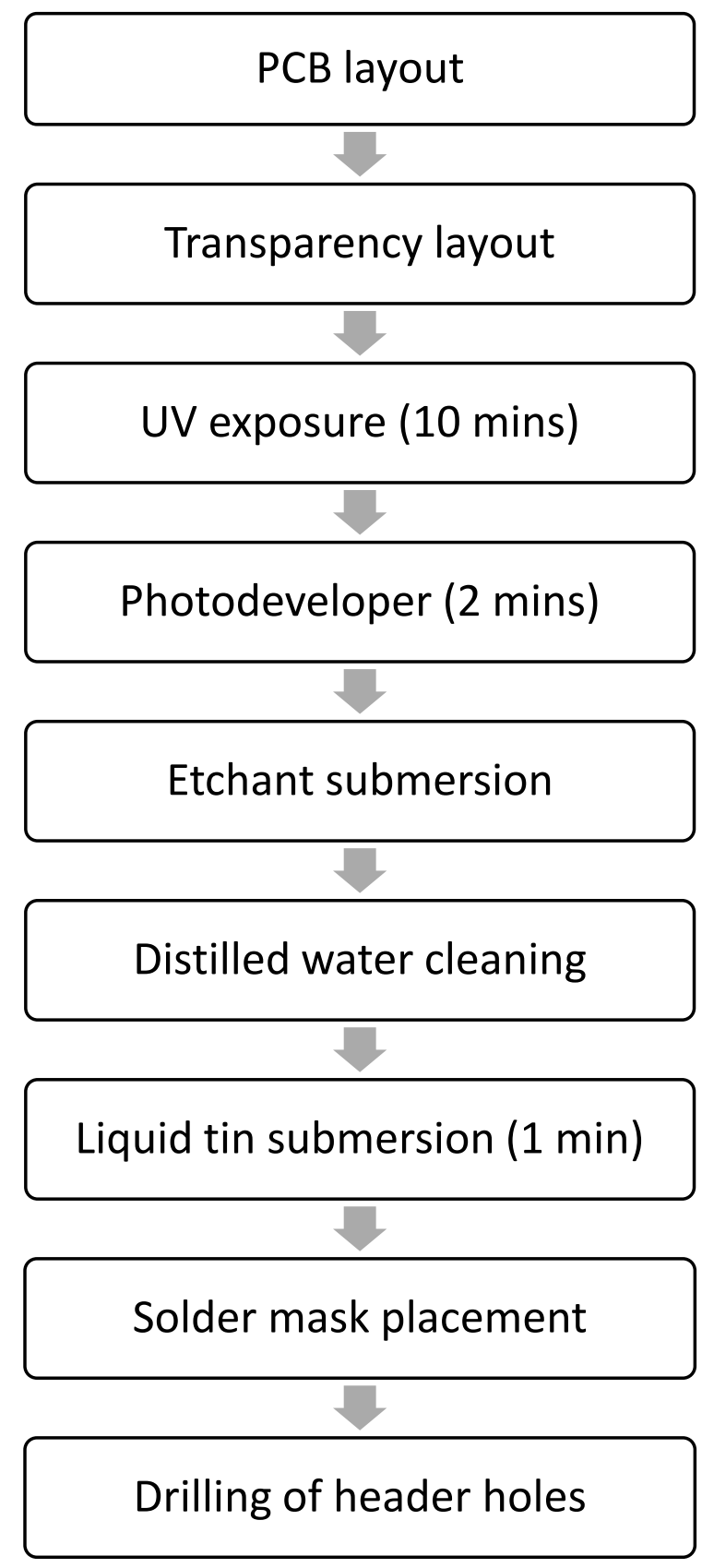

Figure 6-3: PCB fabrication process layout 


\subsection{PCB fabrication method}

To design and manufacture the PCB, photolithographic techniques were used. Figure 6-3 outlines a flowchart outlining the construction methodology adopted for the PCB fabrication methodology. A PCB layout, developed using Cadsoft Eagle ${ }^{\circledR}$ electronics CAD design package, was printed on a transparency as shown in Figure 6-4.

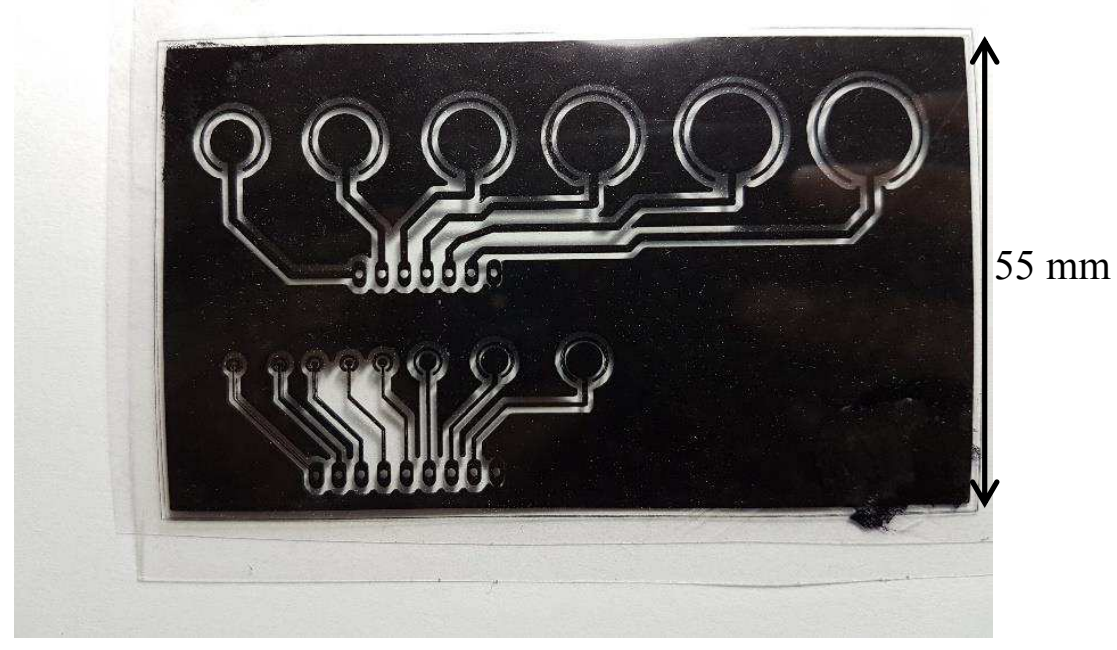

Figure 6-4: Circuit design on transparency

The transparency is placed above the positively pre-sensitized PCB (MG Chemical CAT No. 690) and is exposed to ultraviolet (UV) light for ten minutes' while being pressed down by sheet of UV transparent plexiglass as shown in Figure 6-5. 


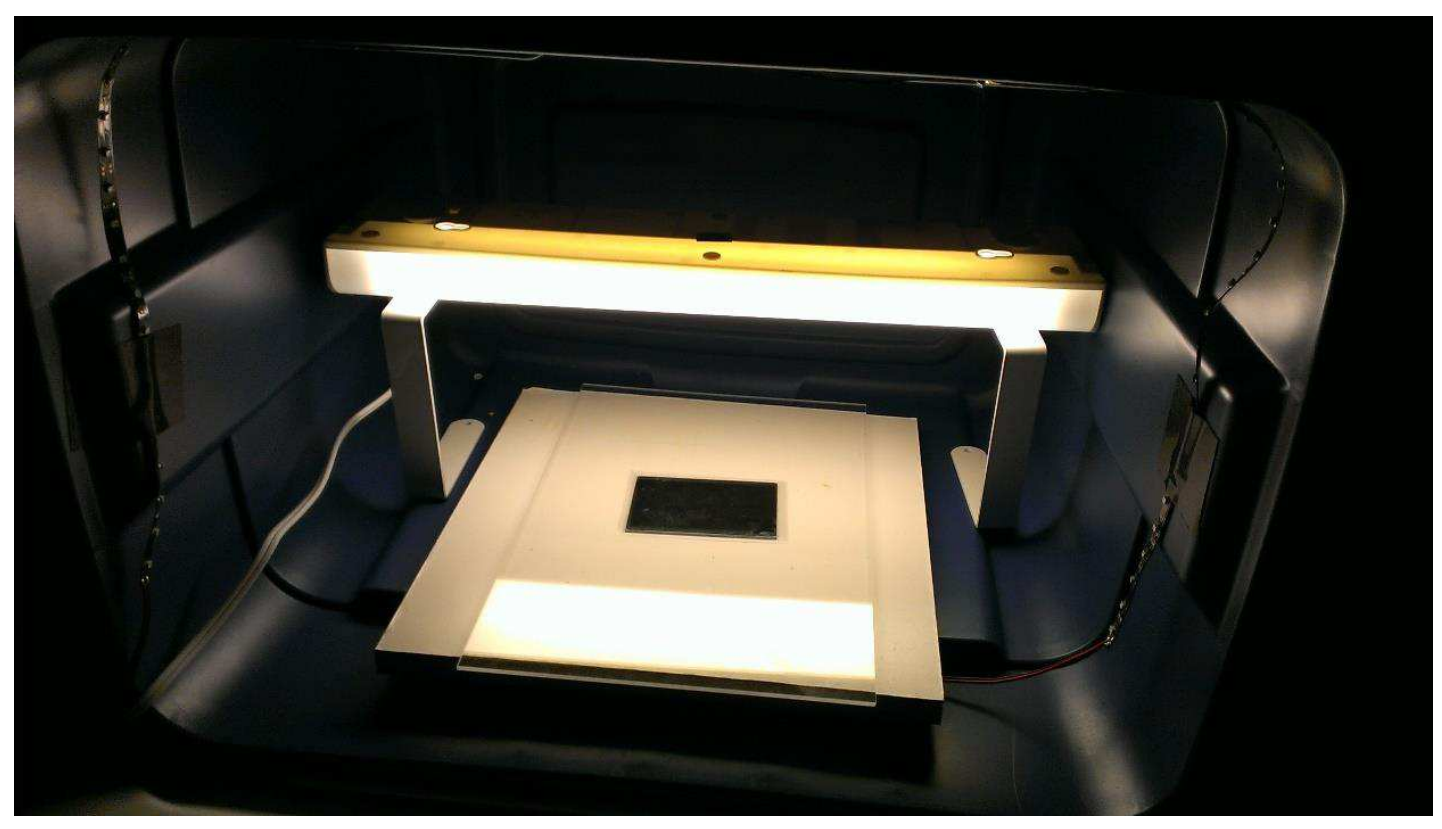

Figure 6-5: UV exposure chamber setup

After the UV exposure, the board is placed in a positive developer fluid (MG Chemicals CAT No. 418) and stirred for two minutes. The resulting design on the copper clad board is show in Figure 6-6.

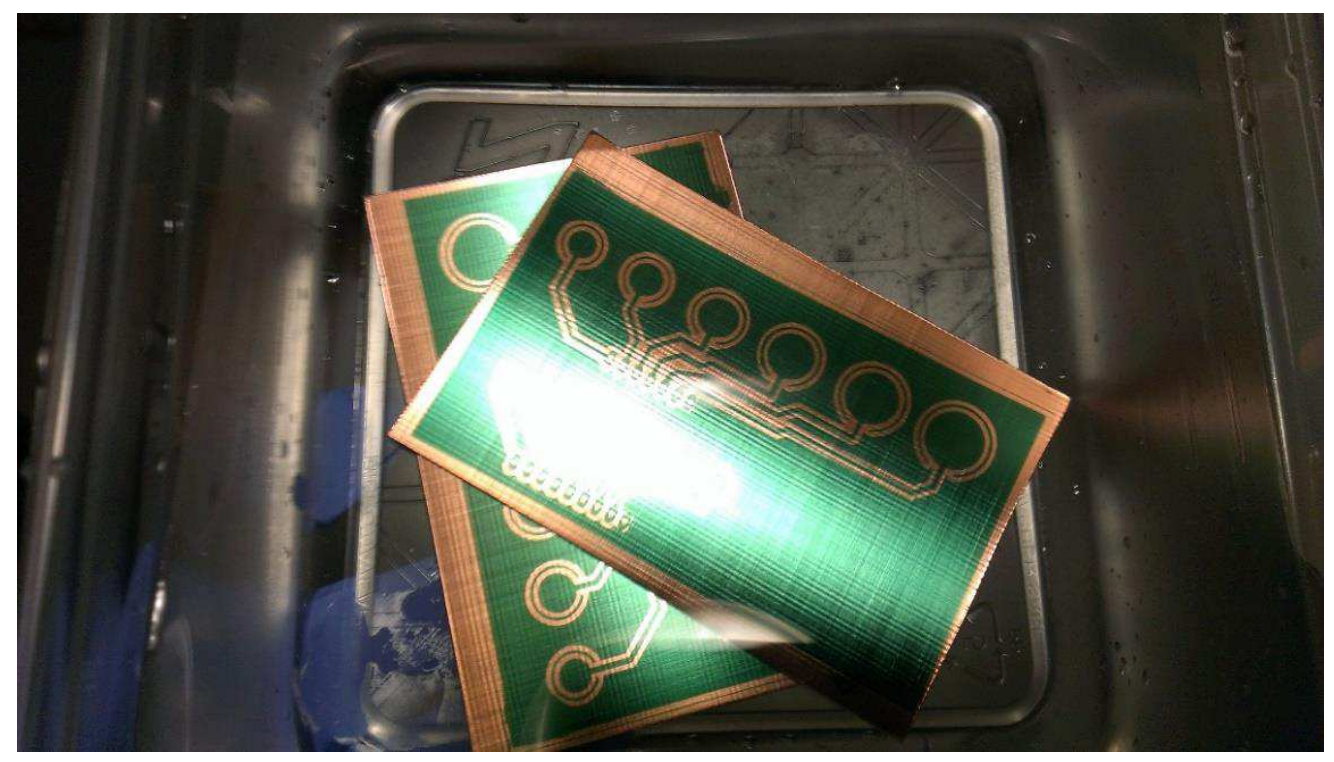

Figure 6-6: Pre-sensitized board after photo development process 
The PCB was later etched using a mixture 2:1 volumetric ratio of hydrogen peroxide and muriatic acid $(\mathrm{HCl}) 31.45 \%$ concentration for 5 minutes. The etchant reacts with the exposed copper producing the board shown in Figure 6-7.
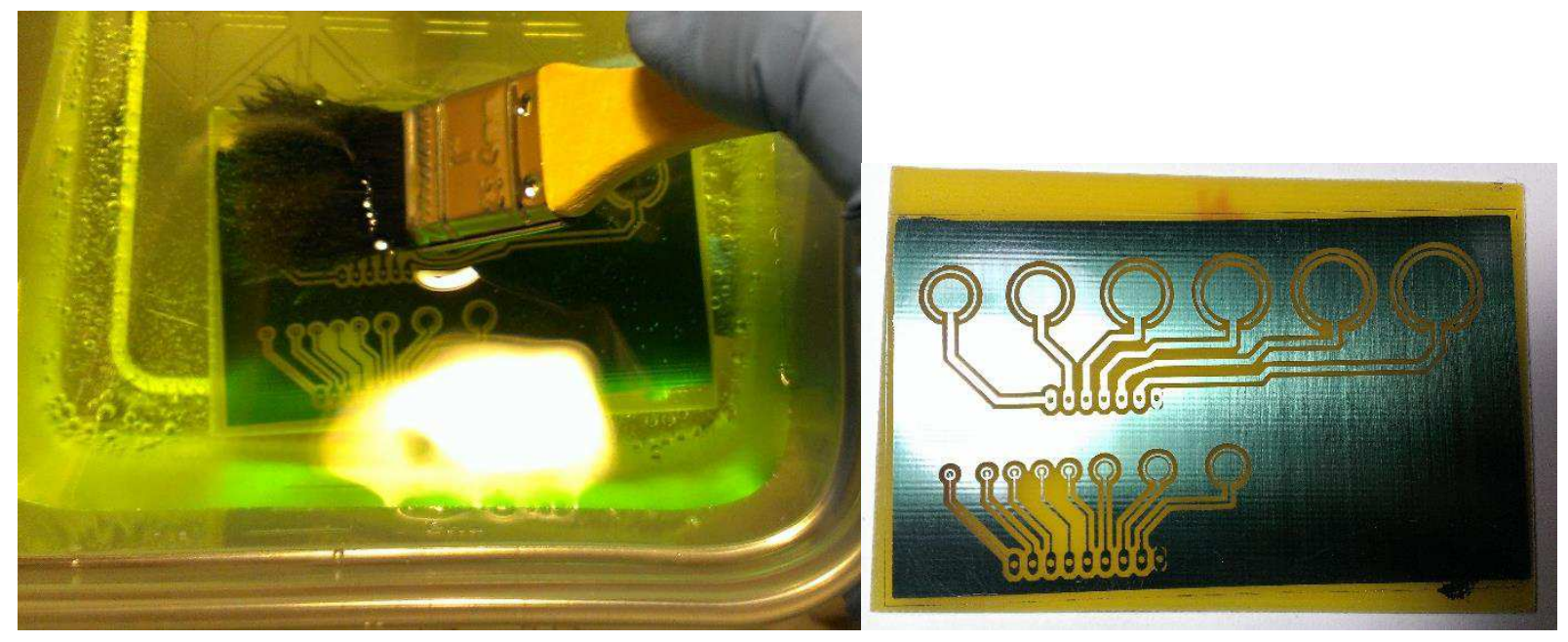

Figure 6-7: Etching process using Muriatic acid.

To protect the traces from corrosion and to improve the adherence of solder to the pads, the PCB was submerged in a liquid tin solution (MG Chemicals CAT No. 421). The solution chemically reacts with copper to form a thin layer of tin on top of the surface as shown in Figure 6-8. Based on the time deposition rate graph shown in Figure 6-9, a one minute deposition time was selected.

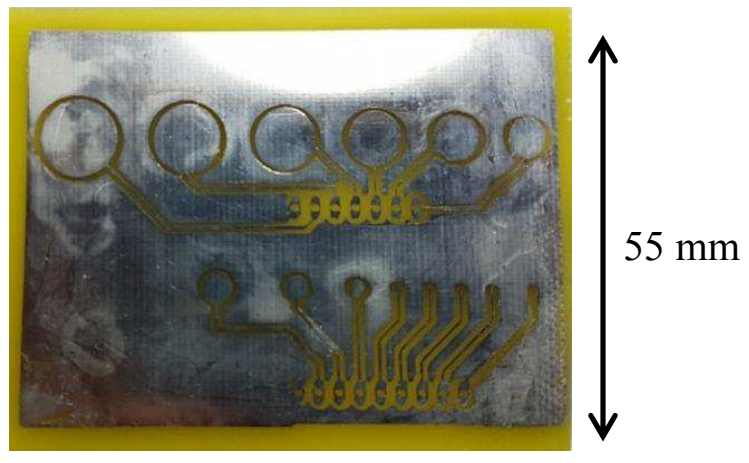

Figure 6-8: PCB appearance following the tinning step. 


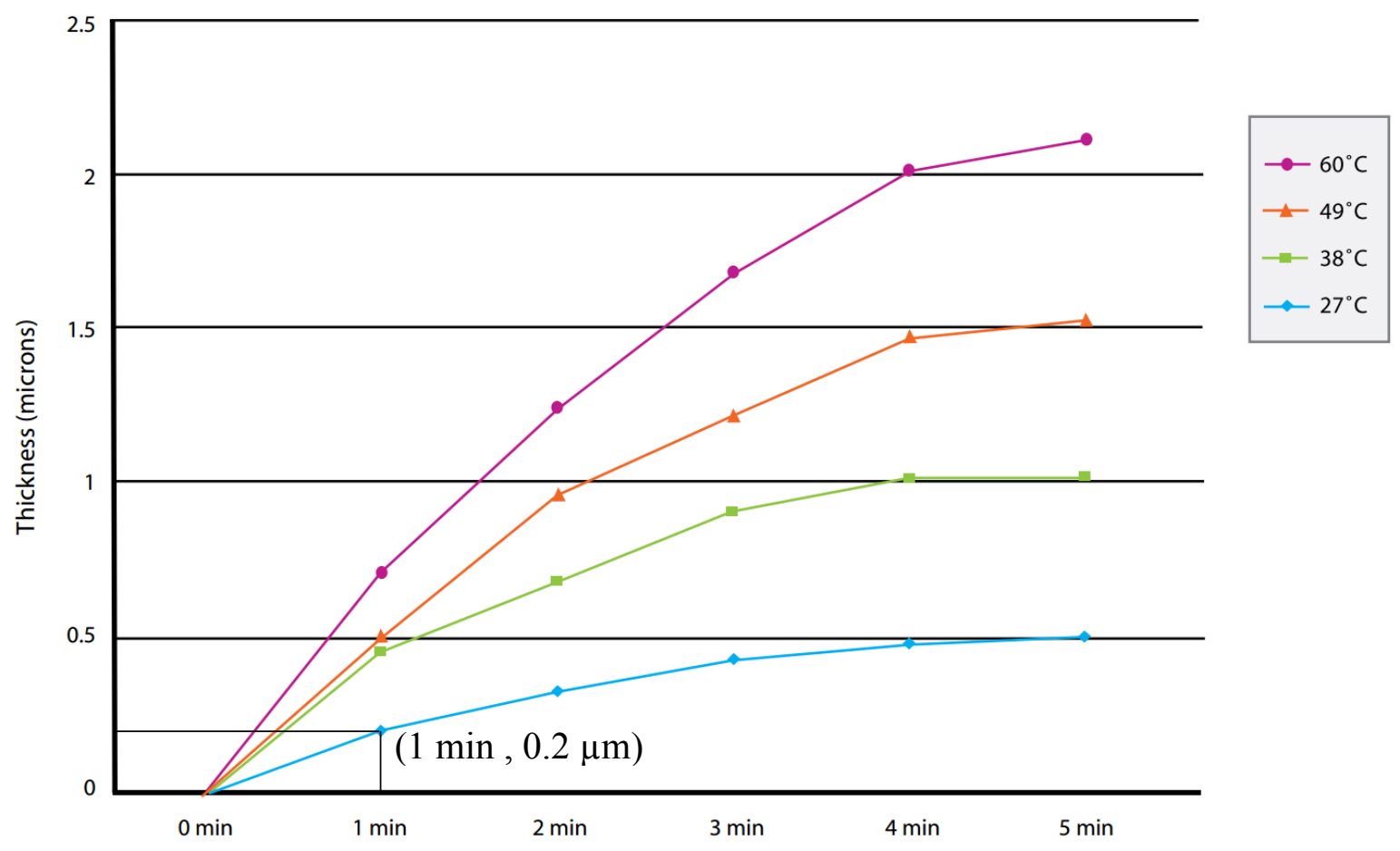

Figure 6-9: Time rate deposition of Liquid Tin solution (MG Chemicals CAT No. 421) [72]

Finally, holes were drilled in the PCB with a number 60 drill bit to attach pin headers to make the board mountable on a breadboard for testing purposes.

In the last step a solder mask layer was applied to further protect the traces and the surface of the PCB from environmental degradation. An adhesive solder mask film was attached to the surface of the PCB and a transparency with the pad layout is placed above the solder mask. The board is exposed to UV light. The uncured mask beneath the printed pad layout is removed by using a basic solution of $1 \mathrm{Mol}$, Sodium Hydroxide $(\mathrm{NaOH})$ solution. 


\subsection{Methodology discussion}

The photolithographic technique offers the most repeatable results while only requiring the printed transparency. The final circuit design outlined in Appendix D is developed using the methodology outlined in this chapter and the results boards are shown in Figure 6-10.

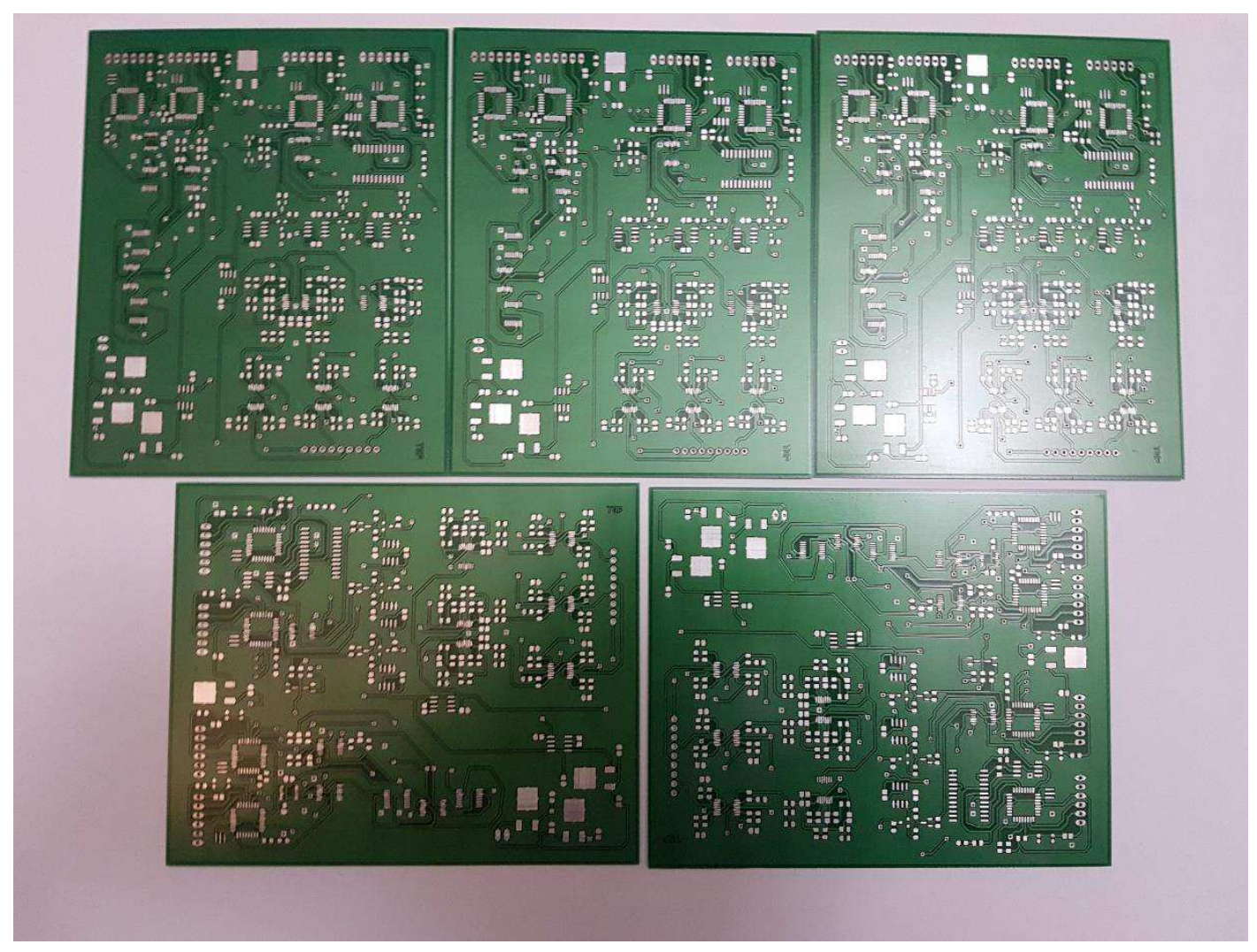

Figure 6-10: Consistency and repeatability test results

To measure the repeatability of the process 2 different integrated circuits (IC) with 2 different pin spacing are considered as shown in Figure 6-11. To measure repeatability of the process, 3 measurements were taken for each set and compared to the design value and are results are listed in Table 6-1. 


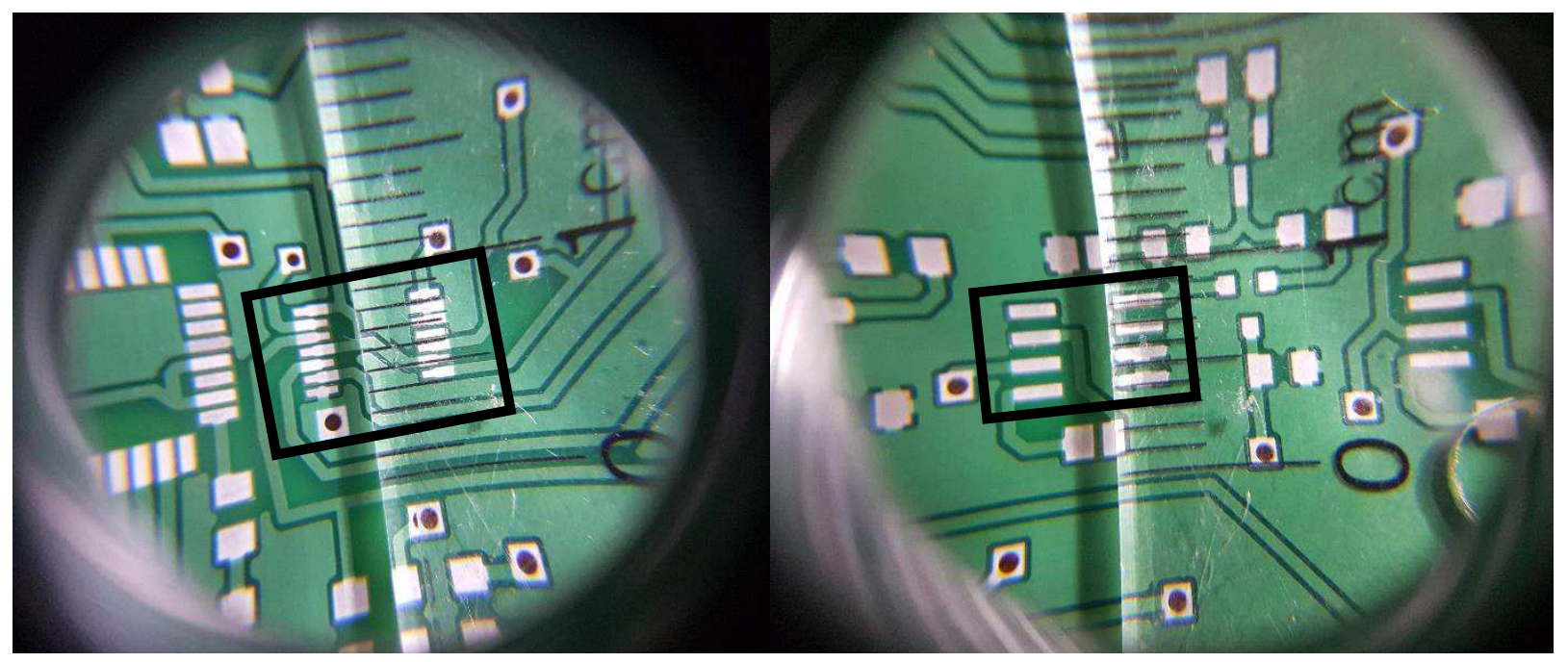
a) AND gate
b) MAX 660

Figure 6-11: Pad layout for two ICs,

Table 6-1: Repeatability test based on IC pin spacing for three PCBs

\begin{tabular}{|c|c|c|c|c|}
\hline Chipset & $\begin{array}{l}\text { Theoretical } \\
\text { Dimension } \\
(\mathrm{mm})[73,74]\end{array}$ & $\begin{array}{c}\text { Sample } 1 \\
(\mathrm{~mm})\end{array}$ & $\begin{array}{c}\text { Sample } 2 \\
(\mathrm{~mm})\end{array}$ & $\begin{array}{c}\text { Sample } 3 \\
(\mathrm{~mm})\end{array}$ \\
\hline AND gate pos. 1 & 0.65 & 0.655 & 0.65 & 0.66 \\
\hline AND gate pos. 2 & 0.65 & 0.65 & 0.65 & 0.65 \\
\hline MAX660 pos. 1 & 1.27 & 1.27 & 1.26 & 1.26 \\
\hline MAX660 pos. 2 & 1.27 & 1.250 & 1.275 & 1.270 \\
\hline
\end{tabular}

Based on results obtained from Table 6-1, the maximum error of $1.5 \%$ is observed. Therefore, the board layout and manufacturing process outlined in this chapter was used to manufacture all the boards for the current research. 


\section{Chapter 7}

\section{Digital Circuit Design}

The system design requirements from chapter 3 outline the performance of the sensor array. This chapter focuses on the discussion regarding the circuit design used to achieve the desired frequency and phase performance. The system design is broken into two phases section; namely, transmission and reception.

In the transmission phase, the wave generation, synchronization and sensor capacitance plays an important role as each sensor's phase determines the constructive and destructive sound pattern as shown by Figure 7-1.

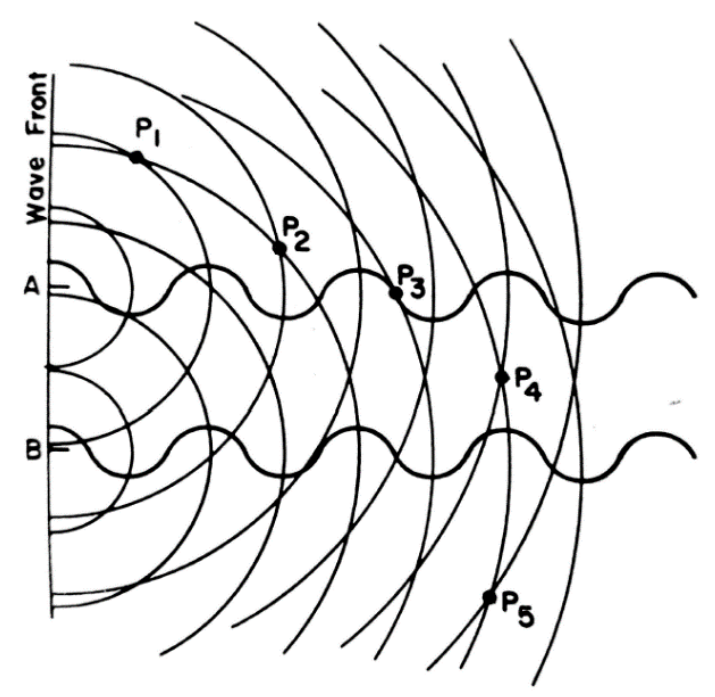

Figure 7-1: Constructive and destructive pattern produced by a two element array [61] 
The propagating wave is reflected from the target and is picked up during the receiver phase. In the reception phase the beamforming algorithm, signal filtering and amplification reduce the noise and focus the reception pattern along the direction of reception. The final signal output produced from the reception process is passed through signal processing phase where the range and the angular position are approximated. Figure 7-2, shows the layout used during the transmission and reception phase. 


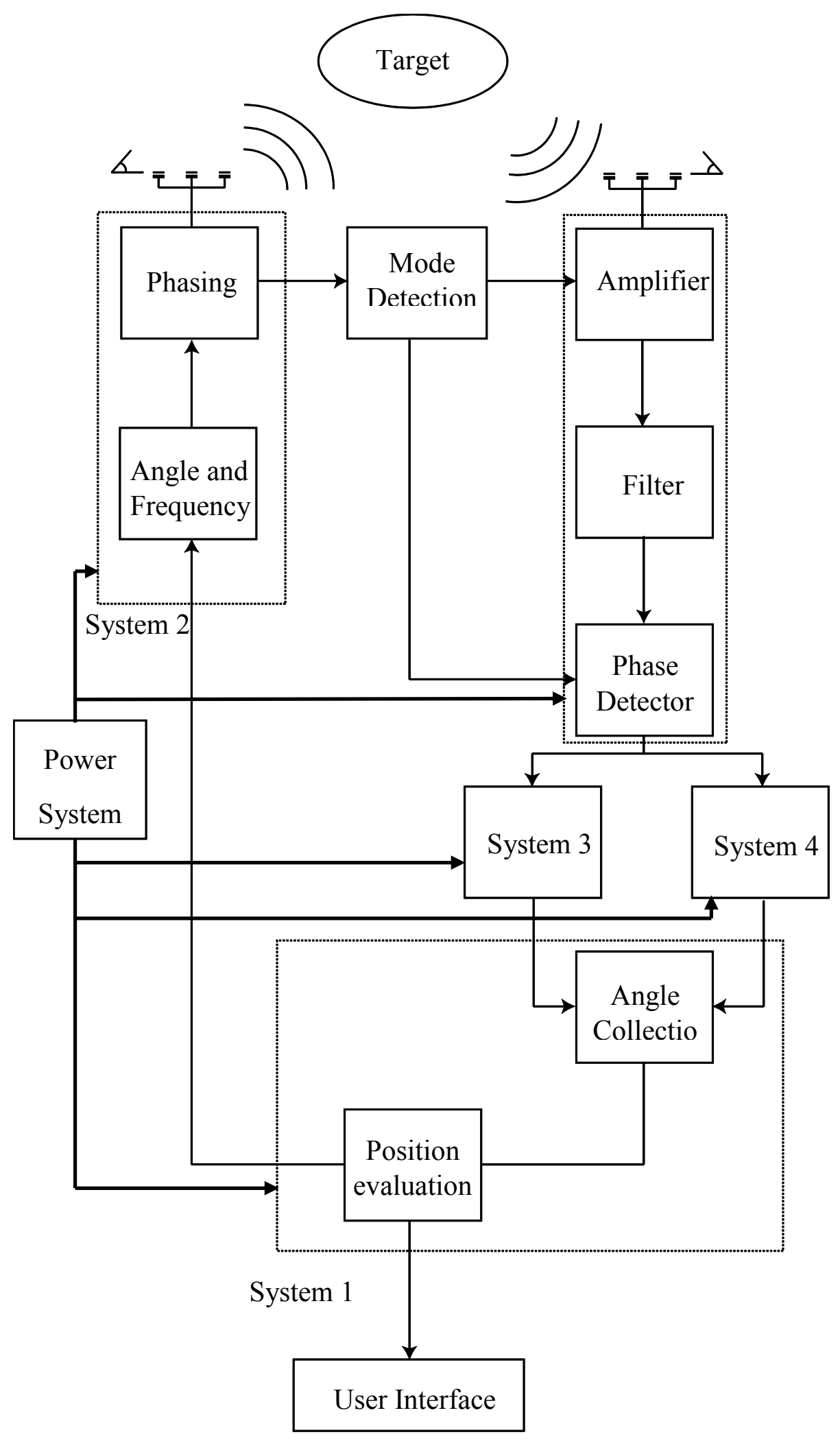

Figure 7-2: High level sensor system architecture. 


\subsection{System 1: Master Device}

System 1 functions as a higher level node or a master device with Systems 2, 3 and 4 acting as slave devices. System 1 serves the client computer directly via USB interface and accepts inputs in the form of user defined angles and frequencies. These angles are then forwarded to System 2 for evaluation of phased array's time delay calculation. Upon reception, the calculated data from System 3 and 4 is forwarded to System 1 to be converted into reception angle, which is the output forwarded to the client computer.

\section{2 .1 System 2: Signal generation}

The variable frequency design under consideration has an operating frequency range of 30 $\mathrm{kHz}$ to $100 \mathrm{kHz}$. Since crystal oscillators and resonators are only available for a specific frequency, by employing a frequency divider (using J-K flip-flop) the output frequency range could be achieved [1]. However, the frequency output would be limited by the frequency of the crystal and the number of flip flop switches used. This dependency on the number of flip flops essentially makes the solution infeasible as the output resolution becomes a direct function of cost and component footprint on the board.

To achieve the desired performance, with a higher resolution, an LM555 timer is used in the asynchronous mode as shown in Figure 7-3, where the frequency is controlled directly by varying the resistance across a digital potentiometer. This arrangement allows for 256 bit resolution on the frequency and eliminates the use of a crystal oscillator completely. Thus reducing the number of components required while providing adequate frequency resolution. 


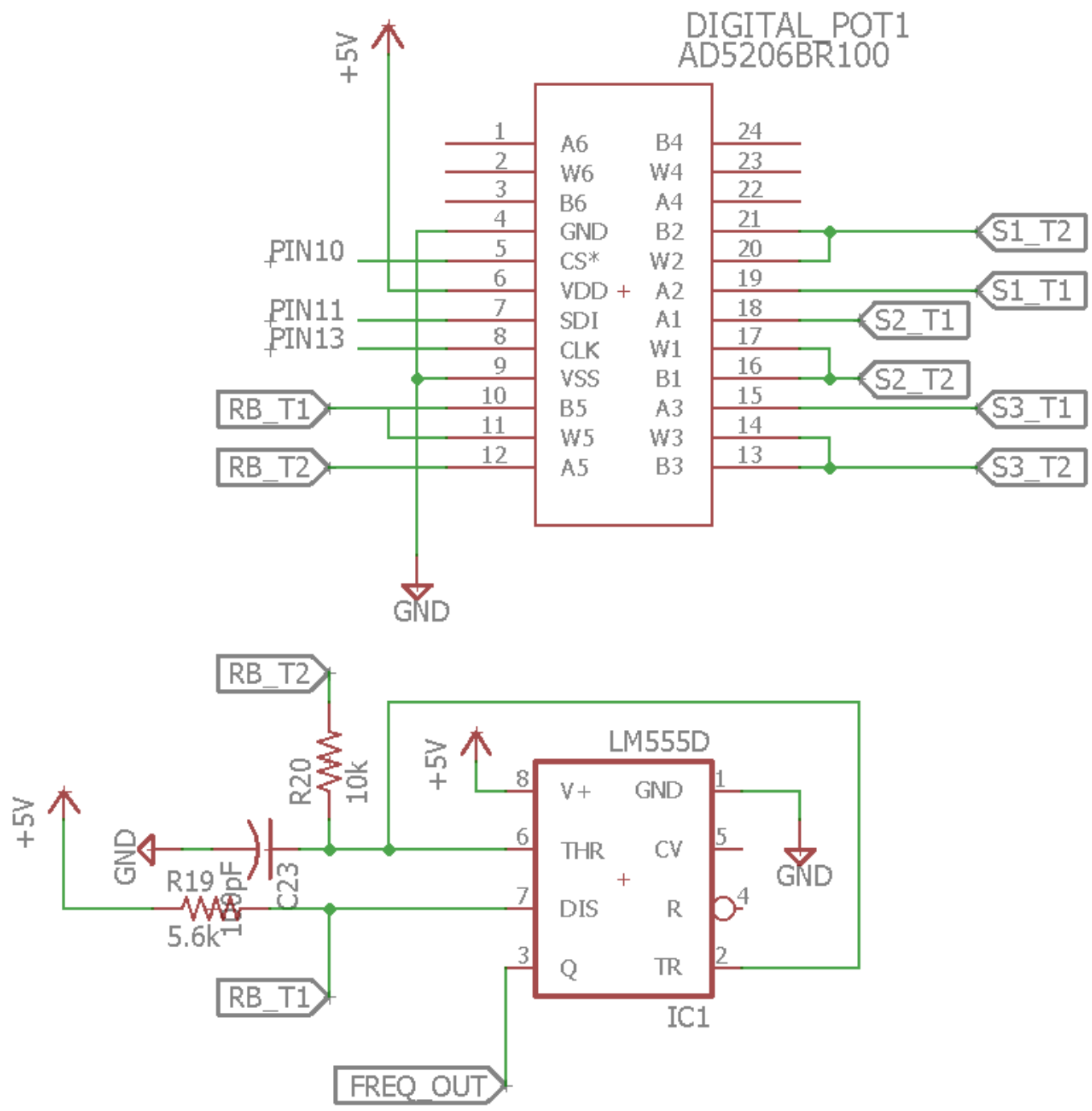

Figure 7-3: Digital potentiometer controlled oscillator

\subsubsection{Phasing and Timing algorithm}

The signal produced by the LM555 timer is used as an external clock input; this input is then used by the internal counter on system 2 to produce the desired frequency that forms the enveloping signal. By changing the phase of the enveloping signal the output beam can be phased in different direction. The rising edge of each enveloping function is synchronized to the enveloped signal in 
order to achieve a phased wave front. The time delay between the rising edges dictates the angle of propagation.

The ATMega 328P-AU microcontroller was selected for the signal processing as it available in a surface mount 32-pin quad-flat package (QFP) [2]. This package requires smaller footprint and offers two 8-bit timers and one 16-bit timer which are used extensively in the phasing of the transmitted waveform. In order to use the ATMega microcontroller, an Arduino bootloader was installed onto the system for programming and interfacing purposes.

The ATMega timers can be preconfigured and have two registers that store the timing configuration as shown in Figure 7-4.

\section{TCCROA - Timer/Counter Control Register A}

\begin{tabular}{|c|c|c|c|c|c|c|c|c|c|}
\hline Bit & 7 & 6 & 5 & 4 & 3 & 2 & 1 & 0 & \\
\hline $0 \times 24(0 \times 44)$ & COM0A1 & COMOAO & СОМ0B1 & СОМов0 & - & - & WGM01 & WGM00 & TCCROA \\
\hline Read/Write & $\mathrm{R} / \mathrm{W}$ & $\mathrm{R} / \mathrm{W}$ & $\mathrm{R} / \mathrm{W}$ & $\mathrm{R} / \mathrm{W}$ & $\mathrm{R}$ & $\mathrm{R}$ & $\mathrm{R} / \mathrm{W}$ & $\mathrm{R} / \mathrm{W}$ & \\
\hline Initial Value & 0 & 0 & 0 & 0 & 0 & 0 & 0 & 0 & \\
\hline
\end{tabular}

\section{TCCROB - Timer/Counter Control Register B}

\begin{tabular}{|c|c|c|c|c|c|c|c|c|c|}
\hline Bit & 7 & 6 & 5 & 4 & 3 & 2 & 1 & 0 & \\
\hline $0 \times 25(0 \times 45)$ & FOCOA & FOCOB & - & - & WGM02 & CS02 & CS01 & CS00 & TCCROB \\
\hline Read/Write & W & W & $\mathrm{R}$ & $\mathrm{R}$ & $\mathrm{R} / \mathrm{W}$ & RM & $\mathrm{R} M \mathrm{~W}$ & $\mathrm{R} / \mathrm{W}$ & \\
\hline Initial Value & 0 & 0 & 0 & 0 & 0 & 0 & 0 & 0 & \\
\hline
\end{tabular}

Figure 7-4: Timer counter control register $0 \mathrm{~A}$ and $0 \mathrm{~B}$ [3]

By setting the TCCRA and TCCRB registers, the output of all three timers can be synchronized. The desired output pulse is passed through an AND gate as shown in to remove any nonlinearities in the signal during transient stages. 
Since the transducer's source capacitance is very low, a higher voltage is applied to produce a greater force between the two plates of the capacitor. This is achieved by using a voltage doubler circuit that is connected to the transducer, and controlled by the output signal from the AND gate shown in Figure 7-5a. The output signal from the microcontroller is fed directly to the B input of the AND gate, while the input A is connected to the variable frequency oscillator described previously. Since the AND gate can only output $5 \mathrm{~V}$, a bipolar junction transistor (BJT) is employed in a common emitter amplifier configuration shown in Figure 7-5b. The common emitter amplifier configuration acts as a signal inverter, to prevent from signal inversion a NPN BJT was employed such that the output signal stayed in phase with the input signal. The voltage doubler design used is presented in Figure 7-5c.

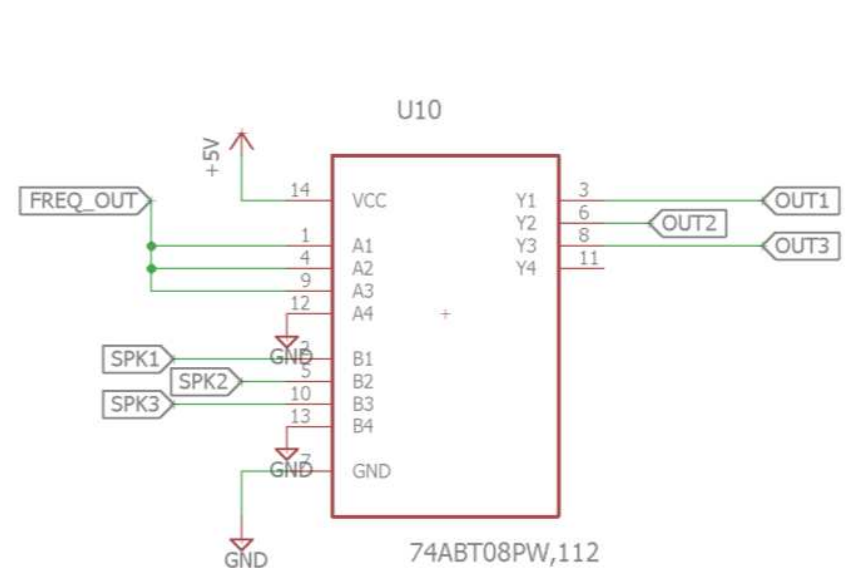

a) AND Gate

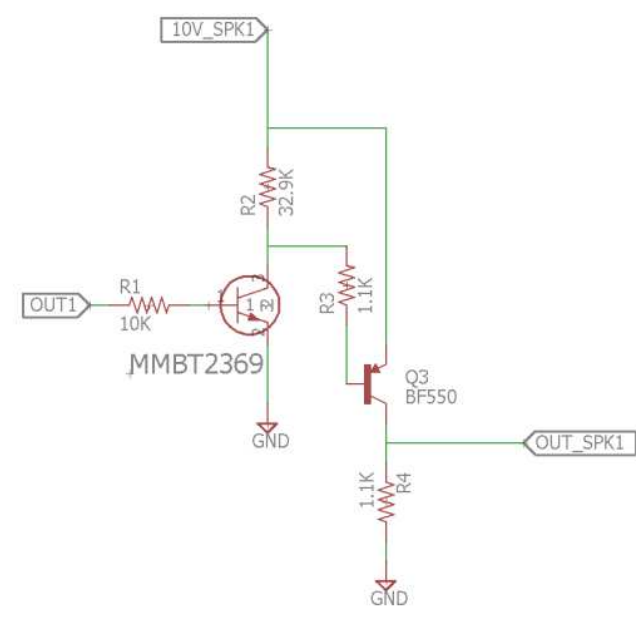

b) Transistor amplifier configuration

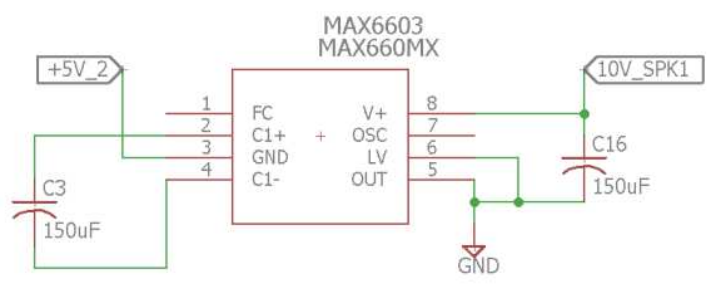

c) Voltage doubler

Figure 7-5: Ultrasonic wave transmitter amplification circuit 


\subsection{Signal reception}

The received signal is the sum of desired signal and the noise signal. Since the received signal has a $1 \mathrm{mV}$ amplitude, any filtration performed at this stage would result in further reduction of the amplitude and possible signal loss. To prevent amplitude reduction, the signal is first passed through an amplification stage. Here the signal is amplified by a factor of $60 \mathrm{~dB}$ or 1000 times, by a non-inverting amplifier configuration.

However, no off-the-shelf audio amplifier was available to perform a $60 \mathrm{~dB}$ amplification in a single stage due to the gain bandwidth product (GBWP), as shown below.

$$
G B W P=\text { Gain } \times \text { Frequency }
$$

Since, GBWP is an operational amplifier's performance characteristic and is a fixed value, increasing the input frequency reduces the output gain achievable using the operational amplifier (op-amp). For an op-amp such as the Texas Instrument's TL074, the GBWP is listed as 3 Mhz. In order to amplify the frequencies at $100 \mathrm{kHz}$, the available gain is 30 times or $29.5 \mathrm{~dB}$. The output range and gain of the amplifier can be increased by using amplification in stages, where the output of one stage is the input of the next stage. This allows for higher gains while also broadening the effective bandwidth and is given by the following relationship:

$$
B W_{\text {total }}=B W \times \sqrt{2^{\frac{1}{\text { stages }}}-1}
$$

According to the current design

$$
B W_{\text {total }}=\frac{3 M h z}{10} \times \sqrt{2^{\frac{1}{3}}-1}=152.95 \mathrm{kHz}
$$


The three stage amplification is selected as the final design to amplify the signal by $60 \mathrm{~dB}$ and the layout is shown in Figure 7-6.

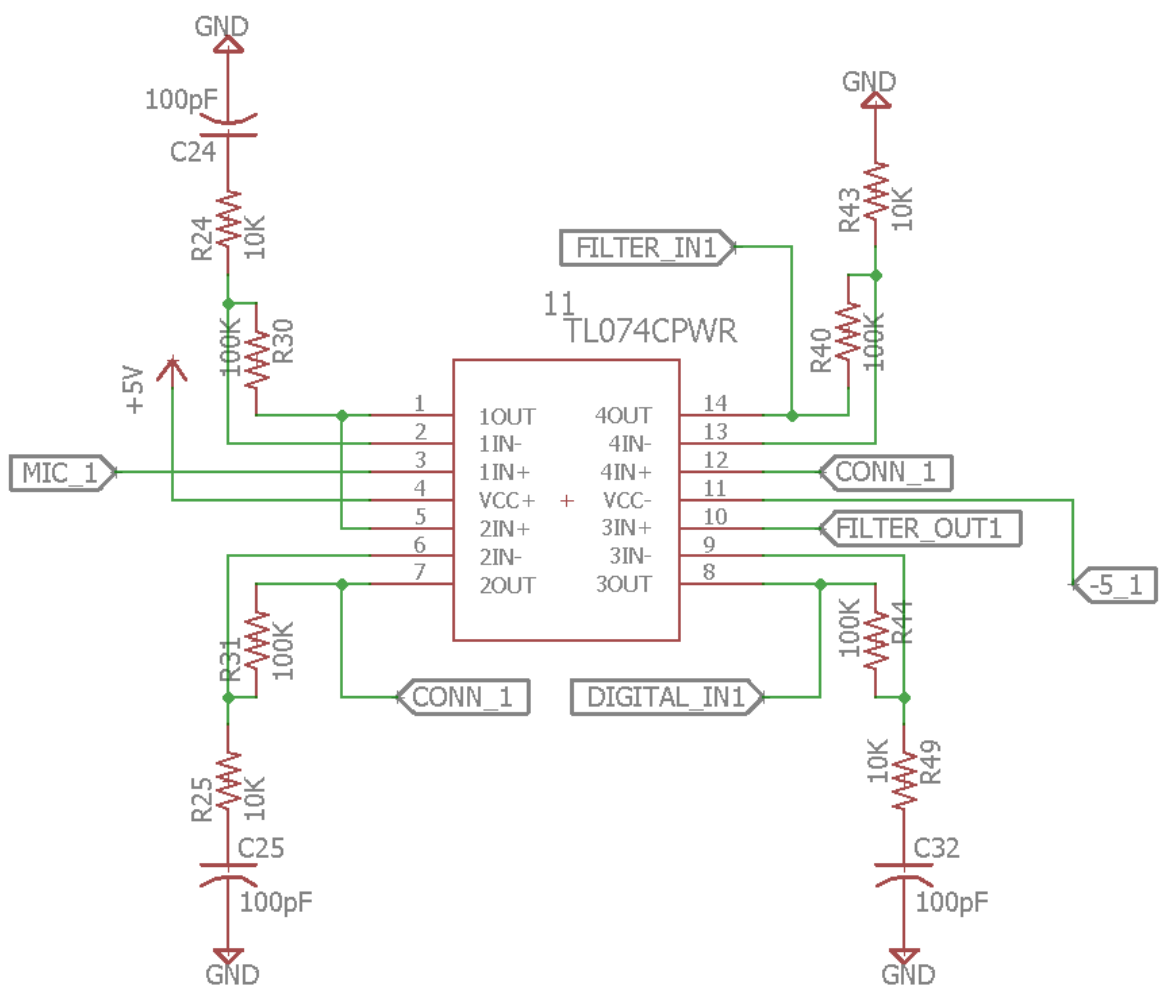

Figure 7-6: Three stage amplifier using Texas Instrument TL074CPWR 


\subsection{Signal Filtration}

After the amplification stage, the signal is passed through a filter that rejects any frequencies outside the range of 30-100 kHz. While ideal performance of a band-pass filter corresponds to the "brick wall effect" as shown in Figure 7-7, the practical performance however offers a larger bandwidth with linear tapering effects.
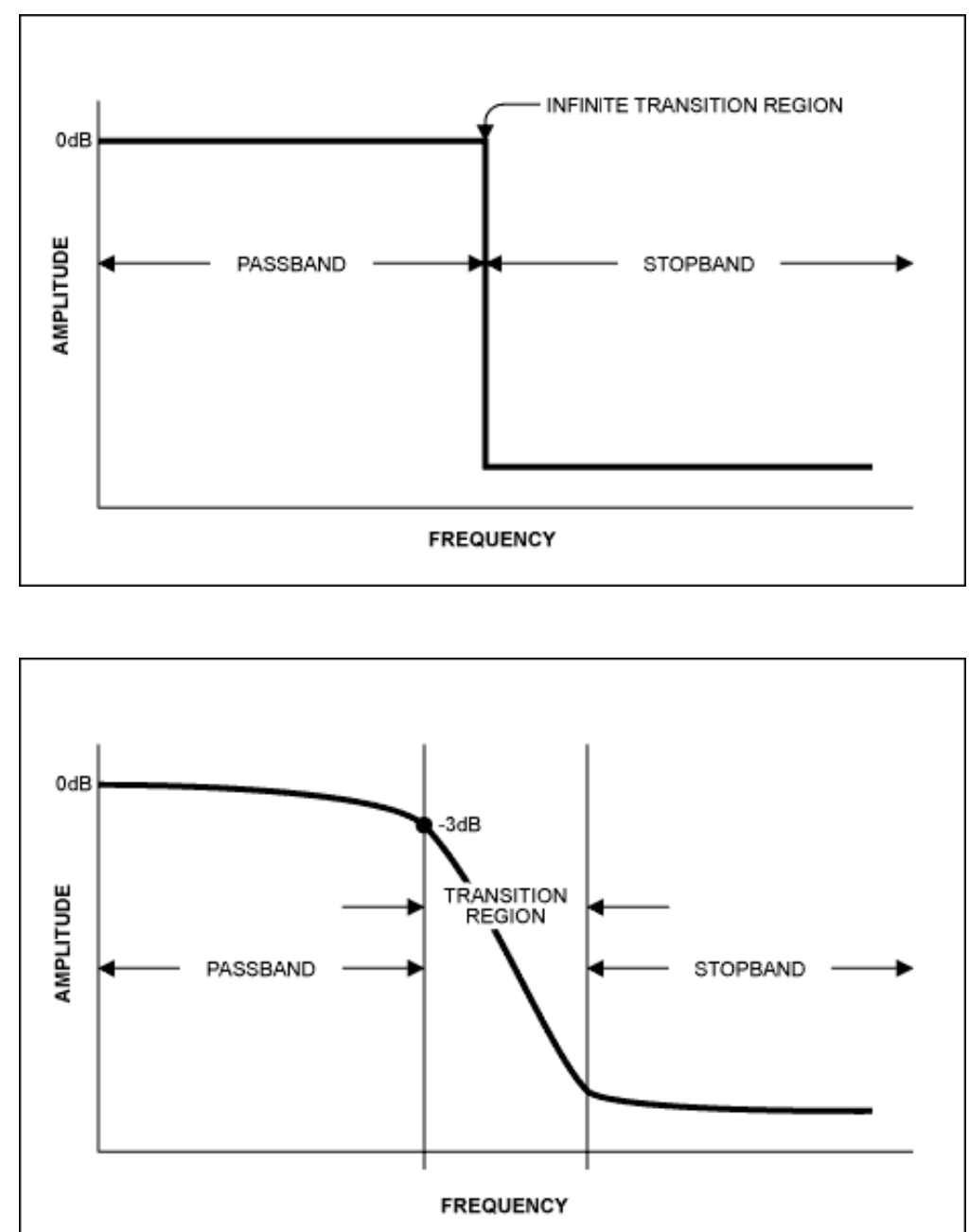

Figure 7-7: Ideal (top) filter performance versus actual (bottom) performance of a filter [75]

To improve on the bandwidth performance, filter designs with higher $Q$ values are considered for analysis and along with higher order as they offer steeper roll off slopes allowing for narrower bandwidths. Figure 7-8 shows the roll off slopes of various filter designs. 

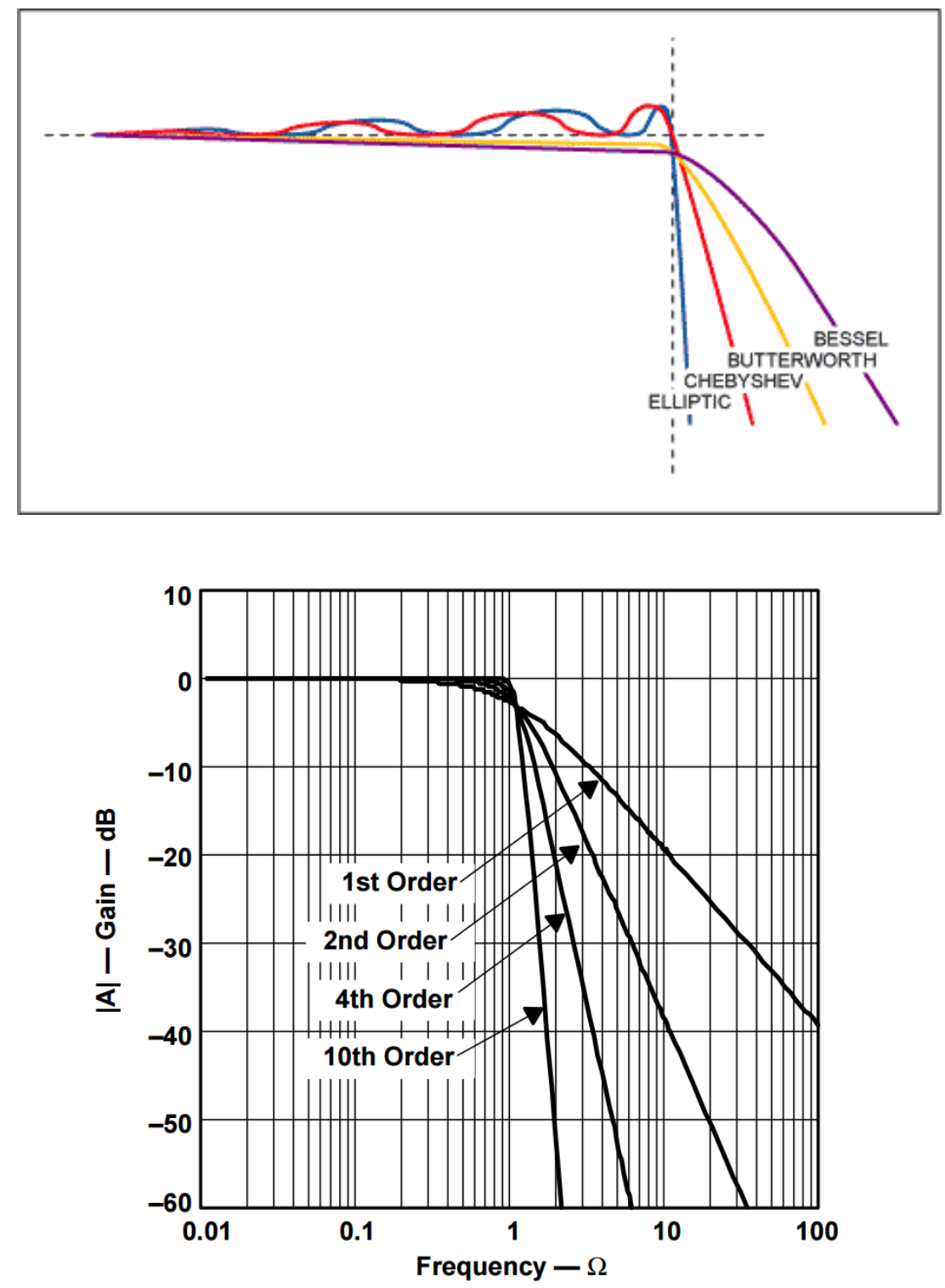

Figure 7-8: Filter types and the effect of the order of the filter. Adapted from [75]

To isolate the reflected signal a fourth-order multiple feedback band-pass filter was designed and is shown in Figure 7-9. 


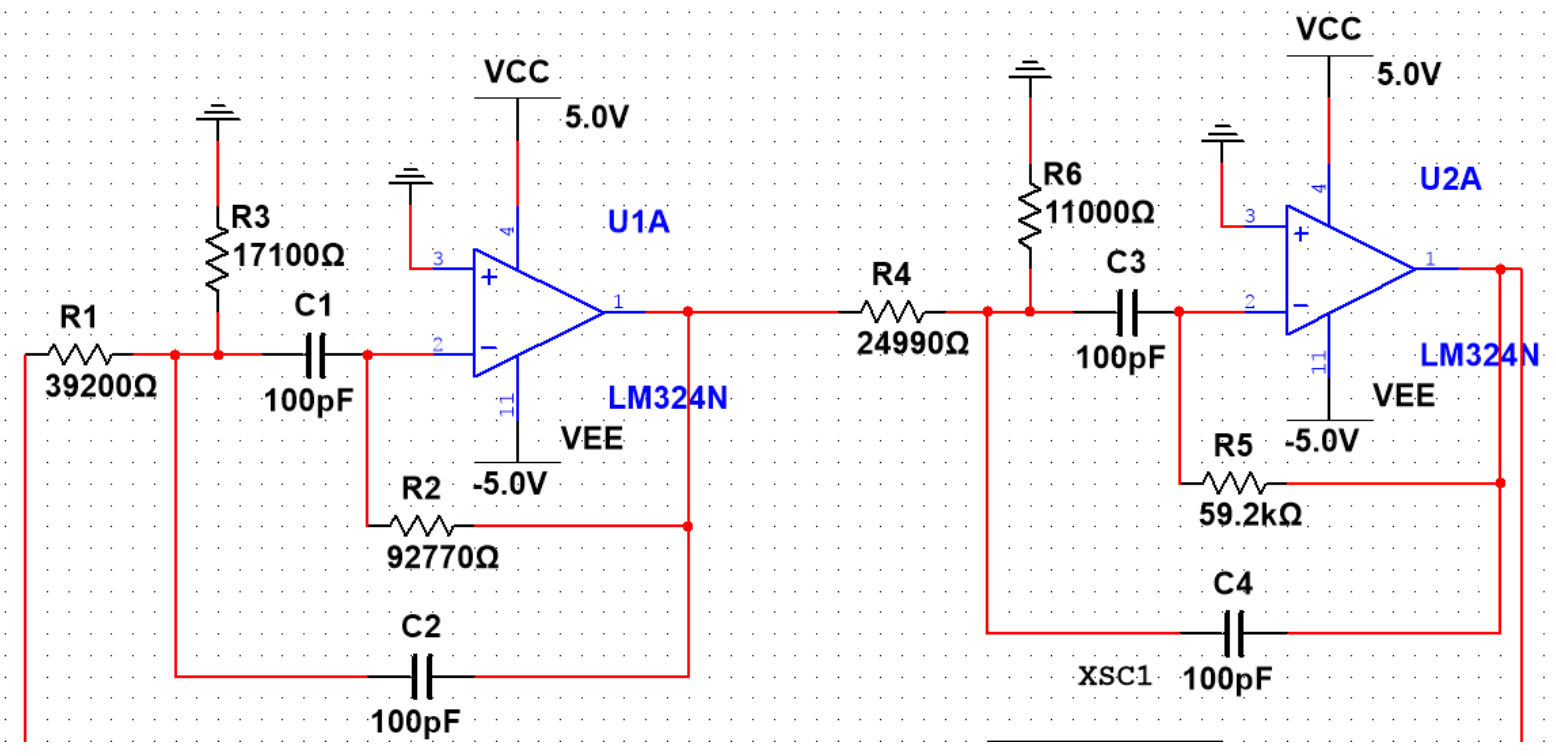

Figure 7-9: Fourth order multiple feedback bandpass filter design

The filter design has two second order multiple feedback system's attached in stages to achieve a fourth order roll-off effect. The center frequency for the first stage is set close to $45 \mathrm{Khz}$ and the second stage is to $67.6 \mathrm{kHz}$ as shown in Figure 7-10. The final fourth order filter has an amplitude that is curbed at higher frequencies due to the attenuation of the second stage second order filter. While the reduction in amplitude is unfavorable, a benefit in the form of steep roll off of 80 $\mathrm{dB} /$ Decade is more attractive as it reduces noise elimination in post-processing. The amplitude loss is recovered by amplifying the output signal by $20 \mathrm{~dB}$ by using another operational amplifier. 


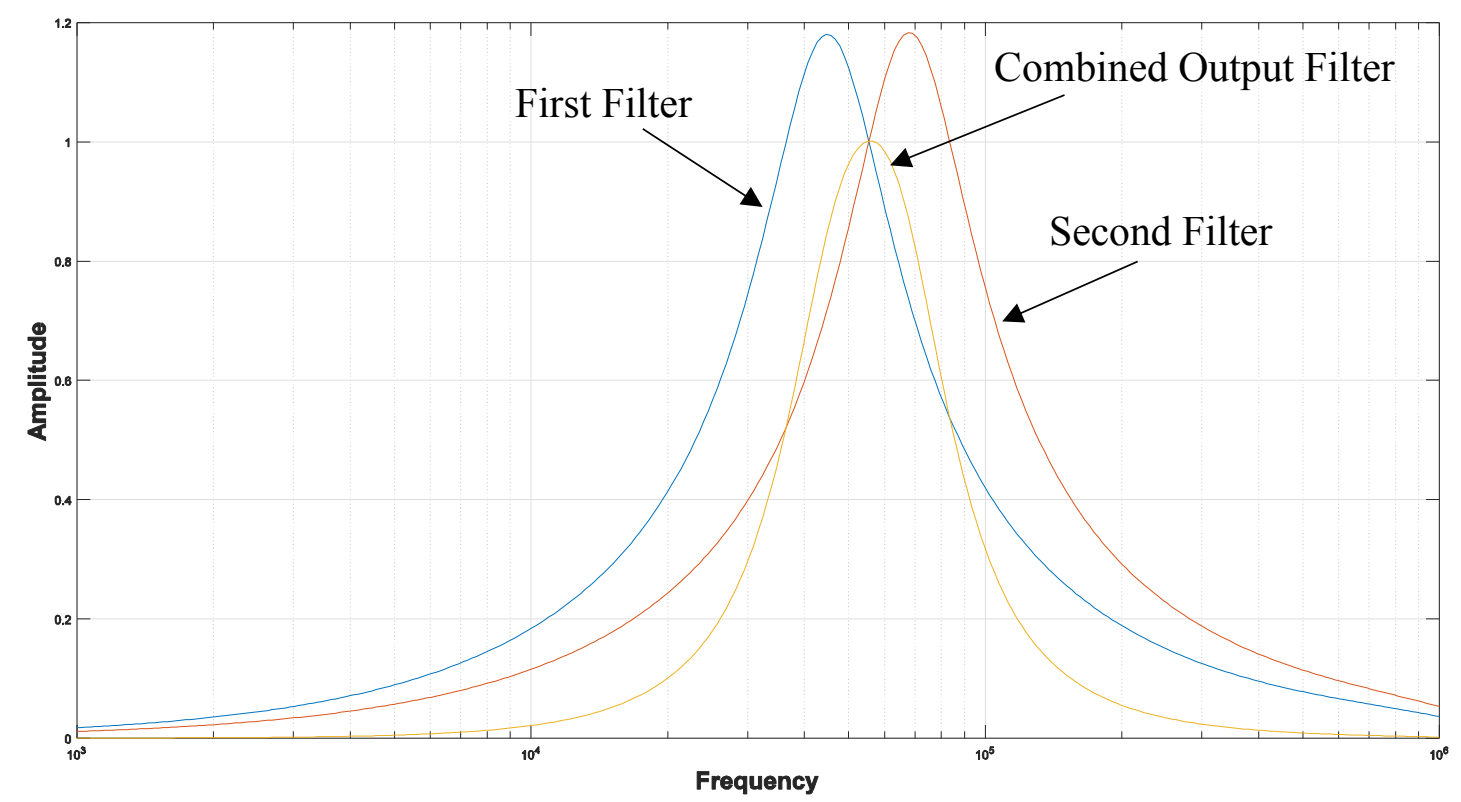

Figure 7-10: Filter frequency vs amplitude performance

\subsection{Phase determination}

The captured signal provides two strands of information namely; position and angle. The angular information is extracted by measuring the relative time delay between two pulses. This can be simply done by using a phase comparator. A block diagram of types of phase comparators available in a phased locked loop are shown in Figure 7-11. 


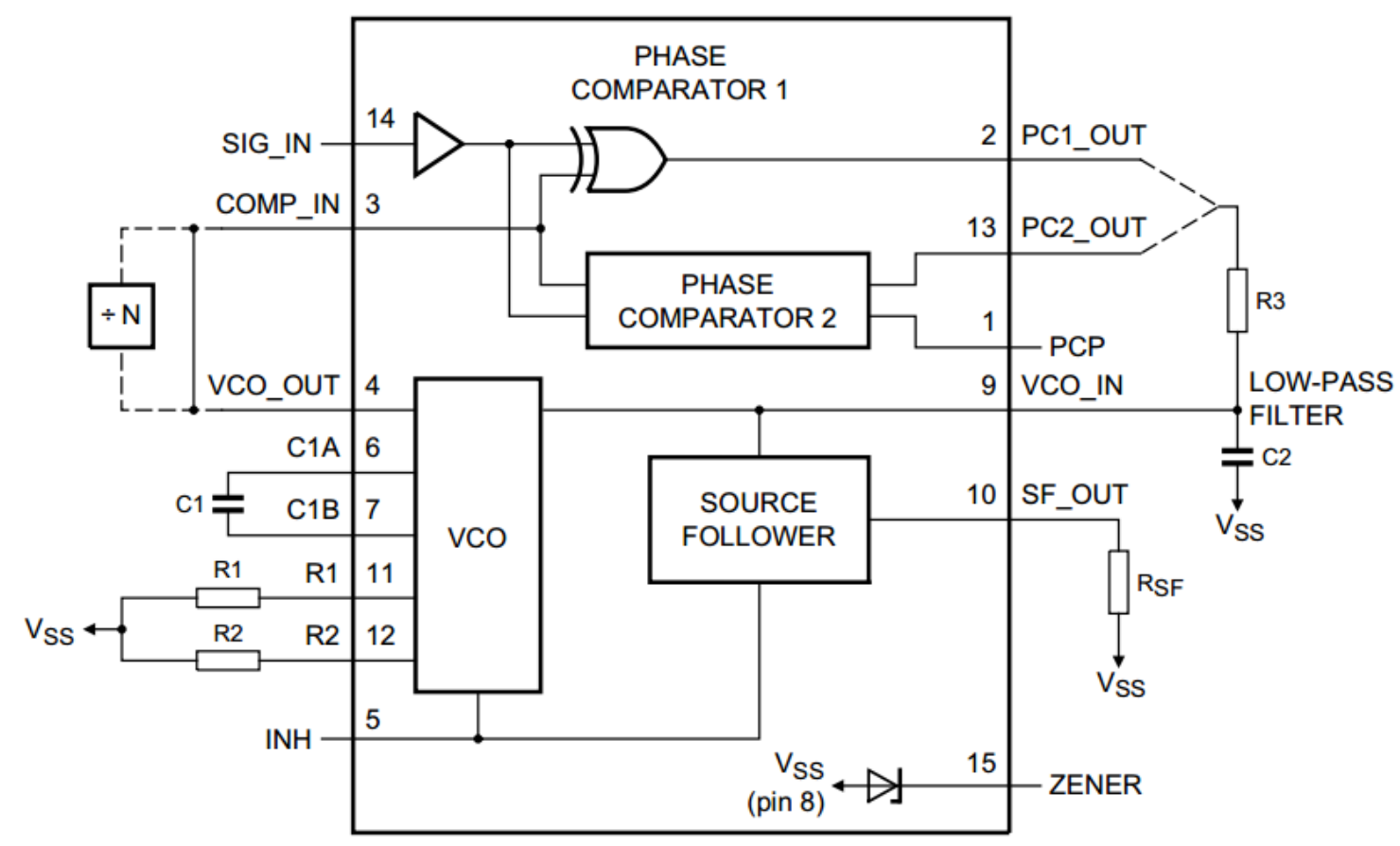

Figure 7-11: Phase comparator selection within a phased lock loop schematic [76]

There are two types of phase comparators available on board, the type 1 phase comparator provides the information about phase difference while type 2 phase comparator provides lead lag information along with phase difference information. It was experimentally found that performance of type 2 phase comparator degrades at frequencies above $90 \mathrm{Khz}$ and is therefore rejected for phase delay evaluation.

In order to determine the angle of the received wave for a 3 element array, two phase comparators are employed; the two phase comparators compare the time difference between pulse 2 and 3 with respect to pulse 1 and are given by Phase1_2 and Phase 1_3 respectively. Figure 7-12 shows the two cases possible for phase determination. 


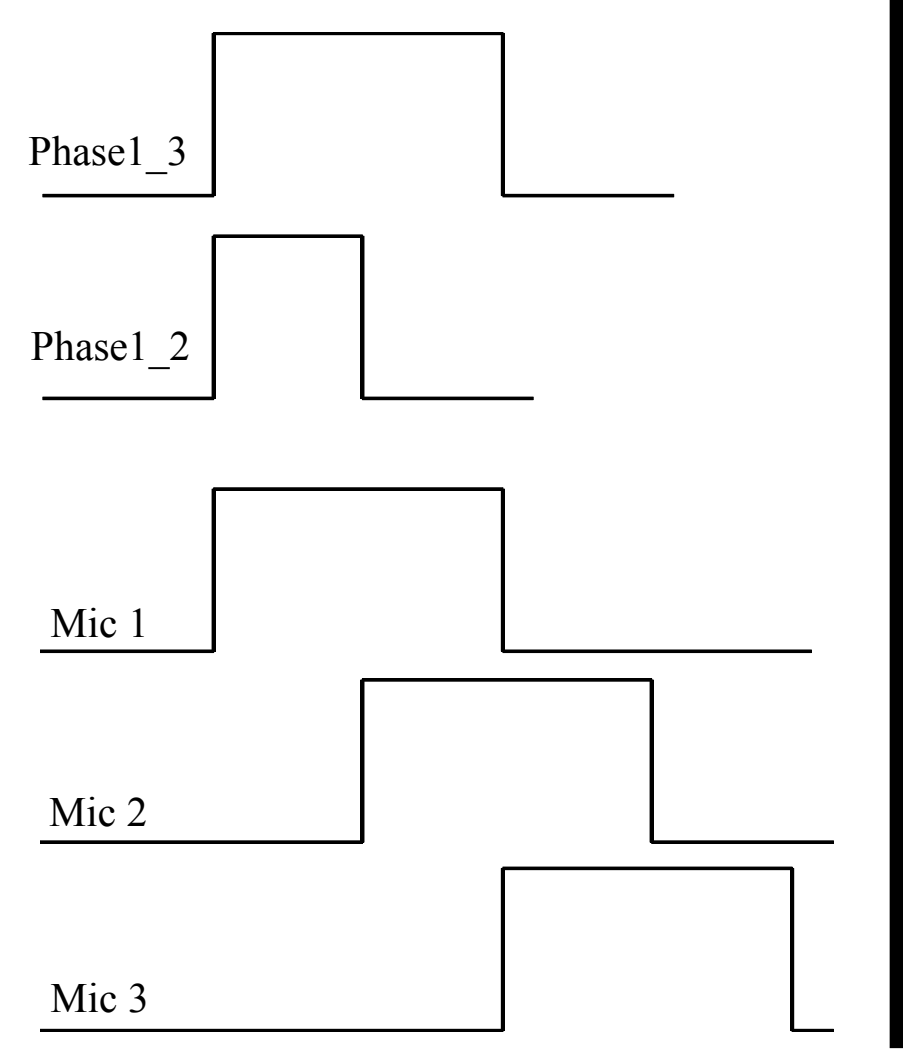

a) Microphone 1

Figure 7-12: Tworelises of phase comparator output

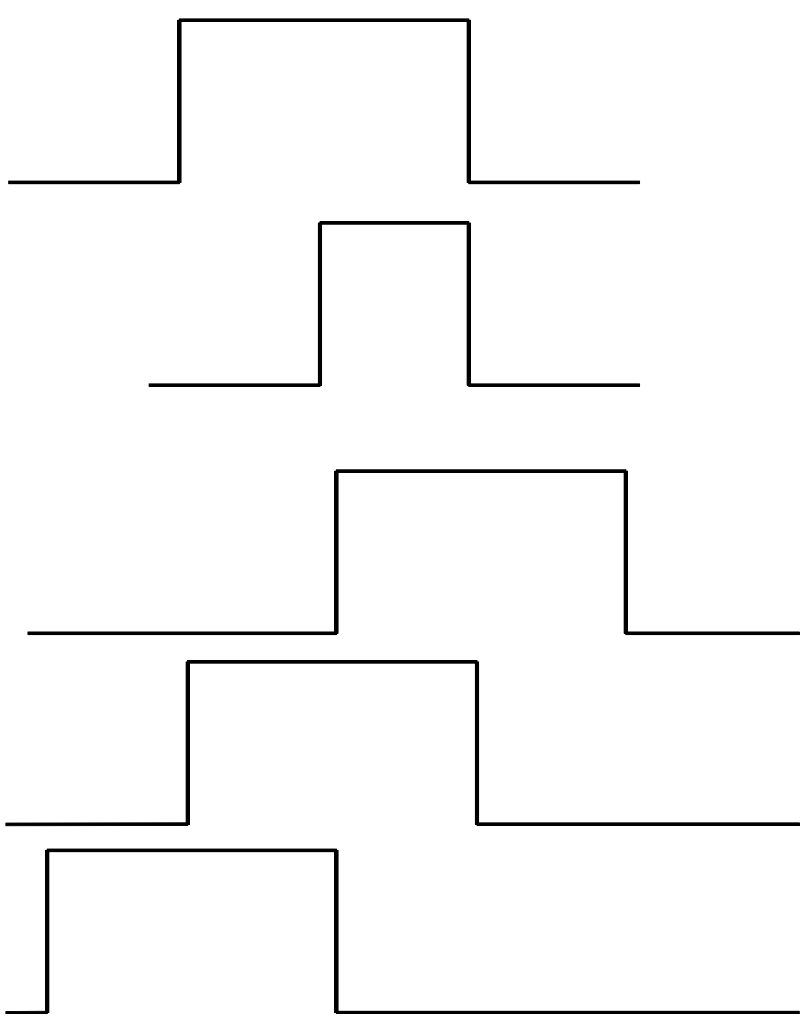

b) Microphone 3

The microphone phased input is given by MIC 1, 2 and 3; upon signal reception, the microphone inputs are compared to the phase comparator outputs. In the case where signal is first received by microphone 1 ( Microphone 1 leading), the output of the microphone is compared to the phase comparator signal.

To associate the phased response with the angle of the sensor an AND gate is employed. The AND gate uses the Mic 3 and Phase1_2 as input producing a time signal time plot as shown in Figure 7-13. 


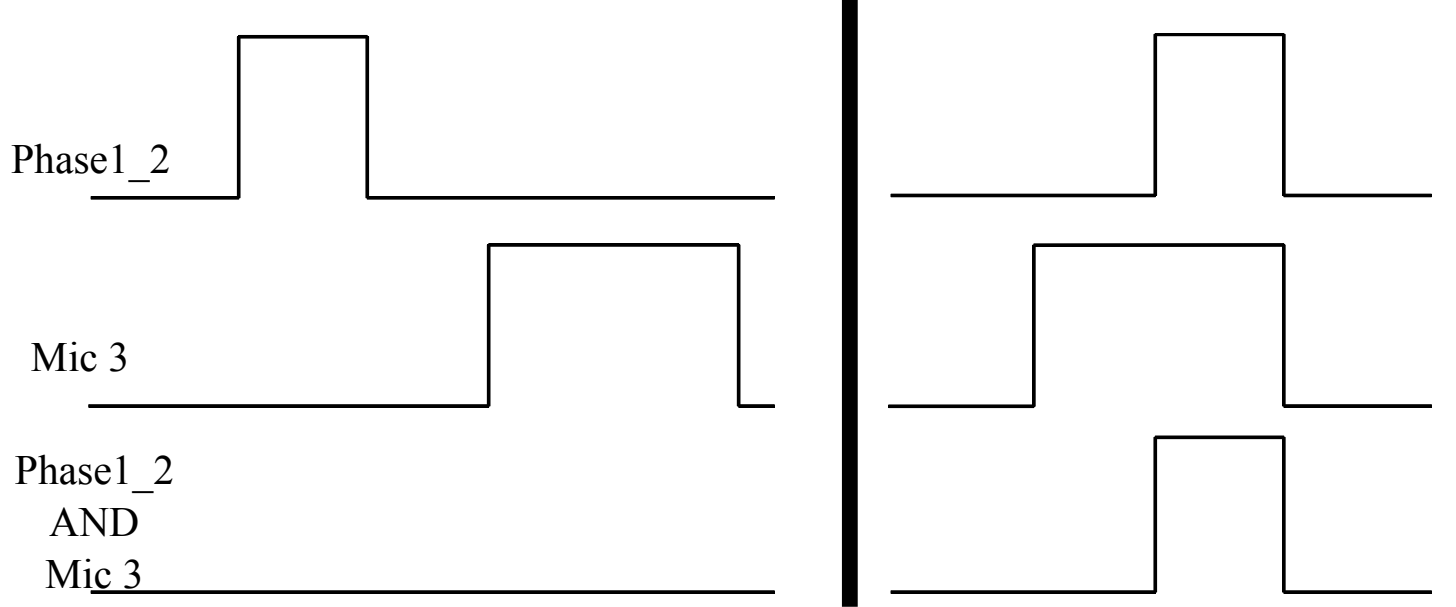

Figure 7-13: Lead/Lag timing diagram for phase for quadrant determination

In case A, when the output of the Mic 3 and Phase1_2 is 1, this implies that signal 1 is lagging and signal 3 is leading thus concluding that the source is in the $0^{\circ}-90^{\circ}$ quadrant. Similarly, in case B, when the output of Mic 3 and Phase1_2 is 0, the signal lies in the $90^{\circ}-180^{\circ}$ quadrant.

\subsection{Phase pulse to analog voltage}

To reduce the signal processing time, the pulse widths are converted into analog voltage using a pulse width modulate (PWM) to analog voltage converter. The Linear Technology's LTC2644-8 bit DAC allows for the conversion of PWM signal into an 8 bit analog voltage that is connected directly to the 10 bit ADC on the AT-MEGA 328p's analog voltage pin. The conversion to analog domain allows for the signal to be captured over a longer span allowing for the value to stabilize, unlike the digital domain that would require a sampling frequency higher than the clock speed of the microcontroller.

\subsection{Mode detection}

A mode detection circuit outlined in Figure 7-14 is now required to complete the feedback loop. The mode detection circuit determines if the system can go into reception mode. The circuit checks 
if any of the sensors are actively emitting and once the transmission stops, the circuit returns a HIGH state. This value is connected to the phase output of the phase comparator by an AND gate shown in Figure 7-14. This also triggers a timing pin on the AT-MEGA 328p's that starts a timer counter to evaluate the time from transmission to reception. The timing signal is used to evaluate the time between the transmission and reception to estimate the position of the target.
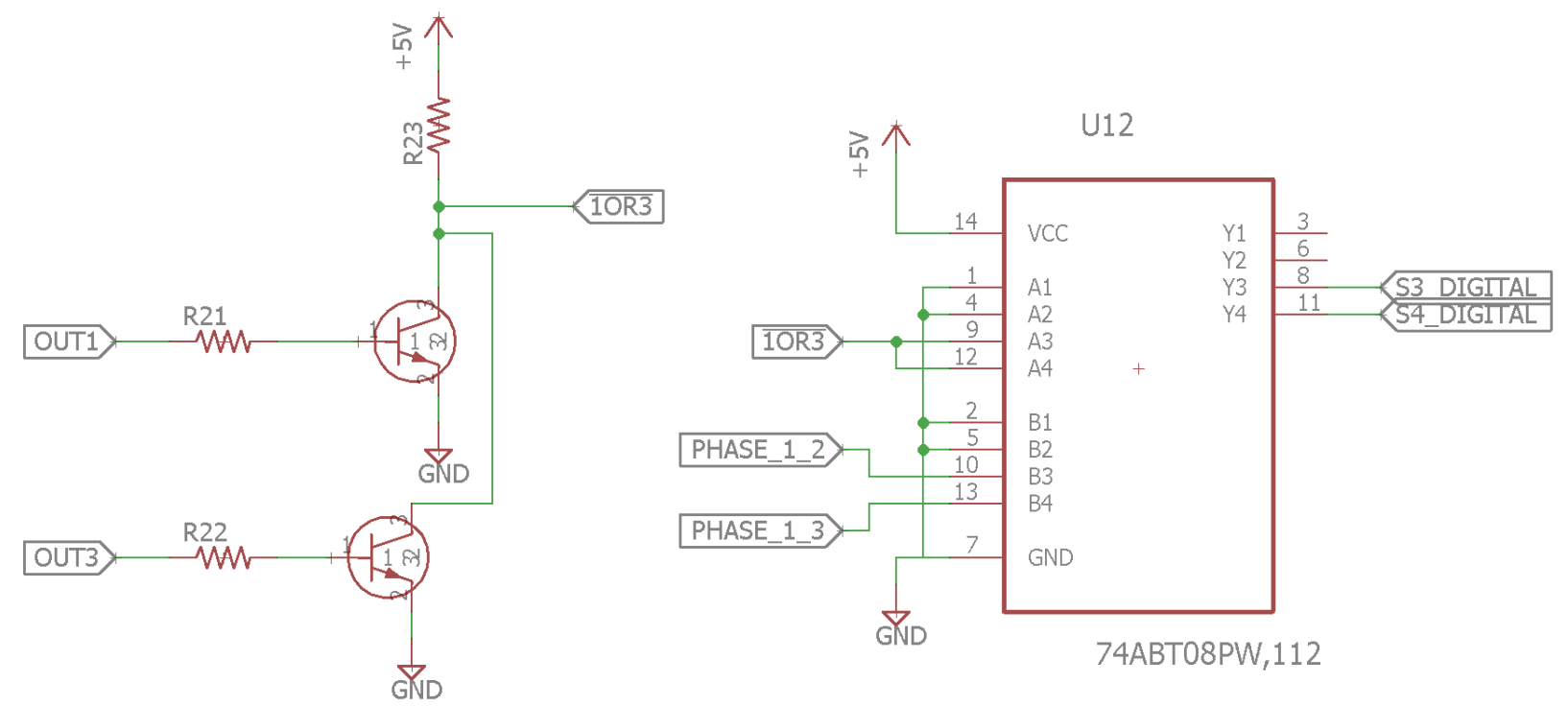

Figure 7-14: Mode sensing circuit using NOR gate and an AND gate.

\subsection{Digital Design}

The digital design described in this chapter forms the basis for digital signal processing used to emit a phased beam and capture the reflected signal. The integrated circuits selected in this chapter are connected to the PCB design discussed in the previous chapter. In order to focus on characterization of the performance of various sensor types, an open ended design with pin terminations is selected. This allows a variety of transducer designs to be tested without altering the system's parameters. 
Two different attachment boards are made, one with a PZT transducer and another with air-capacitive transducer. Both the transducer circuits are design to directly interface with the system design and allow for a direct comparison of performance. The isolation of the system design from the transducer design also allows for the system's power envelope to be defined as a constant. This allows for a direct comparison of the efficiency of each transducer array to convert electrical power to acoustic energy.

Special attention is given to the system power design to avoid noise introduction from the power supplies. Four linear voltage regulators are used to regulate the voltage from the $6 \mathrm{~V}$ battery to 5 $\mathrm{V}$, that is used to power the microcontroller and other active analog devices. The main drawback of linear voltage regulator is the heat dissipation required at higher current. To address the heat concern associated with a single regulator, multiple voltage regulators are used to power analog and digital components.

Since digital signal consist of square waves that include high frequencies, these voltage spikes can directly affect the analog circuitry that is used to measure small analog voltages. The spikes in voltage introduced instantaneous voltages that are amplified by the op-amp, thus saturating the output signal. For this reason, the analog and digital ground planes are kept separate in the circuit design and are connected only at the ground pads of the linear voltage regulators. 


\section{Chapter 8}

\section{Experimental setup}

This chapter describes the testing methodology using an anechoic chamber and an automated sound pressure level (SPL) acquisition system design that measure the performance of the PZT and air-capacitive transducer. To quantify the conversion of the electrical signal in space and time domain, parameters such as sound pressure level and propagation range are used to define the transducer's performance. An anechoic chamber is used to isolate the ambient acoustic noise, for an accurate measurement of the transducer's output SPL.

An automated SPL acquisition system is designed, which includes two stepper motors and an ultrasonic microphone that are connected to Mathworks MATLAB 2016a. The position and angular control are manipulates using the two stepper motors and the SPL acquisition is done via the ultrasonic microphone. By automating the process of SPL acquisition at various points in the field of the transducer, reduces the data acquisition time. Also, by employing stepper motors, accurate position and angular control can be achieved.

\subsection{Evaluation parameters}

Since sound is an alternating pressure wave, the experimental setup aims at evaluating the sound pressure level (SPL) at various angles and distances. The SPL is a relative measurement to a reference sound pressure level and is expressed as [27]:

$$
S P L[d B]=20 \log \left(\frac{p}{p_{0}}\right) ; p_{0}=20 \mu P a
$$


In equation 8.1, $p_{0}$ represents the reference pressure as per the definition of SPL [27]. To convert SPL into a measurable voltage an ultrasonic microphone, Ultramic200K, is used for evaluating the SPL at predetermined locations.

The design of the Ultramic200K includes a microelectromechanical system (MEMS) sensor, specifically, the Knowles ${ }^{\circledR}$ Model: SPU0410LR5H, with the following important specifications:

Table 8-1: Characteristics of Knowles ${ }^{\circledR}$ model: SPU0410LR5H microphone [77]

\begin{tabular}{|l|l|}
\hline Parameters & Value \\
\hline Supply Voltage & 1.8 Volts \\
\hline Sensitivity (94 dB SPL at I kHz) & $-38 \mathrm{dBV} / \mathrm{Pa}$ \\
\hline Signal to noise ratio (94 dB SPL at $1 \mathrm{kHz}$, A weighted) & $63 \mathrm{~dB}(\mathrm{~A})$ \\
\hline Directivity & Omnidirectional \\
\hline
\end{tabular}

One of the most important performance parameters outlined in Table 8-1 is the sensitivity of the sensor. The sensitivity determines the sensor's capability to convert pressure into voltage. From equation 8.1, a 1 Pa pressure is the approximately equal to $94 \mathrm{~dB}$ SPL which is considered to be the reference pressure for further calculation. Similarly, the reference voltage for dBV scale is $1.000 \mathrm{Volts} / \mathrm{Pa}$. The sensitivity can now be converted from $\mathrm{dBV}$ scale to Volts/Pa as follows

The microphone signal is further amplified by $72 \mathrm{~dB}$ via the onboard amplifier. Thus increasing the perceived sensitivity by 3981 times, with the final sensitivity of $132 \mathrm{db}$. Using the final sensitivity, Table 8-2 outlines SPL amplitude of some of the most common condition and the respective output voltages that the sensor will produce 
Table 8-2: Sound source to output voltage comparison, adapted from [6]

\begin{tabular}{|l|l|l|}
\hline Sound Source & SPL (dB) & Output Voltage (V) \\
\hline Passenger Car & 70 & 3.169 \\
\hline Normal Conversation & 50 & 0.3169 \\
\hline Quiet Room & 30 & 0.03169 \\
\hline Reference pressure level & 0 & 0.0010024 \\
\hline
\end{tabular}

\subsection{Conversion from analog to digital domain}

The signal acquired by the microcontroller on board the Ultramic200K converts the analog signal into a 16 bit digital signal with the output values ranging from 0 to 65535 . The highest analog output voltage corresponds to the highest digital output of 65536 . These digital values are acquired by Mathworks ${ }^{\circledR}$ MATLAB 2016a software and are expressed as decibel full scale (dBFS) values calculated as follows:

The SPL can now be fully related to the full digital scale value that is used for the mathematical analysis.

\subsection{Experimental setup}

The experimental setup comprises of an acoustic chamber that consists of two cardboard boxes with foam lining as shown in Figure 8-1a and Figure 8-1b. The foam is used to absorb reflected waves providing a characteristic acoustic impedance boundary condition, where waves propagate infinitely. 


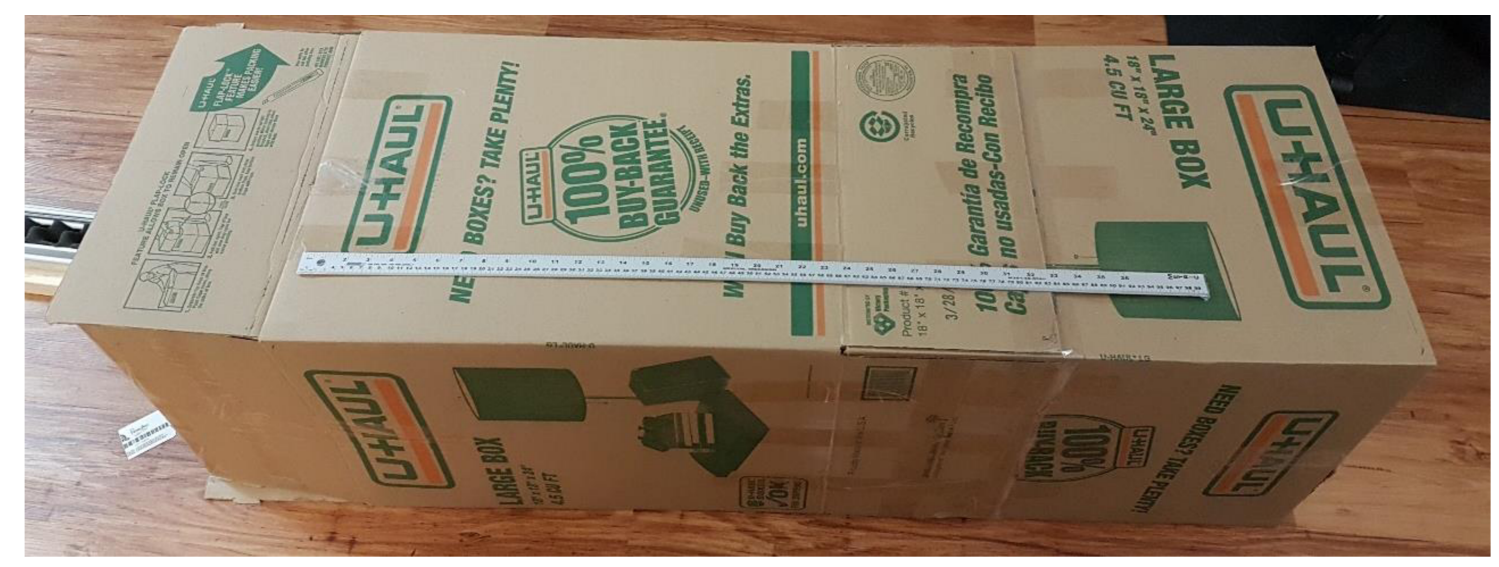

a) Two cardboard boxes joined to make an anechoic chamber

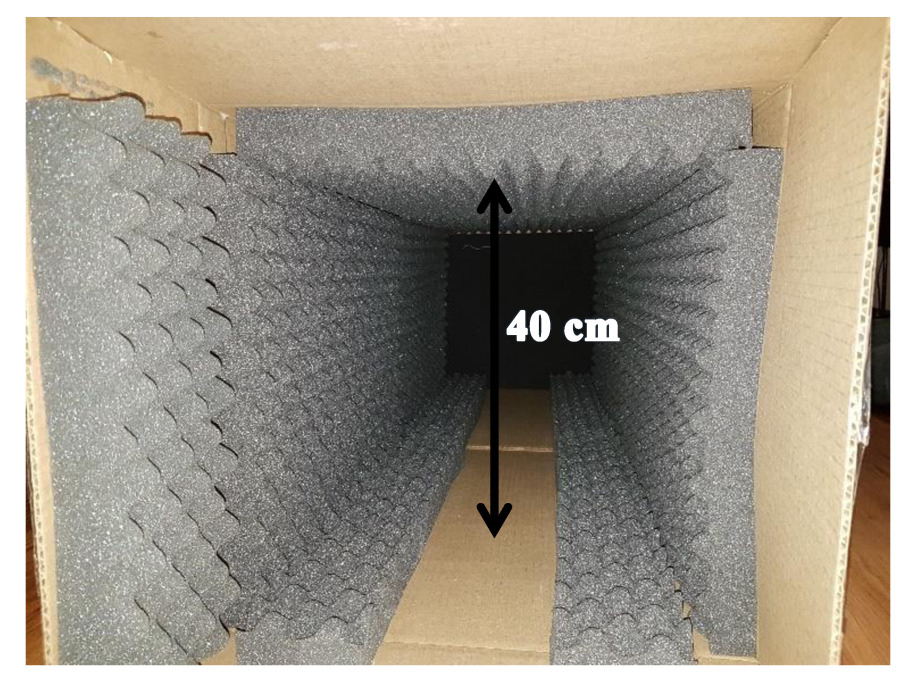

b) Foam lining for sound isolation

Figure 8-1: Internal layout and design of the anechoic chamber

A wooden plank is used as a base for mounting the automated acquisition assembly along with two different size wooden blocks to serve as the mounting and moving block as shown in Figure 8-2. 


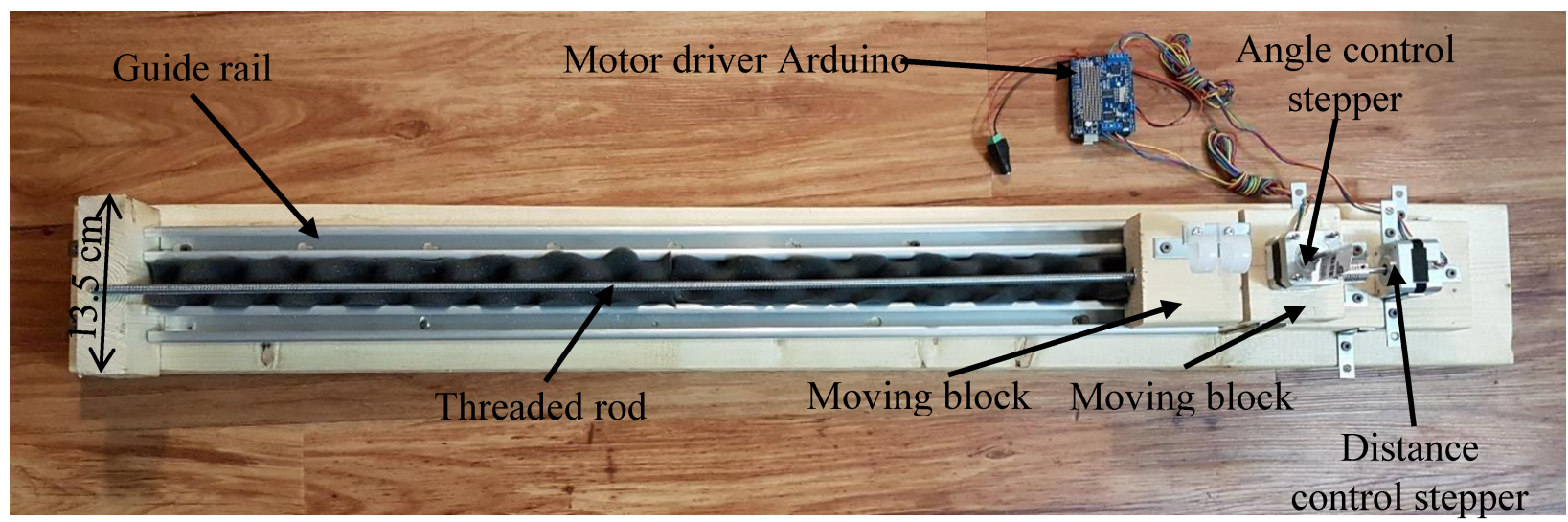

a) Automated acquisition system layout

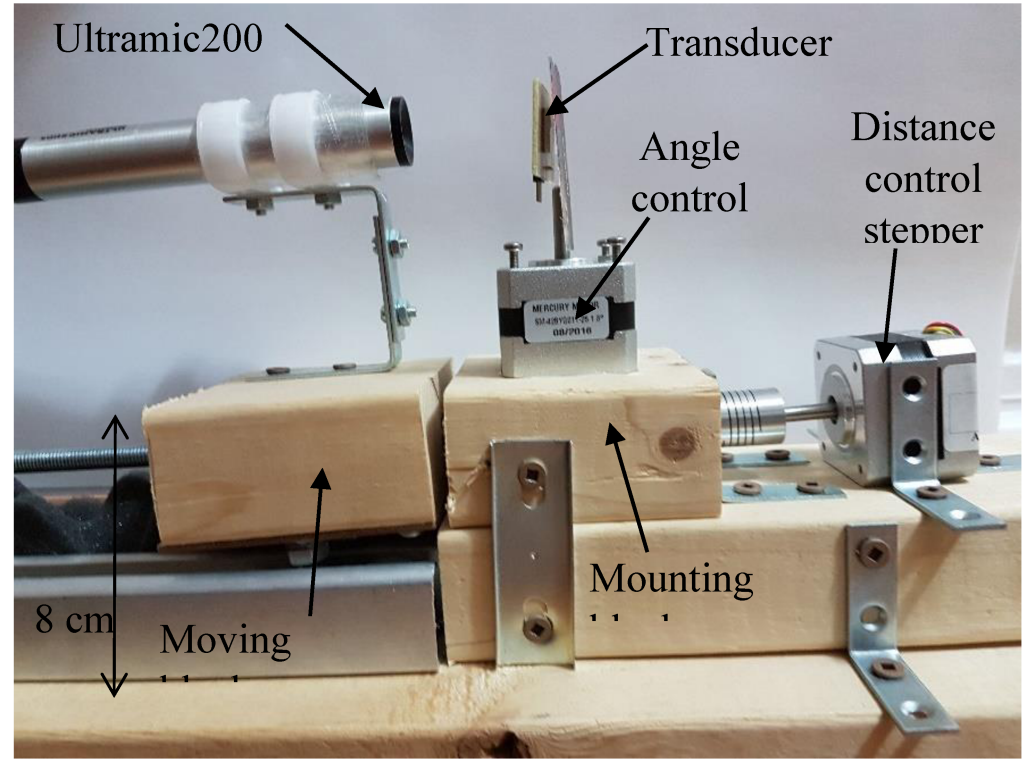

b) Layout of transducer and microphone

Figure 8-2: Automated SPL data acquisition setup.

To allow for relative motion between the mounting block and moving block, a stepper motor was employed. The stepper motor is attached to a threaded rod by a coupler, and a hex nut is used in the form of a worm gear assembly, creating translation motion using rotation. Two guide 
rails are also attached to the base and the moving block to fix the traveling path and direction. The Ultramic200K assembly is then mounted on the moving block using two loop holders.

The transducers are fitted to the second stepper motor located on the mounting block and is used to rotate the incidence angle of the array. Therefore, by using the two stepper motors in conjunction, allowing for range and angular data acquisition.

The Ultramic $200 \mathrm{~K}$ is connected directly to a computer while the stepper motors are attached to an Arduino ${ }^{\circledR}$ MotorShield as shown in Figure 8-3. The data from these devices is directly forwarded to Mathworks ${ }^{\circledR}$ MATLAB 2016a software, where the acoustic data is processed, and a Fast Fourier Transform (FFT) algorithm is used to obtain the dBFS amplitude. These values are collected for all data points and later normalized to generate directivity plots.

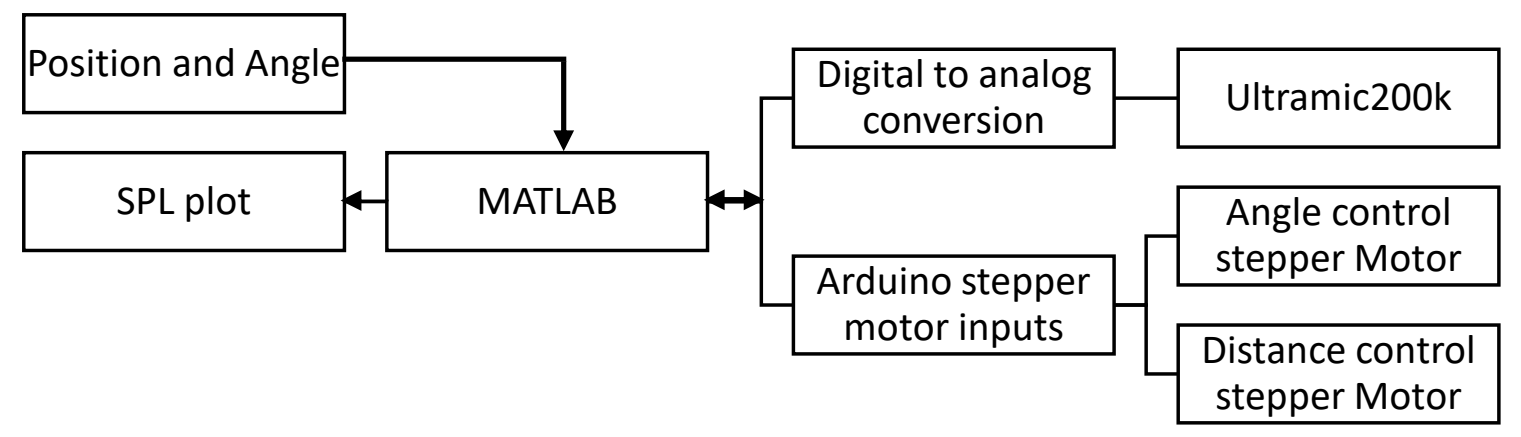

Figure 8-3: Data acquisition system layout

The experimental setup is finally assembled by placing the automated SPL acquisition system is placed inside the anechoic chamber as shown in Figure 8-4. The final assembly is put on a rubber mat for isolating any low frequency noise generated from the floor. 


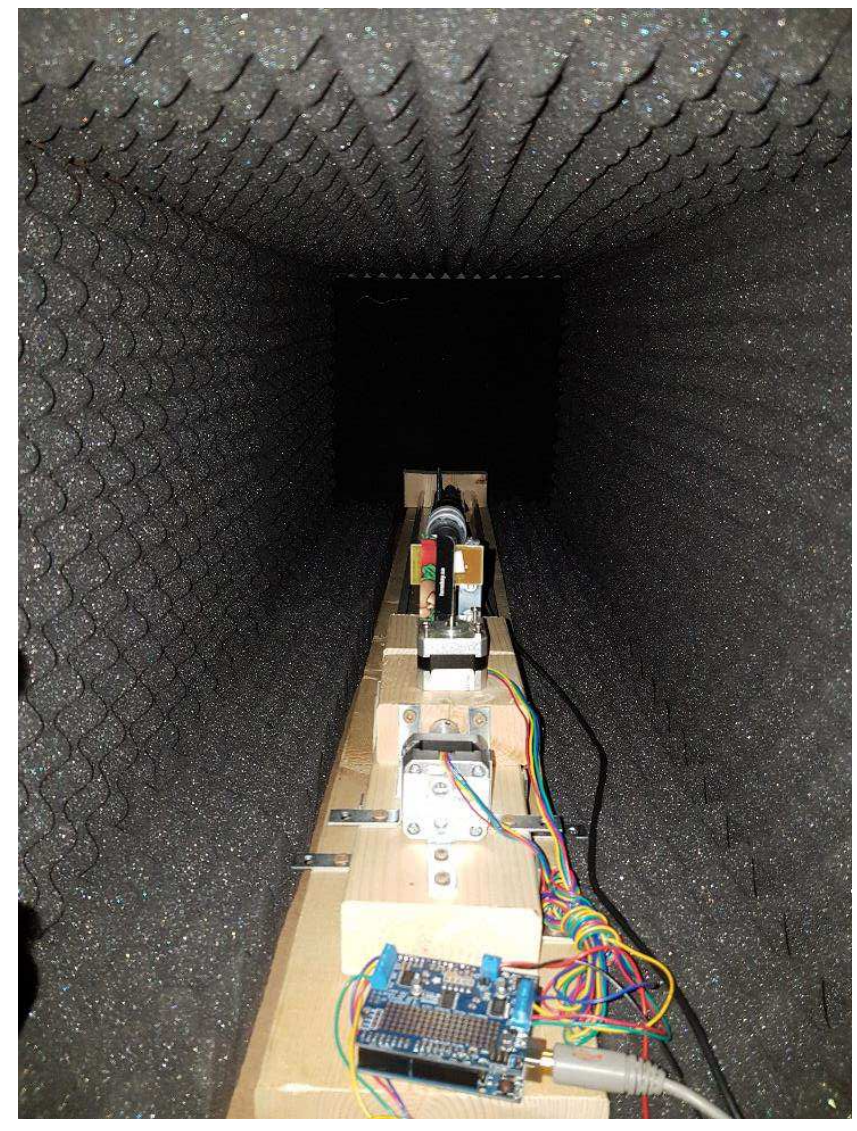

Figure 8-4: Anechoic chamber assembly with automated SPL acquisition

\subsection{Noise characterization}

The mathematical analysis outlined in section 8.1 and 8.2 is very sensitive to external noise since all values are calculated with reference to the highest signal amplitude. The anechoic chamber design discussed in section 8.2 is calibrated to account for the external noise present in the system and is shown in Figure 8-5. 


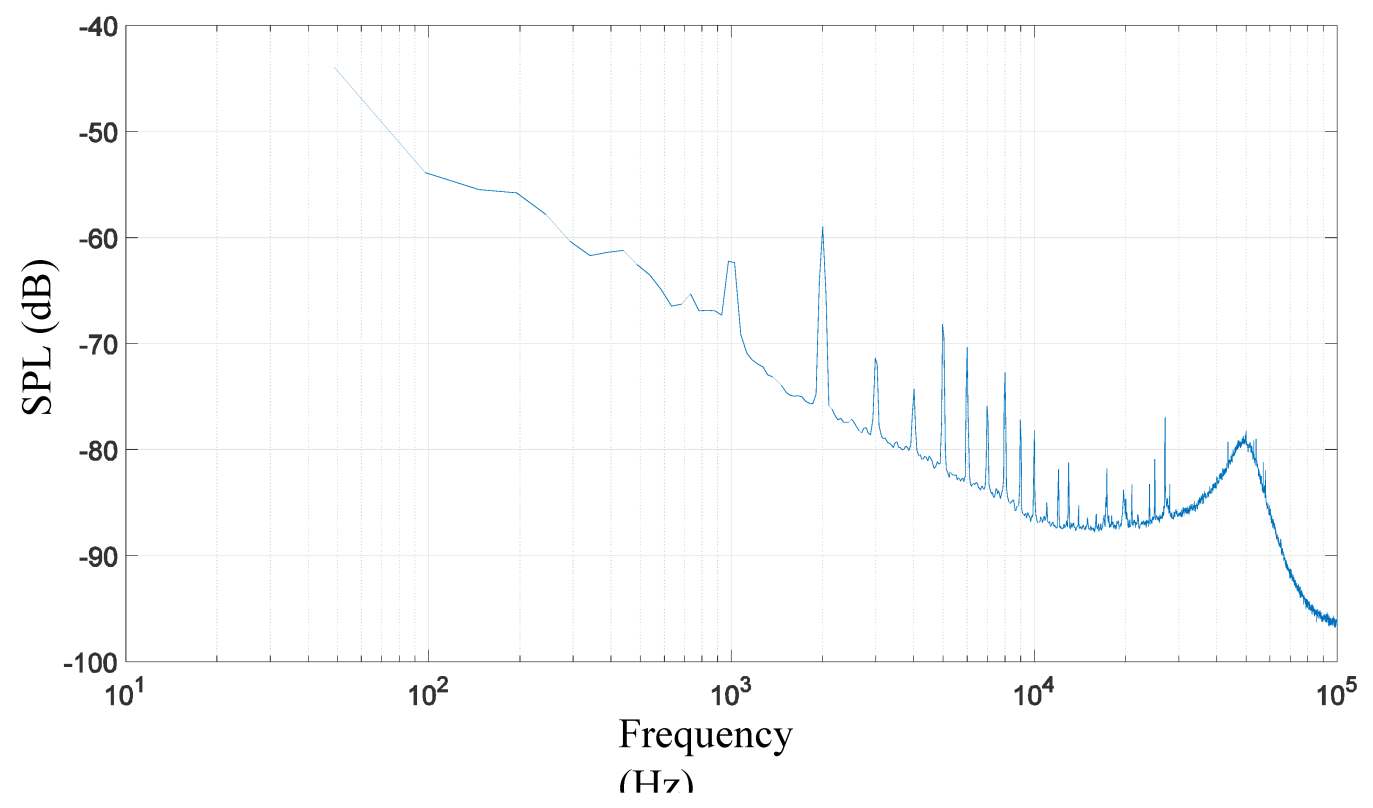

Figure 8-5: External microphone noise characterization

From Figure 8-5, it can be seen that most of the acoustic energy is associated with frequencies below the bandwidth of interest. However, there is acoustic correction required close around $40 \mathrm{kHz}$ range as there is a spike observed. This noise is attributed to the PWM signal used by the motor controller and the stepper motors employed in the anechoic chamber.

Upon further investigation, it was found that in the presence of a $20.63 \mathrm{kHz}$ source, the ambient noise level reduces to levels below -72 dB as shown in Figure 8-6. Therefore, a correction factor is developed for frequencies within the bandwidth of interest to account for the increase in amplitude due to ambient noise. Also, to prevent any noise addition from the stepper motors, the Arduino stepper mode code is modified, and a stepper library is developed that shuts off the power to the stepper motor during data acquisition. 


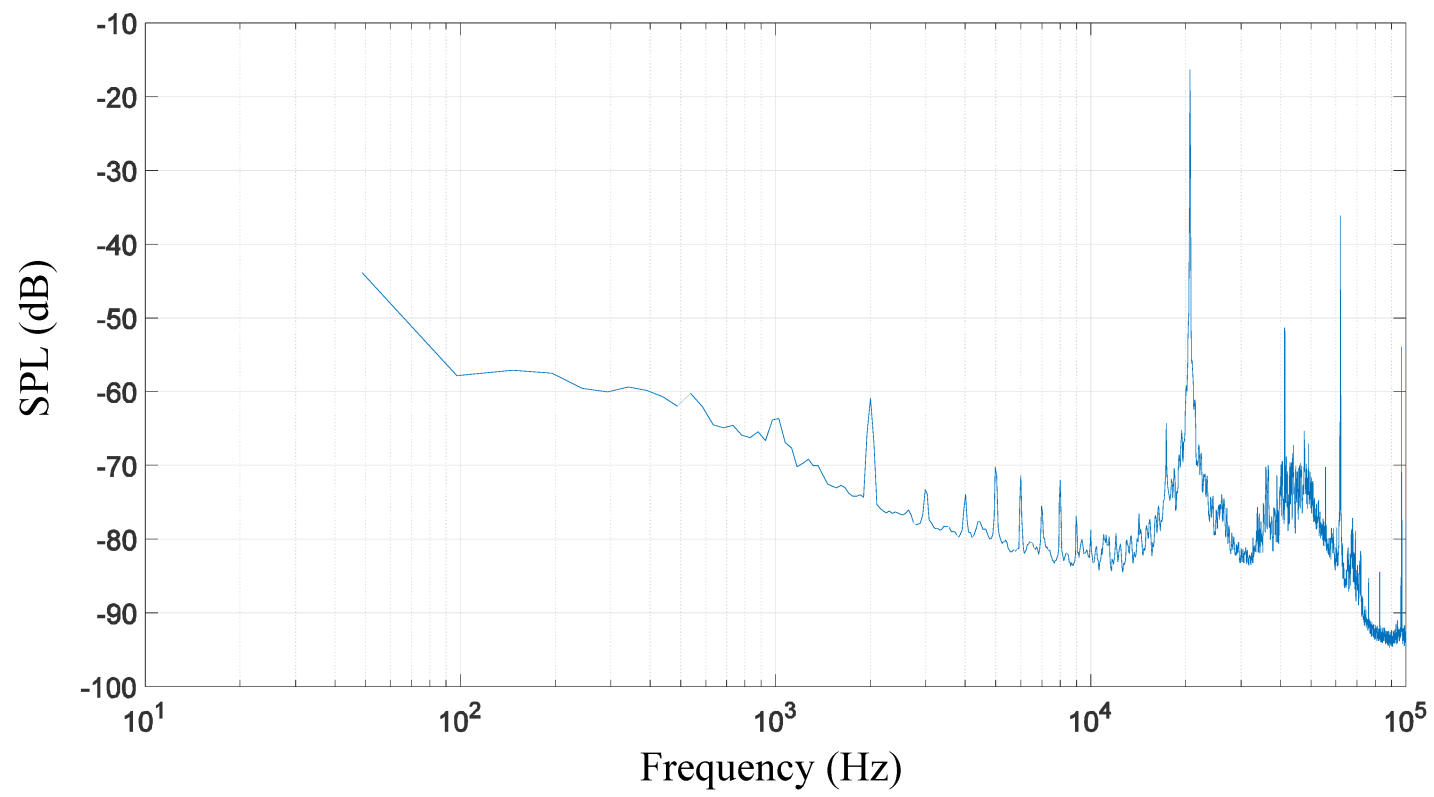

Figure 8-6: Noise spectrum relative to a $20.63 \mathrm{kHz}$ PZT source placed at $0.5 \mathrm{~m}$ distance

The code used to develop the SPL plots and control the stepper motors is provided in Appendix E. 


\section{Chapter 9}

\section{Discussion of experimental results}

This chapter focuses on the results of the circuit design and the phasing algorithm using the experimental setup and data acquisition methodology described in the previous chapter. Two types of transducers are tested in the experimental analysis; namely PZT and air-capacitive transducers. The PZT transducer is very similar to the transducer found in the Parallax Ping ${ }^{\circledR}$ ultrasonic range sensor. This allows for a comparison of the PZT transducer's propagation performance to that of an air- capacitive transducer.

Similarly, the reception performance of both the transducers is also compared by their ability to estimate the position of a $3 \mathrm{~cm} \mathrm{x} 3 \mathrm{~cm}$ square target at a prespecified spatial location.

Using the automated SPL acquisition system, SPL plots are derived for both the transducers and their beam steering and phased array capabilities are discussed. Effects of range, frequency and phase angle control during propagation and the steering of beam forming algorithm during reception are examined. 


\subsection{Range vs sensor type}

The PZT and air-capacitive transducer are placed in the anechoic chamber for range and phase testing. The range testing results are highlighted in Figure 9-1 for the PZT and air-capacitive transducer.

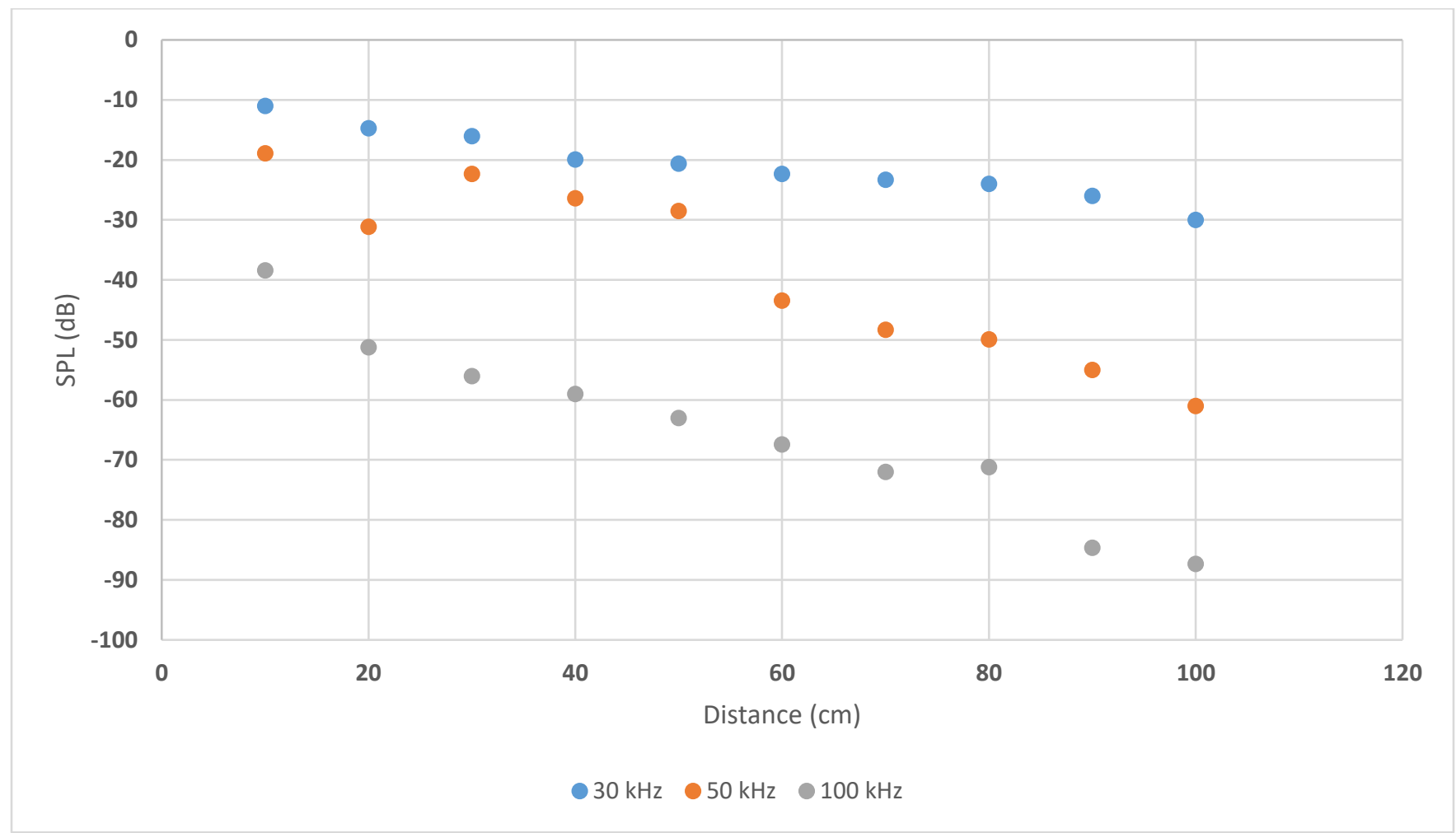

a) PZT transducer 


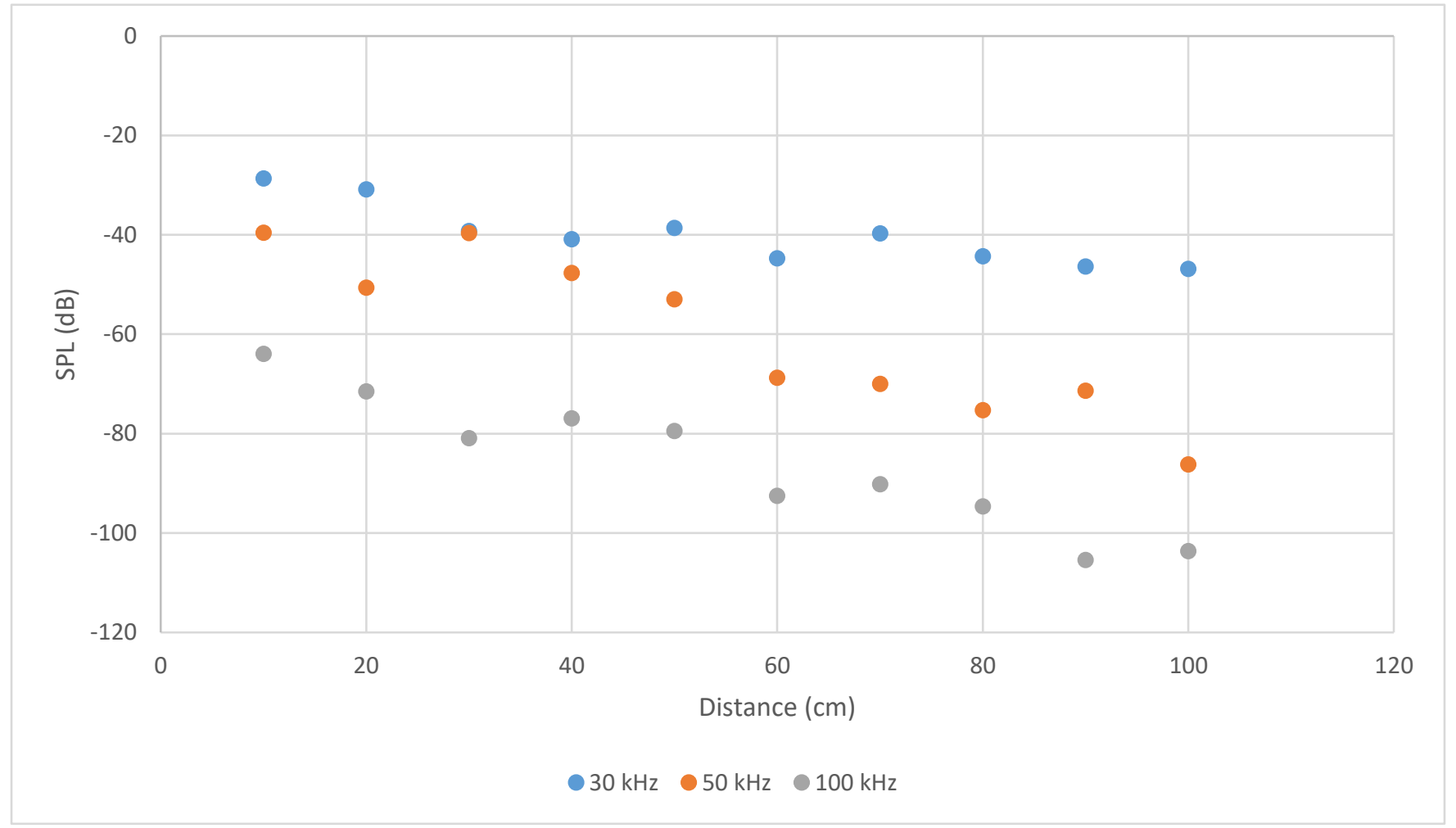

\section{b) Air-capacitive transducer}

Figure 9-1: Comparison of output SPL between the PZT and air-capacitive transducers.

From the results in the above figure, it can be seen that both the transducers follow the $\frac{1}{r^{2}}$ relationship for amplitude reduction. Even though both the sensors are operating at the same voltages and frequency, the output sound pressure level observed is not the same. In the case of air-capacitive transducer, the output pressure is consistently observed to be $25 \mathrm{~dB}$ below the PZT transducer's output.

This reduction is output SPL can be attributed to the very low electrical capacitance of the air-capacitive transducer. The $2.5 \mathrm{pF}$ capacitance of the air-capacitive transducer requires a 10 VDC to activate the back plate of the transducer. Due to the low source capacitance only small 
amounts of charge can be stored on the sensor without damage. The available amplitude range is further reduced by the $10 \mathrm{VDC}$ activation voltage, therefore reducing the output amplitude range that is achievable using the current design.

\subsection{Range vs Frequency}

As the frequency of the sensor is varied, the range response of the sensors changes dramatically due to acoustic impedance mismatch. As shown in Figure 9-1, the increase in frequency has a weighted response on the inverse squared relationship for both types of transducers. In the case of the air-capacitive transducer, at $100 \mathrm{kHz}$, the output SPL falls below 60 decibels at $50 \mathrm{~cm}$. Based on the pre-amplifier design with a $60 \mathrm{~dB}$ maximum amplification, any signal beyond $65 \mathrm{~cm}$ becomes undetectable during the reception phase.

\subsection{Beam Phasing}

The phased array circuit design discussed in Chapter 7 is used to generated a $50 \mathrm{kHz}$ signal for both types of transducers. The phasing algorithm is used to phase the beam at angles of $30^{\circ}$ and $60^{\circ}$ as shown in Figure 9-2.

90

60

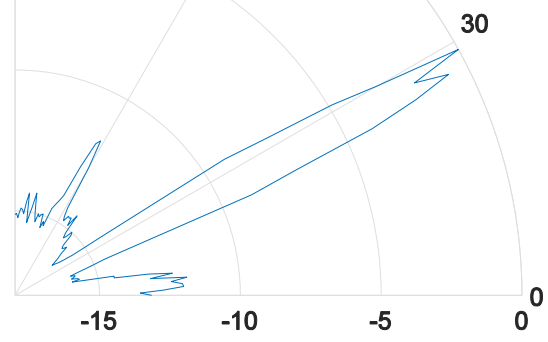

(a) PZT array at $30 \mathrm{deg}$
90
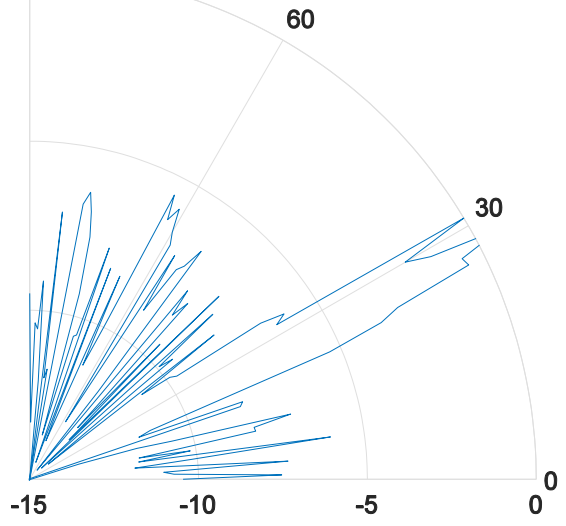

(b) Air-capacitive array at $30 \mathrm{deg}$ 
90

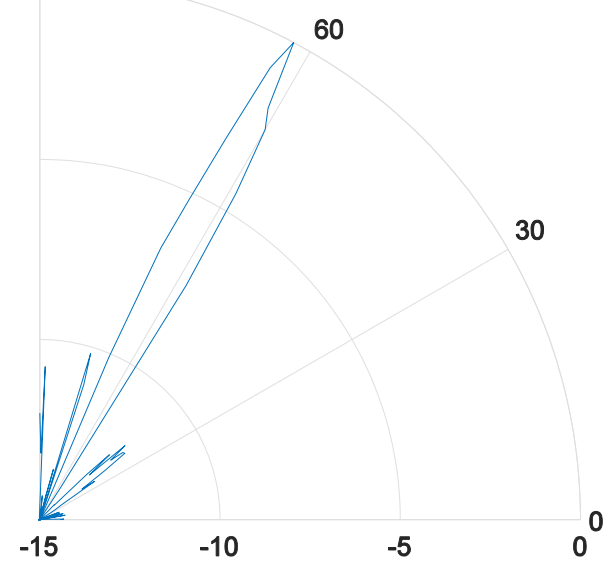

(c) PZT array at $60 \mathrm{deg}$
90

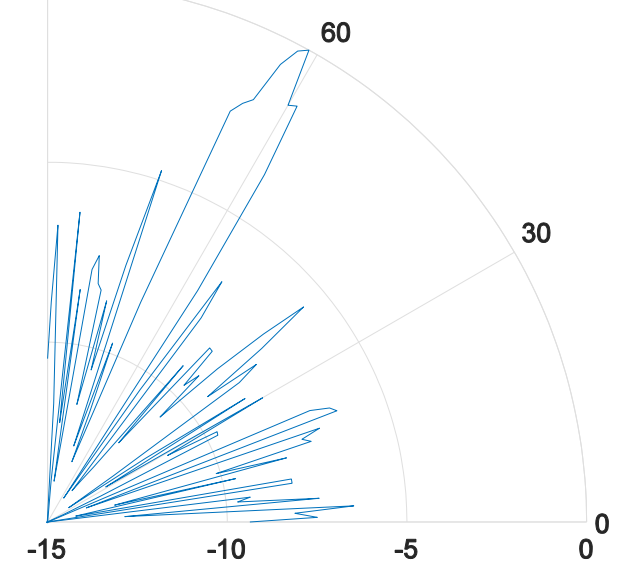

(d) Air-capacitive array at $60 \mathrm{deg}$

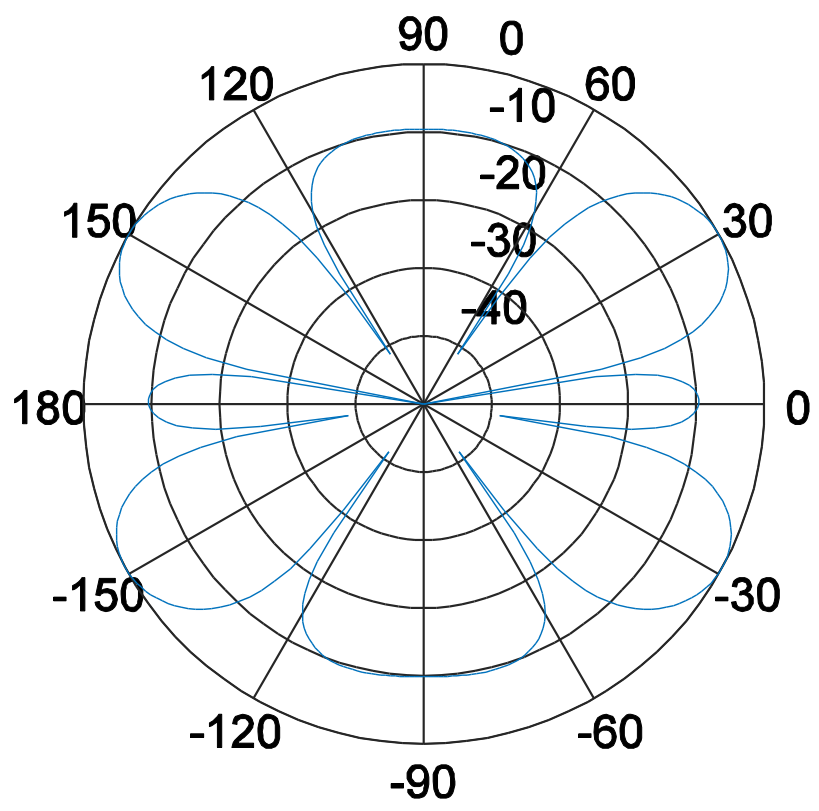

(e) SPL plot of a 3 element phased array beam at 60 degrees at $50 \mathrm{kHz}$ 


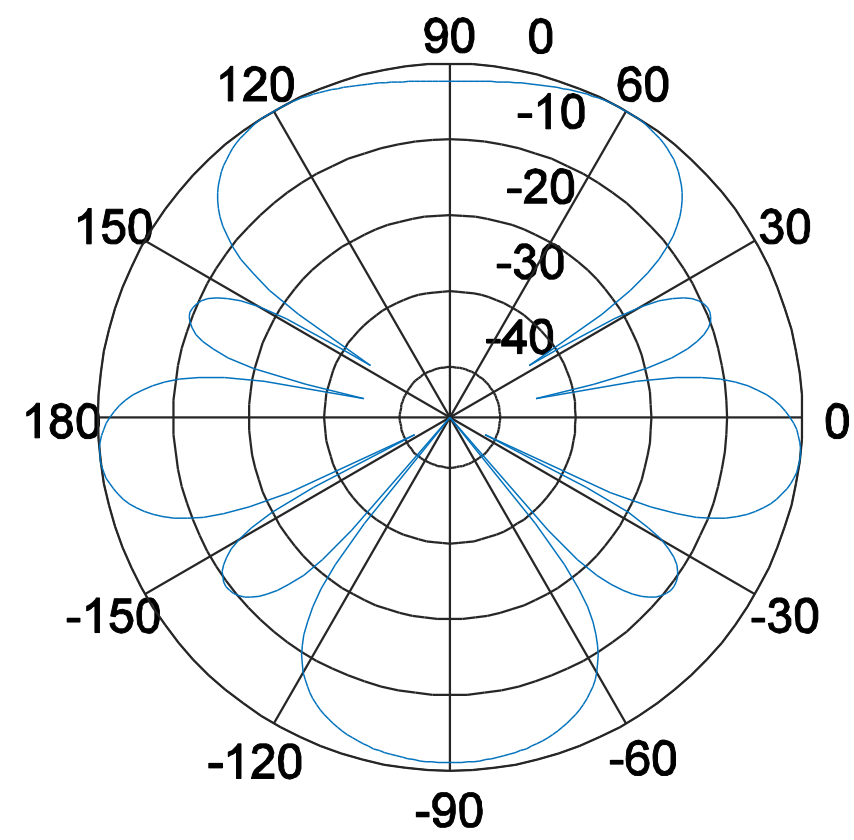

(f) SPL plot of a 3 element phased array beam at 30 degrees at $50 \mathrm{kHz}$

Figure 9-2: Comparison of theoretical performance to the actual performance of a PZT and aircapacitive based phased array transducer.

The phased array response for both types of transducers shown in Figure 9-2 resembles the theoretical performance. The performance difference in the case of the PZT can be attributed to the physical size of the transducer. The PZT transducer is $15 \mathrm{~mm}$ in diameter, this increases the distance between the sensors in the array as compared to the air-capacitive transducer, resulting in coarser beam angle control.

On the other hand, the air-capacitive sensor is observed to have an excessive number of grating lobes. These lobes can be a direct result of increased ambient noise and since the sound pressure level previously observed is lower was compared to the PZT transducer.

From the theoretical performance graph shown in Figure 9-2 e and $\mathbf{f}$, a significant amount of energy is emitted in the side lobes that do not lie on the desired axis of transmission. In the case 
of the anechoic chamber, the foam on the walls absorbs the outgoing wave giving an illusion of an infinite room. In the absence of this characteristic impedance condition, the reverberation from the walls would severely degrade the signal to noise ratio observed by the sensor. The effect of a reduced signal to noise ratio is quite evident in the case of an air-capacitive transducer where large amplitude of noise is present at angles other than the propagation direction.

\subsection{Reception Analysis}

During the reception phase there is no acoustic aperture to direct energy on PZT element, therefore the analysis was only performed on the air-coupled transducer. To evaluate the performance a $3 \mathrm{~cm} \times 3 \mathrm{~cm}$ flat square target was placed at an angle 30 degrees and distance of 55 $\mathrm{cm}$ from the transducer. The operating frequency of the array is selected to be $50 \mathrm{kHz}$. The target's range and the angle are evaluated using TOA algorithm and thirty data points are acquired to perform a statistical analysis.

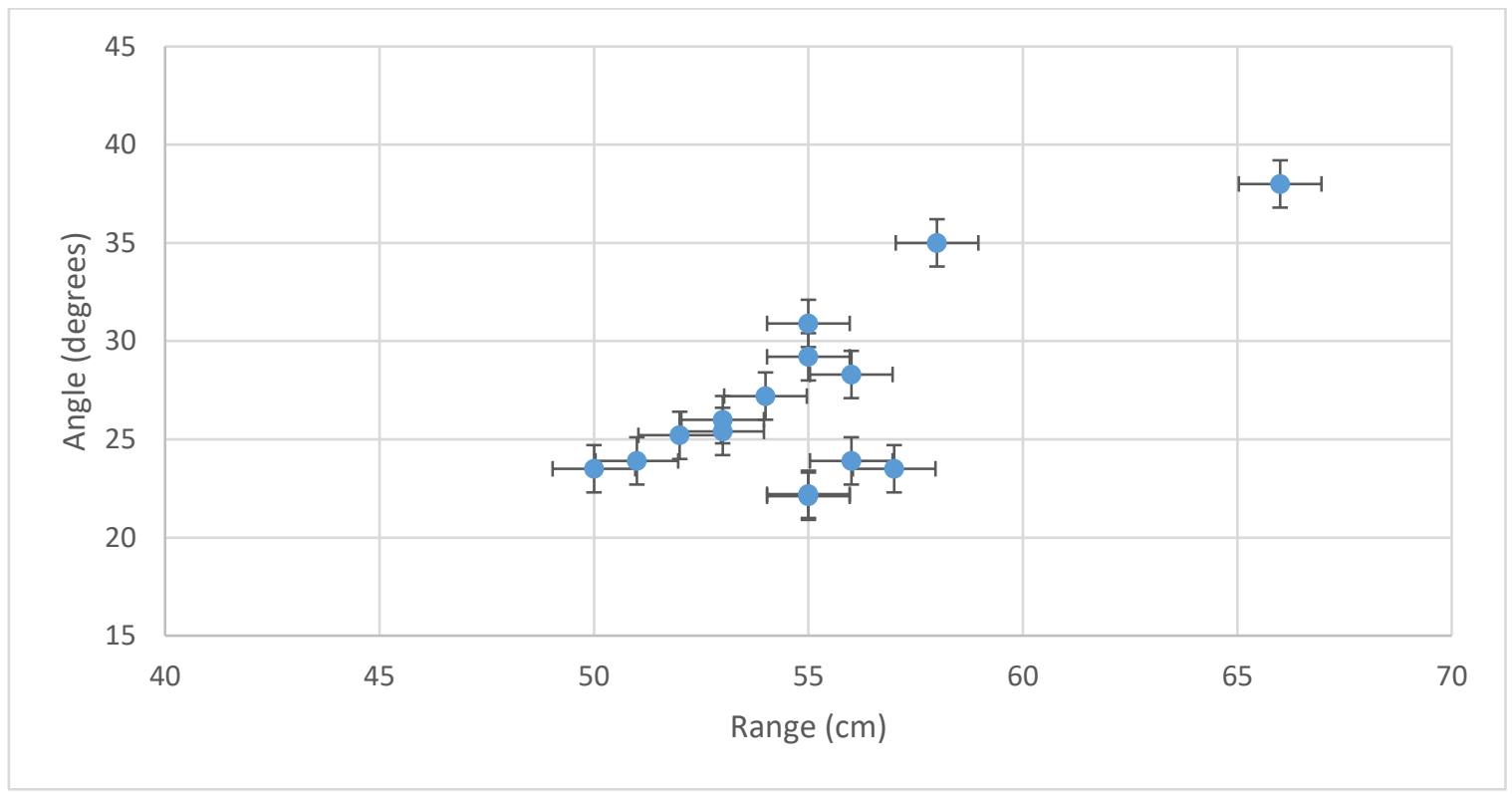

Figure 9-3: Experimental results of range vs angular position 
Figure 9-3 highlights the collected data in terms of range versus angular position; it can readily be seen that the there is only one instance where the sensor can correctly identify the exact position of the target. The data acquired has a mean value of $55.06 \mathrm{~cm}$ for the range and 28.66 degrees for the angular approximation, along with a standard deviation of $3.73 \mathrm{~cm}$ and 4.4 degrees respectively. The standard error in the range is observed to be $0.96 \mathrm{~cm}$ and 1.2 degrees in angular control. The results obtained are comparable to that of a commercially available PZT ultrasonic range sensors that offer a $1 \mathrm{~cm}$ resolution.

The performance of the phased array system is improved over a single element transducer due to the beamforming effect outlined in section 3.14. Upon selection of the propagation angle, the reception beamforming algorithm is also changed to the same angle. This moves the characteristic null to an off axis direction during reception and amplifies the signal reception in the desired direction as shown in Figure 9-4. 

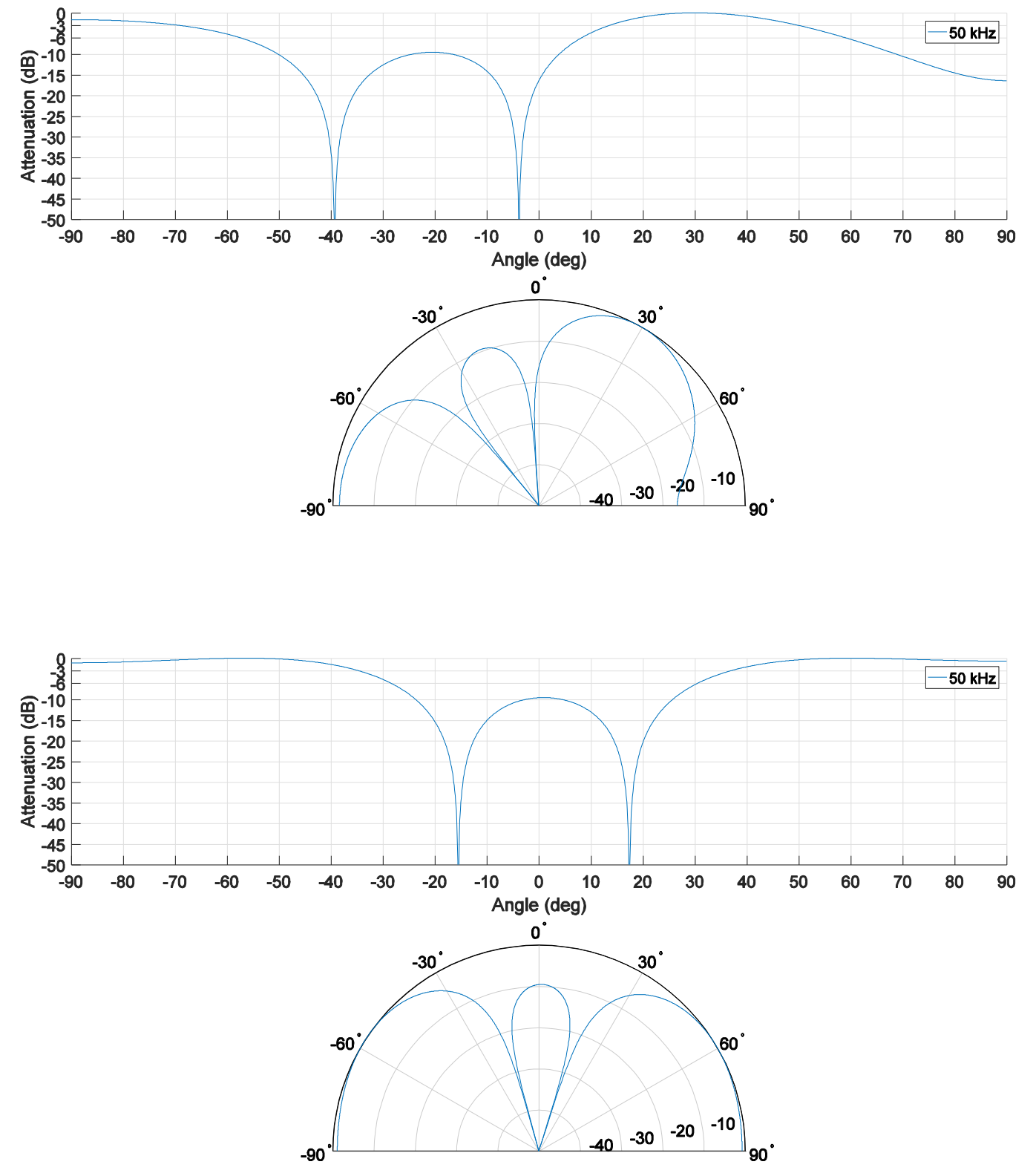

Figure 9-4: Effects of moving reception beam former lobe

The movement of the main reception lobe into the direction of propagation reduces the reverberation that is collected from the environment. Also, moving the reception lobe into the 
direction of propagation forces the null to be present at approximately 25 degrees away from the reception lobe, thus reducing the ambient noise collected from non-axial sources.

\subsection{Reception with holes}

During the reception mode, the air-capacitive transducer serves as a microphone to the system. The design of a microphone is discussed extensively by Ford (ref 78); it is suggested that by drilling holes in the back plate, the acoustic response of the microphone improves. The holes convert the microphone design from a directional microphone to an omnidirectional microphone by allowing pressure sensitivity from behind. The presence of holes reduces the intrinsic change in sensitivity due to change in external pressure as observed when varying altitude [5]. The holes' act as a low pass filter allowing the pressure change to be apparent on both, internal and external face of the Mylar film and an array with back plate holes is shown in Figure 9-5.

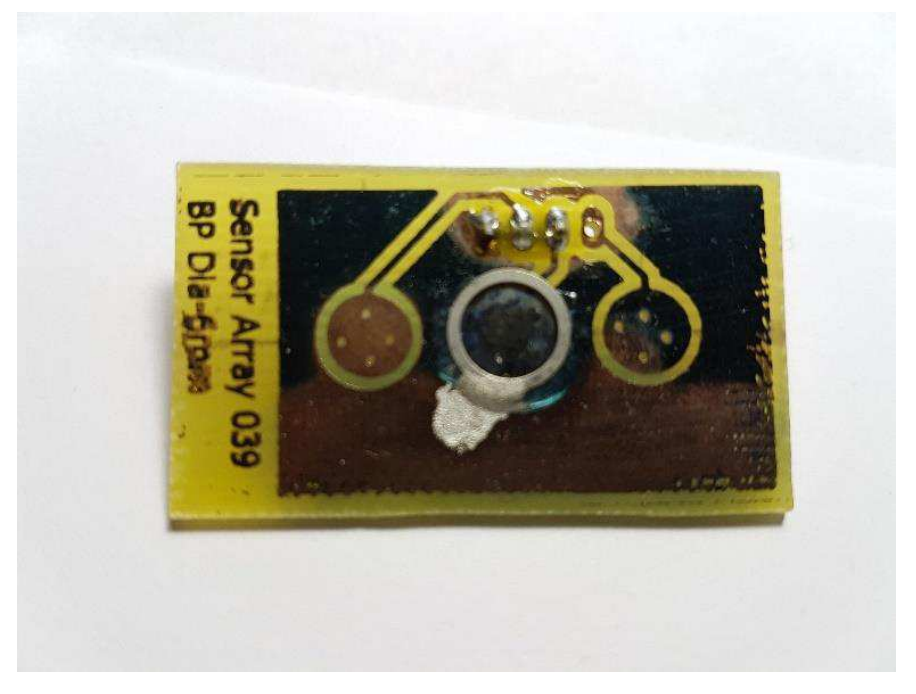

Figure 9-5: Air-capacitive transducer with holes in black plate.

However, this improvement in the sensitivity directly affects the directional nature of the microphone that is critical to the design and is linked to the signal to noise ratio. Also, the holes reduce the surface area of the copper conductor in the back plate, therefore reducing the source 
capacitance of the transducer. The reduction in source capacitance will require higher amplification, resulting in a reduced signal to noise ratio. Due to the adverse effects on the performance of the transducer design, the perforated back plate design is rejected.

\subsection{Discussion of Results}

The phased array design is tested in both as an emitter and as a receiver. From the results it is quite evident that the sensor design and phased array circuitry can work in conjunction to produce a phased beam and locate a target. A good correlation is observed between the theoretical and actual performance of the sensors. Also, both the transducers, PZT and air capacitive have results that are very similar.

However, the performance of the sensor is very poor with respect to the signal to noise ratio during both, propagation and reception. In the case of air-coupled sensor the deterioration in signal to noise ratio is very dominant as expressed by the higher amplitude of the grating lobes. In frequencies above $50 \mathrm{kHz}$, the SNR described in section 3.14, is drastically reduced rendering the output signal useless beyond 0.65 meters. The performance further degrades with the presence of external acoustic sources.

A qualitative study was conducting to study the effect of film tension on frequency response. To study this effect a new batch of transducers were produced with a $500 \mathrm{~g}$ tension weight instead of $1 \mathrm{~kg}$. The reduced film tension seemed to have a significant effect at frequencies above $120 \mathrm{kHz}$, where a secondary low frequency sound is produced by the transducer. The lower frequency noise is attributed to structural reverberation within the Mylar film. 


\section{Chapter 10}

\section{Conclusions and Future Work}

This chapter outlines a summary of the research results and several important conclusions that were made from this research. The research results are discussed and recommendations for future improvements are also detailed in this chapter.

\subsection{Conclusions}

- The resonant operating frequencies of the transducer are determined by analytical analysis using vibratory motion. The results from the analytical analysis are compared to numerical analysis. The analytical results are further compared with numerical results that include fluid structure interaction and the resulting air coupled frequencies are used to excite the transducer.

- Time of arrival (TOA) technique was used to determine the position of the target. The TOA equations are nonlinear and are linearized using least square approach. The linearization reduces the complexity and allows the equations to be solved on a microcontroller platform in real time.

- An in-house PCB manufacturing process using photolithographic techniques was described. A repeatability test is performed by measuring the pin spacing of two IC's as predetermined locations. It is found that the test can be repeated with an accuracy of $1.5 \%$ error in the pin spacing.

- Circuit design was developed using the preselected performance characteristics. The circuit design involves using a variable frequency oscillator design using an LM555 timer. By 
varying the time constant on the charge and discharge cycle, a variable output frequency is observed. A micontroller based phasing algorithm is developed to phase the propagating beam in the desired direction.

- The circuit design also includes the design of an $8^{\text {th }}$ order multiple feedback band pass filter. The design allows for a steep roll off and a pre-characterized amplitude and phase curve in the band pass region.

- The circuit design developed was tested inside an anechoic chamber that is also developed in-house. The system uses two stepper motors to position an ultrasonic microphone and change the angle of incidence of the sensor array. The system is controlled by Mathworks MATLAB program that interfaces with the stepper motors via an Arduino Uno. The ambient noise inside the closed chamber is characterized and is used to offset the results in the analysis.

- Two transducers, PZT and air-capacitive, are tested for their phasing capabilities. The analysis yields that the PZT is capable of producing ultrasonic waves at higher amplitudes as compared to the air-capacitive transducer. The higher amplitudes allows the waves to propagate over longer distances, therefore increasing the range. It was observed experimentally that the range and detection of the phased beam for the PZT transducer extended beyond $100 \mathrm{~cm}$ while the range for an air-capacitive sensor was limited to $60 \mathrm{~cm}$ maximum.

- The phasing effects were found to be bottlenecked by the hardware chosen. The AT-Mega $328 \mathrm{p}$ platform is unable to generate simultaneous phased pulses at 1 degree resolution at $100 \mathrm{kHz}$. Using the 15 degree step resolution at $100 \mathrm{kHz}$, two phase angles, 30 degrees and 60 degrees are used for the analysis. 


\subsection{Recommendations}

- During the course of the research it was observed that the maximum operating frequency of $61 \mathrm{MHz}$ of the AT-Mega 328p poses a severe bottleneck on the phased array performance. It was observed that there is a 23 cycle delay at $16 \mathrm{MHz}$ that is introduced into the system if an analog value is converted into a digital signal. This severely affects the output performance of the phased array transducer as this reduces the minimum phase delay between two signals to a $41 \mathrm{~ns}$. At $100 \mathrm{kHz}$ this minimum phase delay reduces the output resolution to 14.76 degrees per step. To improve on the phasing performance a microcontroller with a higher frequency and accurate timing control need to be investigated.

- Significant improvements in the transducer performance can be achieved by employing micromachining techniques to allow for accurate control of the spacing between the transducer film and back plate. A static port design should be investigated to prevent the change in the transducer's sensitivity with a change in altitude.

- While acceptable results can be achieved with the amateur manufacturing technique involving the film of the transducer, a more robust and repeatable technique shall be investigated such that the performance of each sensor can be standardized. 


\section{References}

References Revised

[1] J. Zufferey, Bio-inspired flying robots. Lausanne: EPFL Press, 2008.

[2] T. Mueller, Introduction to the design of fixed-wing micro air vehicles. New York: American Institute of Aeronautics and Astronautics, 2007.

[3] K. Nonami, Autonomous flying robots. Tokyo: Springer, 2010.

[4] Cdn.solarbotics.com, 2016. [Online]. Available: https://cdn.solarbotics.com/products/photos/4dd354bb3e295d37e702e51da2c0f5be/35231dscn0469_copy.jpg. [Accessed: 06- Aug- 2016].

[5] R. Monzingo, R. Haupt and T. Miller, Introduction to adaptive arrays. Raleigh, NC: SciTech Pub., 2011.

[6] S. Zekavat and R. Buehrer, Position location. Hoboken, N.J.: Wiley-IEEE Press, 2012.

[7] U. Rembold, Robot technology and applications. New York: Marcel Dekker, Inc., 1990.

[8] S. Cetinkunt, Mechatronics with Experiments, Second Edition. John Wiley \& Sons, 2015.

[9] R. Knight, Physics for scientists and engineers; a strategic approach. Pearson Education Inc, 2013.

[10] "Products", Balluff.com, 2016. [Online]. Available: http://www.balluff.com/balluff/MUS/en/products/product_detail.jsp\#/367328. [Accessed: 10- Apr- 2016].

[11] "Products", Balluff.com, 2016. [Online]. Available: http://www.balluff.com/balluff/MUS/en/products/product_detail.jsp\#/367329. [Accessed: 10- Apr- 2016].

[12] "E2K-C Long-distance type/Features | OMRON Industrial Automation", Ia.omron.com, 2016. [Online]. Available: https://www.ia.omron.com/products/family/470/. [Accessed: 10Apr- 2016]. 
[13] 2016. [Online]. Available:

http://literature.rockwellautomation.com/idc/groups/literature/documents/ca/c116-ca504_en-p.pdf. [Accessed: 10- Apr- 2016].

[14] "Capacitive Proximity Sensors", Eatoncanada.ca, 2016. [Online]. Available: http://www.eatoncanada.ca/EatonCA/ProductsSolutions/Electrical/ProductsandServices/Aut omationandControl/SensorsandLimitSwitches/CapacitiveProximitySensors/index.htm\#tabs3. [Accessed: 10- Apr- 2016].

[15] "Products", Balluff.com, 2016. [Online]. Available: http://www.balluff.com/balluff/MDE/en/products/product_detail.jsp\#/138443. [Accessed: 10- Apr- 2016].

[16] "E2Q5 | Omron, Canada", Industrial.omron.ca, 2016. [Online]. Available: https://industrial.omron.ca/en/products/catalogue/sensing/inductive_sensors/longer_distance /e2q5/default.html. [Accessed: 10- Apr- 2016].

[17] "WorldProx Tubular General Purpose Proximity Sensors", Ab.rockwellautomation.com, 2016. [Online]. Available: http://ab.rockwellautomation.com/Sensors-Switches/InductiveProximity-Sensors/872C-General-Purpose-Proximity-Sensors. [Accessed: 11- Apr- 2016].

[18] "E56 Pancake Style Inductive Sensors for Rugged Applications", Eaton.com, 2016. [Online]. Available: http://www.eaton.com/Eaton/ProductsServices/Electrical/ProductsandServices/Automationa ndControl/SensorsLimitSwitches/InductiveProximitySensors/PancakeStyle/index.htm. [Accessed: 11- Apr- 2016].

[19] "Introduction to infrared vision | Resources | Opto Engineering", Opto-engineering.com, 2016. [Online]. Available: http://www.opto-engineering.com/resources/infrared-theory. [Accessed: 10- Nov- 2015].

[20] C. Bohren and D. Huffman, Absorption and scattering of light by small particles. New York: Wiley, 1983.

[21] J. Peatross and M. Ware, Physics of light and optics. 
[22] S. SDE, "GP2Y0A21YK0F :: Optoelectronic Components :: Sharp Devices Europe", Sharpsde.com, 2016. [Online]. Available: https://www.sharpsde.com/products/optoelectroniccomponents/model/GP2Y0A21YK0F/\#productview. [Accessed: 15- Apr- 2016].

[23] “ Sharp GP2Y0A710K0F Infrared Ragne Sensor” 2016. [Online]. Available: https://cdn.sharpsde.com/fileadmin/products/Optoelectronics/Sensors/Specs/GP2Y0A710K0 F_24Aug06_Spec_ED-06G062.pdf. [Accessed: 15- Apr- 2016].

[24] S. SDE, "GP2Y0A02YK0F :: Optoelectronic Components :: Sharp Devices Europe", Sharpsde.com, 2016. [Online]. Available: https://www.sharpsde.com/products/optoelectroniccomponents/model/GP2Y0A02YK0F/\#productview. [Accessed: 15- Apr- 2016].

[25] S. SDE, "GP2Y0A60SZ0F :: Optoelectronic Components :: Sharp Devices Europe", Sharpsde.com, 2016. [Online]. Available: https://www.sharpsde.com/products/optoelectroniccomponents/model/GP2Y0A60SZ0F/\#productview. [Accessed: 15- Apr- 2016].

[26] O. Svelto and D. Hanna, Principles of lasers. New York: Springer, 2010.

[27] D. Ensminger and L. Bond, Ultrasonics. Boca Raton, FL: CRC Press, 2012.

[28] Piezo-Electric Electro-Acoustic Transducers. Cham: Springer International Publishing, 2014.

[29] Coolcomponents.co.uk, 2016. [Online]. Available: https://www.coolcomponents.co.uk/media/catalog/product/m/a/maxsonar-ez1.jpg. [Accessed: 12- Apr- 2016].

[30] Robotshop.com, 2016. [Online]. Available: http://www.robotshop.com/media/files/images2/parallax-ping-ultrasonic-sensor-large.jpg. [Accessed: 12- Apr- 2016].

[31] "MB1000 LV-MaxSonar-EZ0 Ultrasonic Rangefinder", Maxbotix.com, 2016. [Online]. Available: http://www.maxbotix.com/Ultrasonic_Sensors/MB1000.htm. [Accessed: 12Apr- 2016]. 
[32] "MB7060 Outdoor Ultrasonic Sensors from MaxBotix Inc.", Maxbotix.com, 2016. [Online]. Available: http://www.maxbotix.com/Ultrasonic_Sensors/MB7060.htm. [Accessed: 06Aug- 2016].

[33] "PING Ultrasonic Distance Sensor | 28015 | Parallax Inc", Parallax.com, 2016. [Online]. Available: https://www.parallax.com/product/28015. [Accessed: 12- Apr- 2016].

[34] V. Sharapov, Piezoceramic sensors. Berlin: Springer, 2011.

[35] M. Vijaya, Piezoelectric materials and devices. Boca Raton, FL: CRC Press, 2013.

[36] J. Tichì, Fundamentals of piezoelectric sensorics. Berlin: Springer, 2010.

[37] L. Lynnworth, "Ultrasonic Impedance Matching from Solids to Gases", The Journal of the Acoustical Society of America, vol. 36, no. 10, p. 1999, 1964.

[38] S. Kočiš and Z. Figura, Ultrasonic measurements and technologies. London: Chapman \& Hall, 1996.

[39] "Piezoelectric Ceramics Properties and Applications | Morgan Technical Ceramics", Morgantechnicalceramics.com. [Online]. Available: http://www.morgantechnicalceramics.com/products/product-groups/piezo-ceramiccomponents/piezoelectric-ceramics-prop-apps. [Accessed: 30- Jan- 2016].

[40] J. Zufferey, Bio-inspired flying robots. Lausanne: EPFL Press, 2008.

[41] T. Mueller, Introduction to the design of fixed-wing micro air vehicles. New York: American Institute of Aeronautics and Astronautics, 2007.

[42] Tasspm, M, Deeb, A and Laliberte, J," Autonomous Navigation and Control of a MicroAir Vehicle in GPS-denied Environments", winner student paper competition, USC 2012 Conference, Ottawa, November 2012

[43] Kuttruff, H., Acoustics:An Introduction, London: Taylor \& Francis, 2007.

[44] M. Norton and D. Karczub, Fundamentals of noise and vibration analysis for engineers. Cambridge, UK: Cambridge University Press, 2003.

[45] Kim, Y., Sound propagation, Singapore: Wiley, 2010. 
[46] E. Skudrzyk, The foundations of acoustics. Wien: Springer-Verlag, 1971.

[47] M. Moran and H. Shapiro, Fundamentals of engineering thermodynamics. Sixth Edition,Hoboken, N.J.: Wiley, 2008.

[48] F. White, Fluid mechanics. Seventh Edition, New York, N.Y.: McGraw Hill, 2011.

[49] J. Anderson, Fundamentals of Aerodynamics. Fifth Edition, New York, N.Y.: McGraw Hill, 2011.

[50] Rayleigh, J. W. S., The theory of sound., Vol. 1, London, England: Macmillan and Co. LTD., 1937.

[51] Rayleigh, J. W. S., The theory of sound., Vol. 2, London, England: Macmillan and Co. LTD., 1937.

[52] S. Rao, Mechanical vibrations. Upper Saddle River, N.J.: Prentice Hall, 2011.

[53] J. Cheeke, Fundamentals and applications of ultrasonic waves. Boca Raton: CRC Press, 2002.

[54] G. Harris, "Review of transient field theory for a baffled planar piston", The Journal of the Acoustical Society of America, vol. 70, no. 1, p. 10, 1981.

[55] G. Harris, "Transient field of a baffled planar piston having an arbitrary vibration amplitude distribution", The Journal of the Acoustical Society of America, vol. 70, no. 1, p. 186, 1981.

[56] D. Robinson, S. Lees and L. Bess, "Near field transient radiation patterns for circular pistons", IEEE Transactions on Acoustics, Speech, and Signal Processing, vol. 22, no. 6, pp. 395-403, 1974.

[57] P. Stepanishen, "Transient Radiation from Pistons in an Infinite Planar Baffle", The Journal of the Acoustical Society of America, vol. 48, no. 1, p. 1629, 1970.

[58] A. Freedman, "Erratum: Sound Field of a Rectangular Piston [J. Acoust. Soc. Am. 32, 197 (1960)]", The Journal of the Acoustical Society of America, vol. 32, no. 12, p. 1701, 1960. 
[59] J. San Emeterio, "Diffraction impulse response of rectangular transducers", The Journal of the Acoustical Society of America, vol. 92, no. 2, p. 651, 1992.

[60] J. Lockwood, "High-speed method for computing the exact solution for the pressure variations in the nearfield of a baffled piston", The Journal of the Acoustical Society of America, vol. 53, no. 3, p. 735, 1973.

[61] L. Schmerr, Fundamentals of ultrasonic phased arrays. Cham: Springer, 2015.

[62] S. Wooh and Y. Shi, "Optimum beam steering of linear phased arrays", Wave Motion, vol. 29, no. 3, pp. 245-265, 1999.

[63] J. Benesty and J. Chen, Study and design of differential microphone arrays. Heidelberg: Springer, 2013.

[64] L. Jakevičius, A. Demčenko,"Ultrasound attenuation dependence on air temperature in closed chambers", ULTRAGARSAS Journal, vol. 63, no. 1, pp. 18-22, 2008.

[65] M. Vorländer, Auralization. Berlin: Springer, 2008.

[66] L. Ziomek, Fundamentals of acoustic field theory and space-time signal processing. Boca Raton: CRC Press, 1995.

[67] Liessa, Vibrations of Plates, Acoustic Society of America through American Institute of Physics, 1993

[68] Francis s. Tse,"Mechanical Vibration : Theory and application"1 ${ }^{\text {st }}$ edition, Library of congress cataloging in publication data. 1978

[69] E. Volterra, “Dynamics of Vibration”, $1^{\text {st }}$ edition,Columbus Ohio, Charles E. Merill Books, 1965

[70] C. Howard and B. Cazzolato, Acoustic analyses using MATLAB and ANSYS. .

[71] "ANSYS Mechanical APDL Acoustic Analysis Guide", Ansys Manual, 2016. [Online]. Available:

http://148.204.81.206/Ansys/150/ANSYS\%20Mechanical\%20APDL\%20Acoustic\%20Anal ysis\%20Guide.pdf. [Accessed: 16- Apr- 2016]. 
[72] "MG Chemicals CAT No. 421", Mouser Electronics, 2016. [Online]. Available: http://www.mouser.com/ds/2/265/421-16426.pdf. [Accessed: 07- Aug- 2016].

[73] "AND gate 74ABT08CPWR", NXP Semiconductor, 2016. [Online]. Available: http://www.nxp.com/documents/data_sheet/74ABT08.pdf. [Accessed: 12- Apr- 2016].

[74] "MAX 660", Texas Instruments, 2016. [Online]. Available: http://www.ti.com/lit/ds/symlink/max660.pdf. [Accessed: 12- Apr- 2016].

[75] "Chapter 16- Active Filter Design Techniques", Texas Instruments Literature SLOA088, 2016. [Online]. Available: https://focus.ti.com/lit/ml/sloa088/sloa088.pdf. [Accessed: 12Apr- 2016].

[76] "HEF-4046 PLL Datasheet", NXP Semiconductor, 2016. [Online]. Available: http://www.nxp.com/documents/data_sheet/HEF4046B.pdf. [Accessed: 12- Apr- 2016].

[77] "Knowles ${ }^{\circledR}$ Model: SPU0410LR5H Datasheet", Knowles, 2016. [Online]. Available: http://www.knowles.com/kor/content/../3/.../SPU0410LR5H-QB+revH. [Accessed: 12Apr- 2016].

[78] "EEVblog \#602 - Introduction to Microphones", YouTube, 2016. [Online]. Available: https://www.youtube.com/watch?v=ihAG6cMpUlY. [Accessed: 12- Aug- 2016]. 


\section{Appendix A}

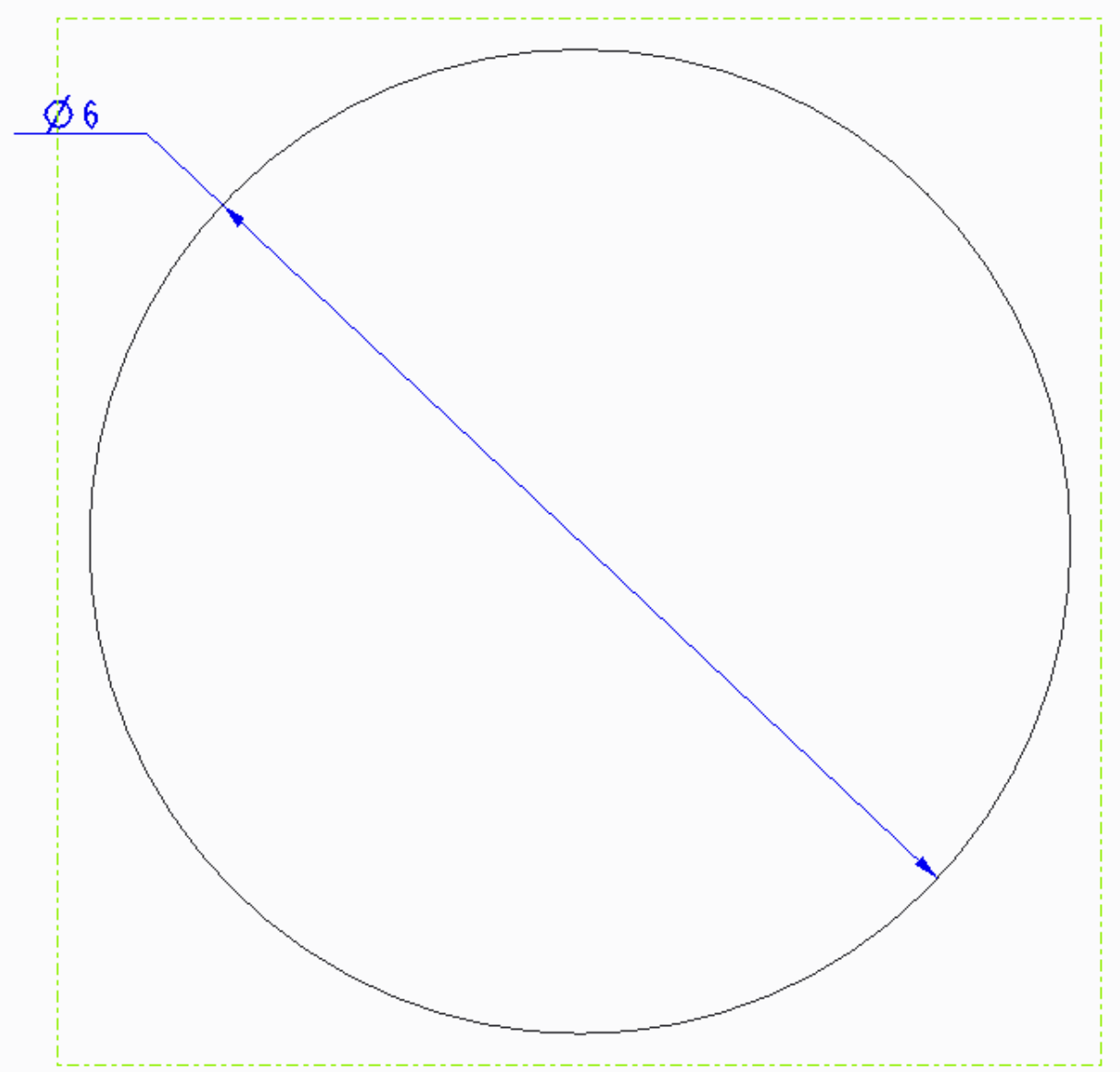

All Dimensions are in $\mathrm{mm}$ 


\section{Appendix B}

Data sheet for Mylar film from Dupont

Table 1

Typical Electrical Properties of Mylar Polyester Film

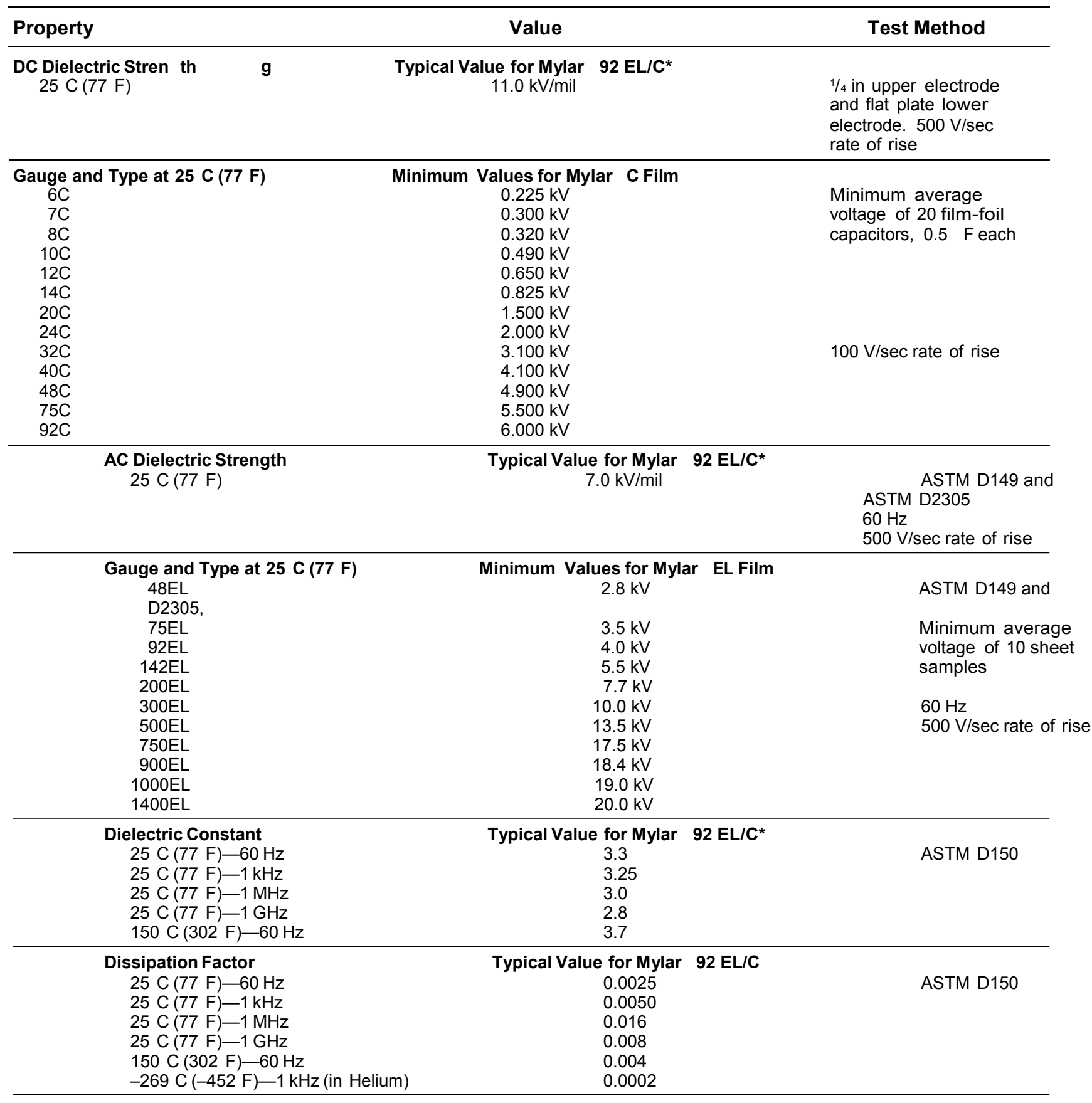


Volume Resistivity

$25 \mathrm{C}(77 \mathrm{~F})$

150 C (302 F) (Type C Film)

Surface Resistivity

$23 \mathrm{C}(73 \mathrm{~F})-30 \% \mathrm{RH}$

$23 \mathrm{C}(73 \mathrm{~F})-80 \% \mathrm{RH}$

Insulation Resistance

$35 \mathrm{C}(95 \mathrm{~F})-90 \% \mathrm{RH}$

Capacitor Insulation

Resistance

$100 \mathrm{C}(212 \mathrm{~F})$

$125 \mathrm{C}(257 \mathrm{~F})$

$150 \mathrm{C}(302 \mathrm{~F})$
Typical Value for Mylar $92 \mathrm{EL} / \mathrm{C}$

$10^{18} \mathrm{ohm} \mathrm{cm}$

$10^{13} \mathrm{ohm} \mathrm{cm}$

$10^{16} \mathrm{ohm} / \mathrm{sq}$

$10^{12} \mathrm{ohm} / \mathrm{sq}$

$10^{12} \mathrm{ohm}$

Typical Value for Mylar $92 \mathrm{C}$

$$
\begin{gathered}
30,000 M-F \\
1,000 M-F \\
100 M-F
\end{gathered}
$$

Based on 0.5 F filmfoil capacitor sections, using single layer, 92 Mylar C

*Data relevant for other types of Mylar 


\section{Appendix C}

Ansys ACT acoustics analysis 


\section{Project}

\begin{tabular}{|r|c|}
\hline First Saved & Monday, May 9, 2016 \\
\hline Last Saved & Wednesday, May 11, 2016 \\
\hline Product Version & 16.0 Release \\
\hline Save Project Before Solution & No \\
\hline Save Project After Solution & No \\
\hline
\end{tabular}

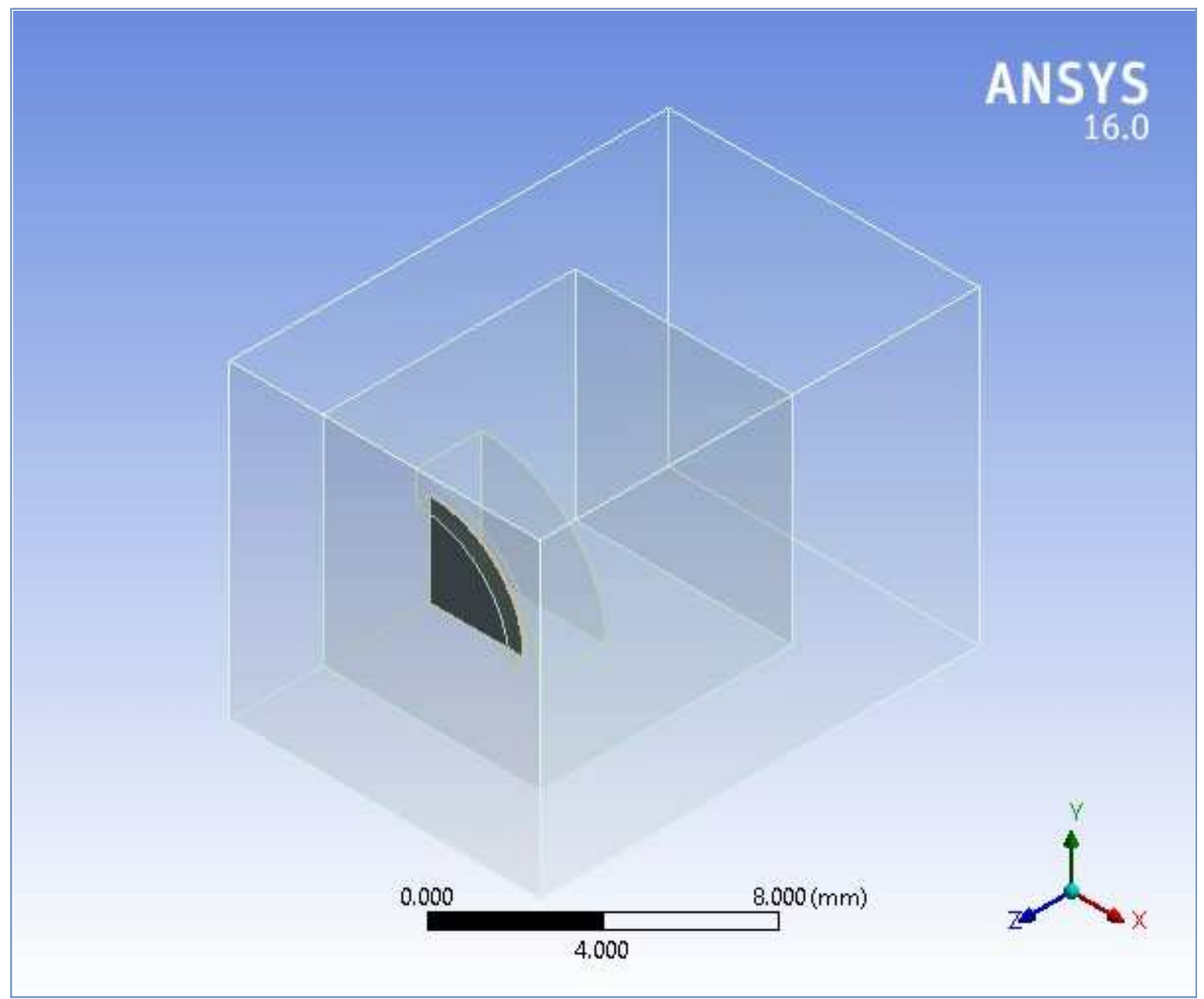




\section{Contents}

- Units

- Model (A4, B4, C4)

o Geometry

- Part

- Parts

- Coordinate Systems

○ Symmetry

- Symmetry Region

○ Connections

o Mesh

- Named Selections

- Harmonic Response (B5)

- Pre-Stress/Modal (None)

- Analysis Settings

- Loads

- Solution (B6)

- Solution Information

- Frequency Response

- Acoustic Pressure

- Acoustic Far Field

$\circ$ Modal (C5)

- Pre-Stress (None)

- Analysis Settings

- Fixed Support

- Loads

- Solution (C6)

- Solution Information

- Total Deformation

- Material Data

○ Structural Steel

- Mylar Celplast

\section{Units}

TABLE 1

\begin{tabular}{|r|c|}
\hline Unit System & Metric $(\mathrm{mm}, \mathrm{kg}, \mathrm{N}, \mathrm{s}, \mathrm{mV}, \mathrm{mA})$ Degrees rad/s Celsius \\
\hline Angle & Degrees \\
\hline Rotational Velocity & rad/s \\
\hline Temperature & Celsius \\
\hline
\end{tabular}

\section{Model (A4, B4, C4)}

Geometry

TABLE 2

Model (A4, B4, C4) > Geometry

file:///C:/Users/Edison/AppData/Roaming/Ansys/v160/Mechanical_Report/Mechanical_Re... 8/8/2016 


\begin{tabular}{|c|c|}
\hline Object Name & Geometry \\
\hline State & Fully Defined \\
\hline & Definition \\
\hline Source & $\begin{array}{c}\text { C:IUsersIEdisonIDocumentsIF_FullAcousticAnalysisWithFSIIFullAcousticAnalysisWithFSI_filesIdp0 } \\
\text { ISYSIDMISYS.agdb }\end{array}$ \\
\hline Type & DesignModeler \\
\hline Length Unit & Meters \\
\hline $\begin{array}{r}\text { Element } \\
\text { Control }\end{array}$ & Program Controlled \\
\hline Display Style & Body Color \\
\hline & Bounding Box \\
\hline Length $\mathrm{X}$ & 10. $\mathrm{mm}$ \\
\hline Length $\mathrm{Y}$ & 10. $\mathrm{mm}$ \\
\hline Length Z & $14.124 \mathrm{~mm}$ \\
\hline & Properties \\
\hline Volume & $1389.4 \mathrm{~mm}^{3}$ \\
\hline Mass & $1.0906 \mathrm{e}-002 \mathrm{~kg}$ \\
\hline $\begin{array}{r}\text { Scale Factor } \\
\text { Value }\end{array}$ & 1. \\
\hline & Statistics \\
\hline Bodies & 5 \\
\hline $\begin{array}{r}\text { Active } \\
\text { Bodies }\end{array}$ & 4 \\
\hline Nodes & 366244 \\
\hline Elements & 227805 \\
\hline Mesh Metric & None \\
\hline & Basic Geometry Options \\
\hline Parameters & Yes \\
\hline $\begin{array}{r}\text { Parameter } \\
\text { Key }\end{array}$ & DS \\
\hline Attributes & No \\
\hline $\begin{array}{r}\text { Named } \\
\text { Selections }\end{array}$ & No \\
\hline \begin{tabular}{r|} 
Material \\
Properties
\end{tabular} & No \\
\hline & Advanced Geometry Options \\
\hline $\begin{array}{r}\text { Use } \\
\text { Associativity }\end{array}$ & Yes \\
\hline $\begin{array}{r}\text { Coordinate } \\
\text { Systems }\end{array}$ & No \\
\hline $\begin{array}{r}\text { Reader } \\
\text { Mode Saves } \\
\text { Updated File }\end{array}$ & No \\
\hline $\begin{array}{r}\text { Use } \\
\text { Instances }\end{array}$ & Yes \\
\hline $\begin{array}{r}\text { Smart CAD } \\
\text { Update }\end{array}$ & No \\
\hline $\begin{array}{r}\text { Compare } \\
\text { Parts On } \\
\text { Update }\end{array}$ & No \\
\hline $\begin{array}{r}\text { Attach File } \\
\text { Via Temp } \\
\text { File }\end{array}$ & Yes \\
\hline \begin{tabular}{r|r} 
Temporary \\
Directory
\end{tabular} & C:IUsers\Edison\AppDatalLocallTemp \\
\hline Analysi & \\
\hline
\end{tabular}

file://C:/Users/Edison/AppData/Roaming/Ansys/v160/Mechanical_Report/Mechanical_Re... 8/8/2016 


\begin{tabular}{|r|c|} 
Type & $3-\mathrm{D}$ \\
\hline Decompose & Yes \\
Disjoint & \\
\hline Geometry & \\
Enclosure & Yes \\
and & \\
Symmetry & \\
\hline Processing &
\end{tabular}

TABLE 3

Model (A4, B4, C4) > Geometry > Body Groups

\begin{tabular}{|r|c|}
\hline Object Name & Part \\
\hline State & Meshed \\
\hline \multicolumn{2}{|r|}{ Graphics Properties } \\
\hline \multicolumn{2}{|r|}{ Visible } \\
\hline \multicolumn{2}{|r|}{ Definition } \\
\hline Suppressed & Yes \\
\hline Assignment & Multiple Materials \\
\hline Coordinate System & Default Coordinate System \\
\hline
\end{tabular}

Bounding Box

\begin{tabular}{|r|c|}
\hline Length $\mathrm{X}$ & 10. $\mathrm{mm}$ \\
\hline Length $\mathrm{Y}$ & $10 . \mathrm{mm}$ \\
\hline Length Z & $14.124 \mathrm{~mm}$ \\
\hline
\end{tabular}

Properties

\begin{tabular}{|r|c|}
\hline Volume & $1389.4 \mathrm{~mm}^{3}$ \\
\hline Mass & $1.0906 \mathrm{e}-002 \mathrm{~kg}$ \\
\hline Centroid X & $5.0536 \mathrm{~mm}$ \\
\hline Centroid Y & $5.0536 \mathrm{~mm}$ \\
\hline Centroid Z & $1.0641 \mathrm{~mm}$ \\
\hline Moment of Inertia Ip1 & $0.27267 \mathrm{~kg} \cdot \mathrm{mm}^{2}$ \\
\hline Moment of Inertia Ip2 & $0.27637 \mathrm{~kg} \cdot \mathrm{mm}^{2}$ \\
\hline Moment of Inertia Ip3 & $0.18053 \mathrm{~kg} \cdot \mathrm{mm}^{2}$ \\
\hline Statistics \\
\hline Nodes & 366244 \\
\hline Elements & 227805 \\
\hline Mesh Metric & None \\
\hline
\end{tabular}

TABLE 4

Model (A4, B4, C4) > Geometry > Part > Parts

\begin{tabular}{|c|c|c|c|c|c|}
\hline Object Name & Solid & Solid & Solid & Solid & Solid \\
\hline State & Suppressed & \multicolumn{4}{|c|}{ Meshed } \\
\hline \multicolumn{6}{|c|}{ Graphics Properties } \\
\hline Visible & No & \multicolumn{4}{|c|}{ Yes } \\
\hline Transparency & & 1 & & 0.1 & \\
\hline \multicolumn{6}{|c|}{ Definition } \\
\hline Suppressed & Yes & \multicolumn{4}{|c|}{ No } \\
\hline Stiffness Behavior & \multicolumn{5}{|c|}{ Flexible } \\
\hline Coordinate System & \multicolumn{5}{|c|}{ Default Coordinate System } \\
\hline $\begin{array}{r}\text { Reference } \\
\text { Temperature }\end{array}$ & \multicolumn{5}{|c|}{ By Environment } \\
\hline \multicolumn{6}{|c|}{ Material } \\
\hline Assignment & Structural Steel & Mylar Celplast & \multicolumn{3}{|c|}{ Structural Steel } \\
\hline Nonlinear Effects & \multicolumn{5}{|c|}{ Yes } \\
\hline $\begin{array}{r}\text { Thermal Strain } \\
\text { Effects }\end{array}$ & \multicolumn{5}{|c|}{ Yes } \\
\hline
\end{tabular}




\section{Bounding Box}

\begin{tabular}{|c|c|c|c|c|c|}
\hline Length X & 4. $\mathrm{mm}$ & 3. $\mathrm{mm}$ & 7. $\mathrm{mm}$ & 3. $\mathrm{mm}$ & 10. $\mathrm{mm}$ \\
\hline Length $\mathrm{Y}$ & 4. $\mathrm{mm}$ & 3. $\mathrm{mm}$ & 7. $\mathrm{mm}$ & 3. $\mathrm{mm}$ & 10. $\mathrm{mm}$ \\
\hline Length Z & $2.124 \mathrm{~mm}$ & $1.2 \mathrm{e}-002 \mathrm{~mm}$ & $8.124 \mathrm{~mm}$ & $5.2 \mathrm{e}-002 \mathrm{~mm}$ & $14.124 \mathrm{~mm}$ \\
\hline \multicolumn{6}{|c|}{ Properties } \\
\hline Volume & $22.987 \mathrm{~mm}^{3}$ & $8.4823 \mathrm{e}-002 \mathrm{~mm}^{3}$ & $374.64 \mathrm{~mm}^{3}$ & $0.36757 \mathrm{~mm}^{3}$ & $1014.3 \mathrm{~mm}^{3}$ \\
\hline Mass & $1.8045 \mathrm{e}-004 \mathrm{~kg}$ & $1.179 \mathrm{e}-007 \mathrm{~kg}$ & $2.9409 \mathrm{e}-003 \mathrm{~kg}$ & $2.8854 \mathrm{e}-006 \mathrm{~kg}$ & $\begin{array}{c}7.9624 \mathrm{e}-003 \\
\mathrm{~kg}\end{array}$ \\
\hline Centroid X & $1.7616 \mathrm{~mm}$ & $1.27 \mathrm{~mm}$ & $3.6088 \mathrm{~mm}$ & $1.27 \mathrm{~mm}$ & $5.5887 \mathrm{~mm}$ \\
\hline Centroid $\mathrm{Y}$ & $1.7616 \mathrm{~mm}$ & $1.27 \mathrm{~mm}$ & $3.6088 \mathrm{~mm}$ & $1.27 \mathrm{~mm}$ & $5.5887 \mathrm{~mm}$ \\
\hline Centroid Z & $0.93309 \mathrm{~mm}$ & $1.658 \mathrm{~mm}$ & $1.0692 \mathrm{~mm}$ & $1.626 \mathrm{~mm}$ & $1.062 \mathrm{~mm}$ \\
\hline Moment of Inertia Ip1 & $\begin{array}{c}1.9379 \mathrm{e}-004 \\
\mathrm{~kg} \cdot \mathrm{mm}^{2}\end{array}$ & $\begin{array}{c}9.5429 \mathrm{e}-008 \\
\mathrm{~kg} \cdot \mathrm{mm}^{2}\end{array}$ & $\begin{array}{c}2.9606 \mathrm{e}-002 \\
\mathrm{~kg} \cdot \mathrm{mm}^{2}\end{array}$ & $\begin{array}{c}2.336 \mathrm{e}-006 \\
\mathrm{~kg} \cdot \mathrm{mm}^{2}\end{array}$ & $\begin{array}{l}0.24676 \\
\mathrm{~kg} \cdot \mathrm{mm}^{2}\end{array}$ \\
\hline Moment of Inertia Ip2 & $\begin{array}{c}3.3109 \mathrm{e}-004 \\
\mathrm{~kg} \cdot \mathrm{mm}^{2}\end{array}$ & $\begin{array}{c}5.1368 \mathrm{e}-008 \\
\mathrm{~kg} \cdot \mathrm{mm}^{2}\end{array}$ & $\begin{array}{c}2.8557 \mathrm{e}-002 \\
\mathrm{~kg} \cdot \mathrm{mm}^{2}\end{array}$ & $\begin{array}{c}1.2577 \mathrm{e}-006 \\
\mathrm{~kg} \cdot \mathrm{mm}^{2}\end{array}$ & $\begin{array}{l}0.22718 \\
\mathrm{~kg} \cdot \mathrm{mm}^{2}\end{array}$ \\
\hline Moment of Inertia Ip3 & $\begin{array}{c}4.1859 \mathrm{e}-004 \\
\mathrm{~kg} \cdot \mathrm{mm}^{2}\end{array}$ & $\begin{array}{c}1.4679 \mathrm{e}-007 \\
\mathrm{~kg} \cdot \mathrm{mm}^{2}\end{array}$ & $\begin{array}{c}2.3909 \mathrm{e}-002 \\
\mathrm{~kg} \cdot \mathrm{mm}^{2}\end{array}$ & $\begin{array}{c}3.5924 \mathrm{e}-006 \\
\mathrm{~kg} \cdot \mathrm{mm}^{2}\end{array}$ & $\begin{array}{l}0.13969 \\
\mathrm{~kg} \cdot \mathrm{mm}^{2}\end{array}$ \\
\hline \multicolumn{6}{|c|}{ Statistics } \\
\hline Nodes & 0 & 5810 & 120810 & 5810 & 266683 \\
\hline Elements & 0 & 791 & 70056 & 791 & 156167 \\
\hline Mesh Metric & \multicolumn{5}{|c|}{ None } \\
\hline
\end{tabular}

\section{Coordinate Systems}

TABLE 5

Model (A4, B4, C4) > Coordinate Systems > Coordinate System

\begin{tabular}{|c|c|c|}
\hline Object Name & Global Coordinate System & \begin{tabular}{|l|l|} 
YZPlane & ZXPlane \\
\end{tabular} \\
\hline State & \multicolumn{2}{|c|}{ Fully Defined } \\
\hline \multicolumn{3}{|c|}{ Definition } \\
\hline Type & \multicolumn{2}{|c|}{ Cartesian } \\
\hline Coordinate System ID & 0. & \\
\hline Coordinate System & & Program Controlled \\
\hline Suppressed & & No \\
\hline \multicolumn{3}{|c|}{ Origin } \\
\hline Origin $\mathrm{X}$ & \multicolumn{2}{|l|}{$0 . \mathrm{mm}$} \\
\hline Origin $Y$ & \multicolumn{2}{|c|}{ 0. $\mathrm{mm}$} \\
\hline Origin Z & \multicolumn{2}{|l|}{ 0. $\mathrm{mm}$} \\
\hline Define By & & Global Coordinates \\
\hline Location & & Defined \\
\hline \multicolumn{3}{|c|}{ Directional Vectors } \\
\hline X Axis Data & {$[1.0 .0]$.} & {$[0.1 .0].[0.0 .1]$.} \\
\hline Y Axis Data & {$[0.1 .0]$.} & {$[0.0 .1].[1.0 .0]$.} \\
\hline Z Axis Data & {$[0.0 .1]$.} & {$[1.0 .0].[0.1 .0]$.} \\
\hline \multicolumn{3}{|c|}{ Principal Axis } \\
\hline Axis & & $\mathrm{X}$ \\
\hline Define By & & Fixed Vector \\
\hline \multicolumn{3}{|c|}{ Orientation About Principal Axis } \\
\hline Axis & & $\mathrm{Y}$ \\
\hline Define By & & Fixed Vector \\
\hline \multicolumn{3}{|c|}{ Transformations } \\
\hline Base Configuration & & Absolute \\
\hline Transformed Configuration & & {$[0.0 .0]$.} \\
\hline
\end{tabular}

\section{Symmetry}

file://C:/Users/Edison/AppData/Roaming/Ansys/v160/Mechanical_Report/Mechanical_Re... 8/8/2016 
TABLE 6

Model (A4, B4, C4) > Symmetry

Object Name Symmetry

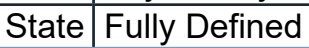

TABLE 7

Model (A4, B4, C4) > Symmetry > Symmetry Region

\begin{tabular}{|c|c|c|}
\hline Object Name & Symmetry Region & Symmetry Region 2 \\
\hline State & \multicolumn{2}{|c|}{ Fully Defined } \\
\hline \multicolumn{3}{|c|}{ Scope } \\
\hline Scoping Method & \multicolumn{2}{|c|}{ Named Selection } \\
\hline Named Selection & Symmetry:YZPlane & Symmetry:ZXPlane \\
\hline \multicolumn{3}{|c|}{ Definition } \\
\hline Scope Mode & \multicolumn{2}{|c|}{ Automatic } \\
\hline Type & \multicolumn{2}{|c|}{ Symmetric } \\
\hline Coordinate System & YZPlane & ZXPlane \\
\hline Symmetry Normal & \multicolumn{2}{|c|}{ Z Axis } \\
\hline Suppressed & \multicolumn{2}{|c|}{ No } \\
\hline
\end{tabular}

\section{Connections}

TABLE 8

Model $($ A4, B4, C4) > Connections

\begin{tabular}{|c|c|}
\hline & \\
\hline Object Name & Connections \\
\hline State & Fully Defined \\
\hline Auto Detection & \\
\hline Generate Automatic Connection On Refresh & Yes \\
\hline Transparency & \\
\hline Enabled & Yes \\
\hline
\end{tabular}

Mesh

TABLE 9

Model (A4, B4, C4) > Mesh

\begin{tabular}{|r|c|}
\hline Object Name & Mesh \\
\hline State & Solved \\
\hline Display & \\
\hline Display Style & Body Color \\
\hline Defaults \\
\hline Physics Preference & Mechanical \\
\hline Relevance & 0 \\
\hline Sizing & \\
\hline Use Advanced Size Function & Off (Part Size Seed) \\
\hline Relevance Center & Coarse \\
\hline Element Size & 0.10 mm \\
\hline Initial Size Seed & Part \\
\hline Smoothing & Medium \\
\hline Transition & Fast \\
\hline Span Angle Center & Coarse \\
\hline Minimum Edge Length & $1.2 \mathrm{e}-002 \mathrm{~mm}$ \\
\hline Inflation & \\
\hline Use Automatic Inflation & None \\
\hline Inflation Option & Smooth Transition \\
\hline Transition Ratio & 0.272 \\
\hline
\end{tabular}

file:///C:/Users/Edison/AppData/Roaming/Ansys/v160/Mechanical_Report/Mechanical_Re... 8/8/2016 


\begin{tabular}{|c|c|}
\hline Maximum Layers & 5 \\
\hline Growth Rate & 1.2 \\
\hline Inflation Algorithm & Pre \\
\hline View Advanced Options & No \\
\hline \multicolumn{2}{|c|}{ Patch Conforming Options } \\
\hline Triangle Surface Mesher & Program Controlled \\
\hline \multicolumn{2}{|c|}{ Patch Independent Options } \\
\hline Topology Checking & No \\
\hline \multicolumn{2}{|l|}{ Advanced } \\
\hline Number of CPUs for Parallel Part Meshing & Program Controlled \\
\hline Shape Checking & Standard Mechanical \\
\hline Element Midside Nodes & Program Controlled \\
\hline Straight Sided Elements & No \\
\hline Number of Retries & Default (4) \\
\hline Extra Retries For Assembly & Yes \\
\hline Rigid Body Behavior & Dimensionally Reduced \\
\hline Mesh Morphing & Disabled \\
\hline \multicolumn{2}{|l|}{ Defeaturing } \\
\hline Pinch Tolerance & Please Define \\
\hline Generate Pinch on Refresh & No \\
\hline Automatic Mesh Based Defeaturing & On \\
\hline Defeaturing Tolerance & Default \\
\hline \multicolumn{2}{|l|}{ Statistics } \\
\hline Nodes & 366244 \\
\hline Elements & 227805 \\
\hline Mesh Metric & None \\
\hline
\end{tabular}

\section{Named Selections}

TABLE 10

Model (A4, B4, C4) > Named Selections $>$ Named Selections

\begin{tabular}{|c|c|c|c|}
\hline Object Name & Open Domain & \begin{tabular}{l|l} 
Symmetry:YZPlane & Symmetry:ZXPlane
\end{tabular} & Problematic Geometry \\
\hline State & & Fully Defined & Suppressed \\
\hline \multicolumn{4}{|c|}{ Scope } \\
\hline Scoping Method & \multicolumn{3}{|c|}{ Geometry Selection } \\
\hline Geometry & & 4 Faces & No Selection \\
\hline \multicolumn{4}{|c|}{ Definition } \\
\hline Send to Solver & Yes & No & Yes \\
\hline Visible & \multicolumn{3}{|c|}{ Yes } \\
\hline Program Controlled Inflation & \multicolumn{3}{|c|}{ Exclude } \\
\hline \multicolumn{4}{|c|}{ Statistics } \\
\hline Type & \multicolumn{2}{|r|}{ Imported } & Manual \\
\hline Total Selection & 4 Faces & 5 Faces & No Selection \\
\hline Suppressed & 0 & 1 & 0 \\
\hline Used by Mesh Worksheet & \multicolumn{3}{|c|}{ No } \\
\hline
\end{tabular}

\section{Harmonic Response (B5)}

TABLE 11

Model (A4, B4, C4) > Analysis

Object Name Harmonic Response (B5)

State Solved

Definition 


\begin{tabular}{|r|c|}
\hline Physics Type & Structural \\
\hline Analysis Type & Harmonic Response \\
\hline Solver Target & Mechanical APDL \\
\hline Options \\
\hline Environment Temperature & $22 .{ }^{\circ} \mathrm{C}$ \\
\hline Generate Input Only & No \\
\hline
\end{tabular}

TABLE 12

Model (A4, B4, C4) > Harmonic Response (B5) > Initial Condition Object Name Pre-Stress/Modal (None)

\begin{tabular}{|r|c|}
\hline Object Name & Pre-Stress/Modal (None) \\
\hline State & Fully Defined \\
\hline \multicolumn{2}{|c|}{ Definition } \\
\hline Pre-Stress Environment & None \\
\hline Modal Environment & None \\
\hline
\end{tabular}

TABLE 13

Model (A4, B4, C4) > Harmonic Response (B5) > Analysis Settings

\begin{tabular}{|c|c|}
\hline Object Name & Analysis Settings \\
\hline State & Fully Defined \\
\hline \multicolumn{2}{|r|}{ Options } \\
\hline $\begin{array}{r}\text { Frequency } \\
\text { Spacing }\end{array}$ & Linear \\
\hline $\begin{array}{r}\text { Range } \\
\text { Minimum }\end{array}$ & $0 . \mathrm{Hz}$ \\
\hline $\begin{array}{r}\text { Range } \\
\text { Maximum }\end{array}$ & $1.5 \mathrm{e}+005 \mathrm{~Hz}$ \\
\hline $\begin{array}{l}\text { Solution } \\
\text { Intervals }\end{array}$ & 300 \\
\hline $\begin{array}{r}\text { Solution } \\
\text { Method }\end{array}$ & Full \\
\hline $\begin{array}{r}\text { Variational } \\
\text { Technology }\end{array}$ & No \\
\hline \multicolumn{2}{|r|}{ Rotordynamics Controls } \\
\hline Coriolis Effect & Off \\
\hline \multicolumn{2}{|r|}{ Output Controls } \\
\hline Stress & Yes \\
\hline Strain & Yes \\
\hline Nodal Forces & No \\
\hline $\begin{array}{r}\text { Calculate } \\
\text { Reactions }\end{array}$ & Yes \\
\hline $\begin{array}{r}\text { General } \\
\text { Miscellaneous }\end{array}$ & Yes \\
\hline \multicolumn{2}{|r|}{ Damping Controls } \\
\hline $\begin{array}{r}\text { Constant } \\
\text { Damping } \\
\text { Ratio } \\
\end{array}$ & 0. \\
\hline $\begin{array}{r}\text { Stiffness } \\
\text { Coefficient } \\
\text { Define By } \\
\end{array}$ & Direct Input \\
\hline $\begin{array}{r}\text { Stiffness } \\
\text { Coefficient }\end{array}$ & 0. \\
\hline $\begin{array}{r}\text { Mass } \\
\text { Coefficient }\end{array}$ & 0. \\
\hline \multicolumn{2}{|r|}{ Analysis Data Management } \\
\hline $\begin{array}{r}\text { Solver Files } \\
\text { Directory }\end{array}$ & $\begin{array}{c}\text { C:IUsers|Edison|Documents|F_FullAcousticAnalysisWithFSIIFullAcousticAnalysisWithFSI_files|dp0 } \\
\text { ISYS-1MMECHI }\end{array}$ \\
\hline
\end{tabular}

file://C:/Users/Edison/AppData/Roaming/Ansys/v160/Mechanical_Report/Mechanical_Re... 8/8/2016 


\begin{tabular}{|r|c|}
$\begin{array}{r}\text { Future } \\
\text { Analysis }\end{array}$ & None \\
\hline $\begin{array}{r}\text { Scratch } \\
\text { Solver Files } \\
\text { Directory }\end{array}$ & \\
\hline $\begin{array}{r}\text { Save MAPDL } \\
\mathrm{db}\end{array}$ & Yes \\
\hline Delete & Yes \\
$\begin{array}{r}\text { Unneeded } \\
\text { Files }\end{array}$ & Active System \\
\hline Solver Units & nmm \\
\hline Solver Unit & \\
System &
\end{tabular}

TABLE 14

\begin{tabular}{|r|c|c|}
\hline Model (A4, B4, C4) $>$ Harmonic Response (B5) $>$ Loads \\
\hline Object Name & Force & Fixed Support \\
\hline State & \multicolumn{2}{|c|}{ Fully Defined } \\
\hline \multicolumn{3}{|c|}{ Scope } \\
\hline Scoping Method & Geometry Selection \\
\hline Geometry & 1 Vertex & 1 Face \\
\hline \multicolumn{3}{|c|}{ Definition } \\
\hline Type & Force & Fixed Support \\
\hline Define By & Components & \\
\hline Coordinate System & Global Coordinate System & \\
\hline X Component & $0 . \mathrm{N}$ & \\
\hline Y Component & $0 . \mathrm{N}$ & \\
\hline Z Component & $3.88 \mathrm{e}-006 \mathrm{~N}$ & \\
\hline X Phase Angle & $0 .^{\circ}$ & \\
\hline Y Phase Angle & $0 .^{\circ}$ & \\
\hline Z Phase Angle & $0 .^{\circ}$ & \\
\hline Suppressed & \multicolumn{2}{|}{ No } \\
\hline
\end{tabular}

TABLE 15

Model (A4, B4, C4) > Harmonic Response (B5) > Loads

\begin{tabular}{|c|c|c|c|}
\hline Object Name & Acoustic Body & Acoustic Body 2 & Acoustic Pressure \\
\hline State & \multicolumn{3}{|c|}{ Fully Defined } \\
\hline \multicolumn{4}{|c|}{ Scope } \\
\hline Scoping Method & \multicolumn{3}{|c|}{ Geometry Selection } \\
\hline Geometry & 2 Bodies & 1 Body & 4 Faces \\
\hline \multicolumn{4}{|c|}{ Definition } \\
\hline Frequency Dependency & \multicolumn{2}{|c|}{ No } & \\
\hline Mass Density & \multicolumn{2}{|c|}{ 1.2041E-09 [kg mm^-1 mm^-1 mm^-1] } & \\
\hline Sound Speed & \multicolumn{2}{|c|}{$343240\left[\mathrm{~mm} \mathrm{sec}^{\wedge}-1\right]$} & \\
\hline Dynamic Viscosity & \multicolumn{2}{|c|}{0 [MPa sec] } & \\
\hline Bulk Viscosity & \multicolumn{2}{|c|}{0 [MPa sec] } & \\
\hline Thermal Conductivity & \multicolumn{2}{|c|}{$0\left[\mathrm{~W} m m^{\wedge}-1 \mathrm{C}^{\wedge}-1\right]$} & \\
\hline Specific Heat $\mathrm{Cp}$ & \multicolumn{2}{|c|}{$0\left[\mathrm{~J} \mathrm{~kg}{ }^{\wedge}-1 \mathrm{C}^{\wedge}-1\right]$} & \\
\hline Specific Heat Cv & \multicolumn{2}{|c|}{$0\left[\mathrm{~J} \mathrm{~kg}^{\wedge}-1 \mathrm{C}^{\wedge}-1\right]$} & \\
\hline Equivalent Fluid of Perforated Material & \multicolumn{2}{|c|}{ No } & \\
\hline Low Reduced Frequency Model & \multicolumn{2}{|c|}{ No } & \\
\hline Reference Pressure & \multicolumn{2}{|c|}{$2 \mathrm{E}-11[\mathrm{MPa}]$} & \\
\hline Reference Static Pressure & \multicolumn{2}{|c|}{$0.101325[\mathrm{MPa}]$} & \\
\hline Acoustic-Structural Coupled Body Options & \multicolumn{2}{|c|}{ Program Controlled Coupled } & \\
\hline Perfectly Matched Layers (PML) & Off & On & \\
\hline
\end{tabular}




\begin{tabular}{|r|c|c|} 
PML Options & Off & \\
\hline Element Coordinate System Number & 0 & \\
\hline Pressure (Real) & & $0[\mathrm{MPa}]$ \\
\hline Pressure (Im) & & $0[\mathrm{MPa}]$ \\
\hline
\end{tabular}

\section{Solution (B6)}

TABLE 16

Model (A4, B4, C4) > Harmonic Response (B5) > Solution

\begin{tabular}{|r|c|}
\hline Object Name & Solution (B6) \\
\hline State & Solved \\
\hline \multicolumn{2}{|c|}{ Adaptive Mesh Refinement } \\
\hline Max Refinement Loops & 1. \\
\hline Refinement Depth & 2. \\
\hline \multicolumn{2}{|c|}{ Information } \\
\hline Status & Done \\
\hline Post Processing \\
\hline Calculate Beam Section Results & No \\
\hline
\end{tabular}

FIGURE 1

Model (A4, B4, C4) > Harmonic Response (B5) > Solution (B6)

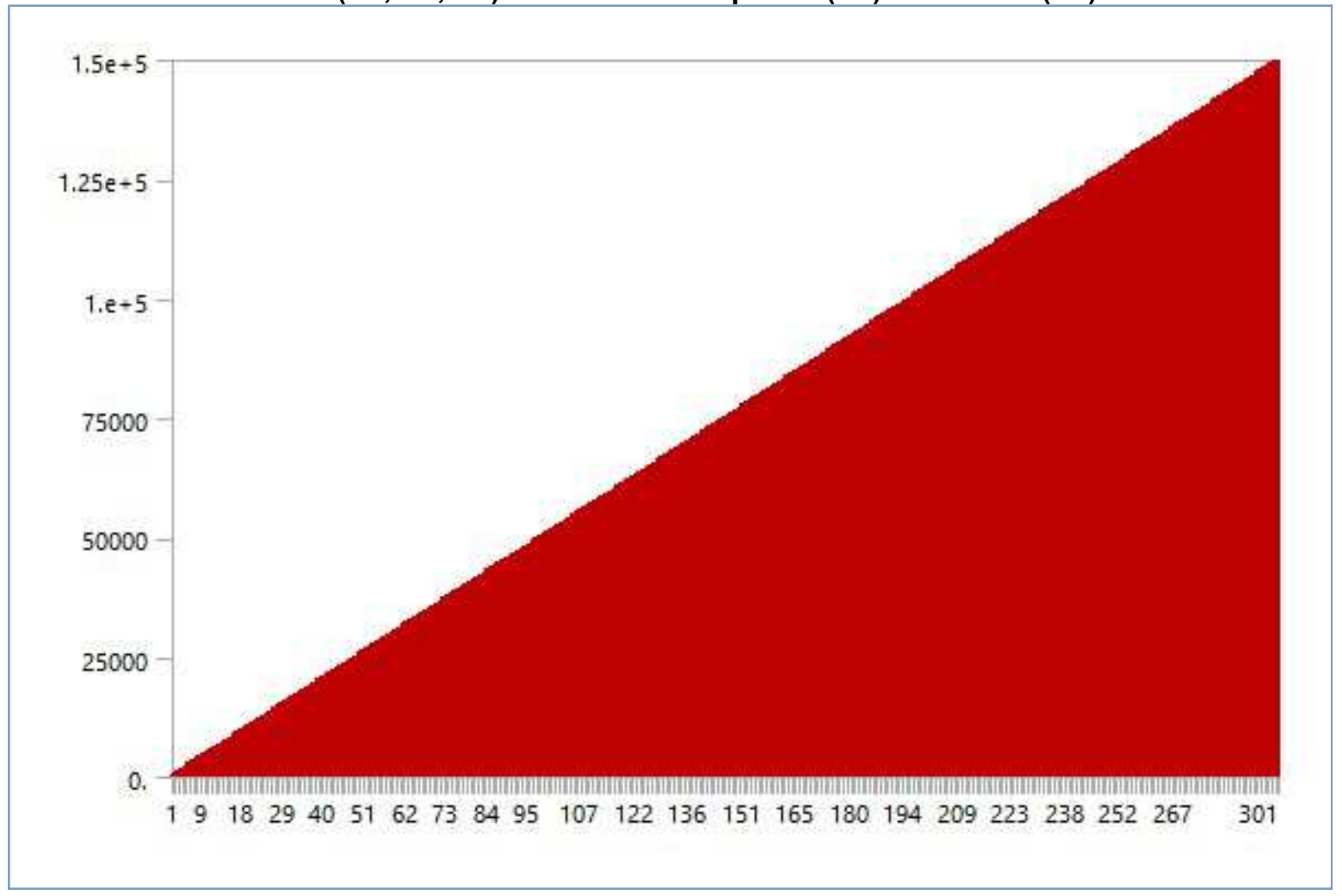

TABLE 17

Model (A4, B4, C4) > Harmonic Response (B5) > Solution (B6) > Solution Information

\begin{tabular}{|r|c|}
\hline Object Name & Solution Information \\
\hline State & Solved \\
\hline Solution Information \\
\hline Solution Output & Solver Output \\
\hline Newton-Raphson Residuals & 0 \\
\hline Update Interval & $2.5 \mathrm{~s}$ \\
\hline &
\end{tabular}

file://C:/Users/Edison/AppData/Roaming/Ansys/v160/Mechanical_Report/Mechanical_Re... 8/8/2016 


\begin{tabular}{|r|c|}
\hline Display Points & All \\
\hline FE Connection Visibility \\
\hline Activate Visibility & Yes \\
\hline Display & All FE Connectors \\
\hline Draw Connections Attached To & All Nodes \\
\hline Line Color & Connection Type \\
\hline Visible on Results & No \\
\hline Line Thickness & Single \\
\hline Display Type & Lines \\
\hline
\end{tabular}

TABLE 18

Model (A4, B4, C4) > Harmonic Response (B5) > Solution (B6) > Result Charts Object Name Frequency Response

\begin{tabular}{r|c|}
\hline Object Name & Frequency Response \\
\hline State & Solved \\
\hline Scope \\
\hline Scoping Method & Geometry Selection \\
\hline Geometry & 1 Body \\
\hline Spatial Resolution & Use Average \\
\hline Definition \\
\hline Type & Directional Deformation \\
\hline Orientation & Z Axis \\
\hline Suppressed & No \\
\hline Options \\
\hline Frequency Range & Use Parent \\
\hline Minimum Frequency & $0 . \mathrm{Hz}$ \\
\hline Maximum Frequency & $1.5 \mathrm{e}+005 \mathrm{~Hz}$ \\
\hline Display & Bode \\
\hline Chart Viewing Style & Log Y \\
\hline Results \\
\hline Maximum Amplitude & $1.5212 \mathrm{e}-004 \mathrm{~mm}$ \\
\hline Frequency & $8500 . \mathrm{Hz}$ \\
\hline Phase Angle & $-28.527^{\circ}$ \\
\hline Real & $1.3365 \mathrm{e}-004 \mathrm{~mm}$ \\
\hline Imaginary & $-7.265 \mathrm{e}-005 \mathrm{~mm}$ \\
\hline
\end{tabular}

FIGURE 2

Model (A4, B4, C4) > Harmonic Response (B5) > Solution (B6) > Frequency Response 


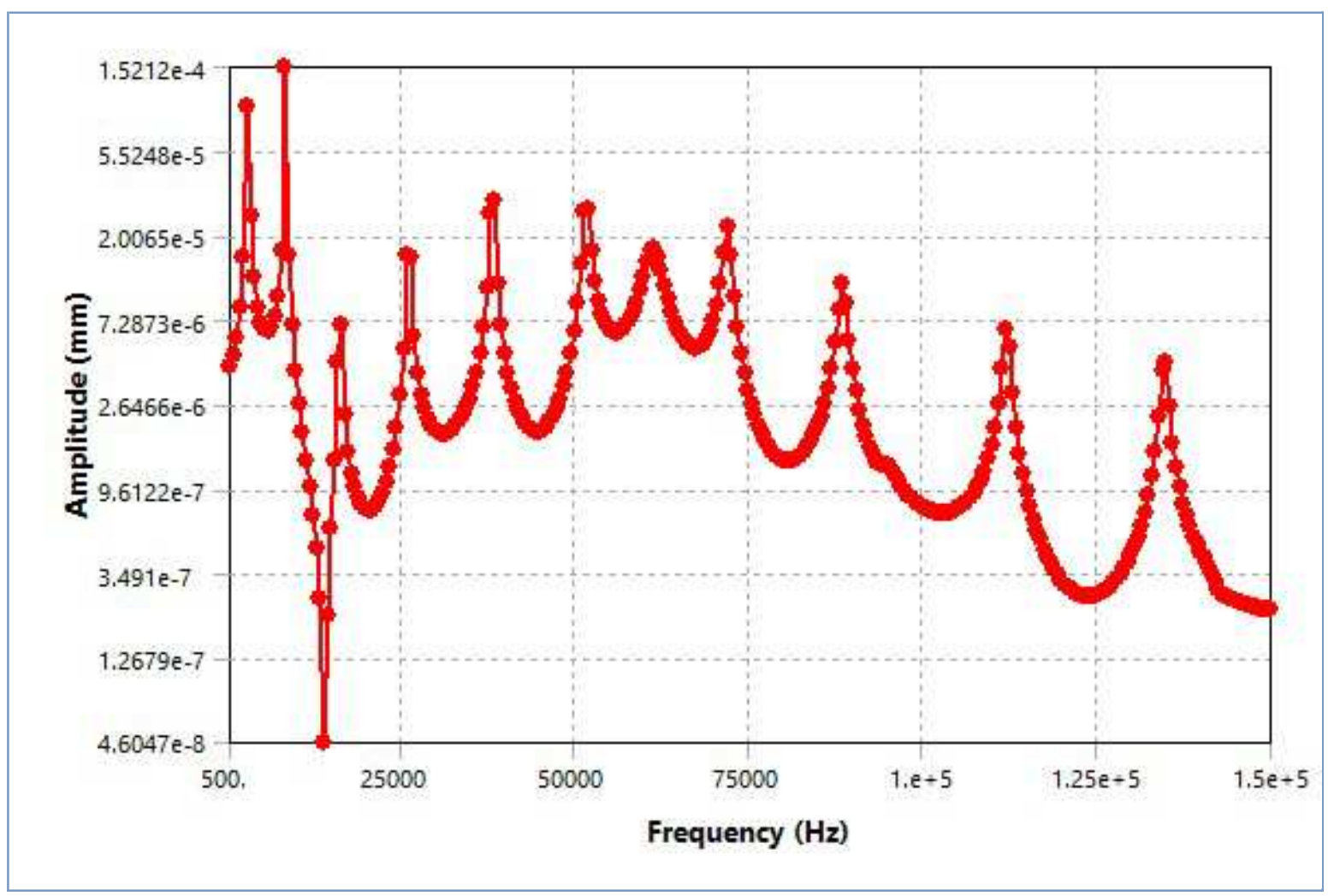

TABLE 19

Model (A4, B4, C4) > Harmonic Response (B5) > Solution (B6) > Acoustic Pressure

\begin{tabular}{|c|c|}
\hline & \\
\hline Object Name & Acoustic Pressure \\
\hline State & Solved \\
\hline & Scope \\
\hline Scoping Method & Geometry Selection \\
\hline Geometry & 3 Bodies \\
\hline & Definition \\
\hline Type & User Defined Result \\
\hline Expression & $=$ PRES \\
\hline Input Unit System & Metric $(\mathrm{mm}, \mathrm{kg}, \mathrm{N}, \mathrm{s}, \mathrm{mV}, \mathrm{mA})$ \\
\hline Output Unit & Pressure \\
\hline By & Frequency \\
\hline Frequency & Last \\
\hline Sweeping Phase & $0 .^{\circ}$ \\
\hline Coordinate System & Global Coordinate System \\
\hline Identifier & \\
\hline Suppressed & No \\
\hline & Results \\
\hline Minimum & $-1.0995 \mathrm{e}-005 \mathrm{MPa}$ \\
\hline Maximum & $2.2149 \mathrm{e}-005 \mathrm{MPa}$ \\
\hline Minimum Occurs On & Solid \\
\hline Maximum Occurs On & Solid \\
\hline & formation \\
\hline Reported Frequency & $1.5 e+005 \mathrm{~Hz}$ \\
\hline
\end{tabular}

FIGURE 3

Model (A4, B4, C4) > Harmonic Response (B5) > Solution (B6) > Acoustic Pressure 


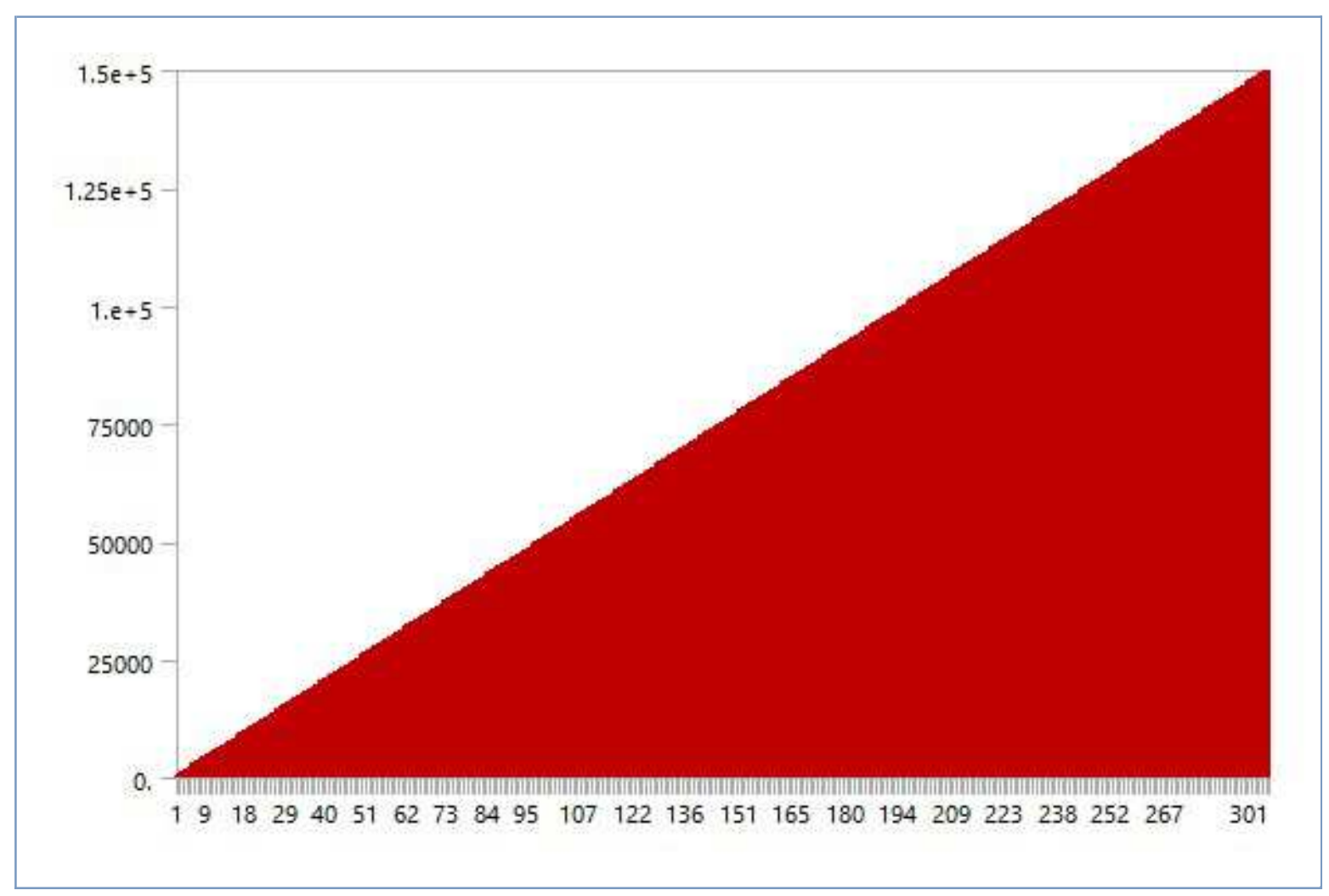

TABLE 20

Model (A4, B4, C4) > Harmonic Response (B5) > Solution (B6) > Acoustic Pressure

\begin{tabular}{|c|c|}
\hline Set & Frequency [Hz] \\
\hline 1. & 500. \\
\hline 2. & 1000. \\
\hline 3. & 1500. \\
\hline 4. & 2000. \\
\hline 5. & 2500. \\
\hline 6. & 3000 . \\
\hline 7. & 3500. \\
\hline 8. & 4000. \\
\hline 9. & 4500. \\
\hline 10. & 5000. \\
\hline 11. & 5500. \\
\hline 12. & 6000. \\
\hline 13. & 6500. \\
\hline 14. & 7000. \\
\hline 15. & 7500. \\
\hline 16. & 8000. \\
\hline 17. & 8500. \\
\hline 18. & 9000. \\
\hline 19. & 9500. \\
\hline 20. & 10000 \\
\hline 21. & 10500 \\
\hline 22. & 11000 \\
\hline 23. & 11500 \\
\hline 24. & 12000 \\
\hline 25. & 12500 \\
\hline 26. & 13000 \\
\hline
\end{tabular}




\begin{tabular}{|l|l|}
\hline 27. & 13500 \\
\hline 28. & 14000 \\
\hline 29. & 14500 \\
\hline 30. & 15000 \\
\hline 31. & 15500 \\
\hline 32. & 16000 \\
\hline 33. & 16500 \\
\hline 34. & 17000 \\
\hline 35. & 17500 \\
\hline 36. & 18000 \\
\hline 37. & 18500 \\
\hline 38. & 19000 \\
\hline 39. & 19500 \\
\hline 40. & 20000 \\
\hline 41. & 20500 \\
\hline 42. & 21000 \\
\hline 43. & 21500 \\
\hline 44. & 22000 \\
\hline 45. & 22500 \\
\hline 46. & 23000 \\
\hline 47. & 23500 \\
\hline 48. & 24000 \\
\hline 49. & 24500 \\
\hline 50. & 25000 \\
\hline 51. & 25500 \\
\hline 52. & 26000 \\
\hline 53. & 26500 \\
\hline 54. & 27000 \\
\hline 55. & 27500 \\
\hline 56. & 28000 \\
\hline 57. & 28500 \\
\hline 58. & 29000 \\
\hline 59. & 29500 \\
\hline 60. & 30000 \\
\hline 61. & 30500 \\
\hline 62. & 31000 \\
\hline 63. & 31500 \\
\hline 64. & 32000 \\
\hline 65. & 32500 \\
\hline 66. & 33000 \\
\hline 67. & 33500 \\
\hline 68. & 34000 \\
\hline 69. & 34500 \\
\hline 70. & 35000 \\
\hline 71. & 35500 \\
\hline 72. & 36000 \\
\hline 73. & 36500 \\
\hline 74. & 37000 \\
\hline 75. & 37500 \\
\hline 76. & 38000 \\
\hline 77. & 38500 \\
\hline 78. & 39000 \\
\hline 79. & 39500 \\
\hline on & \\
\hline 3. \\
\hline 3.
\end{tabular}

file:///C:/Users/Edison/AppData/Roaming/Ansys/v160/Mechanical_Report/Mechanical_Re... 8/8/2016 


\begin{tabular}{|c|c|}
\hline & 40000 \\
\hline 81. & 40500 \\
\hline 82. & 41000 \\
\hline 83. & 41500 \\
\hline 84. & 42000 \\
\hline 85. & 42500 \\
\hline 86. & 43000 \\
\hline 87. & 43500 \\
\hline 88. & 44000 \\
\hline 89. & 44500 \\
\hline 90. & 45000 \\
\hline 91. & 45500 \\
\hline 92. & 46000 \\
\hline 93. & 46500 \\
\hline 94. & 47000 \\
\hline 95. & 47500 \\
\hline 96. & 48000 \\
\hline 97. & 48500 \\
\hline 98. & 49000 \\
\hline 99. & 49500 \\
\hline 100. & 50000 \\
\hline 101. & 50500 \\
\hline 102. & 51000 \\
\hline 103. & 51500 \\
\hline 104. & 52000 \\
\hline 105. & 52500 \\
\hline 106. & 53000 \\
\hline 107. & 53500 \\
\hline 108. & 54000 \\
\hline 109. & 54500 \\
\hline 110. & 55000 \\
\hline 111. & 55500 \\
\hline 112. & 56000 \\
\hline 113. & 56500 \\
\hline 114. & 57000 \\
\hline 115. & 57500 \\
\hline 116. & 58000 \\
\hline 117. & 58500 \\
\hline 118. & 59000 \\
\hline 119. & 59500 \\
\hline 120. & 60000 \\
\hline 121. & 60500 \\
\hline 122. & 61000 \\
\hline 123. & 61500 \\
\hline 124. & 62000 \\
\hline 125. & 62500 \\
\hline 126. & 63000 \\
\hline 127. & 63500 \\
\hline 128. & 64000 \\
\hline 129. & 64500 \\
\hline 130. & 65000 \\
\hline 131. & 65500 \\
\hline 132. & 66000 \\
\hline
\end{tabular}

file:///C:/Users/Edison/AppData/Roaming/Ansys/v160/Mechanical_Report/Mechanical_Re... 8/8/2016 


\begin{tabular}{|c|c|}
\hline & 66500 \\
\hline 134. & 67000 \\
\hline 135. & 67500 \\
\hline 136. & 68000 \\
\hline 137. & 68500 \\
\hline 138. & 69000 \\
\hline 139. & 69500 \\
\hline 140. & 70000 \\
\hline 141. & 70500 \\
\hline 142. & 71000 \\
\hline 143. & 71500 \\
\hline 144. & 72000 \\
\hline 145. & 72500 \\
\hline 146. & 73000 \\
\hline 147. & 73500 \\
\hline 148. & 74000 \\
\hline 149. & 74500 \\
\hline 150. & 75000 \\
\hline 151. & 75500 \\
\hline 152. & 76000 \\
\hline 153. & 76500 \\
\hline 154. & 77000 \\
\hline 155. & 77500 \\
\hline 156. & 78000 \\
\hline 157. & 78500 \\
\hline 158. & 79000 \\
\hline 159. & 79500 \\
\hline 160. & 80000 \\
\hline 161. & 80500 \\
\hline 162. & 81000 \\
\hline 163. & 81500 \\
\hline 164. & 82000 \\
\hline 165. & 82500 \\
\hline 166. & 83000 \\
\hline 167. & 83500 \\
\hline 168. & 84000 \\
\hline 169. & 84500 \\
\hline 170. & 85000 \\
\hline 171. & 85500 \\
\hline 172. & 86000 \\
\hline 173. & 86500 \\
\hline 174. & 87000 \\
\hline 175. & 87500 \\
\hline 176. & 88000 \\
\hline 177. & 88500 \\
\hline 178. & 89000 \\
\hline 179. & 89500 \\
\hline 180. & 90000 \\
\hline 181. & 90500 \\
\hline 182. & 91000 \\
\hline 183. & 91500 \\
\hline 184. & 92000 \\
\hline 185. & 92500 \\
\hline
\end{tabular}

file:///C:/Users/Edison/AppData/Roaming/Ansys/v160/Mechanical_Report/Mechanical_Re... 8/8/2016 


\begin{tabular}{|c|c|} 
& 93000 \\
\hline 187. & 93500 \\
\hline 188. & 94000 \\
\hline 189. & 94500 \\
\hline 190. & 95000 \\
\hline 191. & 95500 \\
\hline 192. & 96000 \\
\hline 193. & 96500 \\
\hline 194. & 97000 \\
\hline 195. & 97500 \\
\hline 196. & 98000 \\
\hline 197. & 98500 \\
\hline 198. & 99000 \\
\hline 199. & 99500 \\
\hline 200. & $1 . e+005$ \\
\hline 201. & $1.005 \mathrm{e}+005$ \\
\hline 202. & $1.01 \mathrm{e}+005$ \\
\hline 203. & $1.015 \mathrm{e}+005$ \\
\hline 204. & $1.02 \mathrm{e}+005$ \\
\hline 205. & $1.025 \mathrm{e}+005$ \\
\hline 206. & $1.03 \mathrm{e}+005$ \\
\hline 207. & $1.035 \mathrm{e}+005$ \\
\hline 208. & $1.04 \mathrm{e}+005$ \\
\hline 209. & $1.045 \mathrm{e}+005$ \\
\hline 210. & $1.05 \mathrm{e}+005$ \\
\hline 211. & $1.055 \mathrm{e}+005$ \\
\hline 212. & $1.06 \mathrm{e}+005$ \\
\hline 213. & $1.065 \mathrm{e}+005$ \\
\hline 214. & $1.07 \mathrm{e}+005$ \\
\hline 215. & $1.075 \mathrm{e}+005$ \\
\hline 216. & $1.08 \mathrm{e}+005$ \\
\hline 217. & $1.085 \mathrm{e}+005$ \\
\hline 218. & $1.09 \mathrm{e}+005$ \\
\hline 219. & $1.095 \mathrm{e}+005$ \\
\hline 220. & $1.1 \mathrm{e}+005$ \\
\hline 221. & $1.105 \mathrm{e}+005$ \\
\hline 222. & $1.11 \mathrm{e}+005$ \\
\hline 223. & $1.115 \mathrm{e}+005$ \\
\hline 224. & $1.12 \mathrm{e}+005$ \\
\hline 225. & $1.125 \mathrm{e}+005$ \\
\hline 226. & $1.13 \mathrm{e}+005$ \\
\hline 227. & $1.135 \mathrm{e}+005$ \\
\hline 228. & $1.14 \mathrm{e}+005$ \\
\hline 229. & $1.145 \mathrm{e}+005$ \\
\hline 230. & $1.15 \mathrm{e}+005$ \\
\hline 231. & $1.155 \mathrm{e}+005$ \\
\hline 232. & $1.16 \mathrm{e}+005$ \\
\hline 233. & $1.165 \mathrm{e}+005$ \\
\hline 234. & $1.17 \mathrm{e}+005$ \\
\hline 235. & $1.175 \mathrm{e}+005$ \\
\hline 236. & $1.18 \mathrm{e}+005$ \\
\hline 237. & $1.185 \mathrm{e}+005$ \\
\hline 238. & $1.19 \mathrm{e}+005$ \\
\hline 220 & \\
\hline & \\
\hline 190
\end{tabular}

file:///C:/Users/Edison/AppData/Roaming/Ansys/v160/Mechanical_Report/Mechanical_Re... 8/8/2016 


\begin{tabular}{|c|c|} 
& $1.195 \mathrm{e}+005$ \\
\hline 240. & $1.2 \mathrm{e}+005$ \\
\hline 241. & $1.205 \mathrm{e}+005$ \\
\hline 242. & $1.21 \mathrm{e}+005$ \\
\hline 243. & $1.215 \mathrm{e}+005$ \\
\hline 244. & $1.22 \mathrm{e}+005$ \\
\hline 245. & $1.225 \mathrm{e}+005$ \\
\hline 246. & $1.23 \mathrm{e}+005$ \\
\hline 247. & $1.235 \mathrm{e}+005$ \\
\hline 248. & $1.24 \mathrm{e}+005$ \\
\hline 249. & $1.245 \mathrm{e}+005$ \\
\hline 250. & $1.25 \mathrm{e}+005$ \\
\hline 251. & $1.255 \mathrm{e}+005$ \\
\hline 252. & $1.26 \mathrm{e}+005$ \\
\hline 253. & $1.265 \mathrm{e}+005$ \\
\hline 254. & $1.27 \mathrm{e}+005$ \\
\hline 255. & $1.275 \mathrm{e}+005$ \\
\hline 256. & $1.28 \mathrm{e}+005$ \\
\hline 257. & $1.285 \mathrm{e}+005$ \\
\hline 258. & $1.29 \mathrm{e}+005$ \\
\hline 259. & $1.295 \mathrm{e}+005$ \\
\hline 260. & $1.3 \mathrm{e}+005$ \\
\hline 261. & $1.305 \mathrm{e}+005$ \\
\hline 262. & $1.31 \mathrm{e}+005$ \\
\hline 263. & $1.315 \mathrm{e}+005$ \\
\hline 264. & $1.32 \mathrm{e}+005$ \\
\hline 265. & $1.325 \mathrm{e}+005$ \\
\hline 266. & $1.33 \mathrm{e}+005$ \\
\hline 267. & $1.335 \mathrm{e}+005$ \\
\hline 268. & $1.34 \mathrm{e}+005$ \\
\hline 269. & $1.345 \mathrm{e}+005$ \\
\hline 270. & $1.35 \mathrm{e}+005$ \\
\hline 271. & $1.355 \mathrm{e}+005$ \\
\hline 272. & $1.36 \mathrm{e}+005$ \\
\hline 273. & $1.365 \mathrm{e}+005$ \\
\hline 274. & $1.37 \mathrm{e}+005$ \\
\hline 275. & $1.375 \mathrm{e}+005$ \\
\hline 276. & $1.38 \mathrm{e}+005$ \\
\hline 277. & $1.385 \mathrm{e}+005$ \\
\hline 278. & $1.39 \mathrm{e}+005$ \\
\hline 279. & $1.395 \mathrm{e}+005$ \\
\hline 280. & $1.4 \mathrm{e}+005$ \\
\hline 281. & $1.405 \mathrm{e}+005$ \\
\hline 282. & $1.41 \mathrm{e}+005$ \\
\hline 283. & $1.415 \mathrm{e}+005$ \\
\hline 284. & $1.42 \mathrm{e}+005$ \\
\hline 285. & $1.425 \mathrm{e}+005$ \\
\hline 286. & $1.43 \mathrm{e}+005$ \\
\hline 287. & $1.435 \mathrm{e}+005$ \\
\hline 288. & $1.44 \mathrm{e}+005$ \\
\hline 289. & $1.445 \mathrm{e}+005$ \\
\hline 290. & $1.45 \mathrm{e}+005$ \\
\hline 291. & $1.455 \mathrm{e}+005$ \\
\hline $2 n ?$ & \\
\hline
\end{tabular}

file:///C:/Users/Edison/AppData/Roaming/Ansys/v160/Mechanical_Report/Mechanical_Re... 8/8/2016 


\begin{tabular}{|c|c|} 
& $1.46 \mathrm{e}+005$ \\
\hline 293. & $1.465 \mathrm{e}+005$ \\
\hline 294. & $1.47 \mathrm{e}+005$ \\
\hline 295. & $1.475 \mathrm{e}+005$ \\
\hline 296. & $1.48 \mathrm{e}+005$ \\
\hline 297. & $1.485 \mathrm{e}+005$ \\
\hline 298. & $1.49 \mathrm{e}+005$ \\
\hline 299. & $1.495 \mathrm{e}+005$ \\
\hline 300. & $1.5 \mathrm{e}+005$ \\
\hline
\end{tabular}

TABLE 21

Model (A4, B4, C4) > Harmonic Response (B5) > Solution (B6) $>$ Loads

\begin{tabular}{|c|c|}
\hline Object Name & Acoustic Far Field \\
\hline State & Solved \\
\hline \multicolumn{2}{|l|}{ Properties } \\
\hline Define By & Result Set \\
\hline Result Set & 4 \\
\hline Boundary Condition On Model Symmetric Plane & No \\
\hline Result & SPL In Cartesian Plot \\
\hline Starting Angle Phi (From X Axis Toward Y Axis) & $0\left[^{\circ}\right]$ \\
\hline Ending Angle Phi & $0\left[^{\circ}\right]$ \\
\hline Number Of Divisions Phi & 0 \\
\hline Starting Angle Theta (From Z Axis Toward X Axis) & $0\left[^{\circ}\right]$ \\
\hline Ending Angle Theta & $90\left[{ }^{\circ}\right]$ \\
\hline Number Of Divisions Theta & 180 \\
\hline Sphere Radius & $3[\mathrm{~mm}]$ \\
\hline Y Axis Rotated & No \\
\hline Model Thickness in Z Direction (2D extension) & $0[\mathrm{~mm}]$ \\
\hline Spatial Radiation Angle & Full Space \\
\hline \multicolumn{2}{|l|}{ Results } \\
\hline Maximum Sound Pressure Level & $0[\mathrm{~dB}]$ \\
\hline Maximum A-weighted Sound Pressure Level & $0[\mathrm{~dB}]$ \\
\hline Maximum Pressure Amplitude & 0 [MPa] \\
\hline Maximum Pressure Phase & $0\left[^{\circ}\right]$ \\
\hline Maximum Directivity & 0 \\
\hline Maximum Scattered Pressure Amplitude & $0[\mathrm{MPa}]$ \\
\hline Maximum Target Strength & $0[\mathrm{~dB}]$ \\
\hline Maximum Sound Power Level & $0[\mathrm{~dB}]$ \\
\hline
\end{tabular}

\section{Modal (C5)}

TABLE 22

Model (A4, B4, C4) > Analysis

\begin{tabular}{|r|c|}
\hline Object Name & Modal (C5) \\
\hline State & Solved \\
\hline \multicolumn{2}{|c|}{ Definition } \\
\hline Physics Type & Structural \\
\hline Analysis Type & Modal \\
\hline Solver Target & Mechanical APDL \\
\hline \multicolumn{2}{|c|}{ Options } \\
\hline Environment Temperature & $22 .{ }^{\circ} \mathrm{C}$ \\
\hline Generate Input Only & No \\
\hline
\end{tabular}

file:///C:/Users/Edison/AppData/Roaming/Ansys/v160/Mechanical_Report/Mechanical_Re... 8/8/2016 
TABLE 23

Model (A4, B4, C4) > Modal (C5) > Initial Condition

\begin{tabular}{|r|c|}
\hline Object Name & Pre-Stress (None) \\
\hline State & Fully Defined \\
\hline Definition \\
\hline Pre-Stress Environment & None \\
\hline
\end{tabular}

TABLE 24

Model $($ A4, B4, C4) $>$ Modal (C5) $>$ Analysis Settings

\begin{tabular}{|c|c|}
\hline Object Name & Analysis Settings \\
\hline State & Fully Defined \\
\hline \multicolumn{2}{|r|}{ Options } \\
\hline \begin{tabular}{r|} 
Max Modes to \\
Find
\end{tabular} & 5000 \\
\hline $\begin{array}{r}\text { Limit Search } \\
\text { to Range } \\
\end{array}$ & Yes \\
\hline $\begin{array}{r}\text { Range } \\
\text { Minimum }\end{array}$ & 1. $\mathrm{Hz}$ \\
\hline $\begin{array}{r}\text { Range } \\
\text { Maximum }\end{array}$ & $1.5 \mathrm{e}+005 \mathrm{~Hz}$ \\
\hline \multicolumn{2}{|r|}{ Solver Controls } \\
\hline Damped & No \\
\hline Solver Type & Unsymmetric \\
\hline \multicolumn{2}{|r|}{ Rotordynamics Controls } \\
\hline Coriolis Effect & Off \\
\hline $\begin{array}{r}\text { Campbell } \\
\text { Diagram }\end{array}$ & Off \\
\hline \multicolumn{2}{|r|}{ Output Controls } \\
\hline Stress & Yes \\
\hline Strain & Yes \\
\hline Nodal Forces & No \\
\hline \begin{tabular}{r|} 
Calculate \\
Reactions
\end{tabular} & Yes \\
\hline $\begin{array}{r}\text { Store Modal } \\
\text { Results }\end{array}$ & For Future Analysis \\
\hline \begin{tabular}{r|} 
General \\
Miscellaneous
\end{tabular} & Yes \\
\hline \multicolumn{2}{|r|}{ Analysis Data Management } \\
\hline $\begin{array}{r}\text { Solver Files } \\
\text { Directory }\end{array}$ & $\begin{array}{c}\text { C:IUsers } \backslash \text { Edison } \backslash \text { DocumentsIF_FullAcousticAnalysisWithFSIIFullAcousticAnalysisWithFSI_filesIdp0 } \\
\text { ISYS-2IMECHI }\end{array}$ \\
\hline $\begin{array}{r}\text { Future } \\
\text { Analysis }\end{array}$ & MSUP Analyses \\
\hline $\begin{array}{r}\text { Scratch } \\
\text { Solver Files } \\
\text { Directory }\end{array}$ & \\
\hline $\begin{array}{r}\text { Save MAPDL } \\
\mathrm{db}\end{array}$ & Yes \\
\hline $\begin{array}{r}\text { Delete } \\
\text { Unneeded } \\
\text { Files }\end{array}$ & Yes \\
\hline Solver Units & Active System \\
\hline $\begin{array}{r}\text { Solver Unit } \\
\text { System }\end{array}$ & $\mathrm{nmm}$ \\
\hline
\end{tabular}

TABLE 25

Model (A4, B4, C4) $>$ Modal (C5) $>$ Loads

file:///C:/Users/Edison/AppData/Roaming/Ansys/v160/Mechanical_Report/Mechanical_Re... 8/8/2016 


\begin{tabular}{|r|c|} 
Object Name & Fixed Support \\
\hline State & Fully Defined \\
\hline \multicolumn{2}{|c|}{ Scope } \\
\hline Scoping Method & Geometry Selection \\
\hline Geometry & 1 Face \\
\hline Definition \\
\hline Type & Fixed Support \\
\hline Suppressed & No \\
\hline
\end{tabular}

TABLE 26

Model (A4, B4, C4) > Modal (C5) > Loads

\begin{tabular}{|c|c|c|}
\hline Object Name & Acoustic Body & Acoustic FSI Interface \\
\hline State & \multicolumn{2}{|l|}{ Fully Defined } \\
\hline \multicolumn{3}{|c|}{ Scope } \\
\hline Scoping Method & \multicolumn{2}{|c|}{ Geometry Selection } \\
\hline Geometry & 3 Bodies & 2 Faces \\
\hline \multicolumn{3}{|c|}{ Definition } \\
\hline Frequency Dependency & No & \\
\hline Mass Density & 1.2041E-09 [kg mm^-1 mm^-1 mm^-1] & \\
\hline Sound Speed & $343240\left[\mathrm{~mm} \mathrm{sec}^{\wedge}-1\right]$ & \\
\hline Dynamic Viscosity & 0 [MPa sec] & \\
\hline Bulk Viscosity & 0 [MPa sec] & \\
\hline Thermal Conductivity & $0\left[\mathrm{~W} \mathrm{~mm} \mathrm{~m}^{\wedge}-1 \mathrm{C}^{\wedge}-1\right]$ & \\
\hline Specific Heat Cp & $0\left[\mathrm{~J} \mathrm{~kg}^{\wedge}-1 \mathrm{C}^{\wedge}-1\right]$ & \\
\hline Specific Heat Cv & $0\left[\mathrm{~J} \mathrm{~kg}^{\wedge}-1 \mathrm{C}^{\wedge}-1\right]$ & \\
\hline Reference Pressure & $2 \mathrm{E}-11[\mathrm{MPa}]$ & \\
\hline Reference Static Pressure & $0.101325[\mathrm{MPa}]$ & \\
\hline Acoustic-Structural Coupled Body Options & Program Controlled Coupled & \\
\hline
\end{tabular}

\section{Solution (C6)}

TABLE 27

Model (A4, B4, C4) > Modal (C5) > Solution

\begin{tabular}{|c|c|}
\hline Object Name & Solution (C6) \\
\hline State & Solved \\
\hline \multicolumn{2}{|c|}{ Adaptive Mesh Refinement } \\
\hline Max Refinement Loops & 1. \\
\hline Refinement Depth & 2. \\
\hline \multicolumn{2}{|l|}{ Information } \\
\hline Status & Done \\
\hline \multicolumn{2}{|l|}{ Post Processing } \\
\hline Calculate Beam Section Results & No \\
\hline
\end{tabular}

The following bar chart indicates the frequency at each calculated mode.

FIGURE 4

Model (A4, B4, C4) > Modal (C5) > Solution (C6) 


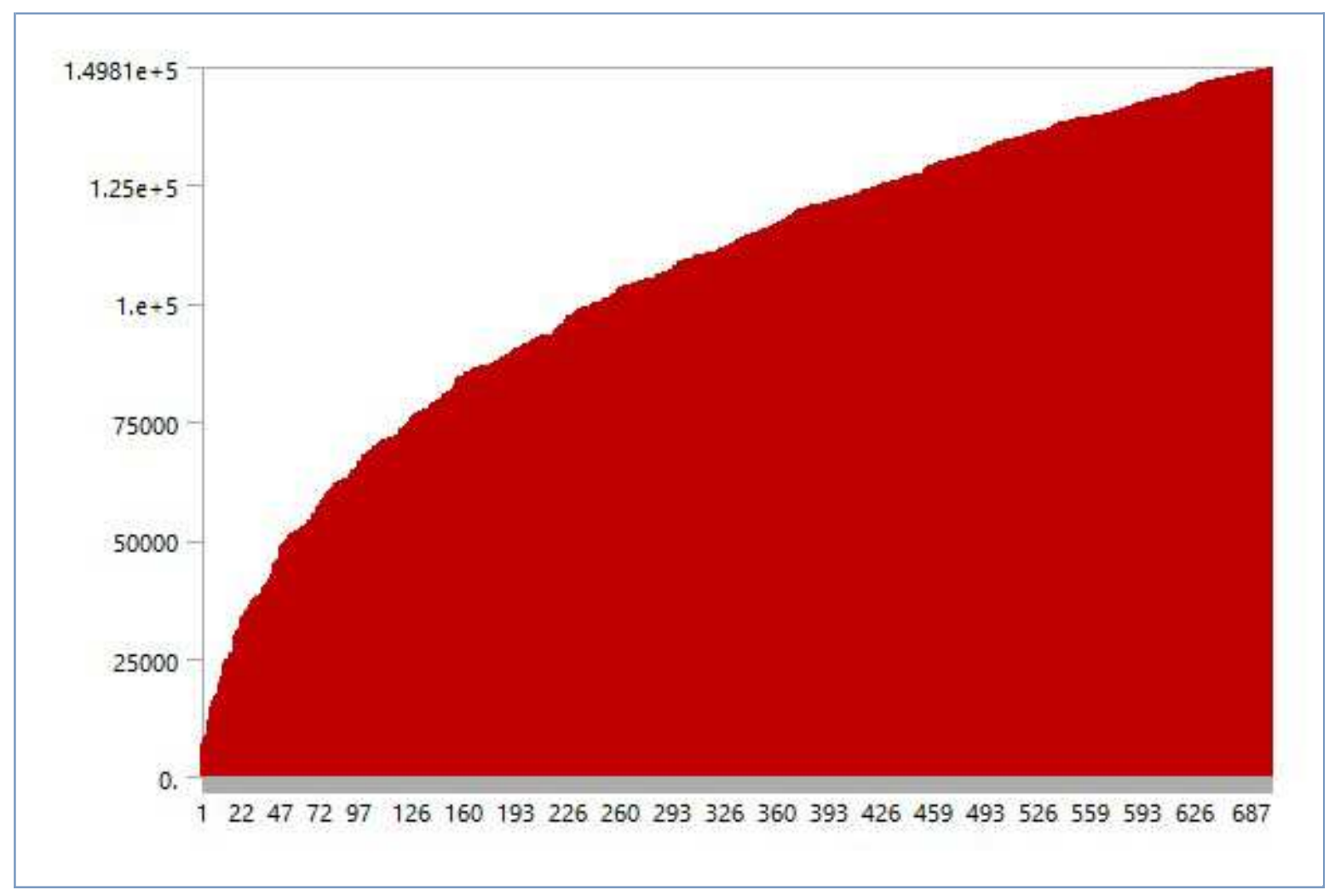

TABLE 28

Model (A4, B4, C4) > Modal (C5) > Solution (C6) \begin{tabular}{|c|c|c|}
\hline Mode & Frequency $[\mathrm{Hz}]$ & Stability $[\mathrm{Hz}]$ \\
\hline
\end{tabular}

\begin{tabular}{|c|c|c|}
\hline 1. & 2972. & -8.9069 \\
\hline 2. & 3102.1 & -9.2809 \\
\hline 3. & 6985.3 & -20.937 \\
\hline 4. & 8376.5 & -25.068 \\
\hline 5. & 8546.7 & -25.489 \\
\hline 6. & 11442 & $-1.4059 \mathrm{e}-003$ \\
\hline 7. & 12086 & -36.229 \\
\hline 8. & 14867 & -44.53 \\
\hline 9. & 16128 & -48.168 \\
\hline 10. & 16289 & -48.291 \\
\hline 11. & 17048 & $-1.0311 \mathrm{e}-002$ \\
\hline 12. & 17349 & $-6.7836 \mathrm{e}-002$ \\
\hline 13. & 18256 & -54.726 \\
\hline 14. & 19880 & $-1.6383 \mathrm{e}-002$ \\
\hline 15. & 21007 & $-2.8115 \mathrm{e}-004$ \\
\hline 16. & 22461 & -67.301 \\
\hline 17. & 24004 & $-2.5852 \mathrm{e}-002$ \\
\hline 18. & 24807 & -0.11921 \\
\hline 19. & 24961 & -74.701 \\
\hline 20. & 25480 & -76.383 \\
\hline 21. & 26145 & -77.88 \\
\hline 22. & 26227 & -72.041 \\
\hline 23. & 26494 & -4.9368 \\
\hline 24. & 29651 & $-7.9475 \mathrm{e}-004$ \\
\hline 25. & 30729 & $-8.4381 \mathrm{e}-002$ \\
\hline 26. & 31177 & -93.435 \\
\hline & & \\
\hline & & \\
\hline
\end{tabular}




\begin{tabular}{|c|c|c|}
\hline 27. & 33065 & -0.46322 \\
\hline 28. & 33744 & -101.16 \\
\hline 29. & 34110 & $-3.1164 e-003$ \\
\hline 30. & 34190 & $-4.6508 \mathrm{e}-003$ \\
\hline 31. & 34924 & -104.6 \\
\hline 32. & 35298 & -0.19085 \\
\hline 33. & 36303 & $-6.8501 e-003$ \\
\hline 34. & 36358 & $-1.0889 \mathrm{e}-002$ \\
\hline 35. & 37292 & -111.46 \\
\hline 36. & 37646 & -8.3714 \\
\hline 37. & 38142 & -0.64971 \\
\hline 38. & 38339 & -3.1606 \\
\hline 39. & 38359 & -100.13 \\
\hline 40. & 38378 & -110.49 \\
\hline 41. & 40107 & $-1.2903 e-002$ \\
\hline 42. & 40162 & $-3.0815 e-002$ \\
\hline 43. & 40274 & $-3.283 e-005$ \\
\hline 44. & 41009 & -122.91 \\
\hline 45. & 41864 & -0.43772 \\
\hline 46. & 41981 & $-3.1288 \mathrm{e}-003$ \\
\hline 47. & 42824 & -0.13745 \\
\hline 48. & 43038 & -129.02 \\
\hline 49. & 44907 & -0.31772 \\
\hline 50. & 45464 & $-1.0254 \mathrm{e}-003$ \\
\hline 51. & 46039 & -137.93 \\
\hline 52. & 48355 & -0.54387 \\
\hline 53. & 48652 & -2.4209 \\
\hline 54. & 49096 & $-7.6258 e-002$ \\
\hline 55. & 49469 & $-8.6527 e-003$ \\
\hline 56. & 49578 & -148.39 \\
\hline 57. & 50005 & $-1.2623 e-003$ \\
\hline 58. & 51164 & -40.486 \\
\hline 59. & 51418 & $-4.4214 e-003$ \\
\hline 60. & 51447 & -18.31 \\
\hline 61. & 51679 & $-1.0343 e-002$ \\
\hline 62. & 51846 & -154.57 \\
\hline 63. & 51949 & -155.7 \\
\hline 64. & 52115 & -50.75 \\
\hline 65. & 52436 & -0.20174 \\
\hline 66. & 52727 & -153.48 \\
\hline 67. & 52789 & -6.0966 \\
\hline 68. & 52873 & $-3.3316 e-002$ \\
\hline 69. & 52907 & $-1.6164 \mathrm{e}-003$ \\
\hline 70. & 53353 & -159.94 \\
\hline 71. & 54076 & -0.56879 \\
\hline 72. & 54328 & -2.4337 \\
\hline 73. & 54396 & $-1.2261 e-003$ \\
\hline 74. & 55481 & $-9.298 \mathrm{e}-005$ \\
\hline 75. & 55502 & -0.75175 \\
\hline 76. & 55959 & -12.806 \\
\hline 77. & 56772 & -0.68168 \\
\hline 78. & 57283 & $-2.5321 e-004$ \\
\hline 79. & 58270 & -10.456 \\
\hline & & \\
\hline
\end{tabular}

file:///C:/Users/Edison/AppData/Roaming/Ansys/v160/Mechanical_Report/Mechanical_Re... 8/8/2016 


\begin{tabular}{|c|c|c|}
\hline & 58312 & -174.74 \\
\hline 81. & 59035 & $-1.3172 \mathrm{e}-003$ \\
\hline 82. & 59712 & $-4.3363 e-003$ \\
\hline 83. & 60287 & -0.24374 \\
\hline 84. & 60289 & -0.8238 \\
\hline 85. & 60468 & $-3.7017 e-003$ \\
\hline 86. & 61053 & -14.518 \\
\hline 87. & 61659 & $-3.1506 e-003$ \\
\hline 88. & 62001 & $-8.1952 e-002$ \\
\hline 89. & 62044 & $-3.3643 e-002$ \\
\hline 90. & 62345 & -16.938 \\
\hline 91. & 62415 & $-1.8092 \mathrm{e}-003$ \\
\hline 92. & 62626 & -0.62297 \\
\hline 93. & 63006 & $-1.6411 \mathrm{e}-002$ \\
\hline 94. & 63039 & -188.79 \\
\hline 95. & 63070 & $-6.8582 e-005$ \\
\hline 96. & 63125 & $-8.5183 e-005$ \\
\hline 97. & 63733 & -20.967 \\
\hline 98. & 63980 & -191.78 \\
\hline 99. & 64682 & -193.9 \\
\hline 100. & 64710 & $-8.0981 e-002$ \\
\hline 101. & 64737 & -1.2663 \\
\hline 102. & 65035 & -0.2383 \\
\hline 103. & 66452 & -198.67 \\
\hline 104. & 66506 & -0.17933 \\
\hline 105. & 66724 & -0.15435 \\
\hline 106. & 68075 & -23.939 \\
\hline 107. & 68168 & -0.53818 \\
\hline 108. & 68596 & -203.25 \\
\hline 109. & 68621 & -143.33 \\
\hline 110. & 68880 & -1.7644 \\
\hline 111. & 69125 & -3.3185 \\
\hline 112. & 69312 & -6.8074 \\
\hline 113. & 69666 & $-4.936 e-002$ \\
\hline 114. & 69692 & -0.15751 \\
\hline 115. & 70055 & -2.4542 \\
\hline 116. & 70234 & $-6.3957 e-002$ \\
\hline 117. & 70817 & -6.952 \\
\hline 118. & 71132 & -1.8637 \\
\hline 119. & 71283 & -1.5482 \\
\hline 120. & 71391 & -12.275 \\
\hline 121. & 71422 & $-1.5827 e-002$ \\
\hline 122. & 71732 & -214.96 \\
\hline 123. & 71756 & $-5.9866 e-002$ \\
\hline 124. & 71769 & $-4.3516 e-003$ \\
\hline 125. & 71831 & $-1.5708 e-004$ \\
\hline 126. & 72116 & -147.68 \\
\hline 127. & 72292 & -1.74 \\
\hline 128. & 72342 & -0.49702 \\
\hline 129. & 72865 & $-2.4157 e-002$ \\
\hline 130. & 73303 & -2.0508 \\
\hline 131. & 73587 & -1.3366 \\
\hline 132. & 73787 & $-5.2619 e-003$ \\
\hline 12 & & \\
\hline
\end{tabular}

file:///C:/Users/Edison/AppData/Roaming/Ansys/v160/Mechanical_Report/Mechanical_Re... 8/8/2016 


\begin{tabular}{|c|c|c|}
\hline & 73945 & $-8.833 e-003$ \\
\hline 134. & 74427 & -2.7156 \\
\hline 135. & 75128 & -1.0864 \\
\hline 136. & 75225 & -4.1706 \\
\hline 137. & 75910 & -0.16858 \\
\hline 138. & 76323 & -0.7787 \\
\hline 139. & 76577 & $-1.979 \mathrm{e}-002$ \\
\hline 140. & 76705 & -0.53992 \\
\hline 141. & 76839 & $-8.3161 e-002$ \\
\hline 142. & 76991 & $-4.6408 e-002$ \\
\hline 143. & 77020 & -230.89 \\
\hline 144. & 77093 & -231.09 \\
\hline 145. & 77437 & -0.31413 \\
\hline 146. & 77684 & -232.72 \\
\hline 147. & 77703 & $-3.7954 e-002$ \\
\hline 148. & 77730 & $-3.7645 e-004$ \\
\hline 149. & 78449 & -4.9569 \\
\hline 150. & 78744 & -0.72815 \\
\hline 151. & 78858 & $-2.5658 \mathrm{e}-003$ \\
\hline 152. & 78940 & $-1.7551 e-002$ \\
\hline 153. & 79490 & $-1.5315 e-002$ \\
\hline 154. & 79505 & $-8.7791 e-002$ \\
\hline 155. & 79578 & -0.10011 \\
\hline 156. & 79861 & -4.3341 \\
\hline 157. & 80277 & -38.469 \\
\hline 158. & 80762 & $-6.8994 e-002$ \\
\hline 159. & 80989 & $-1.3507 e-003$ \\
\hline 160. & 81172 & -0.14261 \\
\hline 161. & 81215 & -0.25128 \\
\hline 162. & 81308 & -21.098 \\
\hline 163. & 81720 & -0.16005 \\
\hline 164. & 82242 & -246.15 \\
\hline 165. & 82498 & -0.31843 \\
\hline 166. & 84074 & -1.7384 \\
\hline 167. & 84329 & -2.2777 \\
\hline 168. & 84543 & -2.079 \\
\hline 169. & 84585 & -5.3374 \\
\hline 170. & 84728 & $-5.6757 e-003$ \\
\hline 171. & 85268 & -0.73941 \\
\hline 172. & 85512 & -2.3322 \\
\hline 173. & 85540 & -255. \\
\hline 174. & 85573 & -3.0033 \\
\hline 175. & 85764 & -1.0137 \\
\hline 176. & 85835 & -0.22658 \\
\hline 177. & 86208 & -0.18298 \\
\hline 178. & 86285 & -258.6 \\
\hline 179. & 86331 & -5.9645 \\
\hline 180. & 86437 & -0.1057 \\
\hline 181. & 86647 & $-1.4959 e-002$ \\
\hline 182. & 86658 & -0.19377 \\
\hline 183. & 86703 & $-4.4732 e-003$ \\
\hline 184. & 86712 & $-6.0508 e-002$ \\
\hline 185. & 86738 & $-1.5006 e-003$ \\
\hline & & \\
\hline
\end{tabular}

file:///C:/Users/Edison/AppData/Roaming/Ansys/v160/Mechanical_Report/Mechanical_Re... 8/8/2016 


\begin{tabular}{|c|c|c|}
\hline & 86823 & $-1.47 e-002$ \\
\hline 187. & 86948 & -0.5361 \\
\hline 188. & 87398 & -252.66 \\
\hline 189. & 87404 & -0.99209 \\
\hline 190. & 87467 & -1.2677 \\
\hline 191. & 87770 & -15.978 \\
\hline 192. & 87971 & -3.6691 \\
\hline 193. & 88255 & -14.924 \\
\hline 194. & 88292 & -1.5578 \\
\hline 195. & 88509 & -58.851 \\
\hline 196. & 88683 & -16.98 \\
\hline 197. & 88913 & -2.3995 \\
\hline 198. & 88965 & -18.292 \\
\hline 199. & 89060 & -3.4383 \\
\hline 200. & 89729 & -26.133 \\
\hline 201. & 89833 & -13.77 \\
\hline 202. & 89922 & -2.1884 \\
\hline 203. & 90107 & -23.287 \\
\hline 204. & 90362 & -270.88 \\
\hline 205. & 90500 & -6.7606 \\
\hline 206. & 90659 & -2.1786 \\
\hline 207. & 90773 & -22.124 \\
\hline 208. & 90820 & -0.92923 \\
\hline 209. & 91286 & -273.63 \\
\hline 210. & 91566 & -0.73076 \\
\hline 211. & 91569 & -84.983 \\
\hline 212. & 91641 & -2.1922 \\
\hline 213. & 91855 & -37.901 \\
\hline 214. & 92016 & -15.863 \\
\hline 215. & 92423 & $-7.1207 e-002$ \\
\hline 216. & 92496 & -9.8936 \\
\hline 217. & 92567 & -19.701 \\
\hline 218. & 92769 & -4.3938 \\
\hline 219. & 92792 & -2.9118 \\
\hline 220. & 93200 & $-6.8371 e-002$ \\
\hline 221. & 93272 & $-3.5979 e-002$ \\
\hline 222. & 93290 & $-9.0173 e-002$ \\
\hline 223. & 93317 & -0.23374 \\
\hline 224. & 93336 & -0.11051 \\
\hline 225. & 93339 & -0.61708 \\
\hline 226. & 93393 & -3.0657 \\
\hline 227. & 93507 & -280.16 \\
\hline 228. & 94060 & -6.8641 \\
\hline 229. & 94328 & -19.452 \\
\hline 230. & 94613 & -0.14011 \\
\hline 231. & 94651 & -1.2742 \\
\hline 232. & 94929 & -33.602 \\
\hline 233. & 95552 & -4.6841 \\
\hline 234. & 95650 & -0.58786 \\
\hline 235. & 96248 & -0.93408 \\
\hline 236. & 96504 & -3.0141 \\
\hline 237. & 97263 & -2.2233 \\
\hline 238. & 97515 & $-9.6817 e-003$ \\
\hline 2 & & \\
\hline
\end{tabular}

file:///C:/Users/Edison/AppData/Roaming/Ansys/v160/Mechanical_Report/Mechanical_Re... 8/8/2016 


\begin{tabular}{|c|c|c|}
\hline & 97547 & -0.52746 \\
\hline 240. & 97581 & -2.4176 \\
\hline 241. & 97932 & $-6.1013 e-002$ \\
\hline 242. & 97971 & -0.21908 \\
\hline 243. & 98453 & -0.18161 \\
\hline 244. & 98600 & $-5.1844 e-003$ \\
\hline 245. & 98683 & -0.61975 \\
\hline 246. & 98884 & -0.27163 \\
\hline 247. & 99118 & $-8.518 e-002$ \\
\hline 248. & 99214 & -0.16216 \\
\hline 249. & 99229 & -297.14 \\
\hline 250. & 99251 & -0.48008 \\
\hline 251. & 99411 & -0.12556 \\
\hline 252. & 99572 & $-6.1632 e-002$ \\
\hline 253. & 99615 & -0.26971 \\
\hline 254. & $1.0004 e+005$ & $-4.2347 e-002$ \\
\hline 255. & $1.0013 e+005$ & $-5.2859 e-003$ \\
\hline 256. & $1.0017 \mathrm{e}+005$ & -0.85376 \\
\hline 257. & $1.0029 e+005$ & -0.10477 \\
\hline 258. & $1.0036 e+005$ & -0.54769 \\
\hline 259. & $1.0067 \mathrm{e}+005$ & -0.3616 \\
\hline 260. & $1.0089 e+005$ & $-3.5653 e-002$ \\
\hline 261. & $1.0091 \mathrm{e}+005$ & $-3.3625 e-003$ \\
\hline 262. & $1.0098 \mathrm{e}+005$ & $-2.3181 e-002$ \\
\hline 263. & $1.0105 e+005$ & -0.26535 \\
\hline 264. & $1.0118 e+005$ & -0.11486 \\
\hline 265. & $1.0164 \mathrm{e}+005$ & -0.17065 \\
\hline 266. & $1.0195 e+005$ & $-3.0246 e-002$ \\
\hline 267. & $1.0196 \mathrm{e}+005$ & -305.6 \\
\hline 268. & $1.0208 e+005$ & -0.21144 \\
\hline 269. & $1.0311 \mathrm{e}+005$ & -1.403 \\
\hline 270. & $1.0315 e+005$ & $-6.0396 e-002$ \\
\hline 271. & $1.0324 \mathrm{e}+005$ & -0.26972 \\
\hline 272. & $1.0331 e+005$ & -0.22813 \\
\hline 273. & & -309.86 \\
\hline 274. & 05 & -0.90255 \\
\hline 275. & $1.0371 \mathrm{e}+005$ & -0.54732 \\
\hline 276. & $1.0375 e+005$ & $-6.3069 e-004$ \\
\hline 277. & $1.0385 e+005$ & -0.28903 \\
\hline 278. & $1.0387 \mathrm{e}+005$ & -0.41678 \\
\hline 279. & $1.0421 e+005$ & $-2.1981 e-002$ \\
\hline 280. & $1.0426 e+005$ & -1.086 \\
\hline 281. & $1.0436 e+005$ & -0.11284 \\
\hline 282. & $1.0441 \mathrm{e}+005$ & -0.62896 \\
\hline 283. & $1.0471 \mathrm{e}+005$ & -313.88 \\
\hline 284. & $1.0474 \mathrm{e}+005$ & -1.3688 \\
\hline 285. & $1.0485 e+005$ & -0.15062 \\
\hline 286. & $1.0489 e+005$ & $-9.6775 e-004$ \\
\hline 287. & $1.0504 \mathrm{e}+005$ & $-8.3904 e-002$ \\
\hline 288. & $1.0513 e+005$ & $-9.8346 e-002$ \\
\hline 289. & $1.0521 e+005$ & $-8.2755 e-003$ \\
\hline 290. & $1.0523 e+005$ & $-3.1182 e-002$ \\
\hline 291. & $1.0524 \mathrm{e}+005$ & $-4.6826 e-002$ \\
\hline
\end{tabular}

file:///C:/Users/Edison/AppData/Roaming/Ansys/v160/Mechanical_Report/Mechanical_Re... 8/8/2016 


\begin{tabular}{|c|c|c|}
\hline 92. & $1.0538 \mathrm{e}+005$ & |-7.2265e-0 \\
\hline 293. & $1.054 \mathrm{e}+005$ & $-7.6316 e-003$ \\
\hline 294. & $1.06 e+005$ & -15.523 \\
\hline 295. & $1.0614 \mathrm{e}+005$ & -0.53058 \\
\hline 296. & $1.0629 e+005$ & -1.6593 \\
\hline 297. & $1.0631 \mathrm{e}+005$ & -0.13778 \\
\hline 298. & $1.0643 e+005$ & -22.251 \\
\hline 299. & $1.065 e+005$ & -0.53743 \\
\hline 300. & $1.0654 \mathrm{e}+005$ & -319.28 \\
\hline 301. & $1.0659 e+005$ & -157.48 \\
\hline 302. & $1.0681 \mathrm{e}+005$ & -315.91 \\
\hline 303. & $1.0701 e+005$ & -1.1452 \\
\hline 304. & $1.0707 e+005$ & -3.8002 \\
\hline 305. & $1.0735 e+005$ & -12.534 \\
\hline 306. & $1.0797 e+005$ & -0.12985 \\
\hline 307. & $1.0816 e+005$ & -1.6585 \\
\hline 308. & $1.0871 \mathrm{e}+005$ & -3.4486 \\
\hline 309. & $1.0872 e+005$ & -0.64277 \\
\hline 310. & $1.0901 \mathrm{e}+005$ & -1.2904 \\
\hline 311. & $1.0903 e+005$ & -4.3599 \\
\hline 312. & $e+005$ & -0.63011 \\
\hline 313. & $1.093 e+005$ & -1.0947 \\
\hline 314. & $1.0937 e+005$ & -0.27092 \\
\hline 315. & $1.094 \mathrm{e}+005$ & $-9.0192 e-002$ \\
\hline 316. & $1.0942 \mathrm{e}+005$ & $-9.8182 e-002$ \\
\hline 317. & $e+005$ & -1.3143 \\
\hline 318. & +005 & -0.4 \\
\hline 319. & +005 & 314 \\
\hline 320. & $1014 e+005$ & -0.5137 \\
\hline 321. & $1024 e+005$ & -4.8624 \\
\hline 322. & $1.1044 \mathrm{e}+005$ & -0.33074 \\
\hline 323. & $1.1047 e+005$ & -0.71022 \\
\hline 324. & $e+005$ & -0.28601 \\
\hline 325. & +005 & -331.11 \\
\hline 326. & $1055 e+005$ & -1.2095 \\
\hline 327. & $1.1067 e+005$ & -0.43601 \\
\hline 328. & $1.1073 e+005$ & $-5.1624 e-002$ \\
\hline 329. & $1.1074 \mathrm{e}+005$ & -0.2356 \\
\hline 330. & $2+005$ & $-3.0363 e-002$ \\
\hline 331. & $e+005$ & -1.5841 \\
\hline 332. & $e+005$ & -2.4243 \\
\hline 333. & $1.1116 e+005$ & $-5.1007 e-002$ \\
\hline 334. & $1.1125 e+005$ & -7.5455 \\
\hline 335. & $1.1146 e+005$ & -3.5824 \\
\hline 336. & $1.1151 e+005$ & -297.23 \\
\hline 337. & $1.1153 e+005$ & -1.0979 \\
\hline 338. & $1.1178 e+005$ & -6.5099 \\
\hline 339. & $1.1193 e+005$ & -25.563 \\
\hline 340. & $1.1211 \mathrm{e}+005$ & -62.484 \\
\hline 341. & $1.1229 e+005$ & -201.45 \\
\hline 342. & $1.1255 e+005$ & -0.13607 \\
\hline 343. & $1.1261 e+005$ & -0.11411 \\
\hline 344. & $1.1275 \mathrm{e}+005$ & -2.5582 \\
\hline
\end{tabular}

file:///C:/Users/Edison/AppData/Roaming/Ansys/v160/Mechanical_Report/Mechanical_Re... 8/8/2016 


\begin{tabular}{|c|c|c|}
\hline & . & 0587 \\
\hline 346. & $1.1345 e+005$ & -9.2848 \\
\hline 347. & $1.1356 e+005$ & -1.0712 \\
\hline 348. & $1.1366 e+005$ & -16.53 \\
\hline 349. & $1.1404 \mathrm{e}+005$ & -0.30396 \\
\hline 350. & $1.1411 e+005$ & -0.40966 \\
\hline 351. & $1.1412 e+005$ & -8.5868 \\
\hline 352. & $1.1434 \mathrm{e}+005$ & -1.8952 \\
\hline 353. & $1.1447 e+005$ & -0.28915 \\
\hline 354. & $1.1451 e+005$ & -0.33292 \\
\hline 355. & $1.1453 e+005$ & -1.2957 \\
\hline 356. & $1.148 \mathrm{e}+005$ & -4.2946 \\
\hline 357. & $1.1489 e+005$ & -0.6612 \\
\hline 358. & $1.1498 e+005$ & -47.765 \\
\hline 359. & $1.1505 e+005$ & -2.6854 \\
\hline 360. & $1.1516 e+005$ & $-2.5287 e-002$ \\
\hline 361. & $1.1553 e+005$ & -0.11744 \\
\hline 362. & $1.1555 \mathrm{e}+005$ & -1.7875 \\
\hline 363. & $1.1566 \mathrm{e}$ & -0.39504 \\
\hline 364. & $1.1579 \mathrm{e}$ & -21.862 \\
\hline 365. & $1.1591 \mathrm{e}+005$ & -0.1055 \\
\hline 366. & $1.1601 e+005$ & -0.15699 \\
\hline 367. & $1.1606 e+005$ & -0.17904 \\
\hline 368. & $1.1608 \mathrm{e}+005$ & -0.71918 \\
\hline 369. & $1.1647 e+005$ & $-3.6914 e-00$ \\
\hline 370. & $1.1653 \mathrm{e}$ & -6.2521 \\
\hline 371. & $1.1669 e+005$ & -0.173 \\
\hline 372. & $1.1714 \mathrm{e}+005$ & -3.1562 \\
\hline 373. & $1.1717 e+005$ & -0.10846 \\
\hline 374. & $1.1741 e+005$ & -5.1573 \\
\hline 375. & $1.1742 e+005$ & -351.71 \\
\hline 376. & $177 \mathrm{e}$ & -1.1102 \\
\hline 377. & $1.1771 \mathrm{e}$ & -0.26631 \\
\hline 378. & $1.182 \mathrm{e}+005$ & -0.26818 \\
\hline 379. & $1.1831 e+005$ & $-7.0248 e-002$ \\
\hline 380. & $1.1861 e+005$ & $-3.8625 e-002$ \\
\hline 381. & $1.1876 e+005$ & -355.96 \\
\hline 382. & 005 & -4.1401 \\
\hline 383. & $36 e+005$ & -0.24483 \\
\hline 384. & $41 e+005$ & -0.53502 \\
\hline 385. & \multirow{2}{*}{$1.1979 \mathrm{e}+005$} & -0.41172 \\
\hline 386. & & -0.16362 \\
\hline 387. & $1.1998 \mathrm{e}+005$ & $-7.5966 e-003$ \\
\hline 388. & $1.2006 \mathrm{e}+005$ & -359.89 \\
\hline 389. & $1.2009 e+005$ & -0.84992 \\
\hline 390. & $1.2017 e+005$ & -1.0314 \\
\hline 391. & $1.2047 e+005$ & -0.71576 \\
\hline 392. & $1.2051 \mathrm{e}+005$ & -0.23416 \\
\hline 393. & $1.2064 e+005$ & $-6.3768 e-002$ \\
\hline 394. & $1.2068 e+005$ & $-9.1785 e-002$ \\
\hline 395. & $1.2071 \mathrm{e}+005$ & $-7.1872 \mathrm{e}-002$ \\
\hline 396. & $1.2076 e+005$ & -0.4683 \\
\hline 397. & $1.2092 \mathrm{e}+005$ & -0.10325 \\
\hline
\end{tabular}

file:///C:/Users/Edison/AppData/Roaming/Ansys/v160/Mechanical_Report/Mechanical_Re... 8/8/2016 


\begin{tabular}{|c|c|c|}
\hline 398. & $1.2094 \mathrm{e}+005$ & $-9.0485 \mathrm{e}-003$ \\
\hline 399. & $1.21 \mathrm{e}+005$ & $-1.0866 \mathrm{e}-002$ \\
\hline 400. & $1.2106 \mathrm{e}+005$ & $-7.5512 \mathrm{e}-003$ \\
\hline 401. & $1.2107 \mathrm{e}+005$ & $-4.3415 \mathrm{e}-003$ \\
\hline 402. & $1.2112 \mathrm{e}+005$ & $-1.058 \mathrm{e}-002$ \\
\hline 403. & $1.213 \mathrm{e}+005$ & -0.13145 \\
\hline 404. & $1.2141 \mathrm{e}+005$ & -0.28084 \\
\hline 405. & $1.2142 \mathrm{e}+005$ & -0.54437 \\
\hline 406. & $1.2158 \mathrm{e}+005$ & $-4.949 \mathrm{e}-002$ \\
\hline 407. & $1.2161 \mathrm{e}+005$ & $-4.2292 \mathrm{e}-002$ \\
\hline 408. & $1.2168 \mathrm{e}+005$ & $-1.1425 \mathrm{e}-002$ \\
\hline 409. & $1.217 \mathrm{e}+005$ & -0.46867 \\
\hline 410. & $1.22 \mathrm{e}+005$ & -0.18696 \\
\hline 411. & $1.2212 \mathrm{e}+005$ & $-4.2471 \mathrm{e}-003$ \\
\hline 412. & $1.2217 \mathrm{e}+005$ & -0.41188 \\
\hline 413. & $1.2221 \mathrm{e}+005$ & $-4.916 \mathrm{e}-003$ \\
\hline 414. & $1.2222 \mathrm{e}+005$ & $-1.4252 \mathrm{e}-002$ \\
\hline 415. & $1.2229 \mathrm{e}+005$ & $-4.9171 \mathrm{e}-002$ \\
\hline 416. & $1.2257 \mathrm{e}+005$ & $-9.912 \mathrm{e}-002$ \\
\hline 417. & $1.2276 \mathrm{e}+005$ & $-5.6878 \mathrm{e}-002$ \\
\hline 418. & $1.2281 \mathrm{e}+005$ & $-1.5873 \mathrm{e}-002$ \\
\hline 419. & $1.2283 \mathrm{e}+005$ & $-9.1265 \mathrm{e}-002$ \\
\hline 420. & $1.2286 \mathrm{e}+005$ & -368.26 \\
\hline 421. & $1.2299 \mathrm{e}+005$ & -368.03 \\
\hline 422. & $1.2314 \mathrm{e}+005$ & -0.85934 \\
\hline 423. & $1.2316 \mathrm{e}+005$ & -0.31843 \\
\hline 424. & $1.2324 \mathrm{e}+005$ & $-9.8441 \mathrm{e}-002$ \\
\hline 425. & $1.2328 \mathrm{e}+005$ & $-3.5648 \mathrm{e}-002$ \\
\hline 426. & $1.2363 \mathrm{e}+005$ & $-3.605 \mathrm{e}-003$ \\
\hline 427. & $1.2385 \mathrm{e}+005$ & $-7.0628 \mathrm{e}-002$ \\
\hline 428. & $1.2386 \mathrm{e}+005$ & -0.87154 \\
\hline 429. & $1.239 \mathrm{e}+005$ & $-8.1031 \mathrm{e}-003$ \\
\hline 430. & $1.2395 \mathrm{e}+005$ & $-3.7558 \mathrm{e}-002$ \\
\hline 431. & $1.2416 \mathrm{e}+005$ & $-6.496 \mathrm{e}-003$ \\
\hline 432. & $1.2441 \mathrm{e}+005$ & $-2.4477 \mathrm{e}-003$ \\
\hline 433. & $1.2442 \mathrm{e}+005$ & $-3.266 \mathrm{e}-002$ \\
\hline 434. & $1.2449 \mathrm{e}+005$ & $-3.1165 \mathrm{e}-003$ \\
\hline 435. & $1.2463 \mathrm{e}+005$ & -0.34441 \\
\hline 436. & $1.2472 \mathrm{e}+005$ & $-1.5821 \mathrm{e}-003$ \\
\hline 437. & $1.2477 \mathrm{e}+005$ & $-2.1997 \mathrm{e}-002$ \\
\hline 438. & $1.2501 \mathrm{e}+005$ & -0.86414 \\
\hline 439. & $1.2504 \mathrm{e}+005$ & -0.22753 \\
\hline 440. & $1.2525 \mathrm{e}+005$ & $-5.5036 \mathrm{e}-002$ \\
\hline 441. & $1.2529 \mathrm{e}+005$ & $-8.0679 \mathrm{e}-003$ \\
\hline 442. & $1.2538 \mathrm{e}+005$ & $-4.2724 \mathrm{e}-002$ \\
\hline 443. & $1.2555 \mathrm{e}+005$ & $-2.7828 \mathrm{e}-002$ \\
\hline 444. & & $-5.2076 \mathrm{e}-002$ \\
\hline 445. & $1.2576 \mathrm{e}+005$ & $-5.4899 \mathrm{e}-002$ \\
\hline 446. & $1.2578 \mathrm{e}+005$ & -0.12645 \\
\hline 447. & $1.2588 \mathrm{e}+005$ & $-4.0955 \mathrm{e}-003$ \\
\hline 448. & $1.2589 \mathrm{e}+005$ & $-1.4101 \mathrm{e}-002$ \\
\hline 449. & $1.2592 \mathrm{e}+005$ & $-4.6287 \mathrm{e}-002$ \\
\hline 450. & $1.2598 \mathrm{e}+005$ & $-1.9626 \mathrm{e}-002$ \\
\hline & & \\
\hline
\end{tabular}

file:///C:/Users/Edison/AppData/Roaming/Ansys/v160/Mechanical_Report/Mechanical_Re... 8/8/2016 


\begin{tabular}{|c|c|c|}
\hline 451. & & \\
\hline 452. & $1.2628 \mathrm{e}+005$ & $-1.1601 e-002$ \\
\hline 453. & $1.2644 \mathrm{e}+005$ & -0.54318 \\
\hline 454. & $1.2672 e+005$ & -0.28643 \\
\hline 455. & $1.2675 \mathrm{e}+005$ & $-5.5614 e-002$ \\
\hline 456. & $1.269 \mathrm{e}+005$ & $-6.7812 e-002$ \\
\hline 457. & $1.2694 \mathrm{e}+005$ & -0.10515 \\
\hline 458. & $1.2697 e+005$ & -0.13445 \\
\hline 459. & $1.2708 \mathrm{e}+005$ & -0.19893 \\
\hline 460. & $1.2713 e+005$ & $-4.0376 e-002$ \\
\hline 461. & $1.2719 \mathrm{e}+005$ & -0.1946 \\
\hline 462. & $1.2726 \mathrm{e}+005$ & $-1.4869 e-002$ \\
\hline 463. & $1.2731 \mathrm{e}+005$ & -379.4 \\
\hline 464. & $1.2742 e+005$ & -0.1866 \\
\hline 465. & $1.2749 e+005$ & $-6.5612 e-002$ \\
\hline 466. & $1.28 e+005$ & -0.46643 \\
\hline 467. & $1.2811 \mathrm{e}+005$ & -0.3424 \\
\hline 468. & $1.2866 \mathrm{e}+005$ & -385.54 \\
\hline 469. & $1.2894 e+005$ & 117 \\
\hline 470. & $1.2896 \mathrm{e}+005$ & 471 \\
\hline 471. & 1.2911 & 836 \\
\hline 472. & $1.2914 e+005$ & -0.32686 \\
\hline 473. & $1.294 e+005$ & 5674 \\
\hline 474. & $1.2966 e+005$ & -0.55296 \\
\hline 475. & $1.2984 e+005$ & 767 \\
\hline 476. & $1.2986 e+005$ & $-9.9566 e-002$ \\
\hline 477. & $1.2992 \mathrm{e}+005$ & 335 \\
\hline 478. & $1.2996 e+005$ & -367.8 \\
\hline 479. & $1.3008 \mathrm{e}+005$ & -0.35867 \\
\hline 480. & $1.3017 e+005$ & $-9.3954 e-002$ \\
\hline 481. & $1.303 e+005$ & -0.62767 \\
\hline 482. & $1.3032 e+005$ & 185 \\
\hline 483. & $1.3047 e+005$ & 589 \\
\hline 484. & $1.3052 e+005$ & -1.0238 \\
\hline 485. & $1.3059 \mathrm{e}+005$ & -0.10715 \\
\hline 486. & $1.3063 e+005$ & -0.12775 \\
\hline 487. & $1.3077 e+005$ & -0.12473 \\
\hline 488. & $1.3082 e+005$ & $-2.7342 e-002$ \\
\hline 489. & $1.3098 \mathrm{e}+005$ & -0.94984 \\
\hline 490. & $1.3106 e+005$ & $-5.483 e-002$ \\
\hline 491. & $1.3108 e+005$ & -0.78365 \\
\hline 492. & $1.3117 e+005$ & $-2.5461 e-002$ \\
\hline 493. & $1.3128 \mathrm{e}+005$ & -0.1677 \\
\hline 494. & $1.3136 e+005$ & -4.3864 \\
\hline 495. & $1.3154 e+005$ & $-4.7507 e-002$ \\
\hline 496. & $1.3169 e+005$ & -0.11627 \\
\hline 497. & $1.317 \mathrm{e}+005$ & $-6.6719 e-002$ \\
\hline 498. & $1.3177 \mathrm{e}+005$ & -1.5987 \\
\hline 499. & $1.3182 \mathrm{e}+005$ & -2.0607 \\
\hline 500. & $1.3185 e+005$ & -1.3136 \\
\hline 501. & $1.3205 e+005$ & -1.3382 \\
\hline 502. & $1.3233 e+005$ & -1.2196 \\
\hline 503. & $1.3254 \mathrm{e}+005$ & -26.49 \\
\hline
\end{tabular}

file:///C:/Users/Edison/AppData/Roaming/Ansys/v160/Mechanical_Report/Mechanical_Re... 8/8/2016 


\begin{tabular}{|c|c|c|}
\hline & $1.3279 e+005$ & -115.37 \\
\hline 505. & $1.3297 e+005$ & -0.95157 \\
\hline 506. & $1.3303 e+005$ & -5.7129 \\
\hline 507. & $1.3317 e+005$ & -4.1241 \\
\hline 508. & $1.3324 \mathrm{e}+005$ & -10.403 \\
\hline 509. & $1.3347 e+005$ & -25.682 \\
\hline 510. & $1.3348 e+005$ & -0.37018 \\
\hline 511. & $1.3361 \mathrm{e}+005$ & -46.977 \\
\hline 512. & $1.3387 e+005$ & -19.114 \\
\hline 513. & $1.3407 e+005$ & -3.3366 \\
\hline 514. & $1.3412 \mathrm{e}+005$ & -38.115 \\
\hline 515. & $1.3413 e+005$ & -15.649 \\
\hline 516. & $1.3423 e+005$ & -5.5494 \\
\hline 517. & $1.343 e+005$ & -161.2 \\
\hline 518. & \multirow{2}{*}{$1.3443 e+005$} & -21.335 \\
\hline 519. & & -1.5882 \\
\hline 520. & $1.3452 \mathrm{e}+005$ & -27.939 \\
\hline 521. & $1.3454 \mathrm{e}+005$ & -45.967 \\
\hline 522. & $1.3468 \mathrm{e}+005$ & -29.45 \\
\hline 523. & $1.3478 e+005$ & -245.12 \\
\hline 524. & $1.3486 e+005$ & -1.6628 \\
\hline 525. & $1.3498 e+005$ & -30.427 \\
\hline 526. & $1.3508 e+005$ & -0.47485 \\
\hline 527. & $1.351 e+005$ & -43.875 \\
\hline 528. & $1.3513 e+005$ & -1.8669 \\
\hline 529. & $1.3516 e+005$ & -7.3801 \\
\hline 530. & $1.3533 e+005$ & -7.8251 \\
\hline 531. & $1.3554 \mathrm{e}+005$ & -3.4528 \\
\hline 532. & $1.3567 e+005$ & -14.655 \\
\hline 533. & $1.3579 e+005$ & -0.49226 \\
\hline 534. & $1.3587 e+005$ & -2.0291 \\
\hline 535. & $1.3594 \mathrm{e}+005$ & -3.1147 \\
\hline 536. & $1.3599 \mathrm{e}+005$ & -3.3485 \\
\hline 537. & $1.3604 \mathrm{e}+005$ & -1.2433 \\
\hline 538. & $1.361 e+005$ & -1.2017 \\
\hline 539. & $1.3627 e+005$ & -6.8588 \\
\hline 540. & $1.3639 e+005$ & -2.5331 \\
\hline 541. & $1.3641 \mathrm{e}+005$ & -408.92 \\
\hline 542. & $1.3643 e+005$ & -0.75576 \\
\hline 543. & $1.3661 \mathrm{e}+005$ & -4.2597 \\
\hline 544. & $1.3669 e+005$ & -409.68 \\
\hline 545. & $1.3681 e+005$ & -409.84 \\
\hline 546. & $1.3708 \mathrm{e}+005$ & -27.171 \\
\hline 547. & $1.3715 \mathrm{e}+005$ & -1.7779 \\
\hline 548. & $1.3731 \mathrm{e}+005$ & -1.8635 \\
\hline 549. & $1.3743 e+005$ & -1.8899 \\
\hline 550. & $1.3778 e+005$ & -0.90329 \\
\hline 551. & $1.3802 \mathrm{e}+005$ & -8.06 \\
\hline 552. & $1.3805 e+005$ & -3.5644 \\
\hline 553. & $1.3819 e+005$ & -8.4031 \\
\hline 554. & $1.3832 \mathrm{e}+005$ & -1.3641 \\
\hline 555. & $1.3835 \mathrm{e}+005$ & -2.5161 \\
\hline 556. & $1.3838 \mathrm{e}+005$ & -0.4145 \\
\hline
\end{tabular}

file:///C:/Users/Edison/AppData/Roaming/Ansys/v160/Mechanical_Report/Mechanical_Re... 8/8/2016 


\begin{tabular}{|c|c|c|}
\hline 557 & $1.3842 e+005$ & 63 \\
\hline 558. & $1.3844 \mathrm{e}+005$ & -0.2499 \\
\hline 559. & $1.3856 e+005$ & -1.7868 \\
\hline 560. & $1.3859 \mathrm{e}+005$ & -27.851 \\
\hline 561. & $1.388 \mathrm{e}+005$ & -1.3115 \\
\hline 562. & $1.3887 e+005$ & -10.022 \\
\hline 563. & $1.3898 \mathrm{e}+005$ & -0.66106 \\
\hline 564. & $1.3902 \mathrm{e}+005$ & -2.4317 \\
\hline 565. & $1.3907 e+005$ & -10.738 \\
\hline 566. & $1.3919 \mathrm{e}+005$ & -0.12855 \\
\hline 567. & $1.3922 \mathrm{e}+005$ & -0.34248 \\
\hline 568. & $1.3931 \mathrm{e}+005$ & -0.56741 \\
\hline 569. & $1.3934 \mathrm{e}+005$ & -3.841 \\
\hline 570. & $1.3935 \mathrm{e}+005$ & -3.9007 \\
\hline 571. & $1.3938 \mathrm{e}+005$ & -2.4856 \\
\hline 572. & $1.394 e+005$ & $-3.4351 e-002$ \\
\hline 573. & $1.3944 \mathrm{e}+005$ & $-7.6902 e-002$ \\
\hline 574. & $1.3947 e+005$ & -0.43407 \\
\hline 575. & $1.3953 e+005$ & $-9.0796 e-002$ \\
\hline 576. & $1.3955 \mathrm{e}+005$ & $-6.8312 e-002$ \\
\hline 577. & $1.396 \mathrm{e}+005$ & -0.27336 \\
\hline 578. & $1.3966 \mathrm{e}+005$ & -0.67316 \\
\hline 579. & $1.3979 \mathrm{e}+005$ & -0.13528 \\
\hline 580. & $1.39 \varepsilon$ & -0.40002 \\
\hline 581. & 1.3988 & -0.13802 \\
\hline 582. & $1.3999 e+005$ & -0.23543 \\
\hline 583. & $1.401 \mathrm{e}+005$ & -8.5534 \\
\hline 584. & $1.4019 \mathrm{e}+005$ & -0.15269 \\
\hline 585. & \multirow{2}{*}{$1.4025 e+005$} & -420.39 \\
\hline 586. & & -0.38294 \\
\hline 587. & 05 & $-1.8921 \mathrm{e}-002$ \\
\hline 588. & $1.4055 \mathrm{e}+005$ & -0.13117 \\
\hline 589. & $1.4056 \mathrm{e}+005$ & -0.64477 \\
\hline 590. & $1.4061 \mathrm{e}+005$ & $-5.8755 e-003$ \\
\hline 591. & $1.4089 \mathrm{e}+005$ & -0.11165 \\
\hline 592. & $1.4097 \mathrm{e}+005$ & -3.3303 \\
\hline 593. & $1.4105 e+005$ & -4.668 \\
\hline 594. & $1.412 e+005$ & -0.16906 \\
\hline 595. & $1.4123 e+005$ & -2.2833 \\
\hline 596. & $1.4135 \mathrm{e}+005$ & -0.73572 \\
\hline 597. & $1.4143 e+005$ & $-8.9344 \mathrm{e}-002$ \\
\hline 598. & $1.4161 \mathrm{e}+005$ & -0.90303 \\
\hline 599. & $1.4176 \mathrm{e}+005$ & -13.595 \\
\hline 600. & $1.4196 \mathrm{e}+005$ & -4.4439 \\
\hline 601. & $1.42 e+005$ & -0.71026 \\
\hline 602. & $1.4215 \mathrm{e}+005$ & -1.6281 \\
\hline 603. & $1.4223 e+005$ & -1.2 \\
\hline 604. & $1.4225 \mathrm{e}+005$ & -0.60688 \\
\hline 605. & $1.4237 e+005$ & -0.19458 \\
\hline 606. & $1.4244 \mathrm{e}+005$ & -3.844 \\
\hline 607. & $1.4247 e+005$ & -3.9019 \\
\hline 608. & $1.4268 \mathrm{e}+005$ & $-4.0943 e-002$ \\
\hline 609. & $1.427 \mathrm{e}+005$ & $-1.3726 e-002$ \\
\hline
\end{tabular}

file:///C:/Users/Edison/AppData/Roaming/Ansys/v160/Mechanical_Report/Mechanical_Re... 8/8/2016 


\begin{tabular}{|c|c|c|}
\hline 610. & $1.4282 \mathrm{e}+005$ & -1.0356 \\
\hline 611. & $1.429 \mathrm{e}+005$ & $-6.9256 e-002$ \\
\hline 612. & $1.4296 \mathrm{e}+005$ & -0.1979 \\
\hline 613. & $1.4317 e+005$ & -1.5698 \\
\hline 614. & $1.4333 e+005$ & -0.30537 \\
\hline 615. & $1.434 \mathrm{e}+005$ & -0.16631 \\
\hline 616. & $1.4341 e+005$ & -0.37849 \\
\hline 617. & $1.4348 \mathrm{e}+005$ & -0.20504 \\
\hline 618. & $1.4351 \mathrm{e}+005$ & -0.10045 \\
\hline 619. & $1.4357 e+005$ & -429.78 \\
\hline 620. & $1.4363 e+005$ & -7.1499 \\
\hline 621. & $1.4371 \mathrm{e}+005$ & -1.431 \\
\hline 622. & \multirow{2}{*}{$1.4375 e+005$} & $-1.034 e-002$ \\
\hline 623. & & $-3.8263 e-002$ \\
\hline 624. & $1.4378 \mathrm{e}+005$ & $-2.7001 e-002$ \\
\hline 625. & $1.4411 \mathrm{e}+005$ & -0.23954 \\
\hline 626. & $1.4419 e+005$ & -0.12799 \\
\hline 627. & $1.4429 e+005$ & $-7.241 \mathrm{e}-002$ \\
\hline 628. & $1.4438 \mathrm{e}+005$ & -0.64654 \\
\hline 629. & $1.4446 e+005$ & -1.1028 \\
\hline 630. & $1.4447 e+005$ & -0.44141 \\
\hline 631. & $1.4455 e+005$ & -0.35402 \\
\hline 632. & $1.4468 e+005$ & -0.68177 \\
\hline 633. & $1.4484 \mathrm{e}+005$ & -0.10742 \\
\hline 634. & $1.4493 e+005$ & -0.44465 \\
\hline 635. & $1.4504 \mathrm{e}+005$ & -0.17084 \\
\hline 636. & $1.4531 \mathrm{e}+005$ & -0.83741 \\
\hline 637. & $1.4535 e+005$ & -0.18252 \\
\hline 638. & $1.4548 \mathrm{e}+005$ & -0.90114 \\
\hline 639. & $1.4586 e+005$ & -0.37781 \\
\hline 640. & $1.4591 \mathrm{e}+005$ & $-5.8753 e-002$ \\
\hline 641. & $1.4605 \mathrm{e}+005$ & -0.65463 \\
\hline 642. & $1.4659 e+005$ & -25.771 \\
\hline 643. & $1.4661 e+005$ & -0.45922 \\
\hline 644. & $1.467 e+005$ & -0.66438 \\
\hline 645. & $1.4673 e+005$ & -0.68494 \\
\hline 646. & $1.4681 \mathrm{e}+005$ & -6.6856 \\
\hline 647. & $1.4684 \mathrm{e}+005$ & -0.2314 \\
\hline 648. & \multirow{2}{*}{$1.4694 e+005$} & -1.798 \\
\hline 649. & & -26.573 \\
\hline 650. & $1.47 e+005$ & -0.15898 \\
\hline 651. & $1.4716 e+005$ & -6.5915 \\
\hline 652. & $1.4726 \mathrm{e}+005$ & -0.32311 \\
\hline 653. & $1.474 \mathrm{e}+005$ & -0.54856 \\
\hline 654. & $1.4741 \mathrm{e}+005$ & -0.2464 \\
\hline 655. & $1.4745 e+005$ & -1.7867 \\
\hline 656. & $1.4746 e+005$ & -1.324 \\
\hline 657. & $1.4754 \mathrm{e}+005$ & -0.1092 \\
\hline 658. & $1.4762 e+005$ & -2.7276 \\
\hline 659. & $1.4767 e+005$ & -0.65342 \\
\hline 660. & $1.4781 e+005$ & -0.92041 \\
\hline 661. & $1.4784 e+005$ & -5.8556 \\
\hline 662. & $1.4788 e+005$ & -0.52415 \\
\hline
\end{tabular}

file:///C:/Users/Edison/AppData/Roaming/Ansys/v160/Mechanical_Report/Mechanical_Re... 8/8/2016 


\begin{tabular}{|l|c|c|}
663. & $1.479 \mathrm{e}+005$ & -0.562 \\
\hline 664. & $1.4792 \mathrm{e}+005$ & -0.60608 \\
\hline 665. & $1.4799 \mathrm{e}+005$ & -443.5 \\
\hline 666. & $1.4816 \mathrm{e}+005$ & $-6.8341 \mathrm{e}-002$ \\
\hline 667. & $1.4821 \mathrm{e}+005$ & $-1.3101 \mathrm{e}-002$ \\
\hline 668. & $1.4825 \mathrm{e}+005$ & -0.34854 \\
\hline 669. & $1.4834 \mathrm{e}+005$ & -1.3112 \\
\hline 670. & $1.4846 \mathrm{e}+005$ & -1.4418 \\
\hline 671. & $1.4858 \mathrm{e}+005$ & -0.10745 \\
\hline 672. & $1.486 \mathrm{e}+005$ & -0.38031 \\
\hline 673. & $1.4868 \mathrm{e}+005$ & $-9.1371 \mathrm{e}-002$ \\
\hline 674. & $1.4873 \mathrm{e}+005$ & -0.12467 \\
\hline 675. & $1.4891 \mathrm{e}+005$ & -2.2593 \\
\cline { 1 - 1 } 676. & & -3.351 \\
\hline 677. & $1.4892 \mathrm{e}+005$ & -0.21003 \\
\hline 678. & $1.4893 \mathrm{e}+005$ & $-4.2471 \mathrm{e}-002$ \\
\hline 679. & $1.4901 \mathrm{e}+005$ & -444.94 \\
\hline 680. & $1.4916 \mathrm{e}+005$ & -0.12097 \\
\hline 681. & $1.4929 \mathrm{e}+005$ & $-1.7586 \mathrm{e}-002$ \\
\hline 682. & $1.4931 \mathrm{e}+005$ & -0.1455 \\
\hline 683. & $1.4935 \mathrm{e}+005$ & -0.32499 \\
\hline 684. & $1.4954 \mathrm{e}+005$ & $-4.8595 \mathrm{e}-002$ \\
\hline 685. & $1.4958 \mathrm{e}+005$ & $-4.6355 \mathrm{e}-002$ \\
\hline 686. & $1.4981 \mathrm{e}+005$ & -0.59712 \\
\hline
\end{tabular}

TABLE 29

Model (A4, B4, C4) > Modal (C5) > Solution (C6) > Solution Information

\begin{tabular}{|r|c|}
\hline Object Name & Solution Information \\
\hline State & Solved \\
\hline Solution Information \\
\hline Solution Output & Solver Output \\
\hline Newton-Raphson Residuals & 0 \\
\hline Update Interval & $0.5 \mathrm{~s}$ \\
\hline Display Points & All \\
\hline FE Connection Visibility \\
\hline Activate Visibility & Yes \\
\hline Display & All FE Connectors \\
\hline Draw Connections Attached To & All Nodes \\
\hline Line Color & Connection Type \\
\hline Visible on Results & No \\
\hline Line Thickness & Single \\
\hline Display Type & Lines \\
\hline
\end{tabular}

TABLE 30

Model (A4, B4, C4) $>$ Modal (C5) $>$ Solution (C6) $>$ Results

\begin{tabular}{|r|c|}
\hline Object Name & Total Deformation \\
\hline State & Solved \\
\hline Scope \\
\hline Scoping Method & Geometry Selection \\
\hline Geometry & All Bodies \\
\hline Definition \\
\hline Type & Total Deformation \\
\hline Mode & 1. \\
\hline Sweeping Phase & $0 .^{\circ}$ \\
\hline
\end{tabular}

file:///C:/Users/Edison/AppData/Roaming/Ansys/v160/Mechanical_Report/Mechanical_Re... 8/8/2016 


\begin{tabular}{|r|c|} 
Identifier & \\
\hline Suppressed & No \\
\hline Results \\
\hline Minimum & $0 . \mathrm{mm}$ \\
\hline Maximum & $8.1148 \mathrm{e}-003 \mathrm{~mm}$ \\
\hline Minimum Occurs On & Solid \\
\hline Maximum Occurs On & Solid \\
\hline Information \\
\hline Frequency & $2972 . \mathrm{Hz}$ \\
\hline Stability & $-8.9069 \mathrm{~Hz}$ \\
\hline
\end{tabular}

TABLE 31

Model (A4, B4, C4) > Modal (C5) > Solution (C6) > Total Deformation

\begin{tabular}{l|l|l|} 
Mode & Frequency $[\mathrm{Hz}]$ & Stability $[\mathrm{Hz}]$ \\
\hline
\end{tabular}

\begin{tabular}{|c|c|c|}
\hline 1. & 2972. & -8.9069 \\
\hline 2. & 3102.1 & -9.2809 \\
\hline 3. & 6985.3 & -20.937 \\
\hline 4. & 8376.5 & -25.068 \\
\hline 5. & 8546.7 & -25.489 \\
\hline 6. & 11442 & $-1.4059 e-003$ \\
\hline 7. & 12086 & -36.229 \\
\hline 8. & 14867 & -44.53 \\
\hline 9. & 16128 & -48.168 \\
\hline 10. & 16289 & -48.291 \\
\hline 11. & 17048 & $-1.0311 e-002$ \\
\hline 12. & 17349 & $-6.7836 e-002$ \\
\hline 13. & 18256 & -54.726 \\
\hline 14. & 19880 & $-1.6383 e-002$ \\
\hline 15. & 21007 & $-2.8115 e-004$ \\
\hline 16. & 22461 & -67.301 \\
\hline 17. & 24004 & $-2.5852 e-002$ \\
\hline 18. & 24807 & -0.11921 \\
\hline 19. & 24961 & -74.701 \\
\hline 20. & 25480 & -76.383 \\
\hline 21. & 26145 & -77.88 \\
\hline 22. & 26227 & -72.041 \\
\hline 23. & 26494 & -4.9368 \\
\hline 24. & 29651 & $-7.9475 e-004$ \\
\hline 25. & 30729 & $-8.4381 e-002$ \\
\hline 26. & 31177 & -93.435 \\
\hline 27. & 33065 & -0.46322 \\
\hline 28. & 33744 & -101.16 \\
\hline 29. & 34110 & $-3.1164 e-003$ \\
\hline 30. & 34190 & $-4.6508 \mathrm{e}-003$ \\
\hline 31. & 34924 & -104.6 \\
\hline 32. & 35298 & -0.19085 \\
\hline 33. & 36303 & $-6.8501 e-003$ \\
\hline 34. & 36358 & $-1.0889 e-002$ \\
\hline 35. & 37292 & -111.46 \\
\hline 36. & 37646 & -8.3714 \\
\hline 37. & 38142 & -0.64971 \\
\hline 38. & 38339 & -3.1606 \\
\hline 39. & 38359 & -100.13 \\
\hline 40. & 38378 & -110.49 \\
\hline
\end{tabular}

file://C:/Users/Edison/AppData/Roaming/Ansys/v160/Mechanical_Report/Mechanical_Re... 8/8/2016 


\begin{tabular}{|c|c|c|}
\hline 41. & 40107 & - $-1.2903 e-002$ \\
\hline 42. & 40162 & $-3.0815 e-002$ \\
\hline 43. & 40274 & $-3.283 e-005$ \\
\hline 44. & 41009 & -122.91 \\
\hline 45. & 41864 & -0.43772 \\
\hline 46. & 41981 & $-3.1288 e-003$ \\
\hline 47. & 42824 & -0.13745 \\
\hline 48. & 43038 & -129.02 \\
\hline 49. & 44907 & -0.31772 \\
\hline 50. & 45464 & $-1.0254 \mathrm{e}-003$ \\
\hline 51. & 46039 & -137.93 \\
\hline 52. & 48355 & -0.54387 \\
\hline 53. & 48652 & -2.4209 \\
\hline 54. & 49096 & $-7.6258 \mathrm{e}-002$ \\
\hline 55. & 49469 & $-8.6527 e-003$ \\
\hline 56. & 49578 & -148.39 \\
\hline 57. & 50005 & $-1.2623 e-003$ \\
\hline 58. & 51164 & -40.486 \\
\hline 59. & 51418 & $-4.4214 \mathrm{e}-003$ \\
\hline 60. & 51447 & -18.31 \\
\hline 61. & 51679 & $-1.0343 e-002$ \\
\hline 62. & 51846 & -154.57 \\
\hline 63. & 51949 & -155.7 \\
\hline 64. & 52115 & -50.75 \\
\hline 65. & 52436 & -0.20174 \\
\hline 66. & 52727 & -153.48 \\
\hline 67. & 52789 & -6.0966 \\
\hline 68. & 52873 & $-3.3316 e-002$ \\
\hline 69. & 52907 & $-1.6164 \mathrm{e}-003$ \\
\hline 70. & 53353 & -159.94 \\
\hline 71. & 54076 & -0.56879 \\
\hline 72. & 54328 & -2.4337 \\
\hline 73. & 54396 & $-1.2261 e-003$ \\
\hline 74. & 55481 & $-9.298 e-005$ \\
\hline 75. & 55502 & -0.75175 \\
\hline 76. & 55959 & -12.806 \\
\hline 77. & 56772 & -0.68168 \\
\hline 78. & 57283 & $-2.5321 e-004$ \\
\hline 79. & 58270 & -10.456 \\
\hline 80. & 58312 & -174.74 \\
\hline 81. & 59035 & $-1.3172 e-003$ \\
\hline 82. & 59712 & $-4.3363 e-003$ \\
\hline 83. & 60287 & -0.24374 \\
\hline 84. & 60289 & -0.8238 \\
\hline 85. & 60468 & $-3.7017 e-003$ \\
\hline 86. & 61053 & -14.518 \\
\hline 87. & 61659 & $-3.1506 e-003$ \\
\hline 88. & 62001 & $-8.1952 e-002$ \\
\hline 89. & 62044 & $-3.3643 e-002$ \\
\hline 90. & 62345 & -16.938 \\
\hline 91. & 62415 & $-1.8092 e-003$ \\
\hline 92. & 62626 & -0.62297 \\
\hline 93. & 63006 & $-1.6411 e-002$ \\
\hline & & \\
\hline
\end{tabular}

file:///C:/Users/Edison/AppData/Roaming/Ansys/v160/Mechanical_Report/Mechanical_Re... 8/8/2016 


\begin{tabular}{|c|c|c|}
\hline & 63039 & -188.79 \\
\hline 95. & 63070 & $-6.8582 e-005$ \\
\hline 96. & 63125 & $-8.5183 e-005$ \\
\hline 97. & 63733 & -20.967 \\
\hline 98. & 63980 & -191.78 \\
\hline 99. & 64682 & -193.9 \\
\hline 100. & 64710 & $-8.0981 e-002$ \\
\hline 101. & 64737 & -1.2663 \\
\hline 102. & 65035 & -0.2383 \\
\hline 103. & 66452 & -198.67 \\
\hline 104. & 66506 & -0.17933 \\
\hline 105. & 66724 & -0.15435 \\
\hline 106. & 68075 & -23.939 \\
\hline 107. & 68168 & -0.53818 \\
\hline 108. & 68596 & -203.25 \\
\hline 109. & 68621 & -143.33 \\
\hline 110. & 68880 & -1.7644 \\
\hline 111. & 69125 & -3.3185 \\
\hline 112. & 69312 & -6.8074 \\
\hline 113. & 69666 & $-4.936 e-002$ \\
\hline 114. & 69692 & -0.15751 \\
\hline 115. & 70055 & -2.4542 \\
\hline 116. & 70234 & $-6.3957 e-002$ \\
\hline 117. & 70817 & -6.952 \\
\hline 118. & 71132 & -1.8637 \\
\hline 119. & 71283 & -1.5482 \\
\hline 120. & 71391 & -12.275 \\
\hline 121. & 71422 & $-1.5827 e-002$ \\
\hline 122. & 71732 & -214.96 \\
\hline 123. & 71756 & $-5.9866 e-002$ \\
\hline 124. & 71769 & $-4.3516 e-003$ \\
\hline 125. & 71831 & $-1.5708 e-004$ \\
\hline 126. & 72116 & -147.68 \\
\hline 127. & 72292 & -1.74 \\
\hline 128. & 72342 & -0.49702 \\
\hline 129. & 72865 & $-2.4157 e-002$ \\
\hline 130. & 73303 & -2.0508 \\
\hline 131. & 73587 & -1.3366 \\
\hline 132. & 73787 & $-5.2619 e-003$ \\
\hline 133. & 73945 & $-8.833 e-003$ \\
\hline 134. & 74427 & -2.7156 \\
\hline 135. & 75128 & -1.0864 \\
\hline 136. & 75225 & -4.1706 \\
\hline 137. & 75910 & -0.16858 \\
\hline 138. & 76323 & -0.7787 \\
\hline 139. & 76577 & $-1.979 e-002$ \\
\hline 140. & 76705 & -0.53992 \\
\hline 141. & 76839 & $-8.3161 e-002$ \\
\hline 142. & 76991 & $-4.6408 \mathrm{e}-002$ \\
\hline 143. & 77020 & -230.89 \\
\hline 144. & 77093 & -231.09 \\
\hline 145. & 77437 & -0.31413 \\
\hline 146. & 77684 & -232.72 \\
\hline 11 & & \\
\hline
\end{tabular}

file://C:/Users/Edison/AppData/Roaming/Ansys/v160/Mechanical_Report/Mechanical_Re... 8/8/2016 


\begin{tabular}{|c|c|c|}
\hline & 77703 & $\mid-3.7954 e-002$ \\
\hline 148. & 77730 & $-3.7645 e-004$ \\
\hline 149. & 78449 & -4.9569 \\
\hline 150. & 78744 & -0.72815 \\
\hline 151. & 78858 & $-2.5658 e-003$ \\
\hline 152. & 78940 & $-1.7551 e-002$ \\
\hline 153. & 79490 & $-1.5315 e-002$ \\
\hline 154. & 79505 & $-8.7791 e-002$ \\
\hline 155. & 79578 & -0.10011 \\
\hline 156. & 79861 & -4.3341 \\
\hline 157. & 80277 & -38.469 \\
\hline 158. & 80762 & $-6.8994 e-002$ \\
\hline 159. & 80989 & $-1.3507 e-003$ \\
\hline 160. & 81172 & -0.14261 \\
\hline 161. & 81215 & -0.25128 \\
\hline 162. & 81308 & -21.098 \\
\hline 163. & 81720 & -0.16005 \\
\hline 164. & 82242 & -246.15 \\
\hline 165. & 82498 & -0.31843 \\
\hline 166. & 84074 & -1.7384 \\
\hline 167. & 84329 & -2.2777 \\
\hline 168. & 84543 & -2.079 \\
\hline 169. & 84585 & -5.3374 \\
\hline 170. & 84728 & $-5.6757 e-003$ \\
\hline 171. & 85268 & -0.73941 \\
\hline 172. & 85512 & -2.3322 \\
\hline 173. & 85540 & -255 \\
\hline 174. & 85573 & -3.0033 \\
\hline 175. & 85764 & -1.0137 \\
\hline 176. & 85835 & -0.22658 \\
\hline 177. & 86208 & -0.18298 \\
\hline 178. & 86285 & -258.6 \\
\hline 179. & 86331 & -5.9645 \\
\hline 180. & 86437 & -0.1057 \\
\hline 181. & 86647 & $-1.4959 e-002$ \\
\hline 182. & 86658 & -0.19377 \\
\hline 183. & 86703 & $-4.4732 e-003$ \\
\hline 184. & 86712 & $-6.0508 e-002$ \\
\hline 185. & 86738 & $-1.5006 e-003$ \\
\hline 186. & 86823 & $-1.47 e-002$ \\
\hline 187. & 86948 & -0.5361 \\
\hline 188. & 87398 & -252.66 \\
\hline 189. & 87404 & -0.99209 \\
\hline 190. & 87467 & -1.2677 \\
\hline 191. & 87770 & -15.978 \\
\hline 192. & 87971 & -3.6691 \\
\hline 193. & 88255 & -14.924 \\
\hline 194. & 88292 & -1.5578 \\
\hline 195. & 88509 & -58.851 \\
\hline 196. & 88683 & -16.98 \\
\hline 197. & 88913 & -2.3995 \\
\hline 198. & 88965 & -18.292 \\
\hline 199. & 89060 & -3.4383 \\
\hline & & \\
\hline
\end{tabular}

file:///C:/Users/Edison/AppData/Roaming/Ansys/v160/Mechanical_Report/Mechanical_Re... 8/8/2016 


\begin{tabular}{|c|c|c|}
\hline & 89729 & -26.133 \\
\hline 201. & 89833 & -13.77 \\
\hline 202. & 89922 & -2.1884 \\
\hline 203. & 90107 & -23.287 \\
\hline 204. & 90362 & -270.88 \\
\hline 205. & 90500 & -6.7606 \\
\hline 206. & 90659 & -2.1786 \\
\hline 207. & 90773 & -22.124 \\
\hline 208. & 90820 & -0.92923 \\
\hline 209. & 91286 & -273.63 \\
\hline 210. & 91566 & -0.73076 \\
\hline 211. & 91569 & -84.983 \\
\hline 212. & 91641 & -2.1922 \\
\hline 213. & 91855 & -37.901 \\
\hline 214. & 92016 & -15.863 \\
\hline 215. & 92423 & $-7.1207 e-002$ \\
\hline 216. & 92496 & -9.8936 \\
\hline 217. & 92567 & -19.701 \\
\hline 218. & 92769 & -4.3938 \\
\hline 219. & 92792 & -2.9118 \\
\hline 220. & 93200 & $-6.8371 e-002$ \\
\hline 221. & 93272 & $-3.5979 e-002$ \\
\hline 222. & 93290 & $-9.0173 e-002$ \\
\hline 223. & 93317 & -0.23374 \\
\hline 224. & 93336 & -0.11051 \\
\hline 225. & 93339 & -0.61708 \\
\hline 226. & 93393 & -3.0657 \\
\hline 227. & 93507 & -280.16 \\
\hline 228. & 94060 & -6.8641 \\
\hline 229. & 94328 & -19.452 \\
\hline 230. & 94613 & -0.14011 \\
\hline 231. & 94651 & -1.2742 \\
\hline 232. & 94929 & -33.602 \\
\hline 233. & 95552 & -4.6841 \\
\hline 234. & 95650 & -0.58786 \\
\hline 235. & 96248 & -0.93408 \\
\hline 236. & 96504 & -3.0141 \\
\hline 237. & 97263 & -2.2233 \\
\hline 238. & 97515 & $-9.6817 e-003$ \\
\hline 239. & 97547 & -0.52746 \\
\hline 240. & 97581 & -2.4176 \\
\hline 241. & 97932 & $-6.1013 e-002$ \\
\hline 242. & 97971 & -0.21908 \\
\hline 243. & 98453 & -0.18161 \\
\hline 244. & 98600 & \begin{tabular}{|l|l|l|}
-5.003 \\
\end{tabular} \\
\hline 245. & 98683 & -0.61975 \\
\hline 246. & 98884 & -0.27163 \\
\hline 247. & 99118 & $-8.518 e-002$ \\
\hline 248. & 99214 & -0.16216 \\
\hline 249. & 99229 & -297.14 \\
\hline 250. & 99251 & -0.48008 \\
\hline 251. & 99411 & -0.12556 \\
\hline 252. & 99572 & $-6.1632 e-002$ \\
\hline & & \\
\hline
\end{tabular}

file:///C:/Users/Edison/AppData/Roaming/Ansys/v160/Mechanical_Report/Mechanical_Re... 8/8/2016 


\begin{tabular}{|c|c|c|}
\hline & 4 & 971 \\
\hline 254. & $1.0004 \mathrm{e}+005$ & $-4.2347 e-002$ \\
\hline 255. & $1.0013 e+005$ & $-5.2859 e-003$ \\
\hline 256. & $1.0017 e+005$ & -0.85376 \\
\hline 257. & $1.0029 e+005$ & -0.10477 \\
\hline 258. & $1.0036 e+005$ & -0.54769 \\
\hline 259. & $1.0067 e+005$ & -0.3616 \\
\hline 260. & $1.0089 e+005$ & $-3.5653 e-002$ \\
\hline 261. & $1.0091 e+005$ & $-3.3625 e-003$ \\
\hline 262. & $1.0098 e+005$ & $-2.3181 e-002$ \\
\hline 263. & $1.0105 e+005$ & -0.26535 \\
\hline 264. & $1.0118 e+005$ & -0.11486 \\
\hline 265. & $1.0164 \mathrm{e}+005$ & -0.17065 \\
\hline 266. & $1.0195 e+005$ & $-3.0246 e-002$ \\
\hline 267. & $1.0196 e+005$ & -305.6 \\
\hline 268. & $1.0208 e+005$ & -0.21144 \\
\hline 269. & $1.0311 e+005$ & -1.403 \\
\hline 270. & $1.0315 e+005$ & $-6.0396 e-002$ \\
\hline 271. & $1.0324 \mathrm{e}+005$ & -0.2 \\
\hline 272. & 1.0331 & -0.22813 \\
\hline 273. & & -309.86 \\
\hline 274. & & -0.90255 \\
\hline 275. & $1.0371 \mathrm{e}+005$ & -0.54732 \\
\hline 276. & $1.0375 \mathrm{e}+005$ & $-6.3069 e-004$ \\
\hline 277. & 1.0385 & -0.2 \\
\hline 278. & $1.0387 e+005$ & -0.4 \\
\hline 279. & $1.0421 e+005$ & $-2.1981 e-002$ \\
\hline 280. & $1.0426 e+005$ & -1.086 \\
\hline 281. & $1.0436 \mathrm{e}+005$ & -0.11284 \\
\hline 282. & $1.0441 e+005$ & -0.62896 \\
\hline 283. & $1.0471 \mathrm{e}+005$ & -313.88 \\
\hline 284. & 1.0474 & -1 . \\
\hline 285. & $1.0485 e+005$ & -0.15062 \\
\hline 286. & $1.0489 e+005$ & $-9.6775 e-004$ \\
\hline 287. & $1.0504 e+005$ & $-8.3904 e-002$ \\
\hline 288. & $1.0513 e+005$ & $-9.8346 e-002$ \\
\hline 289. & $1.0521 e+005$ & $-8.2755 e-003$ \\
\hline 290. & $1.0523 e+005$ & $-3.1182 \mathrm{e}-002$ \\
\hline 291. & $1.0524 \mathrm{e}+005$ & $-4.6826 e-002$ \\
\hline 292. & $1.0538 \mathrm{e}+005$ & $-7.2265 \mathrm{e}-002$ \\
\hline 293. & $1.054 \mathrm{e}+005$ & $-7.6316 e-003$ \\
\hline 294. & $1.06 e+005$ & -15.523 \\
\hline 295. & $1.0614 \mathrm{e}+005$ & -0.53058 \\
\hline 296. & $1.0629 e+005$ & -1.6593 \\
\hline 297. & $1.0631 e+005$ & -0.13778 \\
\hline 298. & $1.0643 e+005$ & -22.251 \\
\hline 299. & $1.065 \mathrm{e}+005$ & -0.53743 \\
\hline 300. & $1.0654 \mathrm{e}+005$ & -319.28 \\
\hline 301. & $1.0659 e+005$ & -157.48 \\
\hline 302. & $1.0681 \mathrm{e}+005$ & -315.91 \\
\hline 303. & $1.0701 e+005$ & -1.1452 \\
\hline 304. & $1.0707 e+005$ & -3.8002 \\
\hline 305. & $1.0735 \mathrm{e}+005$ & -12.534 \\
\hline
\end{tabular}

file:///C:/Users/Edison/AppData/Roaming/Ansys/v160/Mechanical_Report/Mechanical_Re... 8/8/2016 


\begin{tabular}{|c|c|c|}
\hline 306. & $1.0797 e+005$ & -0.12985 \\
\hline 307. & $1.0816 e+005$ & -1.6585 \\
\hline 308. & $1.0871 \mathrm{e}+005$ & -3.4486 \\
\hline 309. & $1.0872 e+005$ & -0.64277 \\
\hline 310. & $1.0901 \mathrm{e}+005$ & -1.2904 \\
\hline 311. & $1.0903 e+005$ & -4.3599 \\
\hline 312. & $1.0907 e+005$ & -0.63011 \\
\hline 313. & $1.093 e+005$ & -1.0947 \\
\hline 314. & $1.0937 e+005$ & -0.27092 \\
\hline 315. & $1.094 e+005$ & $-9.0192 e-002$ \\
\hline 316. & $1.0942 \mathrm{e}+005$ & $-9.8182 e-002$ \\
\hline 317. & $1.0952 e+005$ & -1.3143 \\
\hline 318. & $1.0978 \mathrm{e}+005$ & -0.40034 \\
\hline 319. & $1.1009 e+005$ & -2.7314 \\
\hline 320. & $1.1014 \mathrm{e}+005$ & -0.5137 \\
\hline 321. & $1.1024 \mathrm{e}+005$ & -4.8624 \\
\hline 322. & $1.1044 \mathrm{e}+005$ & -0.33074 \\
\hline 323. & $1.1047 e+005$ & -0.71022 \\
\hline 324. & $1.1049 \mathrm{e}+005$ & -0.28601 \\
\hline 325. & $1.105 e+005$ & -331.11 \\
\hline 326. & $1.1055 e+005$ & -1.2095 \\
\hline 327. & $1.1067 \mathrm{e}+005$ & -0.43601 \\
\hline 328. & $1.1073 e+005$ & $-5.1624 e-002$ \\
\hline 329. & $1.1074 \mathrm{e}+005$ & -0.2356 \\
\hline 330. & $1.108 \mathrm{e}+005$ & \begin{tabular}{|l|}
$-3.0363 e-002$ \\
\end{tabular} \\
\hline 331. & $e+005$ & -1.5841 \\
\hline 332. & $1.1096 \mathrm{e}+005$ & -2.4243 \\
\hline 333. & $1.1116 e+005$ & $-5.1007 e-002$ \\
\hline 334. & $1.1125 e+005$ & -7.5455 \\
\hline 335. & $1.1146 e+005$ & -3.5824 \\
\hline 336. & $1.1151 e+005$ & -297.23 \\
\hline 337. & +005 & -1.0979 \\
\hline 338. & $1.1178 e+005$ & -6.5099 \\
\hline 339. & $1.1193 e+005$ & -25.563 \\
\hline 340. & $1.1211 \mathrm{e}+005$ & -62.484 \\
\hline 341. & $1.1229 e+005$ & -201.45 \\
\hline 342. & $1.1255 \mathrm{e}+005$ & -0.13607 \\
\hline 343. & $e+005$ & -0.11411 \\
\hline 344. & $1.1275 e+005$ & -2.5582 \\
\hline 345. & $1.1306 e+005$ & -0.20587 \\
\hline 346. & $1.1345 e+005$ & -9.2848 \\
\hline 347. & $1.1356 e+005$ & -1.0712 \\
\hline 348. & $1.1366 \mathrm{e}+005$ & -16.53 \\
\hline 349. & $1.1404 \mathrm{e}+005$ & -0.30396 \\
\hline 350. & $1.1411 \mathrm{e}+005$ & -0.40966 \\
\hline 351. & $1.1412 \mathrm{e}+005$ & -8.5868 \\
\hline 352. & $1.1434 \mathrm{e}+005$ & -1.8952 \\
\hline 353. & $1.1447 e+005$ & -0.28915 \\
\hline 354. & $1.1451 e+005$ & -0.33292 \\
\hline 355. & $1.1453 e+005$ & -1.2957 \\
\hline 356. & $1.148 \mathrm{e}+005$ & -4.2946 \\
\hline 357. & $1.1489 e+005$ & -0.6612 \\
\hline 358. & $1.1498 \mathrm{e}+005$ & -47.765 \\
\hline
\end{tabular}

file:///C:/Users/Edison/AppData/Roaming/Ansys/v160/Mechanical_Report/Mechanical_Re... 8/8/2016 


\begin{tabular}{|c|c|c|}
\hline & & \\
\hline 360. & $1516 e+005$ & $-2.5287 e-002$ \\
\hline 361. & $1553 e+005$ & -0.11744 \\
\hline 362. & $.1555 e+005$ & -1.7875 \\
\hline 363. & $.1566 \mathrm{e}+005$ & -0.39504 \\
\hline 364. & $1.1579 e+005$ & -21.862 \\
\hline 365. & $1.1591 e+005$ & -0.1055 \\
\hline 366. & $1601 e+005$ & -0.15699 \\
\hline 367. & $1.1606 e+005$ & -0.17904 \\
\hline 368. & $1.1608 e+005$ & -0.71918 \\
\hline 369. & $1.1647 e+005$ & $3.6914 \mathrm{e}-003$ \\
\hline 370. & $1.1653 e+005$ & -6.2521 \\
\hline 371. & $1.1669 e+005$ & -0.173 \\
\hline 372. & $\mathrm{e}+005$ & -3.1562 \\
\hline 373. & 005 & -0.10846 \\
\hline 374. & $1741 \mathrm{e}$ & -5.1573 \\
\hline 375. & $1742 e+005$ & -351.71 \\
\hline 376. & & -1.1102 \\
\hline 377. & 05 & -0.26631 \\
\hline 378. & & -0.26818 \\
\hline 379. & 005 & $7.0248 \mathrm{e}-002$ \\
\hline 380. & 005 & $-3.8625 e-002$ \\
\hline 381. & 005 & -355.96 \\
\hline 382. & & -4 \\
\hline 383. & & 483 \\
\hline 384. & & 502 \\
\hline 385. & \multirow{2}{*}{$1.1979 e+005$} & -0.41172 \\
\hline 386. & & -0.16362 \\
\hline 387. & $1.1998 \mathrm{e}$ & $-7.5966 e-003$ \\
\hline 388. & & -359.89 \\
\hline 389. & & -0.84992 \\
\hline 390. & & 314 \\
\hline 391. & 05 & -0.71576 \\
\hline 392. & 005 & -0.23416 \\
\hline 393. & 1.20 & $6.3768 \mathrm{e}-002$ \\
\hline 394. & 005 & $-9.1785 e-002$ \\
\hline 395. & & $-7.1872 e-002$ \\
\hline 396. & & -0.4683 \\
\hline 397. & & 325 \\
\hline 398. & 1.20 & $-9.0485 e-003$ \\
\hline 399. & & $-1.0866 \mathrm{e}-002$ \\
\hline 400. & +005 & $-7.5512 e-003$ \\
\hline 401. & $1.2107 e+005$ & $-4.3415 e-003$ \\
\hline 402. & & $\mid-1.058 e-002$ \\
\hline 403. & & 145 \\
\hline 404. & 1.2 & -0.28084 \\
\hline 405. & $1.2142 \mathrm{e}+005$ & -0.54437 \\
\hline 406. & $1.2158 e+005$ & $-4.949 e-002$ \\
\hline 407. & $1.2161 e+005$ & $-4.2292 e-002$ \\
\hline 408. & $1.2168 e+005$ & $-1.1425 e-002$ \\
\hline 409. & 1.21 & -0.46867 \\
\hline 410. & $1.22 e+005$ & -0.18696 \\
\hline 411. & $1.2212 \mathrm{e}+005$ & $-4.2471 e-00$ \\
\hline
\end{tabular}

file:///C:/Users/Edison/AppData/Roaming/Ansys/v160/Mechanical_Report/Mechanical_Re... 8/8/2016 


\begin{tabular}{|c|c|c|}
\hline 412. & +005 & \\
\hline 413. & $1.2221 \mathrm{e}+005$ & $-4.916 e-003$ \\
\hline 414. & $2222 e+005$ & $-1.4252 e-002$ \\
\hline 415. & $2229 \mathrm{e}+005$ & $-4.9171 e-002$ \\
\hline 416. & $1.2257 e+005$ & $-9.912 \mathrm{e}-002$ \\
\hline 417. & $2276 e+005$ & $-5.6878 e-002$ \\
\hline 418. & $.2281 \mathrm{e}+005$ & $-1.5873 e-002$ \\
\hline 419. & $1.2283 e+005$ & $-9.1265 e-002$ \\
\hline 420. & $1.2286 \mathrm{e}+005$ & -368.26 \\
\hline 421. & $1.2299 e+005$ & -368.03 \\
\hline 422. & $1.2314 \mathrm{e}+005$ & -0.85934 \\
\hline 423. & $1.2316 e+005$ & -0.31843 \\
\hline 424. & $.2324 \mathrm{e}+005$ & $-9.8441 e-002$ \\
\hline 425. & $1.2328 \mathrm{e}+005$ & $-3.5648 e-002$ \\
\hline 426. & $1.2363 e+005$ & $-3.605 e-003$ \\
\hline 427. & $1.2385 e+005$ & $-7.0628 \mathrm{e}-002$ \\
\hline 428. & $1.2386 \mathrm{e}+005$ & -0.87154 \\
\hline 429. & $1.239 e+005$ & -8.103 \\
\hline 430. & 239 & $-3.7558 e-002$ \\
\hline 431. & .241 & -6.49 \\
\hline 432. & $.2441 \mathrm{e}+005$ & $-2.4477 e-003$ \\
\hline 433. & $1.2442 e+005$ & $-3.266 e-002$ \\
\hline 434. & $1.2449 \mathrm{e}+005$ & $-3.1165 e-003$ \\
\hline 435. & 246 & \\
\hline 436. & 247 & -1.582 \\
\hline 437. & 247 & $-2.19 s$ \\
\hline 438. & 005 & -0.8 \\
\hline 439. & 005 & 753 \\
\hline 440. & $.2525 \mathrm{e}+005$ & $-5.5036 e-002$ \\
\hline 441. & $2529 e+005$ & $-8.0679 \mathrm{e}-003$ \\
\hline 442. & 253 & -4.272 \\
\hline 443. & \multirow{2}{*}{$1.2555 \mathrm{e}+005$} & -2.78 \\
\hline 444. & & -5.20 \\
\hline 445. & $1.2576 e+005$ & $-5.4899 e-002$ \\
\hline 446. & $1.2578 \mathrm{e}+005$ & -0.12645 \\
\hline 447. & $1.2588 \mathrm{e}+005$ & $-4.0955 e-003$ \\
\hline 448. & $1.2589 e+005$ & -1.410 \\
\hline 449. & 1.259 & -4.628 \\
\hline 450. & $1.2598 \mathrm{e}+005$ & $-1.9626 e-002$ \\
\hline 451. & $1.2626 e+005$ & $-1.6105 e-002$ \\
\hline 452. & $1.2628 \mathrm{e}+005$ & $-1.1601 e-002$ \\
\hline 453. & $1.2644 \mathrm{e}+005$ & -0.54318 \\
\hline 454. & $1.2672 \mathrm{e}+005$ & -0.28643 \\
\hline 455. & 1.2675 & -5.561 \\
\hline 456. & 1.269 & $-6.7812 e-002$ \\
\hline 457. & $1.2694 \mathrm{e}+005$ & -0.10515 \\
\hline 458. & $1.2697 e+005$ & -0.13445 \\
\hline 459. & $1.2708 \mathrm{e}+005$ & -0.19893 \\
\hline 460. & $1.2713 e+005$ & $-4.0376 e-002$ \\
\hline 461. & $1.2719 e+005$ & \\
\hline 462. & $1.2726 \mathrm{e}+005$ & $-1.4869 \mathrm{e}-002$ \\
\hline 463. & $1.2731 \mathrm{e}+005$ & -379.4 \\
\hline 464. & $1.2742 e+005$ & -0.1866 \\
\hline
\end{tabular}

file:///C:/Users/Edison/AppData/Roaming/Ansys/v160/Mechanical_Report/Mechanical_Re... 8/8/2016 


\begin{tabular}{|c|c|c|}
\hline 465. & $1.2749 e+005$ & $-6.5612 \mathrm{e}-0$ \\
\hline 466. & $1.28 e+005$ & -0.46643 \\
\hline 467. & $1.2811 \mathrm{e}+005$ & -0.3424 \\
\hline 468. & $1.2866 e+005$ & -385.54 \\
\hline 469. & $1.2894 \mathrm{e}+005$ & -0.11117 \\
\hline 470. & $1.2896 e+005$ & -0.17471 \\
\hline 471. & $1.2911 e+005$ & -0.64836 \\
\hline 472. & $1.2914 \mathrm{e}+005$ & -0.32686 \\
\hline 473. & $1.294 e+005$ & -0.15674 \\
\hline 474. & $1.2966 \mathrm{e}+005$ & -0.55296 \\
\hline 475. & $1.2984 \mathrm{e}+005$ & -0.30767 \\
\hline 476. & $1.2986 e+005$ & $-9.9566 e-002$ \\
\hline 477. & $1.2992 \mathrm{e}+005$ & -0.40335 \\
\hline 478. & $1.2996 e+005$ & -367.8 \\
\hline 479. & $1.3008 \mathrm{e}+005$ & -0.35867 \\
\hline 480. & $1.3017 e+005$ & $-9.3954 e-002$ \\
\hline 481. & $1.303 e+005$ & -0.62767 \\
\hline 482. & $1.3032 \mathrm{e}+005$ & -0.46185 \\
\hline 483. & $1.3047 e+005$ & -0.30589 \\
\hline 484. & $1.3052 \mathrm{e}+005$ & -1.0238 \\
\hline 485. & $1.3059 \mathrm{e}+005$ & -0.10715 \\
\hline 486. & $1.3063 e+005$ & -0.12775 \\
\hline 487. & $1.3077 e+005$ & -0.12473 \\
\hline 488. & $1.3082 e+005$ & $-2.7342 e-002$ \\
\hline 489. & $1.3098 e+005$ & -0.94984 \\
\hline 490. & $1.3106 e+005$ & $-5.483 e-002$ \\
\hline 491. & $1.3108 \mathrm{e}+005$ & -0.78365 \\
\hline 492. & $1.3117 e+005$ & $-2.5461 e-002$ \\
\hline 493. & $1.3128 \mathrm{e}+005$ & -0.1677 \\
\hline 494. & $1.3136 \mathrm{e}+005$ & -4.3864 \\
\hline 495. & $1.3154 \mathrm{e}+005$ & $-4.7507 e-002$ \\
\hline 496. & $1.3169 \mathrm{e}+005$ & -0.11627 \\
\hline 497. & $1.317 e+005$ & $-6.6719 e-002$ \\
\hline 498. & $1.3177 e+005$ & -1.5987 \\
\hline 499. & $1.3182 \mathrm{e}+005$ & -2.0607 \\
\hline 500. & $1.3185 e+005$ & -1.3136 \\
\hline 501. & $1.3205 e+005$ & -1.3382 \\
\hline 502. & $1.3233 e+005$ & -1.2196 \\
\hline 503. & $1.3254 \mathrm{e}+005$ & -26.49 \\
\hline 504. & $1.3279 e+005$ & -115.37 \\
\hline 505. & $1.3297 e+005$ & -0.95157 \\
\hline 506. & $1.3303 e+005$ & -5.7129 \\
\hline 507. & $1.3317 e+005$ & -4.1241 \\
\hline 508. & $1.3324 \mathrm{e}+005$ & -10.403 \\
\hline 509. & $1.3347 e+005$ & -25.682 \\
\hline 510. & $1.3348 \mathrm{e}+005$ & -0.37018 \\
\hline 511. & $1.3361 e+005$ & -46.977 \\
\hline 512. & $1.3387 \mathrm{e}+005$ & -19.114 \\
\hline 513. & $1.3407 e+005$ & -3.3366 \\
\hline 514. & $1.3412 \mathrm{e}+005$ & -38.115 \\
\hline 515. & $1.3413 e+005$ & -15.649 \\
\hline 516. & $1.3423 e+005$ & -5.5494 \\
\hline 517. & $1.343 e+005$ & -161.2 \\
\hline
\end{tabular}

file:///C:/Users/Edison/AppData/Roaming/Ansys/v160/Mechanical_Report/Mechanical_Re... 8/8/2016 


\begin{tabular}{|c|c|c|}
\hline & $13443 e+0$ & -21.335 \\
\hline 519. & $1.3443 e+0$ & -1.5882 \\
\hline 520. & $1.3452 e+005$ & -27.939 \\
\hline 521. & $1.3454 \mathrm{e}+005$ & -45.967 \\
\hline 522. & $1.3468 \mathrm{e}+005$ & -29.45 \\
\hline 523. & $1.3478 e+005$ & -245.12 \\
\hline 524. & $1.3486 \mathrm{e}+005$ & -1.6628 \\
\hline 525. & $1.3498 e+005$ & -30.427 \\
\hline 526. & $1.3508 e+005$ & -0.47485 \\
\hline 527. & $1.351 e+005$ & -43.875 \\
\hline 528. & $1.3513 e+005$ & -1.8669 \\
\hline 529. & $1.3516 e+005$ & -7.3801 \\
\hline 530. & $1.3533 e+005$ & -7.8251 \\
\hline 531. & $1.3554 \mathrm{e}+005$ & -3.4528 \\
\hline 532. & $1.3567 e+005$ & -14.655 \\
\hline 533. & $1.3579 e+005$ & -0.49226 \\
\hline 534. & $1.3587 e+005$ & -2.0291 \\
\hline 535. & $1.3594 \mathrm{e}+005$ & -3.1147 \\
\hline 536. & $1.3599 \mathrm{e}+005$ & -3.3485 \\
\hline 537. & $1.3604 \mathrm{e}+005$ & -1.2433 \\
\hline 538. & $1.361 \mathrm{e}+005$ & -1.2017 \\
\hline 539. & $1.3627 e+005$ & -6.8588 \\
\hline 540. & $1.3639 e+005$ & -2.5331 \\
\hline 541. & $1.3641 e+005$ & -408.92 \\
\hline 542. & $1.3643 e+005$ & -0.75576 \\
\hline 543. & $1.3661 \mathrm{e}+005$ & -4.2597 \\
\hline 544. & $1.3669 \mathrm{e}+005$ & -409.68 \\
\hline 545. & $1.3681 e+005$ & -409.84 \\
\hline 546. & $1.3708 e+005$ & -27.171 \\
\hline 547. & $1.3715 \mathrm{e}+005$ & -1.7779 \\
\hline 548. & $1.3731 e+005$ & -1.8635 \\
\hline 549. & $1.3743 e+005$ & -1.8899 \\
\hline 550. & $1.3778 e+005$ & -0.90329 \\
\hline 551. & $1.3802 e+005$ & -8.06 \\
\hline 552. & $1.3805 e+005$ & -3.5644 \\
\hline 553. & $1.3819 \mathrm{e}+005$ & -8.4031 \\
\hline 554. & $1.3832 \mathrm{e}+005$ & -1.3641 \\
\hline 555. & $1.3835 e+005$ & -2.5161 \\
\hline 556. & $1.3838 \mathrm{e}+005$ & -0.4145 \\
\hline 557. & $1.3842 \mathrm{e}+005$ & -0.74263 \\
\hline 558. & $1.3844 e+005$ & -0.2499 \\
\hline 559. & $1.3856 \mathrm{e}+005$ & -1.7868 \\
\hline 560. & $1.3859 e+005$ & -27.851 \\
\hline 561. & $1.388 \mathrm{e}+005$ & -1.3115 \\
\hline 562. & $1.3887 e+005$ & -10.022 \\
\hline 563. & $1.3898 e+005$ & -0.66106 \\
\hline 564. & $1.3902 e+005$ & -2.4317 \\
\hline 565. & $1.3907 e+005$ & -10.738 \\
\hline 566. & $1.3919 \mathrm{e}+005$ & -0.12855 \\
\hline 567. & $1.3922 \mathrm{e}+005$ & -0.34248 \\
\hline 568. & $1.3931 \mathrm{e}+005$ & -0.56741 \\
\hline 569. & $1.3934 e+005$ & -3.841 \\
\hline 570. & $1.3935 e+005$ & -3.9007 \\
\hline
\end{tabular}

file:///C:/Users/Edison/AppData/Roaming/Ansys/v160/Mechanical_Report/Mechanical_Re... 8/8/2016 


\begin{tabular}{|c|c|c|}
\hline 571. & $1.3938 e+005$ & 856 \\
\hline 572. & $1.394 \mathrm{e}+005$ & $-3.4351 e-002$ \\
\hline 573. & $1.3944 \mathrm{e}+005$ & $-7.6902 e-002$ \\
\hline 574. & $1.3947 e+005$ & -0.43407 \\
\hline 575. & $1.3953 e+005$ & $-9.0796 e-002$ \\
\hline 576. & $1.3955 e+005$ & $-6.8312 e-002$ \\
\hline 577. & $1.396 \mathrm{e}+005$ & -0.27336 \\
\hline 578. & $1.3966 \mathrm{e}+005$ & -0.67316 \\
\hline 579. & $1.3979 \mathrm{e}+005$ & -0.13528 \\
\hline 580. & $1.398 e+005$ & -0.40002 \\
\hline 581. & $1.3988 \mathrm{e}+005$ & -0.13802 \\
\hline 582. & $1.3999 \mathrm{e}+005$ & -0.23543 \\
\hline 583. & $1.401 \mathrm{e}+005$ & -8.5534 \\
\hline 584. & $1.4019 \mathrm{e}+005$ & -0.15269 \\
\hline 585. & $14025 e+005$ & -420.39 \\
\hline 586. & & -0.38294 \\
\hline 587. & $1.404 \mathrm{e}+005$ & $-1.8921 e-002$ \\
\hline 588. & $1.4055 \mathrm{e}+005$ & -0.13117 \\
\hline 589. & $1.4056 \mathrm{e}+005$ & -0.64477 \\
\hline 590. & $1.4061 \mathrm{e}+005$ & $-5.8755 e-003$ \\
\hline 591. & $1.4089 \mathrm{e}+005$ & -0.11165 \\
\hline 592. & $1.4097 \mathrm{e}+005$ & -3.3303 \\
\hline 593. & $1.4105 \mathrm{e}+005$ & -4.668 \\
\hline 594. & 1.41 & -0.16906 \\
\hline 595. & 1.412 & -2.2833 \\
\hline 596. & $1.4135 \mathrm{e}+005$ & -0.73572 \\
\hline 597. & $1.4143 e+005$ & $-8.9344 \mathrm{e}-002$ \\
\hline 598. & $1.4161 \mathrm{e}+005$ & -0.90303 \\
\hline 599. & $1.4176 \mathrm{e}+005$ & -13.595 \\
\hline 600. & 1.410 & -4.4439 \\
\hline 601. & 1.42 & -0.71026 \\
\hline 602. & $1.4215 e+005$ & -1.6281 \\
\hline 603. & $1.4223 e+005$ & -1.2 \\
\hline 604. & $1.4225 \mathrm{e}+005$ & -0.60688 \\
\hline 605. & $1.4237 e+005$ & -0.19458 \\
\hline 606. & $1.4244 \mathrm{e}+005$ & -3.844 \\
\hline 607. & $1.4247 e+005$ & -3.9019 \\
\hline 608. & $1.4268 \mathrm{e}+005$ & $-4.0943 e-002$ \\
\hline 609. & $1.427 \mathrm{e}+005$ & $-1.3726 e-002$ \\
\hline 610. & $1.4282 \mathrm{e}+005$ & -1.0356 \\
\hline 611. & $1.429 \mathrm{e}+005$ & $-6.9256 e-002$ \\
\hline 612. & $1.4296 e+005$ & -0.1979 \\
\hline 613. & $1.4317 \mathrm{e}+005$ & -1.5698 \\
\hline 614. & $1.4333 e+005$ & -0.30537 \\
\hline 615. & $1.434 \mathrm{e}+005$ & -0.16631 \\
\hline 616. & $1.4341 \mathrm{e}+005$ & -0.37849 \\
\hline 617. & $1.4348 e+005$ & -0.20504 \\
\hline 618. & $1.4351 \mathrm{e}+005$ & -0.10045 \\
\hline 619. & $1.4357 \mathrm{e}+005$ & -429.78 \\
\hline 620. & $1.4363 e+005$ & -7.1499 \\
\hline 621. & $1.4371 \mathrm{e}+005$ & -1.431 \\
\hline 622. & \multirow{2}{*}{$1.4375 e+005$} & $-1.034 e-002$ \\
\hline 623. & & $-3.8263 e-002$ \\
\hline
\end{tabular}

file:///C:/Users/Edison/AppData/Roaming/Ansys/v160/Mechanical_Report/Mechanical_Re... 8/8/2016 


\begin{tabular}{|c|c|c|}
\hline & $1.4378 e+005$ & $2.7001 \mathrm{e}-\mathrm{C}$ \\
\hline 625. & $1.4411 \mathrm{e}+005$ & -0.23954 \\
\hline 626. & $1.4419 \mathrm{e}+005$ & -0.12799 \\
\hline 627. & $1.4429 \mathrm{e}+005$ & $-7.241 e-002$ \\
\hline 628. & $1.4438 \mathrm{e}+005$ & -0.64654 \\
\hline 629. & $1.4446 \mathrm{e}+005$ & -1.1028 \\
\hline 630. & $1.4447 e+005$ & -0.44141 \\
\hline 631. & $1.4455 \mathrm{e}+005$ & -0.35402 \\
\hline 632. & $1.4468 \mathrm{e}+005$ & -0.68177 \\
\hline 633. & $1.4484 \mathrm{e}+005$ & -0.10742 \\
\hline 634. & $1.4493 e+005$ & -0.44465 \\
\hline 635. & $1.4504 \mathrm{e}+005$ & -0.17084 \\
\hline 636. & $1.4531 \mathrm{e}+005$ & -0.83741 \\
\hline 637. & $1.4535 \mathrm{e}+005$ & -0.18252 \\
\hline 638. & $1.4548 \mathrm{e}+005$ & 114 \\
\hline 639. & $1.4586 e+005$ & -0.37781 \\
\hline 640. & $1.4591 \mathrm{e}+005$ & $-5.8753 e-002$ \\
\hline 641. & $1.4605 e+005$ & -0.65463 \\
\hline 642. & 1.46 & -25.771 \\
\hline 643. & $1 e+005$ & -0.4 \\
\hline 644. & $1.467 e+005$ & -0.6 \\
\hline 645. & $1.4673 e+005$ & -0.68494 \\
\hline 646. & $1.4681 \mathrm{e}+005$ & -6.6856 \\
\hline 647. & & -0.2 \\
\hline 648. & \multirow{2}{*}{$1.4694 \mathrm{e}+005$} & -1.798 \\
\hline 649. & & -26 . \\
\hline 650. & 1.4 & -0.15898 \\
\hline 651. & $1.4716 \mathrm{e}+005$ & -6.5915 \\
\hline 652. & $1.4726 e+005$ & -0.32311 \\
\hline 653. & $1.474 \mathrm{e}+005$ & -0.54856 \\
\hline 654. & $1.4741 e+005$ & -0.2464 \\
\hline 655. & 005 & -1.7867 \\
\hline 656. & 1.47 & -1.324 \\
\hline 657. & $1.4754 \mathrm{e}+005$ & -0.1092 \\
\hline 658. & $1.4762 \mathrm{e}+005$ & -2.7276 \\
\hline 659. & $1.4767 e+005$ & -0.65342 \\
\hline 660. & $1.4781 \mathrm{e}+005$ & -0.9 \\
\hline 661. & $e+005$ & -5.8556 \\
\hline 662. & $1.4788 \mathrm{e}+005$ & -0.52415 \\
\hline 663. & $1.479 \mathrm{e}+005$ & -0.562 \\
\hline 664. & $1.4792 \mathrm{e}+005$ & -0.60608 \\
\hline 665. & $1.4799 e+005$ & -443.5 \\
\hline 666. & $1.4816 e+005$ & $-6.8341 e-002$ \\
\hline 667. & $1.4821 \mathrm{e}+005$ & $-1.3101 e-002$ \\
\hline 668. & $1.4825 \mathrm{e}+005$ & -0.34854 \\
\hline 669. & $1.4834 \mathrm{e}+005$ & -1.3112 \\
\hline 670. & $1.4846 e+005$ & -1.4418 \\
\hline 671. & $1.4858 \mathrm{e}+005$ & -0.10745 \\
\hline 672. & $1.486 e+005$ & -0.38031 \\
\hline 673. & $1.4868 \mathrm{e}+005$ & $-9.1371 e-002$ \\
\hline 674. & $1.4873 e+005$ & -0.12467 \\
\hline 675. & \multirow{2}{*}{$1.4891 e+005$} & -2.2593 \\
\hline 676. & & -3.351 \\
\hline
\end{tabular}

file:///C:/Users/Edison/AppData/Roaming/Ansys/v160/Mechanical_Report/Mechanical_Re... 8/8/2016 


\begin{tabular}{|l|c|c|}
677. & $1.4892 \mathrm{e}+005$ & -0.21003 \\
\hline 678. & $1.4893 \mathrm{e}+005$ & $-4.2471 \mathrm{e}-002$ \\
\hline 679. & $1.4901 \mathrm{e}+005$ & -444.94 \\
\hline 680. & $1.4916 \mathrm{e}+005$ & -0.12097 \\
\hline 681. & $1.4929 \mathrm{e}+005$ & $-1.7586 \mathrm{e}-002$ \\
\hline 682. & $1.4931 \mathrm{e}+005$ & -0.1455 \\
\hline 683. & $1.4935 \mathrm{e}+005$ & -0.32499 \\
\hline 684. & $1.4954 \mathrm{e}+005$ & $-4.8595 \mathrm{e}-002$ \\
\hline 685. & $1.4958 \mathrm{e}+005$ & $-4.6355 \mathrm{e}-002$ \\
\hline 686. & $1.4981 \mathrm{e}+005$ & -0.59712 \\
\hline
\end{tabular}

\section{Material Data}

\section{Structural Steel}

TABLE 32

Structural Steel $>$ Constants

\begin{tabular}{|c|c|}
\hline Density & $7.85 \mathrm{e}-006 \mathrm{~kg} \mathrm{~mm}^{\wedge}-3$ \\
\hline Coefficient of Thermal Expansion & $1.2 e-005 C^{\wedge}-1$ \\
\hline Specific Heat & $4.34 \mathrm{e}+005 \mathrm{~mJ} \mathrm{~kg}^{\wedge}-1 \mathrm{C}^{\wedge}-1$ \\
\hline Thermal Conductivity & $6.05 \mathrm{e}-002 \mathrm{~W} \mathrm{mm^{ \wedge } - 1 \mathrm { C } ^ { \wedge } - 1}$ \\
\hline Resistivity & 1.7e-004 ohm mm \\
\hline
\end{tabular}

TABLE 33

Structural Steel > Compressive Ultimate Strength

Compressive Ultimate Strength $\mathrm{MPa}$

0

TABLE 34

Structural Steel > Compressive Yield Strength

Compressive Yield Strength MPa

250

TABLE 35

Structural Steel $>$ Tensile Yield Strength

Tensile Yield Strength MPa

250

TABLE 36

Structural Steel $>$ Tensile Ultimate Strength

Tensile Ultimate Strength MPa

460

TABLE 37

Structural Steel > Isotropic Secant Coefficient of Thermal Expansion

Reference Temperature C

22

TABLE 38

Structural Steel $>$ Alternating Stress Mean Stress

\begin{tabular}{|l|l|l} 
Alternating Stress MPa & Cycles & Mean Stress MPa
\end{tabular}

\begin{tabular}{|c|c|c|}
\hline 3999 & 10 & 0 \\
\hline 2827 & 20 & 0 \\
\hline & &
\end{tabular}

file://C:/Users/Edison/AppData/Roaming/Ansys/v160/Mechanical_Report/Mechanical_Re... 8/8/2016 


\begin{tabular}{|c|c|c|}
\hline 1896 & 50 & 0 \\
\hline 1413 & 100 & 0 \\
\hline 1069 & 200 & 0 \\
\hline 441 & 2000 & 0 \\
\hline 262 & 10000 & 0 \\
\hline 214 & 20000 & 0 \\
\hline 138 & $1 . e+005$ & 0 \\
\hline 114 & $2 . e+005$ & 0 \\
\hline 86.2 & $1 . e+006$ & 0 \\
\hline
\end{tabular}

TABLE 39

Structural Steel > Strain-Life Parameters

\begin{tabular}{|c|r|r|r|r|r|}
\hline $\begin{array}{r}\text { Strength } \\
\text { Coefficient MPa }\end{array}$ & $\begin{array}{r}\text { Strength } \\
\text { Exponent }\end{array}$ & $\begin{array}{r}\text { Ductility } \\
\text { Coefficient }\end{array}$ & $\begin{array}{r}\text { Ductility } \\
\text { Exponent }\end{array}$ & $\begin{array}{r}\text { Cyclic Strength } \\
\text { Coefficient MPa }\end{array}$ & $\begin{array}{r}\text { Cyclic Strain } \\
\text { Hardening Exponent }\end{array}$ \\
\hline 920 & -0.106 & 0.213 & -0.47 & 1000 & 0.2 \\
\hline
\end{tabular}

TABLE 40

Structural Steel > Isotropic Elasticity

\begin{tabular}{|c|c|c|c|c|}
\hline Temperature C & Young's Modulus MPa & Poisson's Ratio & Bulk Modulus MPa & Shear Modulus MPa \\
\hline & $2.0+005$ & 0.3 & $1.6667 e+005$ & 76923
\end{tabular}

TABLE 41

Structural Steel $>$ Isotropic Relative Permeability

Relative Permeability

10000

\section{Mylar Celplast}

TABLE 42

Mylar Celplast $>$ Constants

\begin{tabular}{|c|c|}
\hline Density & $1.39 \mathrm{e}-006 \mathrm{~kg} \mathrm{~mm}^{\wedge}-3$ \\
\hline Coefficient of Thermal Expansion & $1.7 e-005 C^{\wedge}-1$ \\
\hline Thermal Conductivity & $1.5481 \mathrm{e}-004 \mathrm{~W} \mathrm{~mm} \mathrm{~m}^{\wedge}-1 \mathrm{C}^{\wedge}-1$ \\
\hline Resistivity & 1.e+020 ohm mm \\
\hline
\end{tabular}

TABLE 43

Mylar Celplast > Isotropic Elasticity

\begin{tabular}{|l|l|l|l|l|}
\hline Temperature C & Young's Modulus MPa & Poisson's Ratio & Bulk Modulus MPa & Shear Modulus MPa \\
\hline
\end{tabular}

\begin{tabular}{|l|c|c|c|}
\hline 4088.4 & 0.38 & 5678.3 & 1481.3
\end{tabular}

TABLE 44

Mylar Celplast > Constant Damping Coefficient

Constant Damping Coefficient

3.e-003

TABLE 45

Mylar Celplast > Tensile Ultimate Strength

Tensile Ultimate Strength MPa

199.95

TABLE 46

Mylar Celplast > Tensile Yield Strength

Tensile Yield Strength MPa

96.527

file:///C:/Users/Edison/AppData/Roaming/Ansys/v160/Mechanical_Report/Mechanical_Re... 8/8/2016 


\section{Appendix D}

Electrical circuit design 


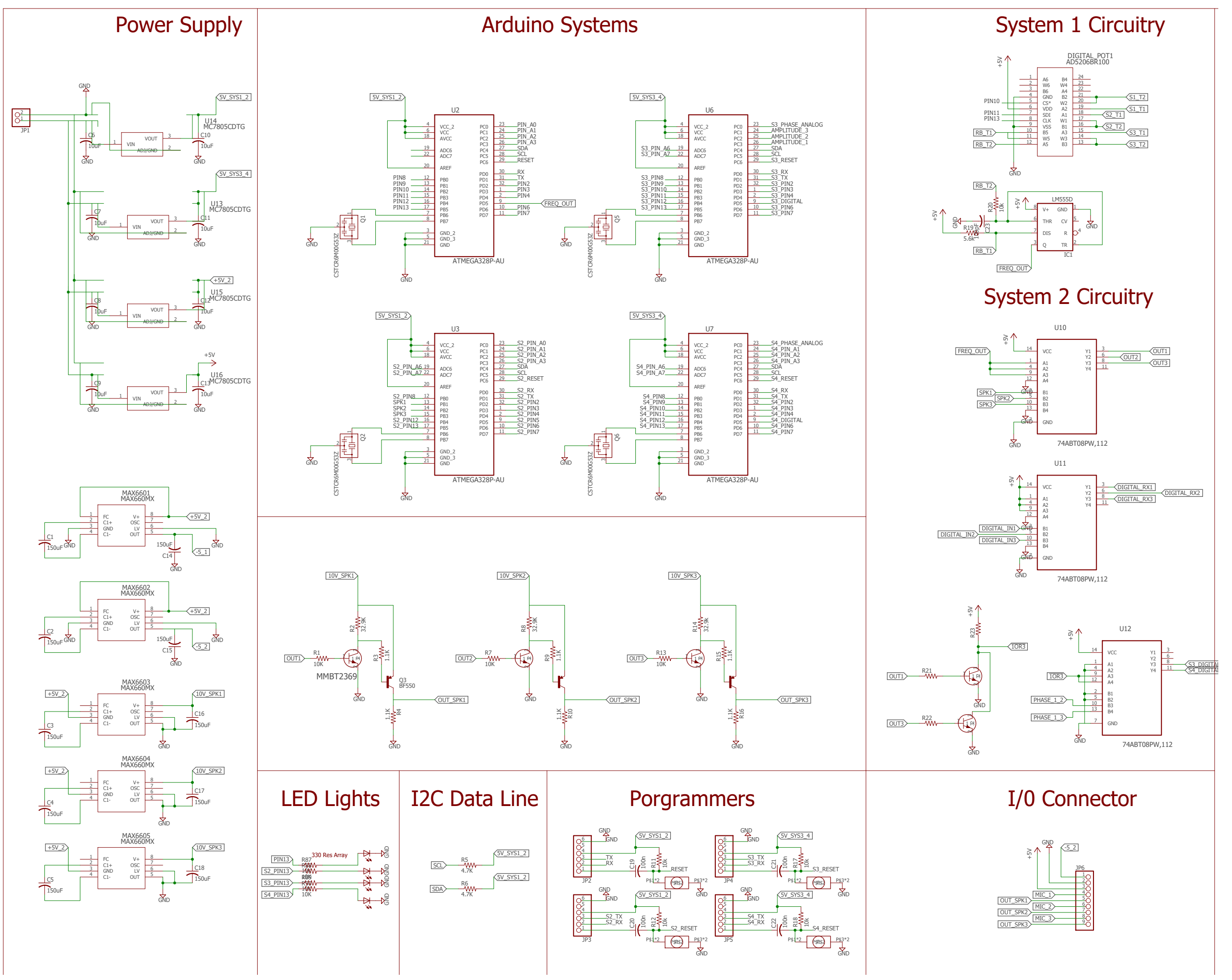




\section{System 3 Circuitry}

\section{Band Pass Filter}

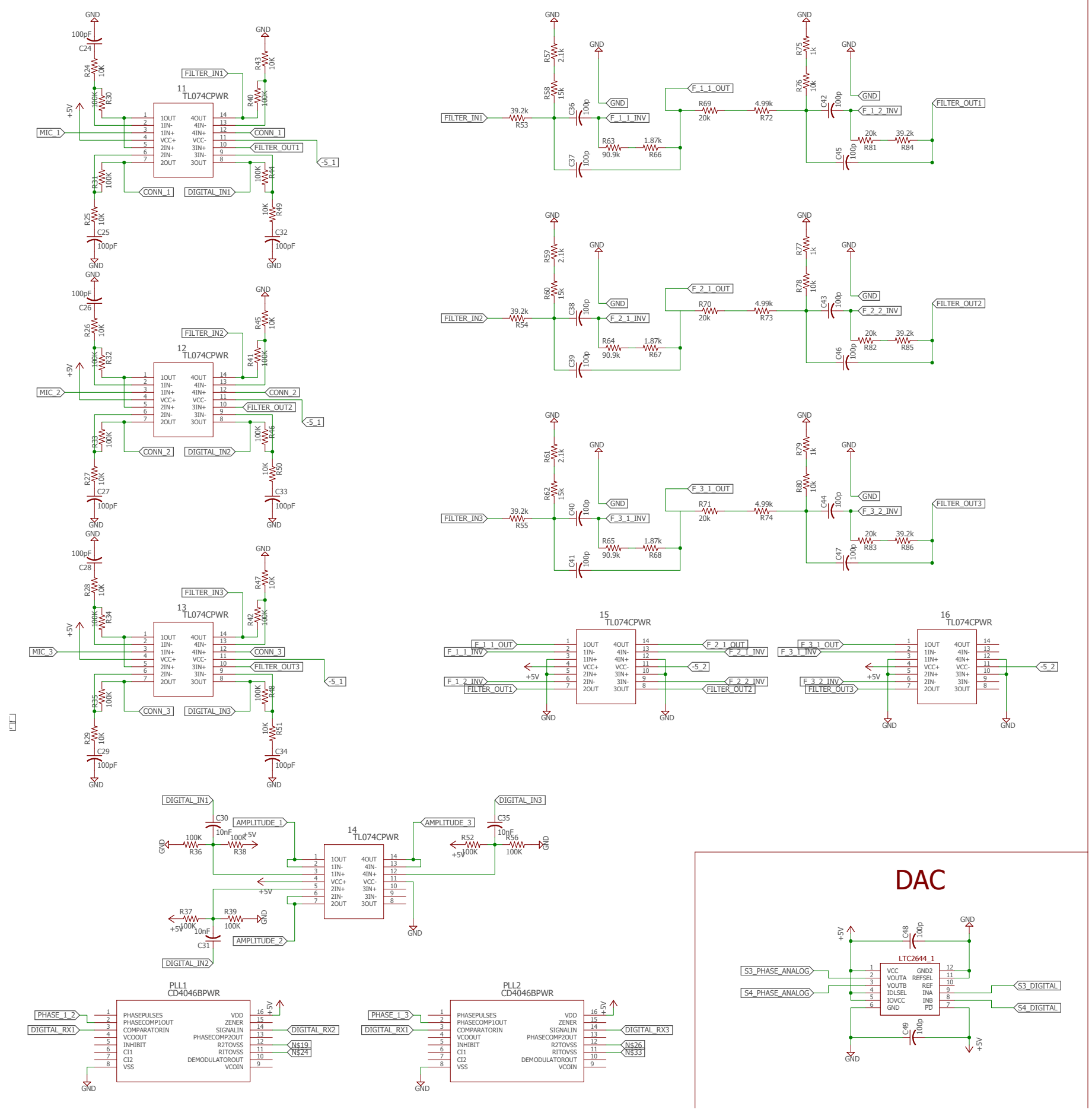


Appendix E

SPL Code 


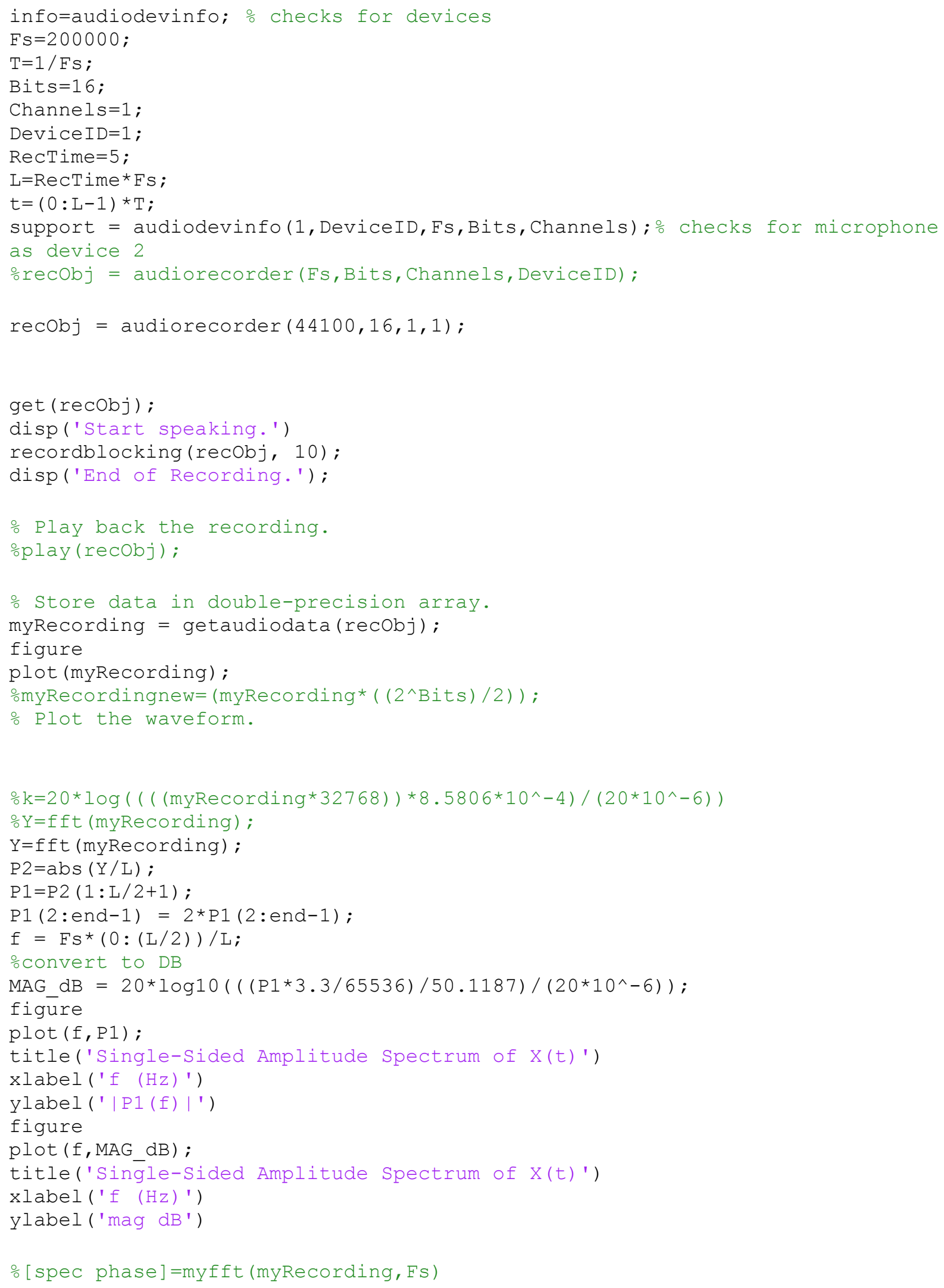

